EVALDO BALDIN DIAS

\title{
AVALIAÇÃO DE INDICADORES DE CONTINUIDADE E SEU IMPACTO NO PLANEJAMENTO DE SISTEMAS DE DISTRIBUIÇÃO
}

\author{
Dissertação apresentada à Escola \\ Politécnica da Universidade de São Paulo \\ para obtenção do Título de Mestre em \\ Engenharia.
}

São Paulo

2002 


\section{EVALDO BALDIN DIAS}

\section{AVALIAÇÃO DE INDICADORES DE CONTINUIDADE E SEU IMPACTO NO PLANEJAMENTO DE SISTEMAS DE DISTRIBUIÇÃO}

Dissertação apresentada à Escola

Politécnica da Universidade de São Paulo para obtenção do Título de Mestre em Engenharia.

Área de Concentração:

Sistemas de Potência

Orientador:

Carlos César Barioni de Oliveira

São Paulo

2002 
Dias, Evaldo Baldin

Avaliação de indicadores de continuidade e seu impacto no planejamento de sistemas de distribuição / Evaldo Baldin Dias. São Paulo, 2002. 139p.

Dissertação (Mestrado) -- Escola Politécnica da Universidade de São Paulo. Departamento de Energia e Automação Elétricas.

1.Distribuição de energia elétrica - Confiabilidade 2.Distribuição de energia elétrica - Planejamento de redes 3.Indicadores de continuidade de fornecimento I.Universidade de São Paulo. Escola Politécnica.Departamento de Energia e Automação Elétricas III.t. 
Aos meus pais, que sempre me serviram como exemplo de determinação.

"Não basta ensinar ao homem uma especialidade, porque se tornará assim como uma máquina utilizável, mas não uma personalidade. É necessário que adquira um sentimento, um senso prático daquilo que vale a pena ser empreendido, daquilo que é belo, do que é moralmente correto." 


\section{AGRADECIMENTOS}

Ao Prof. Dr. Carlos César Barioni de Oliveira, pela sua dedicação, direcionamento e incentivo.

À Márcia Fazion, pela sua paciência, compreensão e auxílio nas revisões.

Ao Eng. Luis René Manhães, pela sua colaboração e apoio.

À minha família e a todos que, de alguma forma auxiliaram ou contribuíram com o desenvolvimento do presente trabalho. 


\section{RESUMO}

Análises de confiabilidade do fornecimento de energia elétrica em redes de distribuição têm sido intensificadas, principalmente nas últimas três décadas. Este trabalho apresenta uma metodologia capaz de quantificar os impactos de vários tipos de ações de engenharia, nos indicadores de confiabilidade, para grandes sistemas reais. Dessa forma, é possível prever - ainda na etapa de planejamento - como, cada uma das opções de obras afetará a confiabilidade do fornecimento. São apresentados métodos para cálculo das estimativas: da Duração Equivalente de Interrupção por Consumidor (DEC), da Freqüência Equivalente de Interrupção por Consumidor (FEC), da Duração de Interrupção Individual por Consumidor (DIC), da Freqüência de Interrupção Individual por Consumidor (FIC) e da Energia não Distribuída (END), para os sistemas de distribuição primário e secundário, considerando-se as interrupções não programadas, dentro do novo contexto de regulamentação do Setor Elétrico Brasileiro. A partir dessa metodologia, são apresentadas diversas simulações e discutidos os efeitos provocados por cada uma das proposições de planejamento, sobre cada um dos indicadores de confiabilidade. Paralelamente, está sendo desenvolvida uma rotina computacional, que integrada a um programa de planejamento já existente, contribuirá para o aprimoramento dos estudos na área. 


\begin{abstract}
Reliability analysis due to power distribution systems have been increased specially in the last three decades. This publication presents a methodology which be able to measure the impact of several engineering proposals, in the reliability index, for real large systems. Thus it's possible forecast - during the planning - how each action affects the reliability. It presents an analytical method for estimate: System Average Interruption Duration Index (SAIDI), System Average Interruption Frequency Index (SAIFI), Interruption Duration for Each Individual Costumer Index (DIC), Interruption Frequency for Each Individual Costumer Index (FIC) and Energy not Supplied (ENS), for medium and low voltage distribution systems, regarding not scheduled interruptions, within the new context of Brazilian regulation. After presentation of the method, several simulations are processed and discussed the effects of each engineering proposals in each reliability index. One software is being developed simultaneously and will be integrated to another software of planning already implemented. Thus, this new tool will be a powerful aid to improve planning studies.
\end{abstract}




\section{SUMÁRIO}

\section{RESUMO}

LISTA DE FIGURAS

LISTA DE TABELAS

LISTA DE ABREVIATURAS E SIGLAS

LISTA DE SÍMBOLOS

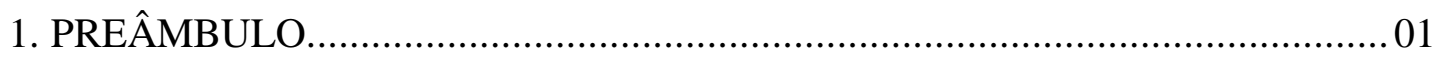

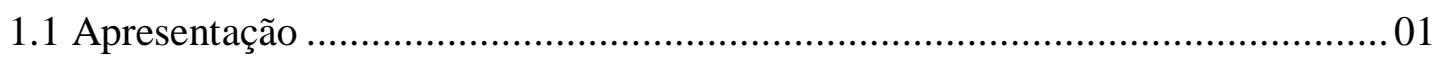

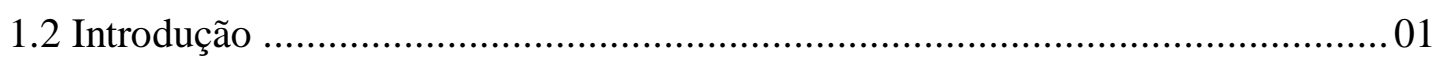

1.3 Indicadores de qualidade do serviço, relacionados com a duração e freqüência de interrupções, para consumidores atendidos em tensão

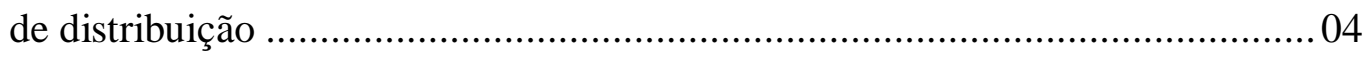

1.3.1 Indicadores controlados para a etapa de adaptação ...................................... 04

1.3.1.1 Períodos de apuração do DEC, FEC, DIC e FIC ........................................ 06

1.3.1.2 Universos de apuração do DEC e FEC ....................................................... 07

1.3.1.3 Universos de apuração do DIC e FIC …................................................. 07

1.3.2 Indicadores controlados para a etapa de transição........................................ 08

1.3.3 Indicadores controlados para a etapa de maturidade ................................... 08

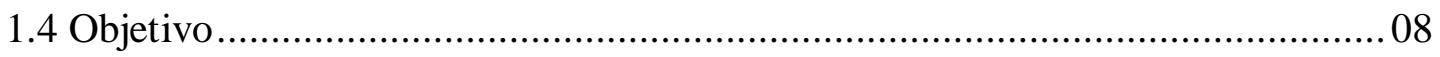

2. ANÁLISE DA BIBLIOGRAFIA ............................................................... 11

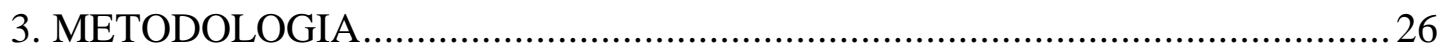

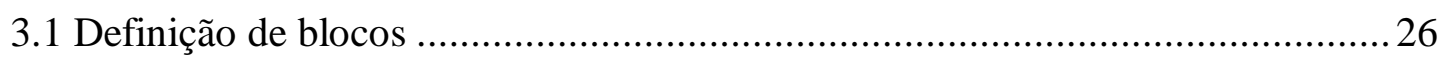

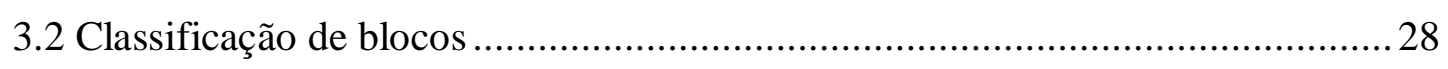

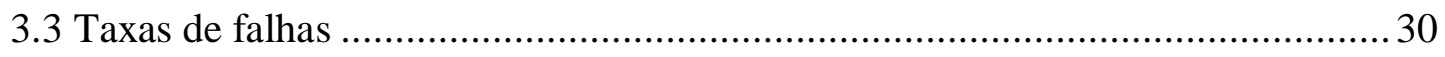

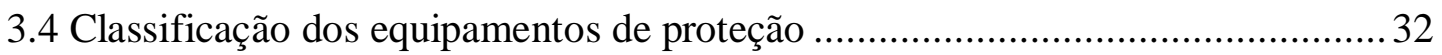

3.5 Consequiências dos tipos de equipamentos de proteção para a

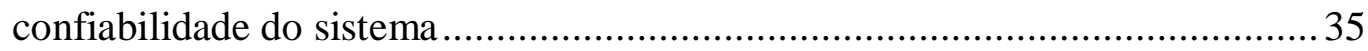

3.6 Associação da classificação dos blocos, com suas probabilidades de

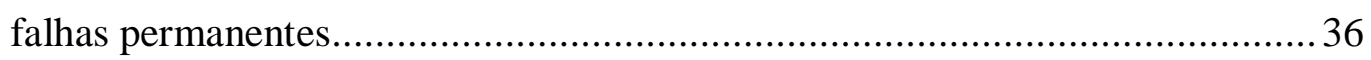

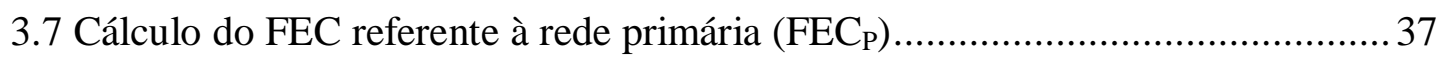

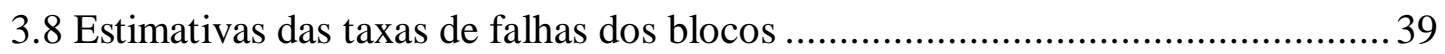


3.9 Tempos envolvidos nos restabelecimentos dos blocos

3.10 Associação da classificação dos blocos, com seus tempos de restabelecimento

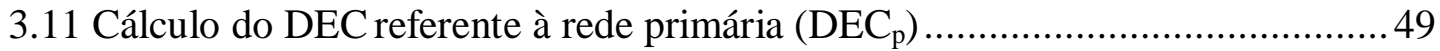

3.12 Estimativas dos tempos de restabelecimento na rede primária .......................52

3.13 Cálculo da energia não distribuída referente à rede primária $\left(\mathrm{END}_{\mathrm{P}}\right) \ldots \ldots \ldots \ldots \ldots . . .56$

3.14 Consideração das taxas de falhas dos equipamentos instalados na rede primária 57

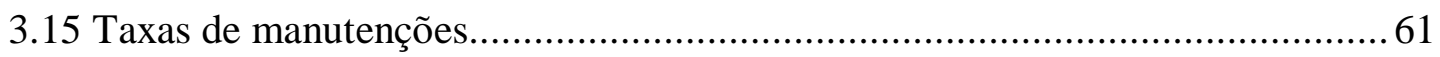

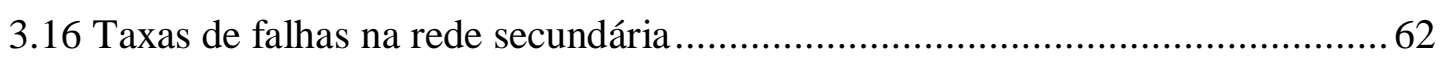

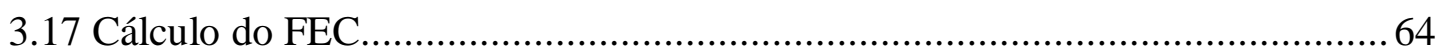

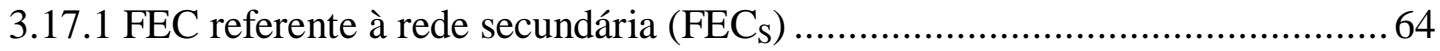

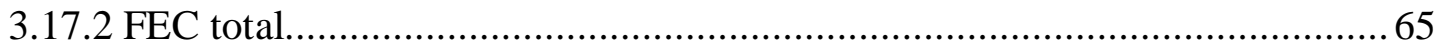

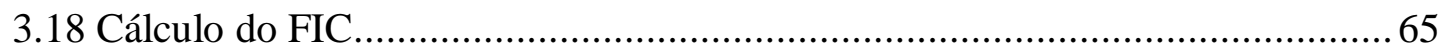

3.19 Tempos envolvidos nos restabelecimentos da rede secundária........................66

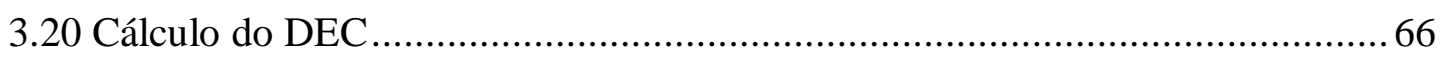

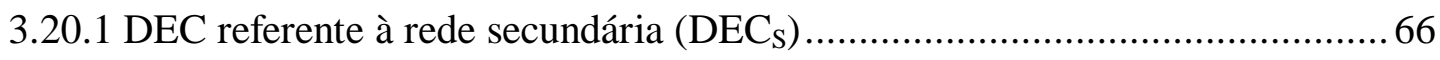

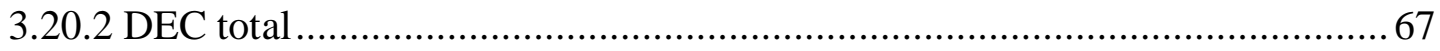

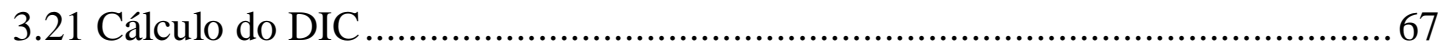

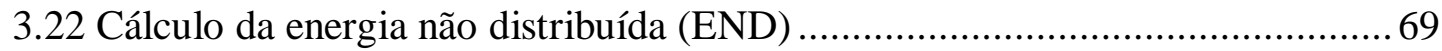

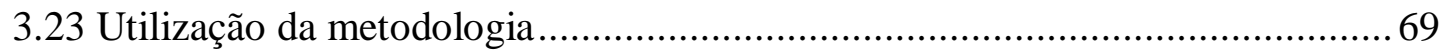

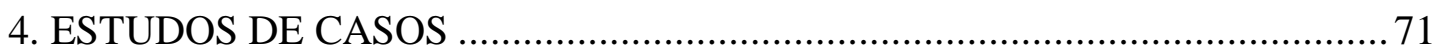

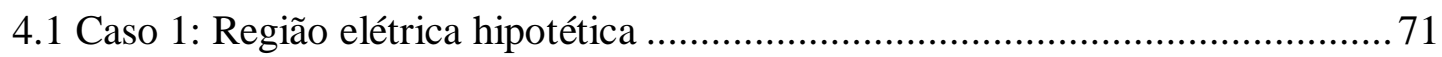

4.1.1 Condições iniciais para cálculos na rede primária ........................................ 72

4.1.2 Condições iniciais para cálculos na rede secundária ...................................... 74

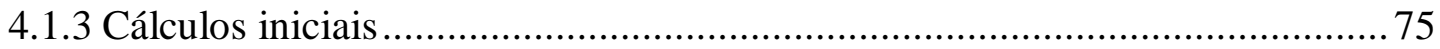

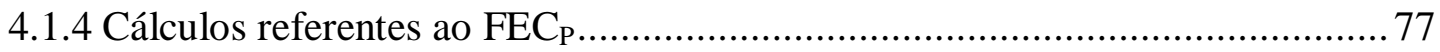

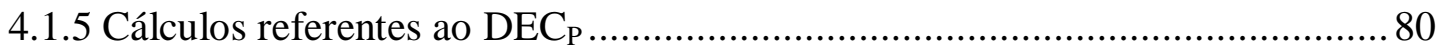

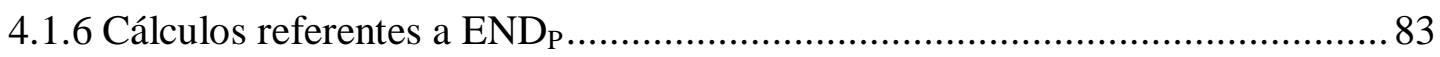

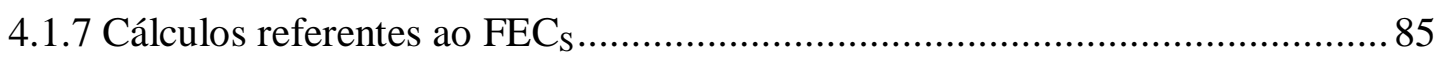

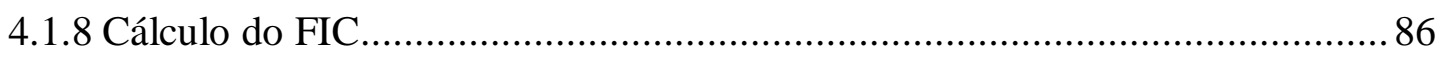

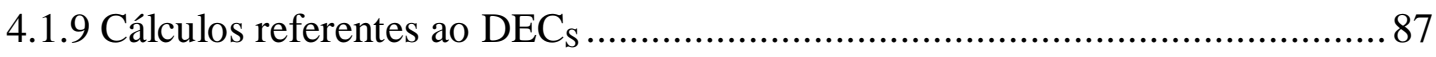




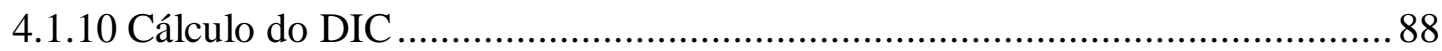

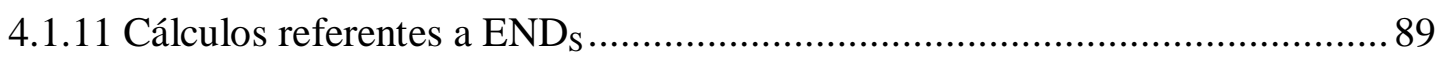

4.1.12 Discussão dos primeiros resultados ..................................................... 90

4.1.13 Análise dos impactos das ações de planejamento nos indicadores

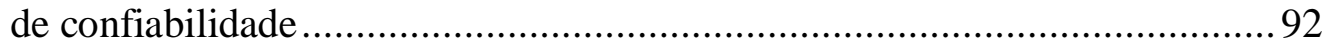

4.1.13.1 Substituição do tipo de rede primária...................................................... 92

4.1.13.2 Instalação de dispositivo de seccionamento ........................................... 94

4.1.13.3 Instalação de dispositivos de proteção ...................................................... 96

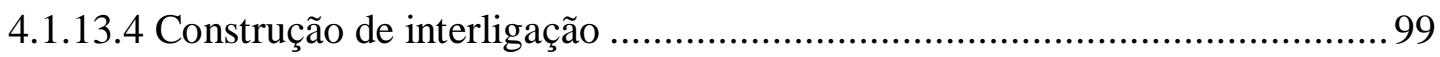

4.1.13.5 Automação de dispositivos de proteção e/ou seccionamento.................... 101

4.1.13.6 Substituição do tipo de rede secundária ................................................. 102

4.1.13.7 Desmembramento de circuito secundário ............................................. 103

4.1.14 Comparação técnico-econômica das opções ................................................ 104

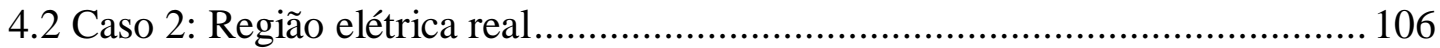

4.2.1 Descrição da região elétrica analisada ...................................................... 106

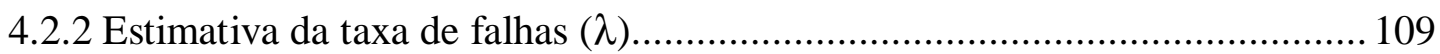

4.2.3 Estimativa dos tempos de restabelecimento ................................................ 109

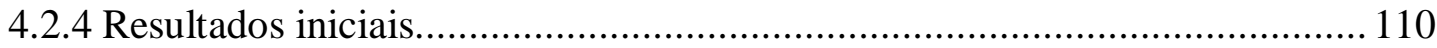

4.2.5 Análise dos impactos das ações de planejamento nos indicadores

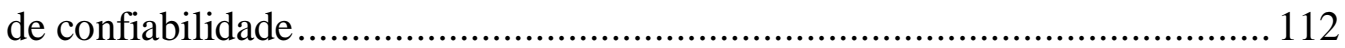

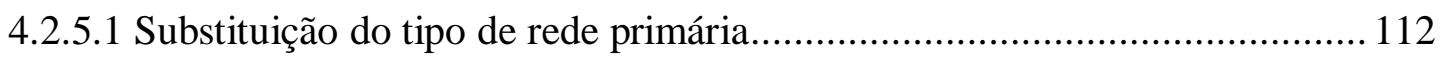

4.2.5.2 Instalação de dispositivos de seccionamento ........................................... 113

4.2.5.3 Instalação de dispositivos de proteção ................................................. 115

4.2.5.4 Construções de interligações ................................................................ 119

4.2.5.5 Automação de dispositivos de preteção e/ou seccionamento...................... 121

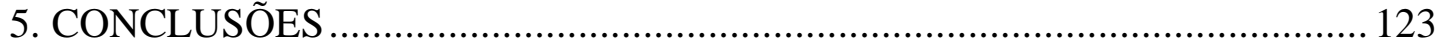

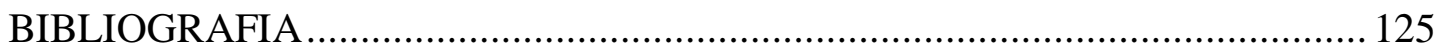

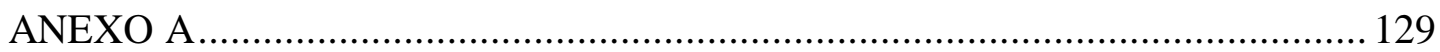




\section{LISTA DE FIGURAS}

Figura 2.1-1 - Alimentador subdividido em blocos ........................................... 15

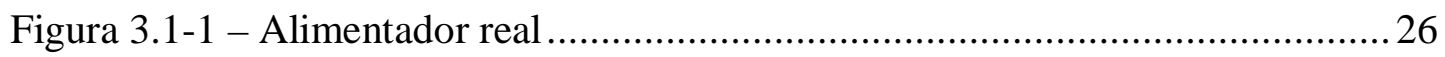

Figura 3.1-2 - Equivalente do alimentador real ............................................ 27

Figura 3.4-1 - Coordenação entre religador e elos fusíveis.................................. 32

Figura 3.4-2 - Curvas de atuação dos dispositivos de proteção .............................. 33

Figura $3.8-1$ - Regiões elétricas ............................................................... 43

Figura 3.9-1 - Rede com dois alimentadores manobráveis ................................ 44

Figura 3.12-1 - Distribuições de probabilidades para duas variáveis com mesma média.................................................................... 53

Figura 3.12-2 Ajustamento da função densidade ao histograma..............................54

Figura 3.12-3 - Distribuições para os três tempos considerados .............................55

Figura 3.16-1 - Rede de distribuição secundária ..............................................63

Figura 3.21-1 - Distribuição de probabilidade para DIC ...................................... 68

Figura 4.1-1 - Região elétrica hipotética ..................................................... 71

Figura 4.1.3-1 - Equivalente da região elétrica................................................ 76

Figura 4.1.13.2-1 - Instalação de chave faca no bloco 5 ...................................... 94

Figura 4.1.13.4-1 - Construção de interligação ................................................... 99

Figura 4.2.1-1 - Região elétrica real ....................................................... 108 


\section{LISTA DE TABELAS}

Tabela 1.3.1 - Indicadores controlados na etapa de maturidade 08

Tabela 2.1-1 - Matriz de Restabelecimento dos Blocos. 16

Tabela 3.2-1 - Matriz de classificação de blocos..................................................2 29

Tabela 3.6-1 - Matriz de quantidades prováveis de defeitos 36

Tabela 3.7-1 - Matriz das ponderações do número de consumidores associados aos blocos afetados.

Tabela 3.10-1 - Tempos de restabelecimento para linhas i, sem blocos do tipo Restabelecível nem Transferível.

Tabela 3.10-2 - Tempos de restabelecimento para linhas i, ou com blocos do tipo Restabelecível ou com blocos do tipo Transferível

Tabela 3.10-3 - Tempos de restabelecimento para linhas i, tanto com blocos do tipo Restabelecível como do tipo Transferível

Tabela 3.10-4 - Matriz da duração da indisponibilidade dos blocos.

Tabela 3.11-1 - Matriz das ponderações dos consumidores à duração da indisponibilidade dos blocos

Tabela 3.13-1 - Matriz das ponderações dos consumos associados às durações das indisponibilidades dos blocos.

Tabela 3.14-1 - Matriz de classificação de blocos, considerando-se os equipamentos como blocos especiais

Tabela 3.14-2 - Matriz de quantidades prováveis de defeitos, considerando-se as taxas de falhas dos equipamentos

Tabela 3.23-1 - Quadro comparativo 70

Tabela 4.1.1-1 - Dados dos blocos da rede primária. 73

Tabela 4.1.1-2 - Tempos de restabelecimento para áreas urbana e rural 74

Tabela 4.1.2-1 - Dados da rede de distribuição secundária e número de Consumidores

Tabela 4.1.3-1 - Matriz de classificação de blocos 76 
Tabela 4.1.4-1 - Matriz de quantidades prováveis de defeitos na rede primária.

Tabela 4.1.4-2 - Matriz das ponderações do número de consumidores associados aos blocos afetados.

Tabela 4.1.4-3 - Dados dos blocos da rede primária, considerando-se o histórico das taxas de falhas para a região elétrica considerada...... 78

Tabela 4.1.4-4 - Matriz de quantidades prováveis de defeitos na rede primária, considerando-se as taxas de falhas próprias da região

Tabela 4.1.4-5 - Número de interrupções anuais prováveis em cada bloco

Tabela 4.1.4-6 - Matriz das ponderações dos consumidores associados aos blocos afetados

Tabela 4.1.4-7 - Contribuições absolutas e relativas das falhas de cada bloco para o $\mathrm{FEC}_{\mathrm{P}}$ da região elétrica

Tabela 4.1.5-1 - Matriz da duração da indisponibilidade dos blocos

Tabela 4.1.5-2 - Matriz das ponderações dos consumidores à duração da indisponibilidade dos blocos

Tabela 4.1.5-3 - Tempos de restabelecimento para áreas urbana e rural 82

Tabela 4.1.5-4 - Matriz das duração da indisponibilidade dos blocos, após acertos dos tempos de restabelecimento 82

Tabela 4.1.5-5 - Matriz das ponderações dos consumidores à duração da indisponibilidade dos blocos, após acertos dos tempos de restabelecimento.

Tabela 4.1.5-6 - Tempo anual médio em que os blocos estarão interrompidos, em horas

Tabela 4.1.5-7 - Contribuições absolutas e relativas das falhas de cada bloco, para o $\mathrm{DEC}_{\mathrm{P}}$ da região elétrica

Tabela 4.1.6-1 - Matriz das ponderações dos consumos associados às durações das indisponibilidades dos blocos

Tabela 4.1.6-2 - Contribuições absolutas e relativas das falhas de cada bloco, para a $\mathrm{END}_{\mathrm{P}}$ da região elétrica

Tabela 4.1.6-3 - ENDP por bloco..... 84 
Tabela 4.1.7-1 - Número de interrupções devido a falhas no circuito secundário

Tabela 4.1.8-1 - FIC para cada um dos consumidores ligados nos respectivos circuitos.

Tabela 4.1.9-1 - Duração das interrupções, devido a falhas no circuito secundário, em horas

Tabela 4.1.10-1 - DIC para cada um dos consumidores ligados nos respectivos circuitos

Tabela 4.1.11-1 - END , em kWh 90

Tabela 4.1.12-1 - Resultados globais

Tabela 4.1.12-2 - Principais resultados na rede primária

Tabela 4.1.12-3 - Outros resultados globais 91

Tabela 4.1.13.1-1 - Previsão dos resultados globais, com substituição do tipo de rede primária

Tabela 4.1.13.1-2 - Outros resultados previstos para a substituição da rede primária

Tabela 4.1.13.1-3 - DIC e FIC para os circuitos ligados ao alimentador 1

Tabela 4.1.13.2-1 - Previsão dos resultados globais, com instalação de dispositivo de seccionamento.

Tabela 4.1.13.2-2 - Outros resultados previstos, com a instalação de dispositivo de seccionamento 95

Tabela 4.1.13.2-3 - DIC para os circuitos ligados aos blocos 7 e 8 96

Tabela 4.1.13.3-1 - Previsão dos resultados globais, com substituição de chave fusível por religador automático de distribuição

Tabela 4.1.13.3-2 - Outros resultados previstos, com a substituição de chave fusível por religador automático de distribuição 97

Tabela 4.1.13.3-3 - DIC e FIC para os circuitos ligados ao bloco 6. 97

Tabela 4.1.13.3-4 - Previsão dos resultados globais, com substituição de chave faca por seccionalizador, além da substituição anterior. 98

Tabela 4.1.13.3-5 - Outros resultados previstos, com substituição de chave faca por seccionalizador, além da substituição anterior. 
Tabela 4.1.13.3-6 - DIC e FIC previstos, com substituição de chave faca por seccionalizador, além da substituição anterior

Tabela 4.1.13.4-1 - Previsão dos resultados globais, com a interligação entre alimentadores

Tabela 4.1.13.4-2 - Outros resultados previstos, com a interligação entre Alimentadores. 100

Tabela 4.1.13.5-1 - Previsão dos resultados globais com automação da rede 101

Tabela 4.1.13.5-2 - Outros resultados previstos com automação da rede. 101

Tabela 4.1.13.5-3 - DIC previstos com automação da rede 102

Tabela 4.1.13.6-1 - Indicadores após substituição da rede secundária 103

Tabela 4.1.13.7-1 - Indicadores após desmembramento do circuito secundário..... 103

Tabela 4.1.14-1 - Quadro comparativo para o exemplo 105

Tabela 4.2.1-1 - Dados dos alimentadores da região elétrica considerada 106

Tabela 4.2.1-2 - Tempos de restabelecimento para áreas urbana e rural 107

Tabela 4.2.3-1 - Tempos de restabelecimento para áreas urbana e rural 110

Tabela 4.2.4-1 - Dados globais da região elétrica

Tabela 4.2.4-2 - Resultados por Subestação 111

Tabela 4.2.4-3 - Resultados por Alimentador

Tabela 4.2.5.1-1 - Dados globais da região elétrica, após substituição dos condutores do bloco 423

Tabela 4.2.5.1-2 - Resultados por subestação

Tabela 4.2.5.1-3 - Resultados por alimentador

Tabela 4.2.5.2-1 - Indicadores globais da região elétrica, após instalação de dispositivos de seccionamento.

Tabela 4.2.5.2-2 - Resultados por subestação

Tabela 4.2.5.2-3 - Resultados por alimentador. 114

Tabela 4.2.5.3-1 - Indicadores globais após instalação de chaves fusíveis. 
Tabela 4.2.5.3-3 - Resultados por alimentador

Tabela 4.2.5.3-4 - Blocos que mais contribuem para o $\mathrm{DEC}_{\mathrm{P}}$ de cada Alimentador, conforme Anexo A

Tabela 4.2.5.3-5 - Indicadores globais após instalação de religadores automáticos de distribuição

Tabela 4.2.5.3-6 - Resultados por subestação 118

Tabela 4.2.5.3-7 - Resultados por alimentador 118

Tabela 4.2.5.4-1 - Indicadores globais após interligações

Tabela 4.2.5.4-2 - Resultados por subestação 119

Tabela 4.2.5.4-3 - Resultados por alimentador 120

Tabela 4.2.5.5-1 - Indicadores globais com automação 121

Tabela 4.2.5.5-2 - Resultados por subestação 121

Tabela 4.2.5.5-3 - Resultados por alimentador 


\section{LISTA ABREVIATURAS E SIGLAS}

ANEEL Agência Nacional de Energia Elétrica

CPFL Companhia Paulista de Força e Luz

CSPE Comissão de Serviços Públicos de Energia

DEC Duração Equivalente de Interrupção por Consumidor

DIC Duração de Interrupção Individual por Consumidor

DNAEE Departamento Nacional de Águas e Energia Elétrica

END Energia não Distribuída

FEC Freqüência Equivalente de Interrupção por Consumidor

FIC Frequiência de Interrupção Individual por Consumidor

FMEA Análise dos Modos e Efeitos das Falhas

FP Fator de Falhas Permanentes

FTA Análise da Árvore das Falhas

IQT Índice de Queima de Transformadores de distribuição

MTTR Tempo Médio de Reparo

PTR Pontos de Telecontrole de Rede

SE Subestação de distribuição

TA Tempo de tranferência automática dos blocos

TF Tempo médio de preparação da turma de emergência, localização do defeito e reparo do transformador de distribuição

TL Tempo médio de preparação da turma de emergência, localização do defeito e abertura da chave de seccionamento e/ou proteção imediatamente a montante do bloco com defeito

TM Tempo de transferência manual dos blocos

TR Tempo médio de reparo do bloco (MTTR) 
TS Tempo médio de preparação da turma de emergência, localização do defeito e reparo da rede secundária de distribuição

TT Tempo de transferência dos blocos 


\section{LISTA DE SÍMBOLOS}

$\mathrm{Ca}$ (i) número de consumidores do universo considerado, atingidos na interrupção $i$

t(i) tempo de duração, em horas e centésimos de hora, da interrupção $i$

Cs número total de consumidores do universo considerado

FECm calculado de maneira idêntica ao FEC, porém levando-se em conta apenas interrupções momentâneas

$\lambda_{\mathrm{M}} \quad$ taxa de falhas momentâneas, referente a faltas que são eliminadas automaticamente, após religamento

$\lambda_{\mathrm{S}} \quad$ taxa de falhas permanentes, referente a faltas que requerem a presença da equipe de campo, para restabelecimento da energia

$\lambda_{\mathrm{j}} \quad$ taxa de falhas anual do bloco $j$

$\lambda_{\text {redet }}$ taxa de falhas por quilômetro para o tipo de rede $t$

$l_{\mathrm{t}} \quad$ porção do comprimento do bloco $j$, que possui o tipo de rede $t$, em quilômetros

$\mathrm{PI}_{\mathrm{j}} \quad$ quantidade provável de interrupções, devido a defeito permanente no bloco $j$

$\mathrm{FEC}_{\mathrm{P}}$ parcela do $F E C$ referente a falhas originadas na rede de distribuição primária

$\mathrm{NI}_{\mathrm{P}}(\mathrm{j}) \quad$ quantidade total média de interrupções não programadas do bloco $j$, originadas na rede de distribuição primária, durante o período analisado

$\mathrm{N}(\mathrm{j}) \quad$ número de consumidores ligados ao bloco $j$

$\mathrm{CFEC}_{\mathrm{P}}(\mathrm{i})$ contribuição do bloco $i$ para o $F E C_{P}$

$\mathrm{DEC}_{\mathrm{P}}$ parcela do $D E C$ referente a falhas originadas na rede de distribuição primária

$\operatorname{DI}_{\mathrm{P}}(\mathrm{j})$ duração total das interrupções do bloco $\mathrm{j}$, devido a ocorrências não programadas, originadas na rede distribuição primária, durante o período analisado

$\mathrm{CDEC}_{\mathrm{P}}(\mathrm{i})$ contribuição do bloco $i$ para o $D E C_{P}$.

$\mu \quad$ média 
$E_{\mathrm{P}}$ parcela da $E N D$ referente a falhas originadas na rede de distribuição primária

C(i) consumo anual do bloco $i$

$\operatorname{CEND}_{\mathrm{P}}(\mathrm{i})$ contribuição do bloco $i \mathrm{p} /$ a $E N D_{P}$

$\operatorname{END}_{\mathrm{P}}(\mathrm{j}) \quad$ energia não distribuída para o bloco $j$

$\lambda_{\mathrm{j}}{ }^{\prime} \quad$ taxa anual de manutenções do bloco $j$

$\lambda_{\text {redet }}{ }^{\prime}$ taxa de manutenções por quilômetro, para o tipo de rede $t$

$\mathrm{NI}_{\mathrm{S}}(\mathrm{i}) \quad$ número médio de interrupções a que estarão sujeitos todos os consumidores atendidos pelo transformador $i$, devido a falhas provenientes do próprio equipamento ou da respectiva rede secundária

$\lambda_{\mathrm{QT}}(\mathrm{i}) \quad$ taxa de falhas do transformador $i$

$\lambda_{\mathrm{RS}}$ (i) taxa de falhas da rede secundária atendida pelo transformador $i$

$\lambda_{\mathrm{RSt}}$ taxa de falhas por quilômetro, da rede secundária tipo $t$

FEC $_{S} \quad$ parcela do $F E C$ referente a falhas originadas na rede de distribuição secundária

Ns(i) número de consumidores ligados à rede secundária atendida pelo transformador $i$

NIPJ quantidade provável de interrupções - não programadas, originadas na rede de distribuição primária - do bloco onde está ligado o transformador $j$, durante o período analisado, conforme equação 3.7-1

$\mathrm{DEC}_{\mathrm{S}} \quad$ parcela do $D E C$ referente a falhas originadas na rede de distribuição secundária

$\mathrm{DI}_{\mathrm{S}}(\mathrm{i})$ tempo estimado, durante o qual os consumidores ligados ao circuito $i$ ficarão sem energia, devido a interrupções originadas no respectivo circuito secundário, durante o período considerado

DIPJ duração total provável das interrupções - não programadas, originadas na rede de distribuição primária - do bloco onde está ligado o transformador $j$, durante o período analisado, conforme equação 3.11-1. 


\section{PREÂMBULO}

\subsection{APRESENTAÇÃO}

Este trabalho está estruturado em cinco capítulos.

No primeiro, é apresentado um breve panorama que antecede o programa de privatizações no setor elétrico brasileiro, bem como discutidos alguns ingredientes que estiveram presentes naquele período.

Também são apresentados alguns aspectos da nova regulamentação do setor elétrico nacional, além das razões que motivaram o desenvolvimento da metodologia desenvolvida, através do delineamento de seus objetivos.

No capítulo 2 são apresentadas algumas das bibliografias consultadas, onde são revistos trabalhos pertinentes ao assunto e analisados documentos que contribuíram de maneira bastante significativa, para o desenvolvimento deste trabalho.

O capítulo 3 descreve a metodologia de análise dos impactos das ações de planejamento, nos indicadores de confiabilidade dos sistemas de distribuição. Através dela é possível estimar os efeitos de cada implementação planejada, nos indicadores $D E C, F E C, D I C, F I C$ e energia não distribuída $(E N D)$, sendo possível a comparação de diversas alternativas propostas.

São ainda apresentados alguns direcionadores que auxiliam as tomadas de decisão.

No capítulo 4 são simulados dois casos: um numa rede hipotética e um numa rede real, onde são comparados e discutidos os resultados de algumas proposições. Neles é possível verificar a eficiência e a aplicabilidade prática do modelo.

No capítulo 5 são apresentadas as principais conclusões e recomendações.

\subsection{INTRODUÇÃO}

Desde o final da década de 70, o setor elétrico internacional tem passado por profundas mudanças, iniciadas pelo governo de Margaret Tatcher na Inglaterra, que defendia a redução da presença do Estado na economia. [1]

Começavam assim vários debates, em diversos países, sobre as conseqüências da privatização de monopólios naturais e os diferentes modelos para torná-la viável. 
No Brasil, segundo Leite, a transição para uma nova política de energia, iniciada na década de 90, vem sofrendo várias influências, como a grave crise financeira do Estado, com a deterioração da administração pública e a impossibilidade de transferência de recursos do Tesouro para o setor de eletricidade, como havia ocorrido desde a fase inicial da intervenção estatal até o final da década de 60. [2]

No cenário internacional, com a globalização da economia, começam a predominar as transações estritamente financeiras sobre o comércio de bens e serviços.

No campo político brasileiro, disputas estaduais e desobediência civil das concessionárias regionais, em relação ao cumprimento das decisões do órgão regulador e à Constituição Federal de 1988 - que não atribuía para o Poder Público estadual e municipal responsabilidades explícitas de investimento na expansão dos serviços de energia elétrica - comprometiam o alcance das diretrizes energéticas nacionais.

Outros aspectos relevantes foram: o aumento da força política de grandes consumidores, pressionando a redução de tarifas e a forte influência de empreiteiros, que passavam a interferir no plano de obras das concessionárias públicas, pois dependiam dessas obras estatais para suas ações empresariais.

A reunião desses ingredientes, somados a outros - como a falta de estímulo à eficiência - levou ao aumento do endividamento e à inviabilidade financeira do setor elétrico.*

Visando corrigir os principais problemas discutidos, o governo Fernando Henrique Cardoso optou pela privatização das empresas estatais federais e exerceu forte influência sobre os governos estaduais, para que também trilhassem esse caminho.

* MARANHÃO, R. Curso Avançado de Administração. Fundação Getúlio Vargas Escola de Administração de Empresas de São Paulo. Material de aula, Outubro 1996 a Agosto 1997. 
Dentre as semelhanças observadas na reestruturação de diversos países que também implementaram esse tipo de participação privada, percebe-se forte estímulo à concorrência, com a tentativa de se manter um grau satisfatório de regulamentação, que não prejudique a liberdade de mercado e estabeleça regras para garantir os interesses das Nações.*

Com a privatização das empresas concessionárias de energia elétrica, foram assinados contratos de concessão com o Poder Concedente (Agência Nacional de Energia Elétrica - ANEEL), que estabelecem um conjunto de exigências, obrigações, procedimentos, indicadores de natureza técnica e comercial, além de penalidades, com o objetivo de assegurar a qualidade dos serviços prestados por essas empresas aos consumidores.

A legislação passou a estabelecer limites diferenciados para cada uma das empresas concessionárias, baseando-se em seus históricos, visando preservar e/ou aumentar a qualidade do fornecimento existente antes das privatizações.

O Estado, através da ANEEL e de órgãos estaduais - como a Comissão de Serviços Públicos de Energia (CSPE), no caso de São Paulo - passa a exercer as atividades de regulador e fiscalizador das concessionárias, quanto ao correto cumprimento das obrigações assumidas.

Algumas empresas já estão atuando dentro desse novo contexto e assinaram Contratos de Concessão, comprometendo-se a cumprir todas as regras relacionadas à sistemática de controle da qualidade do fornecimento de energia elétrica, neles dispostas.

Esse controle está sendo executado em etapas sucessivas, considerando indicadores e padrões individuais e coletivos, sendo que, a violação dos padrões individuais definidos poderá gerar penalidades para as concessionárias em favor dos consumidores, assim como a violação de padrões coletivos acarretará recolhimentos ao órgão regulador.

* MACKERRON, G. "O Modelo Inglês de Energia Elétrica". Palestra. CPFL, julho 1999. 
Os vários indicadores controlados contemplam três enfoques: a qualidade do atendimento comercial, a qualidade do produto e a qualidade do serviço. O presente trabalho estará abordando os aspectos que influenciam esse último - especialmente os relacionados à duração e à freqüência de interrupções individuais e coletivas onde há grande possibilidade de interações com as atividades de Planejamento do Sistema de Distribuição das empresas.

\subsection{INDICADORES DE QUALIDADE DO SERVIÇO, RELACIONADOS COM A DURAÇÃO E FREQÜÊNCIA DE INTERRUPÇÕES, PARA CONSUMIDORES ATENDIDOS EM TENSÃO DE DISTRIBUIÇÃO}

Os Contratos de Concessão das empresas distribuidoras apresentam algumas variações entre si. Alguns são cronologicamente divididos em duas ou três etapas, além de diferentes períodos e universos de apuração.

Entretanto, todos buscam o objetivo comum de se estabelecer regras claras, que possam regular os serviços de eletricidade.

Neste item serão apresentados alguns termos que aparecem nesses Contratos de Concessão [3], visando a familiarização com seus principais conceitos.

\subsubsection{Indicadores controlados para a etapa de adaptação}

Normalmente inicia-se a partir da assinatura do Contrato de Concessão. Nessa etapa são definidos pelo órgão regulador, os seguintes indicadores:

\section{a. DEC (Duração Equivalente de Interrupção por Consumidor)}

Exprime o intervalo de tempo contínuo ou não em que, em média, cada consumidor do universo avaliado ficou privado do fornecimento de energia elétrica, no período de apuração, considerando-se as interrupções iguais ou superiores a 1 minuto, ou a 3 minutos, dependendo do Contrato.

Fórmula de cálculo:

$D E C=\frac{\sum_{i=1}^{N} C a(i) \times t(i)}{C s}$ [horas/consumidor] 
Onde:

$D E C$ é a duração equivalente de interrupção por consumidor, expressa em horas e centésimos de hora, por cliente;

Ca(i) é o número de consumidores do universo considerado, atingidos na interrupção $i$;

t(i) é o tempo de duração, em horas e centésimos de hora, da interrupção $i$;

(i) é o número da interrupção considerada, variando de 1 a $N$, sendo $N$ o número de interrupções ocorridas durante o período de apuração;

Cs é o número total de consumidores do universo considerado, entendido como sendo o número de consumidores existentes no último dia de cada mês de apuração no caso de apuração mensal e média aritmética dos números de consumidores existentes nos últimos dias de cada mês do período, no caso de apuração trimestral ou anual.

\section{b. FEC (Freqüência Equivalente de Interrupção por Consumidor)}

Exprime o número de interrupções que, em média, cada consumidor do universo avaliado sofreu no período de apuração, considerando-se as interrupções iguais ou superiores a 1 minuto, ou a 3 minutos, dependendo do Contrato.

Fórmula de cálculo:

$F E C=\frac{\sum_{i=1}^{N} C a(i)}{C s}$ [interrupções/consumidor]

Onde:

FEC é a freqüência equivalente de interrupções por consumidor, expressa com 2 casas decimais;

$\mathrm{Ca}(i)$ é o número de consumidores do universo considerado, atingidos na interrupção (i);

(i) é o número da interrupção considerada, variando de 1 a $N$, sendo $N$ o número de interrupções ocorridas durante o período de apuração;

Cs é o número total de consumidores do universo considerado, entendido como sendo o número de consumidores existentes no último dia de cada mês de apuração no caso de apuração mensal e média aritmética dos números de consumidores existentes nos últimos dias de cada mês do período, no caso de 
apuração trimestral ou anual.

\section{c. DIC (Duração de Interrupção Individual por Consumidor)}

Exprime o intervalo de tempo, contínuo ou não, em que um determinado consumidor ficou privado do fornecimento de energia elétrica, no período de apuração, considerando-se as interrupções maiores ou iguais a 1 minuto, ou a 3 minutos, dependendo do Contrato.

Fórmula de cálculo:

$D I C=\sum_{i=1}^{N} t(i)$ [horas]

Onde:

DIC é a duração das interrupções do consumidor considerado, expressa em horas e centésimos de hora;

t(i) é o tempo de duração, em horas e centésimos de hora, da interrupção (i);

(i) é o índice de cada interrupção variando de 1 a N;

$N$ é o número de interrupções do consumidor considerado, no período de apuração.

\section{d. FIC (Freqüiência de Interrupção Individual por Consumidor)}

Exprime o número de interrupções que um determinado consumidor sofreu no período de apuração, considerando-se as interrupções maiores ou iguais a 1 minuto, ou a 3 minutos, dependendo do Contrato.

Fórmula de cálculo:

$F I C=N$ [interrupções]

Onde:

FIC é a freqüência das interrupções do consumidor considerado;

$N$ é o número de interrupções do consumidor considerado, no período de apuração.

Pode-se constatar que o $D E C$ é igual à média dos valores de $D I C$, assim como o $F E C$ é igual à média dos valores de FIC.

\subsubsection{Períodos de apuração do DEC, FEC, DIC e FIC}

Período de apuração dos indicadores DEC, FEC, DIC e FIC é definido como o 
intervalo de tempo entre o início e o fim da contabilização das interrupções de fornecimento de energia elétrica dos consumidores de um determinado universo de apuração.

São utilizados os períodos mensais, trimestrais e anuais, sendo que as apurações mensais são realizadas para cada um dos meses do ano e as trimestrais correspondem a cada trimestre civil.

Já as apurações anuais, que também são realizadas mensalmente, englobam todas as interrupções das apurações mensais dos últimos 12 meses, incluindo-se o mês de apuração.

\subsubsection{Universos de apuração do DEC e FEC}

Os indicadores $D E C$ e $F E C$ podem ser apurados para diferentes universos, como por exemplo:

- Sistema de Distribuição da empresa: Inclui todos os consumidores atendidos em tensão de distribuição. Considera, portanto, todos os consumidores atendidos com tensão nominal igual ou inferior a $34,5 \mathrm{kV}$.

- Sistema de Distribuição de Área de Concessão: Inclui todos os consumidores de cada uma das áreas de concessão atendidos em tensão de distribuição. Considera, portanto, todos os consumidores atendidos com tensão nominal igual ou inferior a $34,5 \mathrm{kV}$ da área de concessão.

- Conjuntos de consumidores: Inclui todos os consumidores pertencentes a cada um dos conjuntos em vigor e definidos pelo DNAEE.

\subsubsection{Universos de apuração do DIC e FIC}

São apurados os indicadores DIC e FIC para os seguintes universos:

- Consumidores atendidos por sistema subterrâneo;

- Consumidores atendidos em alta tensão;

- Consumidores atendidos em média tensão situados em zona urbana;

- Consumidores atendidos em baixa tensão situados em zona urbana, inclusive os pertencentes a conjuntos com menos de 1.000 consumidores; 
- Consumidores localizados em zona rural.

\subsubsection{Indicadores controlados para a etapa de transição}

Nessa etapa, para o caso específico de DEC, FEC, DIC e FIC, permanecem os mesmos indicadores da etapa de adaptação.

\subsubsection{Indicadores controlados para a etapa de maturidade}

Nessa etapa são controlados os indicadores da etapa anterior acrescentando-se, nos universos de apuração, novo agrupamento de consumidores denominado famílias de redes.

A tabela abaixo apresenta o resumo dos indicadores individuais e coletivos até aqui abordados, a serem controlados:

Tabela 1.3-1 - Indicadores controlados na etapa de maturidade

\begin{tabular}{|c|c|c|}
\hline Indicador & Abrangência & Período de Apuração \\
\hline DEC & $\begin{array}{c}\text { Toda empresa/Áreas de } \\
\text { Concessão/Conjuntos/Famílias }\end{array}$ & Mensal/Trimestral/Anual \\
\hline FEC & $\begin{array}{c}\text { Toda empresa/Áreas de } \\
\text { Concessão/Conjuntos/Famílias }\end{array}$ & Mensal/Trimestral/Anual \\
\hline DIC & Individual & Reclamação ou Auditoria \\
\hline FIC & Individual & Reclamação ou Auditoria \\
\hline
\end{tabular}

\subsection{OBJETIVO}

Há tempos que as concessionárias de energia elétrica têm realizado acompanhamentos de alguns indicadores de qualidade, como é o caso do $D E C$ e do FEC, regulamentados pela Portaria n 046/DNAEE de 17/04/1978. Entretanto, no caso de várias concessionárias, não havia tanta necessidade de rigor no controle dos padrões estabelecidos, porque seus índices sempre estiveram bastante melhores que 
os determinados pela legislação.

Isso ocorria basicamente porque, por parte dessas empresas, havia a disposição de se privilegiar a qualidade do fornecimento, sem análises acuradas de custos. Além disso, a legislação estabelecia as mesmas exigências para todas as concessionárias, das diferentes regiões, com diferentes características e exigências de mercado.

Sendo assim, de maneira geral, as grandes distribuidoras do Sul e Sudeste do Brasil não tinham dificuldade no cumprimento dos padrões estabelecidos nacionalmente.

Agora, com a fixação de padrões de qualidade mais exigentes, onde foram estabelecidos limites diferenciados para cada uma das empresas concessionárias, além da definição de diferentes períodos de apuração e vários universos de abrangência, torna-se bastante importante a busca pela sistematização de métodos de análise e melhoria dos índices de qualidade, obtendo-se assim soluções mais eficazes.

Geralmente, para casos em que se busca a melhoria de um indicador específico para uma determinada região, são realizadas inspeções e definidas ações de melhoramentos globais pela Área de Manutenção.

Essas ações de Manutenção são bastante importantes e contribuem significativamente para a melhoria da qualidade do fornecimento de energia elétrica; porém, embora seja bastante razoável admitir, que qualquer obra de melhoria na rede elétrica influenciará positivamente na qualidade de fornecimento a determinada área, não é trivial dimensionar os ganhos na implementação de determinadas ações, em cada um dos indicadores.

Fica clara, portanto, a necessidade de se desenvolver ferramentas e mecanismos, visando direcionar ações específicas, na busca da melhoria de um ou outro índice em particular, ao invés de implementações não focadas, de correções de pouca profundidade e da conquista de resultados parciais.

Em 1964, Todd já advertia sobre a necessidade dessa quantificação. Assim seria possível analisar os efeitos específicos, que determinadas propostas de novos projetos e mudanças nos sistemas elétricos iriam causar nas interrupções de fornecimento aos consumidores. [4]

Sendo assim, propõe-se que, já na etapa de Planejamento, sejam realizados levantamentos prévios de várias possibilidades de interferências em cada um dos 
indicadores de qualidade, quando da concepção do Sistema Elétrico. Dessa forma, é possível obter sinalizações das conseqüências do que será implementado, reduzindose gastos futuros com ações paliativas de Manutenção.

A incorporação dos estudos de confiabilidade ao processo de planejamento amplia o nível de análise das alternativas, auxiliando nas tomadas de decisão, além de identificar soluções de menor custo, sem prejudicar a qualidade do fornecimento. [5] O modelo aqui proposto deverá ser capaz de estimar os efeitos das ações de Planejamento, nos índices de confiabilidade futuros - particularmente DEC, FEC, DIC e FIC - além do cálculo da energia não distribuída (END), com base nas interrupções não programadas, visando possibilitar a avaliação dos impactos promovidos por diferentes proposições, seja através da instalação de novos equipamentos de proteção e/ou seccionamento, seja pela construção de interligações, que possibilitem caminhos alternativos de suprimento, seja pela reconfiguração do sistema, ou pela utilização de diferentes tecnologias de redes, ou automação de equipamentos, etc, considerando-se esse novo contexto do Setor Elétrico.

Em suma, pretende-se apresentar uma metodologia para análise das consequiências das interrupções não programadas, na confiabilidade do Sistema Elétrico de Distribuição.

Essa metodologia está sendo estruturada, de maneira a se tornar uma rotina computacional, que integrada a um programa de planejamento já existente e apresentado por Manhães [6], deverá transformar-se numa poderosa ferramenta, capaz de viabilizar análises comparativas, entre as diversas alternativas de planejamento propostas. 


\section{ANÁLISE DA BIBLIOGRAFIA}

Neste Capítulo, inicialmente serão revisadas as referências de caráter geral e posteriormente, as que mais influenciaram o presente trabalho.

Billinton realizou um levantamento das mais relevantes publicações sobre a aplicação de métodos probabilísticos na análise de confiabilidade de sistemas de potência até o início da década de 70 e relata que o despertar do interesse nessa área evidenciou-se por volta de 1933. [7]

Nesse ano, Lyman afirma que os padrões para definição de reserva de capacidade de geração, visando melhorar a continuidade do serviço, poderiam ser melhor definidos, através de rigorosos estudos sobre o desempenho de equipamentos, variações de carga, probabilidade relativa entre os diferentes tipos de falhas e de continuidade do serviço, para diferentes pontos do sistema. [8]

Esse procedimento produziria os melhores resultados, com os menores custos.

Dessa forma, o custo da confiabilidade de um elemento em cada seção do sistema poderia ser determinado e comparado. Com isso haveria a possibilidade de direcionamento de investimentos em partes do sistema, onde há maior probabilidade de se obter os melhores resultados.

Baseando-se na taxa de falhas de cada equipamento, seria ainda possível estabelecer as probabilidades de indisponibilidade do fornecimento, que equivale ao tempo médio em que os consumidores ficariam sem energia, no período considerado. [9] De acordo com Patton, o tratamento dos dados relacionados a taxas de falhas e a tempos envolvidos no restabelecimento do fornecimento pode ser realizado, mediante a utilização de técnicas estatísticas, como Diagramas de Dispersão, Métodos de Regressão Linear e estabelecimento de Distribuições de Probabilidade e Intervalos de Confiança [10]

Além das medidas de indisponibilidade, também discutidas por Todd [4], outras podem ser estabelecidas, como por exemplo, as apresentadas por Gaver; Montmeat; Patton:

- Número anual médio de interrupções por consumidor (F);

- Tempo de interrupção total anual médio por consumidor $(\mathrm{H})$;

- Tempo médio de restabelecimento $(\mathrm{R})$; 
- Número máximo de interrupções anuais esperado, para qualquer consumidor (Fmax);

- Tempo máximo de restabelecimento experimentado por qualquer consumidor $(\mathrm{R} \max )$;

- Probabilidade de algum consumidor vir a sofrer interrupções por período superior a um tempo especificado.

Essas medidas podem ser obtidas a partir do levantamento das taxas de falhas por quilômetro, dos diferentes tipos de estruturas e linhas, para duas condições climáticas: tempestade e tempo normal. [11]

Além disso, devem ser consideradas as taxas de manutenções e as curvas de distribuição dos tempos de reparo, para as diferentes condições atmosféricas e durante manutenções. [11] [12]

A separação de dados, considerando-se as diferentes condições climáticas é bastante importante, para o correto tratamento estatístico das informações, pois há grande variação no comportamento dos componentes do sistema elétrico, sob diferentes condições atmosféricas. Entretanto, para o objetivo a que se propõe o presente trabalho - que é a comparação macro entre alternativas de planejamento, considerando-se as estimativas de indicadores anuais - não será adotado tal procedimento.

Conforme apresentado por Oprisan et al., além das anteriores, uma série de outras relações pode ser obtida, mediante o estabelecimento de procedimentos eficientes de coleta e registro de ocorrências [13], visando à análise do desempenho dos sistemas ou de seus diversos componentes como, por exemplo, os propostos por Connor; Parkins:

- Número de faltas por unidade, num período de tempo. Exemplo: Número de faltas por $100 \mathrm{~km}$ de rede aérea, ou número de falhas para cada 100 transformadores por ano;

- Consumidor-hora interrompido por consumidor atendido por ano;

- Consumidor-hora interrompido por falta;

- Energia interrompida por consumidor interrompido por ano;

- Relação entre o número de interrupções de consumidores e o número total de 
consumidores atendidos.

Alguns dos benefícios de se trabalhar com dados estatísticos, a partir de um procedimento padrão para a construção e manutenção de um banco de dados históricos, são:

- Possibilidade de se estimar o número de faltas que irão ocorrer num determinado tipo de rede;

- Comparação entre os dados históricos e os resultados obtidos após a implementação de uma determinada ação de melhoria, a fim de se verificar os ganhos obtidos com a solução implementada. [14]

Algumas metodologias passaram então a ser desenvolvidas, visando quantificar e estimar parâmetros de confiabilidade, utilizando diferentes técnicas, como a aplicação repetida de reduções séries e paralelas [Bazovsky apud Nolan; O'Kelly; Fahy [15]] e o estabelecimento de equações de estado, através da álgebra Booleana e das Cadeias de Markov, discutidas por DeSieno; Stine. [16]

De acordo com Christiaanse, outros métodos foram sendo desenvolvidos, objetivando viabilizar análises práticas em sistemas reais, com maior número de variáveis [17], ou ainda, buscando tornar as análises mais acuradas, através da investigação das diferentes distribuições de probabilidade, conforme apresentado por Billinton; Wojczynski [18] e por Billinton; Goel. [19]

Métodos de Análise dos Modos e Efeitos das Falhas (FMEA), bem como da Árvore das Falhas (FTA), também podem ser utilizados para sistemas elétricos, através do estabelecimento de diagramas de blocos de confiabilidade.

De acordo com Helman; Andery, a partir desses diagramas, é possível identificar o quanto uma falha em determinado componente pode influenciar no desempenho dos demais componentes, ou do sistema globalmente considerado [20], além de possibilitar a identificação dos Conjuntos Mínimos de Corte. [21]

Entretanto, devido à complexidade das configurações do sistema elétrico e à variedade de componentes e suas formas de operação, é difícil aplicar diretamente o FMEA para a elaboração de um programa computacional, que possa ter uma utilização generalizada em Sistemas de Distribuição. Billinton; Wang sustentam tal afirmação e propõem um método bastante interessante, que pode ser generalizado 
para análise de confiabilidade em Sistemas de Distribuição [22].

Outro modelo menos genérico, mas igualmente interessante, que serviu de base para a elaboração de um programa computacional, é apresentado por Kjolle; Sand. Tratase de uma metodologia analítica baseada nas contribuições de todos os componentes e suas consequiências, para as interrupções de fornecimento aos diferentes pontos de carga. O algoritmo acumula índices de confiabilidade para cada ponto de carga, devido à contribuição de cada componente e, ao final da contabilização, apresenta o índice total acumulado. [23]

De acordo com Goel; Billinton, com o aumento da velocidade e capacidade de processamento dos computadores, tem aumentado a utilização das técnicas de simulação de Monte Carlo, nas análises de confiabilidade [24], além da incorporação de novos conceitos, como a utilização de redes neurais [25] e da lógica "Fuzzy" [26].

2.1 SILVA, E. S.; MANHÃES, L. R.; OLIVEIRA, P. R. P.; JOLY, S. V. Z. “Previsão de Confiabilidade de Alimentadores". CPFL. Relatório Interno, 1992. [27]

É apresentada uma metodologia para a previsão dos indicadores de confiabilidade: $D E C, \quad F E C$ e Energia não Distribuída $(E N D)$, referentes a interrupções não programadas, originadas na rede primária de distribuição, considerando-se que os alimentadores são compostos por blocos, delimitados por dispositivos de proteção e/ou seccionamento.

A partir daí, inicia-se a verificação das conseqüências que uma falha em cada um dos blocos, causa nos demais.

Isso é realizado a partir do estabelecimento de uma lógica de classificação dos blocos, quando da ocorrência de falha no sistema.

Tomando-se como exemplo a figura apresentada pelos próprios autores: 


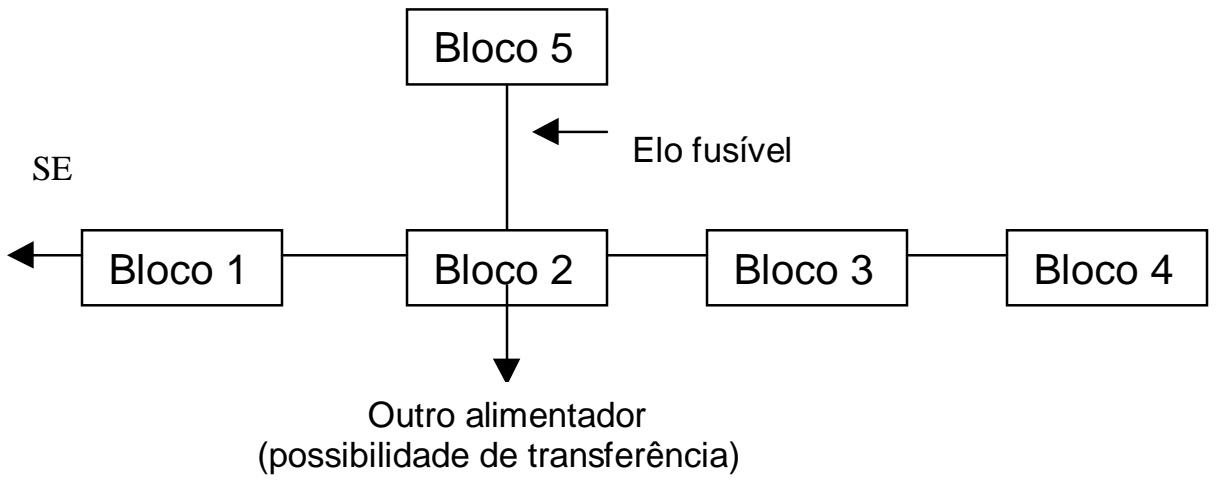

Figura 2.1-1 - Alimentador subdividido em blocos

É possível classificar os blocos em:

- Não atingível (N): Quando o bloco não é interrompido por falha originada no bloco defeituoso em análise. No exemplo da Figura 2.1-1, pode-se perceber que, quando ocorre falha no bloco 5 , os blocos 1, 2, 3 e 4 serão classificados como Não atingível;

- Restabelecível (R): Quando o fornecimento de energia ao bloco pode ser restabelecido, mediante o isolamento do bloco com defeito, através da abertura de chave de seccionamento e/ou proteção a montante. No exemplo: quando há falha no bloco 2, será classificado como Restabelecível o bloco 1;

- Transferível (T): Quando o fornecimento de energia ao bloco pode ser restabelecido, mediante a realização de manobra e transferência da alimentação, através de caminho alternativo. No exemplo: quando ocorre falha no bloco1, todos os demais serão classificados como Transferível, pois podem ser alimentados por outro alimentador;

- Irrestabelecível (I): Quando não é possível restabelecer o fornecimento ao bloco, antes que seja efetuado reparo no bloco defeituoso. No exemplo: quando ocorre falha no bloco 2, os blocos 2, 3, 4 e 5 serão classificados como Irrestabelecível;

- Irrestabelecível com Espera de Transferência (IE): É um tipo de bloco que, além de só poder ter seu restabelecimento após reparo, ainda tem que aguardar o tempo necessário para transferência de blocos do tipo Transferível. No exemplo: caso ocorra defeito no bloco 1 , ele próprio será considerado como Irrestabelecível com Espera de Transferência. 
Então, pode-se montar uma matriz que, para o exemplo da Figura 2.1-1, seria do tipo:

Tabela 2.1-1 - Matriz de Restabelecimento dos Blocos

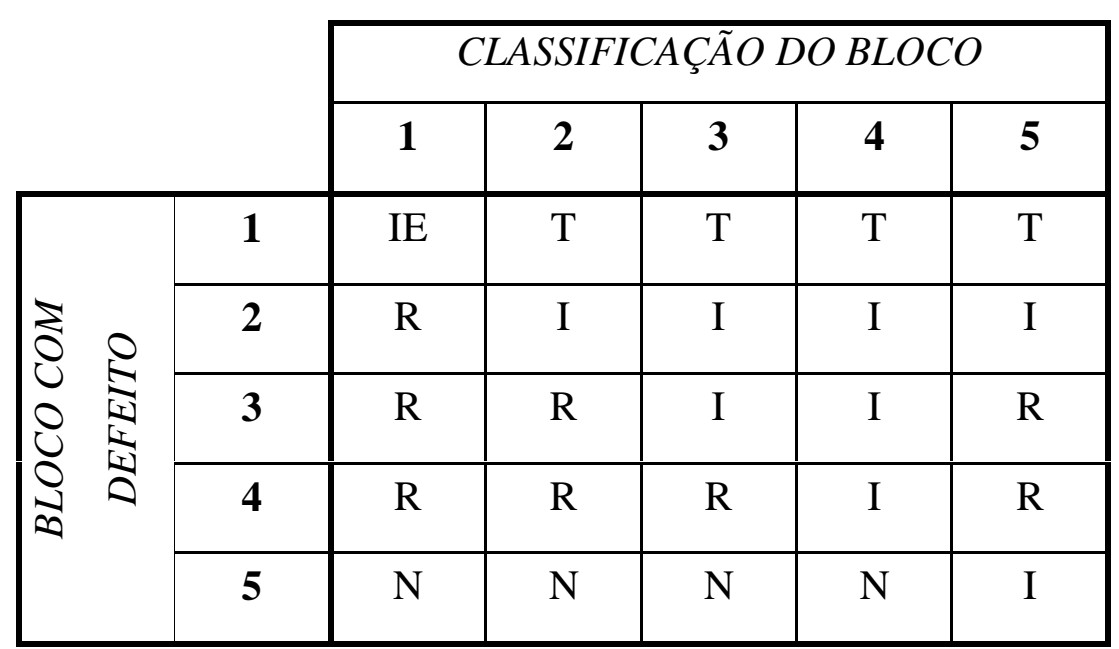

São também definidos tempos médios para as diversas etapas do procedimento de restabelecimento dos blocos:

- Tempo de Conhecimento (TC): Período entre a ocorrência da interrupção e a tomada de conhecimento pela empresa;

- Tempo de Preparo (TP): Período de mobilização da turma de emergência;

- Tempo de Localização (TL): Período entre o início do deslocamento da turma, localização do defeito, abertura da chave a montante do bloco defeituoso e restabelecimento dos blocos do tipo Restabelecível;

- Tempo de Transferência (TT): Período para transferência dos blocos localizados a jusante do bloco defeituoso;

- Tempo de Reparo (TR): Período que inclui a execução de serviços de reparo e restabelecimento do fornecimento;

- Tempo de Manobra para Volta da Configuração Original (TV): Período de realização de manobras, visando o retorno da rede à sua configuração normal.

Com base nos tempos anteriormente apresentados, é então definida a duração da interrupção (TI) de cada bloco, de acordo com sua classificação, ou seja:

- Os blocos do tipo Não Atingível não sofrerão interrupção, então: 
$T I(N)=0$.

- Os blocos do tipo Restabelecível ficarão interrompidos durante o tempo:

$T I(R)=T C+T P+T L$.

- Os blocos do tipo Transferível ficarão interrompidos durante o tempo:

$T I(T)=T C+T P+T L+T T+T V$.

- Os blocos do tipo Irrestabelecível ficarão interrompidos durante o tempo:

$T I(I)=T C+T P+T L+T R$.

- Os blocos do tipo Irrestabelecível com Espera de Transferência ficarão interrompidos durante o tempo:

$T I(I E)=T C+T P+T L+T T+T R$.

A partir da Tabela 2.1-1 são então criadas duas novas matrizes, que se relacionam, respectivamente, à quantidade e a duração das interrupções. São elas: Matriz de Quantidade de Interrupções $(Q I)$ e a Matriz de Duração das Interrupções (DI).

Os elementos da Matriz QI são obtidos da seguinte forma:

$q(i, j)=K[r(i, j)] x \mathrm{NIPi}$

$N I P i=\left[\left(\lambda i_{U} \times L i_{U}\right)+\left(\lambda i_{R} \times L i_{R}\right)\right]$

Onde:

$q(i, j)$ é o elemento que fornece a informação do número de interrupções a que estará sujeito o bloco $j$, devido a interrupções originadas no bloco $i$;

$K[r(i, j)]$ é a constante que indica quantas interrupções sofrerá o bloco $j$, para cada interrupção no bloco $i$. Essa proporção é estabelecida de acordo com a Matriz de Restabelecimento dos Blocos. Se o elemento $r(i, j)$ for do tipo $N$, então $K[N]=0$; ou seja, qualquer interrupção no bloco $i$, não causará interrupção no bloco $j$. Para os demais blocos tem-se: $K[R]=K[I]=K$ $[I E]=1$ e $K[T]=2 ;$

$N I P i$ é o número de interrupções no bloco $i$ motivadas por falhas no próprio bloco;

$\lambda i_{U}, \lambda i_{R}$ são as taxas de falhas urbana e rural atribuídas ao bloco $i$, por unidade de comprimento;

$L i_{U}, L i_{R}$ são os comprimentos urbano e rural do bloco $i$.

A razão do fator $K[r(i, j)]=2$, para os blocos do tipo Transferível, é justificada 
pelos autores pela necessidade de interrupção para que haja manobras, visando o retorno à configuração original, o que não parece razoável, já que manobras não devem provocar mais interrupção. E mesmo em raros casos em que esse procedimento seja imperativo, deverá ser operacionalizado em tempo inferior à contabilização para os indicadores $D E C$ e $F E C$.

Os elementos da segunda Matriz (Duração das Interrupções) são construídos, conforme equação:

$d(i, j)=N I P i \times\left\{\frac{\left\{T I[r(i, j)]_{U} \times L i_{U}\right\}+\left\{T I[r(i, j)]_{R} \times L i_{R}\right\}}{L i_{U}+L i_{R}}\right\}$

Onde:

$d(i, j)$ é o elemento que fornece a informação da duração das interrupções a que estará sujeito o bloco $j$, devido a interrupções originadas no bloco $i$;

$T I[r(i, j)]_{U R}$ é a duração das interrupções a que estará sujeito o bloco $j$, quando da ocorrência de defeito originado no bloco $i$. Esse tempo é estabelecido a partir do relacionamento entre a Matriz de Restabelecimento dos Blocos e as equações de 2.1-1 a 2.1-5.

A quantidade total de interrupções de um determinado bloco, durante um período de análise, será:

$Q I T b=\sum_{i=1}^{N} q(i, b)$

Onde:

$q(i, b)$ são os elementos da Matriz $Q I$, pertencentes à coluna $b$; $N$ é o número total de blocos envolvidos na análise.

A duração total das interrupções de um determinado bloco $b$, durante um período de análise, será:

$D I T b=\sum_{i=1}^{N} d(i, b)$

Onde:

$d(i, b)$ são os elementos da Matriz $D I$, pertencentes à coluna $b$.

Os indicadores de confiabilidade podem ser calculados como: 
$F E C=\frac{\sum_{b=1}^{N} Q I T(b) \times N C(b)}{\sum_{b=1}^{N} N C(b)}$

$D E C=\frac{\sum_{b=1}^{N} D I T(b) \times N C(b)}{\sum_{b=1}^{N} N C(b)}$

$E N D=\sum_{b=1}^{N} \frac{E(b)}{730} \times D I T(b)$

Onde:

$N C(b)$ é o número de consumidores dos blocos;

$E(b)$ é o consumo mensal dos blocos.

A idéia da correlação entre a classificação dos blocos e o número de interrupções ao qual estarão submetidos é bastante interessante. Entretanto, não são considerados os efeitos da presença dos diferentes tipos de dispositivos de proteção e/ou seccionamento, na confiabilidade do sistema em análise. Dessa forma, um bloco que possui um religador automático de distribuição - que tem a capacidade de coordenação e religamento - a montante, é tratado da mesma maneira que outro, que possua uma chave fusível - que não apresenta nenhuma das características anteriores.

Por tal razão, também não são discutidos os efeitos de falhas momentâneas, no número de interrupções permanentes.

\subsection{SIMÕES, A. C. "Análise do Custo-Benefício da Instalação de Equipamentos} de Proteção em Redes Aéreas de Distribuição”. Dissertação de Mestrado Escola Politécnica da Universidade de São Paulo (SP), 1997. [28]

Este trabalho apresenta uma metodologia capaz de subsidiar a tomada de decisão quanto à definição de locais e tipos de equipamentos de proteção ou seccionamento mais apropriados, a serem instalados em determinada rede primária de distribuição. É apresentada uma descrição do funcionamento dos diversos dispositivos de proteção presentes nas redes, sendo classificados de acordo com suas capacidades de religamento e coordenação. 
A partir dessa classificação, são investigados os diferentes benefícios obtidos com a instalação de cada tipo de equipamento para a redução do custo da energia não distribuída, quando da ocorrência de falhas em cada um dos trechos da rede primária de distribuição.

Esses custos são calculados antes e após a instalação do equipamento. E para que seja economicamente viável, é necessário que a economia obtida com a diminuição do custo das interrupções, provocada pela instalação do equipamento, seja maior que o custo de aquisição, instalação e manutenção do mesmo, durante toda sua vida útil.

O custo da energia não distribuída pode ser genericamente calculado como sendo:

$C E N D=P x C E x T$

Onde:

CEND é o custo da energia não distribuída;

$P$ é a potência média interrompida;

$C E$ é o custo da energia, por kWh, sentido pelo consumidor;

$T$ é a duração da interrupção.

O tempo $T$ é calculado por:

$T=T i+T d e s l+T l o c+T 2$

Onde:

Ti é o tempo inicial médio, que engloba o tempo para receber a reclamação, mais a localização do provável trecho defeituoso no mapa, mais a preparação da turma de emergência;

Tdesl é o tempo de deslocamento da turma até o equipamento operado, calculado a partir de uma velocidade média de deslocamento e da distância a ser percorrida pela equipe até o equipamento operado;

Tloc é o tempo de localização do defeito, medido a partir da velocidade média de deslocamento e da distância a ser percorrida pela equipe (que é igual ao comprimento de rede após o equipamento operado e a montante de outros equipamentos de proteção);

T2 é o tempo médio de reparo.

À equação 2.2-1 são associadas as probabilidades de falhas de cada trecho analisado, 
considerando-se as características dos equipamentos de proteção existentes a montante e suas capacidades de eliminação de falhas momentâneas.

Foi desenvolvido um programa computacional, onde são realizadas algumas simulações, apresentados os resultados e discutidos os benefícios obtidos com a instalação de cada equipamento de proteção e/ou seccionamento e as variações desses benefícios, em função do comprimento dos alimentadores, da carga passante, da posição do equipamento no alimentador e do produto comprimento x potência.

Portanto, o trabalho aborda as implicações das interrupções não programadas originadas na rede primária de distribuição, para o cálculo da energia não distribuída, considerando cada dispositivo de proteção e/ou seccionamento. No entanto, não inclui a possibilidade de manobras, visando transferências de trechos a jusante do trecho defeituoso, antes mesmo que seja efetuado reparo, nem discute ganhos com a automação desses dispositivos.

\subsection{BROWN, R. E.; OCHOA, J. R. "Distribution System Reliability: Default} Data and Model Validation". IEEE Transactions on Power Systems, Vol. 13, $\mathbf{n}^{\circ}$ 2, May 1998. [29]

É apresentado um método para se contornar um entrave às análises de confiabilidade dos sistemas de distribuição da maioria das empresas concessionárias: a insuficiência de dados históricos, tais como taxas de falhas de linhas e equipamentos, tempos de restabelecimento, etc..

A despeito dessa deficiência, no entanto, a maioria das concessionárias possui dados históricos de indicadores como $D E C, F E C$, etc..

A idéia, então, é inicialmente calcular os valores dos indicadores de confiabilidade, a partir de dados publicados, que foram coletados em outros sistemas e verificar se os valores calculados são semelhantes aos dados históricos do sistema em análise.

São utilizados os indicadores FEC (Frequiência Equivalente de Interrupção por Consumidor), DEC (Duração Equivalente de Interrupção por Consumidor), referentes a interrupções permanentes e FECm (calculado de maneira idêntica ao $F E C$, porém levando-se em conta apenas interrupções momentâneas).

São também definidas outras variáveis de interesse: 
- $\lambda_{M}$ : taxa de falhas momentâneas, referente a faltas que são eliminadas automaticamente, após re-energização;

- $\lambda_{s}$ : taxa de falhas permanentes, referente a faltas que requerem a presença da equipe de campo, para restabelecimento da energia;

- MTTR: tempo médio de reparo, referente ao tempo despendido pela equipe de campo, para restabelecer o sistema.

Quando os valores calculados para os indicadores (DEC, FEC e FECm), utilizandose parâmetros de outros sistemas, não coincidem com os valores históricos disponíveis, são necessários ajustes.

No entanto, há centenas de parâmetros de componentes que poderiam ser ajustados. Por essa razão, faz-se necessário definir quais desses parâmetros deverão ser selecionados para se submeterem às alterações.

Buscando esse objetivo, pode-se reduzir a quantidade dos parâmetros, através do agrupamento de componentes, em diferentes classes. Um exemplo seria considerar uma única taxa de falhas por unidade de comprimento, para todas as redes aéreas de distribuição, independente das seções transversais de seus condutores, ou dos materiais que os compõem.

Mesmo assim, ainda haveria muitas variáveis que poderiam ser ajustadas.

Embora as concessionárias não disponham de dados históricos suficientes para determinar os parâmetros de confiabilidade de todos os componentes de seus sistemas, é possível que disponham de alguns deles, que podem também ser utilizados. Além disso, podem ser estabelecidas relações entre os mesmos, através da utilização de multiplicadores.

Dessa forma, pode haver algumas relações históricas entre os dados disponíveis, como por exemplo: em redes aéreas em regiões fortemente arborizadas que por ventura apresentem taxas de falhas duas vezes maiores que em regiões sem arborização, poder-se-ia escrever que:

$\lambda_{M}$ da região $A=2 \times \lambda_{M}$ da região $B$.

Para auxiliar na escolha dos parâmetros de confiabilidade que deverão ser ajustados, são apresentadas análises de sensibilidade, que possibilitam medir quanto o valor de uma função se altera, quando determinado parâmetro varia. 
É apresentado um caso teste, representado pelo sistema Bus 2 - RBTS descrito por Allan et al. [30], onde se pôde constatar que o FECm é muito mais sensível ao parâmetro $\lambda_{M}$, assim como o $F E C$ é mais sensível ao $\lambda_{S}$ e, o $D E C$, embora seja mais sensível ao $\lambda_{S}$ e ao $M T T R$, também apresenta razoável sensibilidade para o parâmetro indisponibilidade de religadores automáticos de distribuição.

Portanto, em vista dos resultados anteriores, sugere-se, por exemplo, que, caso o valor de FECm calculado não esteja coincidindo com o valor de FECm histórico, deve-se ajustar o valor de $\lambda_{M}$, visando alcançar tal objetivo.

É, então, proposta uma forma de se obter adequadamente os valores de três parâmetros de confiabilidade $\left(\lambda_{M}, \lambda_{S}\right.$ e $\left.M T T R\right)$, para redes aéreas, em dois passos:

Como o MTTR não afeta os valores de FEC e FECm, então $\lambda_{M}$ pode ser escolhido de tal forma a possibilitar o ajustamento entre os valores de FECm calculado e FECm histórico. Da mesma forma, $\lambda_{s}$ pode ser definido objetivando o ajustamento entre os valores de FEC calculado e FEC histórico.

Isso é conseguido utilizando-se derivadas parciais, ou aproximações por métodos de perturbação, onde os valores novos podem ser encontrados, ajustando-se os anteriores:

$\lambda_{\text {NOVO }}=\lambda_{\text {ANTERIOR }}+\Delta \lambda$.

Após realizadas as iterações anteriores e obtidos os valores de $\lambda_{M}$ e $\lambda_{S}$, pode-se determinar o MTTR, através da comparação entre os valores do DEC calculado e do DEC histórico.

O grande legado desse trabalho é possibilitar a validação de modelos de confiabilidade de sistemas de distribuição, através do ajustamento dos parâmetros de confiabilidade, de forma que os resultados calculados (esperados, ou previstos) utilizando tais parâmetros sejam similares aos dados históricos.

Além disso, as concessionárias ainda poderão checar a validade do modelo que utilizam, comparando os resultados previstos com os efetivamente obtidos no sistema real.

Tais conceitos também são utilizados em nosso trabalho. Entretanto, como não há dados históricos suficientes para os valores de $F E C m$, será utilizado um fator de falhas permanentes (FP), conforme definido por Simões [28], que possibilita estabelecer uma relação entre $\lambda_{M}$ e $\lambda_{s}$. 
2.4 BROWN, R. E.; HANSON, A. P.; WILLIS, H. L.; LUEDTKE, F. A.; BORN, M. F. "Assessing the Reliability of Distribution Systems". IEEE Computer Applications in Power, Vol. 14, no 1, Jan 2001. [31]

É apresentada uma ferramenta computacional desenvolvida a partir de uma parceria entre a $\mathrm{ABB}$ e a concessionária americana Commonwealth Edison (ComEd), onde técnicas de avaliação de confiabilidade são integradas às de engenharia e planejamento da distribuição.

Assim como são analisados os carregamentos e quedas de tensão de um sistema, através de modelos tradicionais de fluxo de carga, também o programa computacional de confiabilidade pode prever a freqüência e duração de interrupções. O modelo baseia-se na topologia do sistema e nos dados de confiabilidade dos componentes e possibilita quantificar os impactos de diferentes opções de engenharia e planejamento.

Foram avaliadas 450 subestações, totalizando mais de 3300 alimentadores em $15 \mathrm{kV}$, onde cada um foi considerado com carregamento igual ao seu valor máximo registrado no ano de 1999.

Os dados de confiabilidade das subestações foram baseados no histórico de três anos. Os resultados são apresentados de forma geográfica, onde os valores são visualmente identificados com diferentes cores.

Foram realizadas:

\section{- Avaliações das condições de carregamento máximo}

Equipamentos sobrecarregados podem degradar os níveis de confiabilidade, pois em geral, a confiabilidade diminui quando aumentam os carregamentos.

O programa computacional apresenta os resultados de forma geográfica, identificando com cores, diferentes percentuais de carregamentos, dos diversos componentes do sistema.

\section{- Análises de confiabilidade}

É utilizado um modelo analítico para previsão das interrupções, para cada consumidor do sistema. Isso é feito simulando-se os impactos de cada contingência e ponderando-se esses impactos, com as probabilidades de ocorrência. 
A partir daí, é possível obter índices de confiabilidade para alimentadores, subestações, etc..

- Análise dos impactos dos componentes do sistema na confiabilidade

São calculadas as contribuições (o peso) de cada componente do sistema, para cada indicador de confiabilidade.

\section{- Identificação das restrições de transferências de cargas}

São apresentadas as restrições de transferências de cargas em sistemas cujas manobras acarretariam níveis de carregamento superiores aos permitidos.

\section{- Identificação e priorização de projetos, com base na relação benefício/custo}

A relação de melhorias é gerada por regras heurísticas e algoritmos especiais, chamados sistemas inteligentes.

São identificados potenciais projetos, baseados nos resultados do sistema (carregamento máximo, confiabilidade, contribuição dos componentes para a confiabilidade e restrições de manobras) e priorizados, com base na relação benefício/custo.

As categorias básicas de opções para melhoria da confiabilidade analisadas foram:

$\checkmark$ Análise de capacidade de transferência. Caso a bitola do condutor seja o impeditivo, talvez o recondutoramento seja a melhor solução;

$\checkmark$ Novas obras de interligação;

$\checkmark$ Instalação de dispositivos de proteção e seccionamento;

$\checkmark$ Automação de alimentadores.

A apresentação dos resultados, através de visualização geográfica, é bastante positiva e possibilita maior facilidade nas análises de comportamento e desempenho do sistema elétrico.

A integração dos programas computacionais de confiabilidade e de planejamento representa uma poderosa ferramenta de análise sistêmica dos conjuntos elétricos, capaz de promover uma excelente combinação e comparação dos resultados. 


\section{METODOLOGIA}

\subsection{DEFINIÇÃO DE BLOCOS}

Cada alimentador de distribuição pode ser dividido em partes, que denominaremos blocos e que são delimitados por dispositivos de proteção e/ou seccionamento. Cada bloco é composto por trechos de redes primárias, com seus respectivos cabos, comprimentos e transformadores de distribuição.

Sendo assim, tomando-se um alimentador, com a seguinte configuração real:

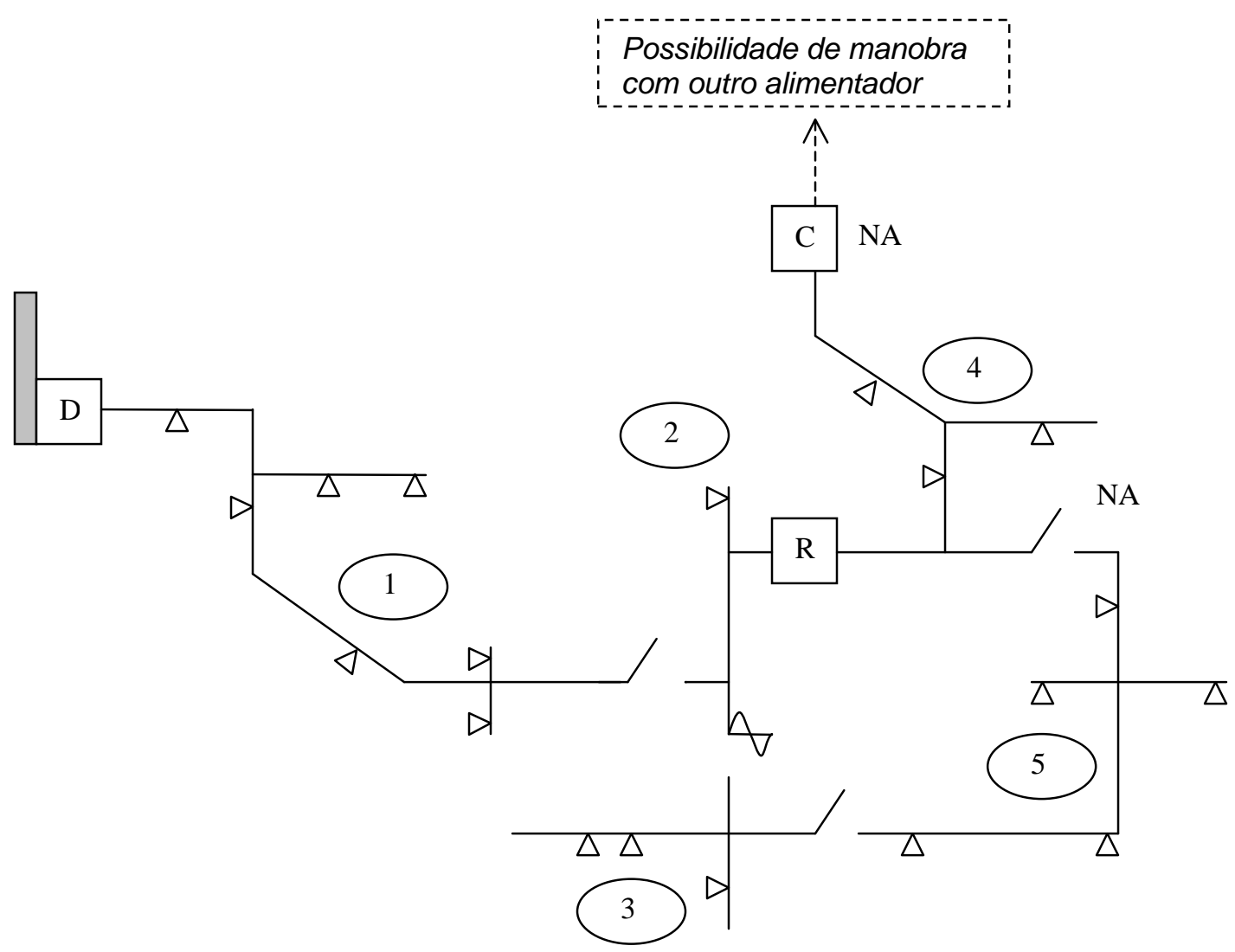

Figura 3.1-1 - Alimentador real 
Onde:

Barramento de 15 kV da Subestação de Distribuição;

D Disjuntor;

R Religador Automático de Distribuição;

C NA Chave Trifásica Normalmente Aberta (interligação entre dois alimentadores distintos);

$ـ \quad$ Chave Faca Normalmente Fechada;

8- Chave Fusível;

$\triangle \quad$ Transformador de Distribuição;

$J_{-}^{\text {NA }} \quad$ Chave Faca Normalmente Aberta (NA);

3 Número do Bloco.

Podemos representá-lo, de forma esquemática, conforme figura abaixo, onde apresentamos os blocos marcados com números e suas respectivas chaves de proteção e/ou seccionamento:

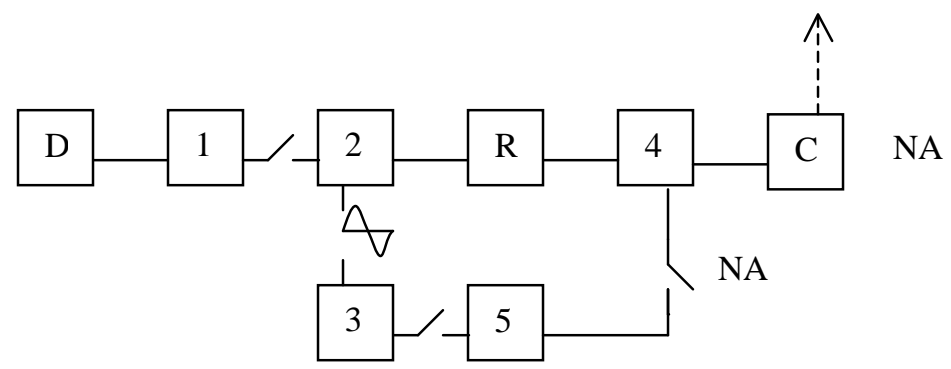

Figura 3.1-2 - Equivalente do alimentador real 


\subsection{CLASSIFICAÇÃO DE BLOCOS}

Os blocos podem ser classificados considerando-se diferentes características, como por exemplo, a região em que está inserido - urbana ou rural - ou por vários outros parâmetros que se pretenda agrupar.

Propõe-se nesse momento, classificar os blocos, de acordo com sua condição de restabelecimento, quando da ocorrência de defeito permanente na rede de distribuição, de maneira razoavelmente similar à apresentada por Silva et al. [27]

Serão sempre consideradas apenas manobras simples, ou seja, que consideram a abertura e o fechamento de apenas duas chaves, sendo uma normalmente fechada e uma normalmente aberta, respectivamente, para blocos a montante e a jusante do bloco com defeito.

Assim sendo, dado um bloco $\underline{\beta}$ onde ocorre uma falha, os demais poderão ser classificados em:

\section{a. Bloco Não Atingido (N):}

Quando a falha no bloco $\underline{\beta}$, não interrompe o fornecimento ao bloco analisado.

Utilizando-se a Figura 3.1-2, podemos verificar que os blocos 1, 2 e 4 são do tipo Não Atingido, quando da ocorrência de defeito no bloco 3, pois os elos fusíveis deverão interromper ofornecimento apenas aos blocos 3 e 5 .

\section{b. Bloco Restabelecível (R):}

Quando é possível restabelecer o fornecimento ao bloco analisado, através da abertura de um dispositivo de seccionamento localizado a montante do bloco $\underline{\beta}$.

Na Figura 3.1-2, o bloco 1 seria Restabelecível, caso ocorresse um defeito no bloco 2, pois a chave faca a montante desse bloco seria aberta e o disjuntor religado.

\section{c. Bloco Transferível (T):}

Quando se pode restabelecer o fornecimento ao bloco analisado, alimentando-o através de alteração na configuração.

Exemplo seria o bloco 5, quando da ocorrência de defeito no bloco 3, pois a chave faca a jusante do bloco 3 seria aberta e a chave faca a jusante do bloco 5 seria fechada. 


\section{d. Bloco Permanentemente Interrompido (I):}

Quando só é possível sua reenergização após reparo da falha no bloco $\beta$.

No caso da Figura 3.1-2, os blocos 2, 3 e 5 seriam Permanentemente Interrompidos, caso houvesse falha no bloco 2 e só poderiam ser restabelecidos após o reparo da falha, pois o bloco 1 seria Restabelecível - conforme já explicado - e o bloco 4 seria Transferível, através da abertura do Religador Automático de Distribuição e fechamento da chave a óleo de interligação com outro alimentador. *

Dessa forma, é realizada uma investigação para se determinar, quais os efeitos que uma falha em cada um dos blocos causa nos demais.

Pode-se montar uma matriz, onde suas linhas representam os blocos defeituosos $\underline{\beta} \mathrm{e}$ as colunas, a classificação dos demais blocos.

No caso de um alimentador como esquematizado na Figura 3.1-2, teríamos:

Tabela 3.2-1 - Matriz de classificação de blocos

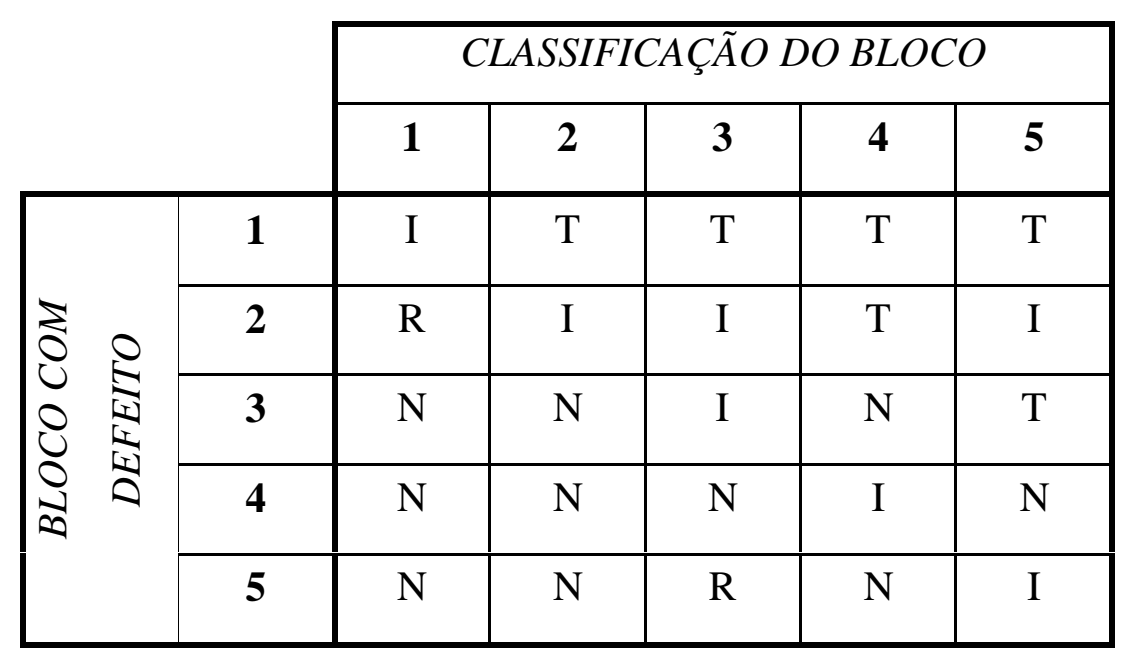

* Nota do autor: Nesse caso, os blocos 3 e 5 também poderiam ser do tipo Transferível, através da abertura da chave fusível e do fechamento da chave faca normalmente aberta a jusante do bloco 5. Entretanto, neste trabalho, só serão consideradas manobras simples para cada um dos eventos: manobras simples para bloco Restabelecível e manobras simples para bloco Transferível. 
Pode-se perceber que, quando da ocorrência de defeito permanente no bloco 5 , o bloco 3 é classificado como Restabelecível e nos conduz ao elemento $b_{53}=R$.

Obviamente, todos os elementos da diagonal principal da matriz serão classificados como Permanentemente Interrompido, pois somente poderão ser restabelecidos após reparo, já que a falha é proveniente do próprio bloco.

\subsection{TAXAS DE FALHAS}

Pode-se medir o desempenho histórico dos vários elementos presentes nos sistemas elétricos, em função do número de falhas, visando se estabelecer a probabilidade que cada elemento tem de falhar, dentro de um determinado período de tempo considerado.

São, então, estabelecidas taxas de falhas médias para cada um dos componentes e, de acordo com o arranjo desses elementos (configuração das redes), procura-se prever futuras interrupções no fornecimento de energia elétrica.

As taxas de falhas anuais dos diversos equipamentos presentes nos sistemas elétricos podem ser obtidas com razoável facilidade, considerando-se o percentual de cada tipo de equipamento que sofre avaria a cada ano, em relação à quantidade total existente instalada.

Para o caso dos trechos (ramos) dos alimentadores, pode-se associar taxas de falhas a cada um dos blocos, considerando-se o tipo de rede existente e sua respectiva extensão. Assim, ter-se-ia para o bloco $j$ uma taxa de falhas igual a $\lambda_{j}$, que representa a taxa de falhas do bloco $j$, em número de defeitos anuais. Essa taxa de falhas pode ser obtida, segundo a expressão:

$\lambda_{j}=\lambda_{\text {redet }} x l_{t}$

Onde:

$\lambda_{j}$ é a taxa de falhas anual do bloco $j$

$\lambda_{\text {redet }}$ é a taxa de falhas por $\mathrm{km}$ para o tipo de rede $t$;

$l_{t}$ é a porção do comprimento do bloco, que possui o tipo de rede $t$, em quilômetros.

Para blocos compostos por vários tipos de rede, a equação 3.3-1 pode ser escrita como: 
$\lambda_{j}=\sum_{=1}^{N} \lambda_{\text {redet }} x l_{t}$

Entretanto, a obtenção dessas taxas de falhas dos diferentes tipos de redes de alimentadores de distribuição não é simples, uma vez que nem sempre se consegue determinar em qual parte do sistema a falha foi originada.

Além disso, esses sistemas estão mais sujeitos a interferências externas - quando comparados com os de transmissão - sejam do meio ambiente, sejam do homem, tais como ventos, descargas atmosféricas, árvores, pássaros, pipas, vandalismo, etc., que nem sempre podem ser identificadas.

Por essas razões, tais taxas de falhas sofrem forte influência também das características locais.

Sendo assim, pode-se dizer que, se forem construídos vários sistemas elétrica e mecanicamente idênticos, ao mesmo tempo, contendo os mesmos elementos quanto à tecnologia, tipos de condutores, equipamentos, etc. - em regiões bastante diferentes, pode-se obter taxas de falhas sensivelmente heterogêneas.

Não se pode, portanto, desprezar as características regionais, em que os sistemas elétricos estão inseridos.

Outro fator que dificulta o estabelecimento das taxas de falhas dos blocos, através de correlações diretas, são os tipos de equipamentos de proteção que estão presentes nos circuitos analisados.

Como nem sempre se pode determinar em qual bloco ocorreu a falha, que originou determinada interrupção - caracterizada pela atuação de um equipamento de proteção - deve-se avaliar as diferentes características desses equipamentos.

Por hora, iremos considerar que é possível determinar as taxas de falhas dos diferentes blocos, em função do comprimento dos trechos, levando-se em conta a equação 3.3-1 ou a 3.3-2.

Posteriormente será apresentada uma forma de se considerar tanto as características regionais, como a presença dos diversos tipos de dispositivos de proteção, para a determinação das taxas de falhas dos blocos. 


\subsection{CLASSIFICAÇÃO DOS EQUIPAMENTOS DE PROTEÇÃO}

Cada equipamento de proteção pode ser classificado de acordo com suas características e contribuições para a minimização dos efeitos das interrupções, nos diferentes blocos de alimentadores, conforme relatado por Simões [28].

Entretanto, antes dessa classificação, é interessante que sejam discutidos três conceitos.

\section{- Capacidade de Religamento:}

Quando o equipamento realiza automaticamente uma ou mais operações de fechamento, visando restabelecer o fornecimento de energia.

\section{- Capacidade de Coordenação:}

Quando o equipamento alterna suas operações de maneira coordenada com outros dispositivos instalados a jusante do mesmo.

Supondo que haja um religador automático de distribuição a montante de uma chave fusível e que ocorra um defeito a jusante dessa última, conforme esquema da figura abaixo:

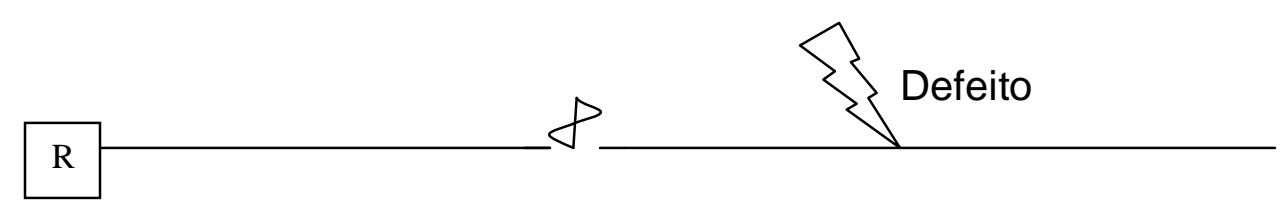

Figura 3.4-1 - Coordenação entre religador e elos fusíveis

As curvas de atuação dos equipamentos podem ser representadas conforme Figura 3.4-2. 


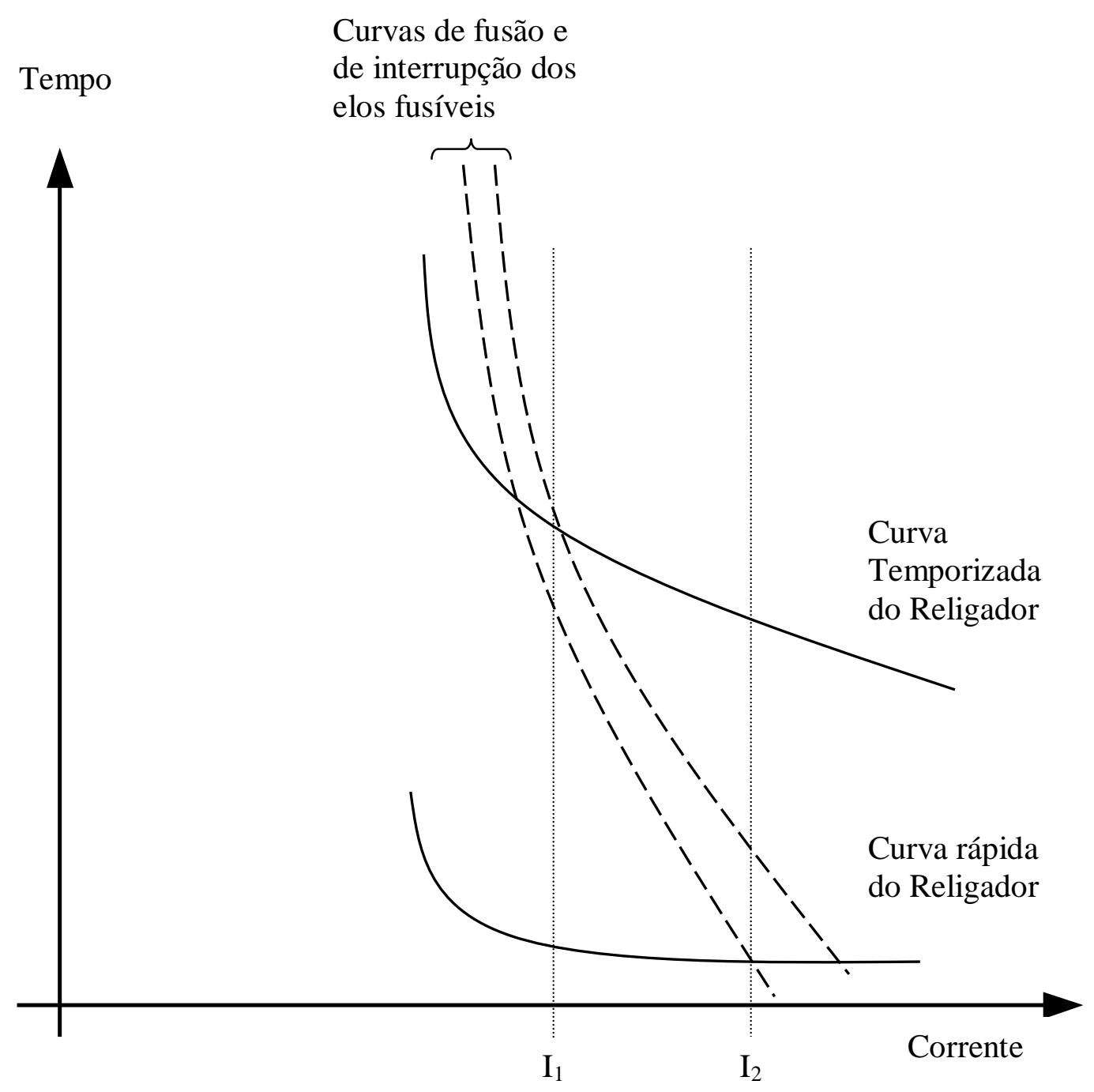

Figura 3.4-2 - Curvas de atuação dos dispositivos de proteção

Onde se pode perceber que:

Quando da ocorrência de curto-circuito com valores inferiores a $\mathrm{I}_{2}$, haverá atuação da curva rápida do religador automático de distribuição sem que ocorra a queima dos elos fusíveis. Isso evita que defeitos momentâneos venham a causar interrupções permanentes;

Então, o religador efetuará o religamento, porém passando agora a atuar em sua curva temporizada;

Caso o defeito não seja eliminado após esse religamento, haverá a fusão do elo fusível, isolando o trecho defeituoso (considerando-se correntes de defeito 
compreendidas entre $\mathrm{I}_{1}$ e $\mathrm{I}_{2}$ );

Pode-se, então, dizer que o religador automático de distribuição possui capacidade de religamento e de coordenação. E essa última, nesse caso, se verifica perfeitamente, para correntes de defeito compreendidas entre $I_{1}$ e $I_{2}$. Entretanto, no presente trabalho, será assumido que essa condição será válida para todos os valores de correntes de defeito.

\section{- Seletividade}

Capacidade do equipamento de proteção mais próximo da falta atuar e isolar o defeito de maneira mais rápida que o equipamento de retaguarda.

Pode-se perceber pela Figura 3.4-2 que, caso o defeito não seja eliminado pela atuação da curva rápida do religador, o elo fusível é que isolará o trecho defeituoso.

No presente trabalho, será considerado que todos os equipamentos de proteção apresentarão tal capacidade, para todos os valores de correntes de defeito.

Assim, podemos classificar os equipamentos em três grupos:

\section{a. Equipamento de proteção com capacidade de religamento e coordenação}

Esse tipo de equipamento, conforme já discutido, tem a característica de realizar uma sucessão de desligamentos e religamentos automáticos, na tentativa de eliminar faltas de natureza momentânea, que ocorram a jusante do mesmo, sem prejuízo da continuidade de serviço. Com isso, busca-se a redução da necessidade da intervenção do homem para a correção do defeito.

Entretanto, se a falta persistir - não vindo a ser eliminada - a interrupção do fornecimento deverá ser feita pelo equipamento mais próximo do ponto com problemas.

Nesse grupo são enquadrados os religadores automáticos de distribuição, conforme já apresentado.

b. Equipamento de proteção com capacidade de religamento, mas sem capacidade de coordenação

Esse equipamento também tem a característica de realizar uma sucessão de desligamentos e religamentos automáticos, na tentativa de eliminar faltas de natureza momentânea, sem causar interrupções permanentes, porém somente para falhas que 
ocorram nas zonas compreendidas entre ele e o próximo dispositivo de proteção localizado a jusante do mesmo.

Esse tipo de equipamento não possui a capacidade de alternar sua operação entre diferentes curvas (rápida e temporizada, por exemplo).

Nessa categoria podem ser citadas as chaves fusíveis religadoras e os disjuntores, nas saídas das subestações. Para efeito de classificação, pode-se incluir também, nesse grupo, os seccionalizadores, pois estão sempre associados a equipamentos a montante, que possuem religamento.

\section{c. Equipamento de proteção sem capacidade de religamento}

Nessa categoria estão as chaves fusíveis, que não possuem a capacidade de eliminação de faltas momentâneas, sem causar interrupções permanentes.

\subsection{CONSEQÜENCIAS DOS TIPOS DE EQUIPAMENTOS DE PROTEÇÃO PARA A CONFIABILIDADE DO SISTEMA}

Para o caso do cálculo do número de interrupções permanentes a que está sujeito determinado bloco, devemos analisar os tipos de equipamentos de proteção que estão presentes a montante do referido bloco.

Dessa forma, podemos utilizar a seguinte lógica:

1) Se o equipamento de proteção imediatamente a montante do bloco $j$ analisado não tem capacidade de religamento:

1.1) E se há equipamento de proteção com religamento e coordenação a montante do equipamento de proteção analisado em 1 , a quantidade provável de interrupções de $j$ será:

$P I_{j}=\lambda_{j} x F P$

1.2) E se não há equipamento com religamento e coordenação a montante do analisado em 1, a quantidade provável de interrupções de $j$ será:

$P I_{j}=\lambda_{j}$

2) Se o equipamento de proteção imediatamente a montante do bloco $j$ analisado tem religamento, a quantidade provável de interrupções de $j$ será:

$P I_{j}=\lambda_{j} x F P$ 
Onde:

$P I_{j}$ é a quantidade provável de interrupções, devido a defeito permanente no bloco $j$;

$\lambda_{j}$ é a taxa de falhas total (permanentes e momentâneas) do bloco $j$, em número de defeitos por ano;

FP é o Fator de Falhas Permanentes. É a relação entre a quantidade de defeitos permanentes e a quantidade total de defeitos.

\subsection{ASSOCIAÇÃO DA CLASSIFICAÇÃO DOS BLOCOS, COM SUAS PROBABILIDADES DE FALHAS PERMANENTES}

Tomando-se a Tabela 3.2-1, é possível associar a cada bloco com defeito, a sua probabilidade de falhar permanentemente e, então, obter uma nova matriz, que considera os efeitos causados nos demais blocos.

E recorrendo-se à lógica apresentada no item 3.5, para a determinação das $P I_{j}$, temse:

Tabela 3.6-1 - Matriz de quantidades prováveis de defeitos

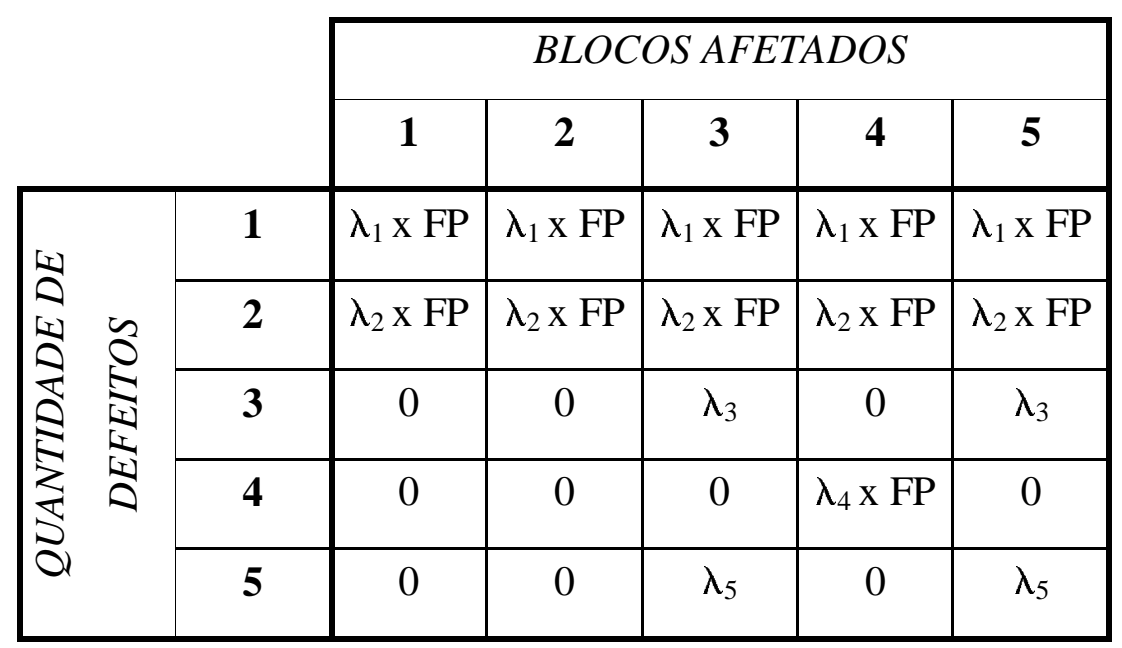

Da Tabela 3.6-1, conclui-se que:

- Os blocos classificados como Não Atingidos (N) não serão interrompidos. Todos os demais estarão sujeitos a interrupções, condicionadas à quantidade provável de falha de cada um dos blocos analisados e dos tipos de equipamentos de proteção presentes no sistema; 
- A interrupção permanente no bloco 1 , que deverá ocorrer $\left[\lambda_{l} x F P\right]$ vezes, no período considerado, causará interrupção em todos os blocos do alimentador, pois o equipamento de proteção imediatamente a montante do bloco 1 analisado tem religamento. Trata-se no caso, de um disjuntor;

- A interrupção permanente no bloco 2, que deverá ocorrer $\left[\lambda_{2} x F P\right]$ vezes, no período considerado, causará interrupção em todos os blocos do alimentador, pois o equipamento de proteção imediatamente a montante do bloco 2 analisado tem religamento. Trata-se no caso, de um disjuntor;

- A interrupção permanente no bloco 3, que deverá ocorrer $\lambda_{3}$ vezes, no período considerado, causará interrupção nos blocos 3 e 5 , pois o equipamento de proteção imediatamente a montante do bloco 3 analisado não tem religamento (chave fusível) e não há equipamento com religamento e coordenação a montante deste (que nesse caso é um disjuntor);

- A interrupção permanente no bloco 4, que deverá ocorrer $\left[\lambda_{4} \times F P\right]$ vezes, no período considerado, causará interrupção apenas no próprio bloco 4, pois o equipamento de proteção imediatamente a montante do bloco 4 tem religamento. Trata-se no caso, de um religador automático de distribuição;

- A interrupção permanente no bloco 5, que deverá ocorrer $\lambda_{5}$ vezes, no período considerado, causará interrupção nos blocos 3 e 5 , pois o equipamento de proteção imediatamente a montante do bloco 3 analisado não tem religamento (chave fusível) e não há equipamento com religamento e coordenação a montante deste (que nesse caso é um disjuntor);

\subsection{CÁLCULO DO FEC REFERENTE À REDE PRIMÁRIA $\left(\right.$ FEC $\left._{p}\right)$}

Pode-se perceber ainda que, se efetuarmos o somatório no sentido das colunas da matriz da Tabela 3.6-1, teremos a quantidade total média de interrupções não programadas, originadas na rede de distribuição primária $\left[\mathrm{NI}_{\mathrm{P}}(\mathrm{j})\right]$ dos blocos representados, durante o período analisado:

$N I_{P}(j)=\sum_{i=1}^{N} b(i, j)$

Assim, se o período de análise for de um ano, espera-se que os blocos 1 e 2 tenham 
$\left[\lambda_{1} x F P+\lambda_{2} x F P\right]$ interrupções anuais; que os blocos 3 e 5 fiquem interrompidos $\left[\lambda_{1} x F P+\lambda_{2} x F P+\lambda_{3}+\lambda_{5}\right]$ vezes e que o bloco 4 tenha $\left[\lambda_{1} x F P+\lambda_{2} x F P+\lambda_{4} x\right.$ FP] interrupções ao longo do ano.

Se houvesse somente consumidores primários no alimentador, já se teriam as estimativas de FIC para cada um deles. Isso é válido para consumidores do grupo A4. Porém, no caso principalmente de blocos urbanos - onde há vários consumidores ligados à rede secundária - há necessidade de considerações adicionais, que serão apresentadas oportunamente, quando forem discutidos os cálculos de DIC e FIC.

Associando-se o número de consumidores de cada um dos blocos [N(j)] que deverão ser afetados pelos defeitos, pode-se re-escrever a matriz da Tabela 3.6-1, conforme a seguir:

Tabela 3.7-1 - Matriz das ponderações do número de consumidores associados aos blocos afetados

\begin{tabular}{|c|c|c|c|c|c|c|c|}
\hline & \multicolumn{5}{|c|}{ BLOCOS AFETADOS } \\
\hline & & & 1 & 2 & 3 & 4 & 5 \\
\hline \multirow{5}{*}{\multicolumn{2}{|c|}{ 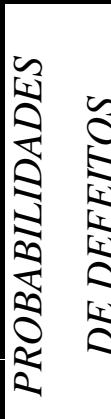 }} & 1 & $\lambda_{1} \times \mathrm{FP} \times \mathrm{N}_{1}$ & $\lambda_{1} \times \mathrm{FP} \times \mathrm{N}_{2}$ & $\lambda_{1} \times \mathrm{FP} \times \mathrm{N}_{3}$ & $\lambda_{1} \times \mathrm{FP} \times \mathrm{N}_{4}$ & $\lambda_{1} \times \mathrm{FP} \times \mathrm{N}_{5}$ \\
\hline & & 2 & $\lambda_{2} \times \mathrm{FP} \times \mathrm{N}_{1}$ & $\lambda_{2} \times \mathrm{FP} \times \mathrm{N}_{2}$ & $\lambda_{2} \times \mathrm{FP} \times \mathrm{N}_{3}$ & $\lambda_{2} \times \mathrm{FP} \times \mathrm{N}_{4}$ & $\lambda_{2} \times \mathrm{FP} \times \mathrm{N}_{5}$ \\
\hline & & 3 & 0 & 0 & $\lambda_{3} \times N_{3}$ & 0 & $\lambda_{3} \times \mathrm{N}_{5}$ \\
\hline & & 4 & 0 & 0 & 0 & $\lambda_{4} \times \mathrm{FP} \times \mathrm{N}_{4}$ & 0 \\
\hline & & 5 & 0 & 0 & $\lambda_{5} \times \mathrm{N}_{3}$ & 0 & $\lambda_{5} \times \mathrm{N}_{5}$ \\
\hline
\end{tabular}

Pode-se, assim, obter o $F E C_{P}$ do alimentador da Figura 3.1-1, somando-se todos os elementos da matriz da Tabela 3.7-1 e dividindo-se o resultado pelo número total de consumidores do alimentador:

$F E C_{P}=\frac{\sum_{i, j=1}^{N} b(i, j)}{C s}$ [interrupções $/$ consumidor $]$

Esse $F E C_{P}$ refere-se, naturalmente, às interrupções não programadas, originadas na rede de distribuição primária e poderia também ser calculado por: 
$F E C_{P}=\frac{\sum_{j=1}^{N} N I_{P}(j) \times N(j)}{C s}$ [interrupções/consumidor]

Outra informação interessante é que, se somarmos os elementos na direção das linhas e dividirmos pelo número total de consumidores do alimentador, obteremos as contribuições efetivas de cada um dos blocos para o $F E C_{P}$ anterior:

$\operatorname{CFEC}_{P}(i)=\frac{\sum_{j=1}^{N} b(i, j)}{C s}$

Onde:

$\operatorname{CFEC}_{P}(i)$ é a contribuição do bloco $i$ para o $F E C_{P}$.

Esse resultado é bastante importante, pois pode direcionar ações específicas a serem implementadas nos blocos que mais afetam o referido indicador de qualidade.

\subsection{ESTIMATIVAS DAS TAXAS DE FALHAS DOS BLOCOS}

Está claro que, se as informações sobre taxas de falhas de cada um dos tipos de redes, por quilômetro, estiverem disponíveis, basta que seja empregada a metodologia até aqui apresentada, que se terá a estimativa do $F E C_{P}$, calculado conforme equação 3.7-2.

Em geral, as concessionárias de energia possuem uma série de dados sobre a operação de diversos tipos de equipamentos e materiais, bem como históricos de ocorrências e anomalias em seus sistemas.

No item 3.3 já foram apresentadas algumas formas de quantificação de taxas de falhas. Entretanto, conforme discutido naquela oportunidade, há algumas dificuldades na obtenção dessa informação.

Por essa razão, propõe-se que sejam utilizados os próprios registros históricos de $F E C$, pois, juntamente com o $D E C$, constituem algumas das informações mais confiáveis dentre as disponíveis nos bancos de dados das concessionárias, uma vez que retratam quais consumidores ficaram efetivamente interrompidos e durante quanto tempo.

Partindo-se desse pressuposto e da metodologia para cálculo do $F E C_{P}$ apresentada no 
item 3.7, é possível obter as taxas de falhas de cada um dos blocos a partir dos valores de $F E C_{P}$ históricos e posteriormente recalcular os $F E C_{P}$ futuros, conforme apresentado por Brown; Ochoa. [29].

Portanto, supondo que o alimentador da Figura 3.1-1 possua um só tipo de rede $p$, a Tabela 3.7-1 poderá ser re-escrita, substituindo-se todos os termos $\lambda_{j}$ por $l_{j} x \lambda_{\text {redep }}$, conforme equação 3.3-1.

Dessa forma, o termo $\lambda_{\text {redep }}$ será comum a todos os termos da nova tabela gerada e o cálculo de $F E C_{P}$, de acordo com a equação 3.7-2 será:

$F E C_{P}=\lambda_{\text {redep }} x \frac{\sum_{i, j=1}^{N} b^{\prime}(i, j)}{C s}$ [interrupções/consumidor]

De onde se pode escrever:

$\lambda_{\text {redep }}=F E C_{\text {Phistórico }} x \frac{C s}{\sum_{i, j=1}^{N} b^{\prime}(i, j)}$ [interrupções/consumidor]

Assim, há possibilidade do cálculo dos $F E C_{P}$ futuros, para as diferentes proposições - que poderão contemplar a instalação de novos equipamentos de proteção e/ou seccionamento, novas construções de interligações e reconfigurações do sistema utilizando-se a sistemática apresentada no item 3.7.

Para o cálculo das taxas de falhas de um outro alimentador que possua somente um tipo de rede $q$, pode-se proceder da mesma forma, visando a obtenção de $\lambda_{\text {redeq }}$.

Há empresas que possuem percentuais superiores a 99\% de suas redes de distribuição primária, no padrão trifásico aéreo convencional, com cabos nus [32].

Entretanto, para os casos em que haja alimentadores que não sejam formados pelo mesmo tipo de rede, pode-se estabelecer relações entre as diferentes taxas de falhas dos diferentes tipos de redes.

Dessa forma, supondo-se que, numa dada região estejam presentes os alimentadores:

- ALI01, que possui somente um tipo de rede $p$,

- ALI02, que possui somente um tipo de rede $q$,

- ALIO3, com ambos os tipos de redes $p$ e $q$;

pode-se calcular $\lambda_{\text {redep }}$ para o alimentador ALIO1 e $\lambda_{\text {redeq }}$ para o alimentador ALIO2, através da equação 3.8-2. 
Para o cálculo de $\lambda_{\text {redep }}$ para o alimentador ALIO3, utilizam-se os valores anteriormente calculados e, considerando-se $K q$ constante, faz-se:

$\lambda_{\text {redeq }}=K q \times \lambda_{\text {redep }}$

E substituindo-se os termos $\lambda_{\text {redeq }}$ da equação 3.8-3, na equação 3.8-2, tem-se $\lambda_{\text {redep }}$ e consequentemente $\lambda_{\text {redeq }}$ para o alimentador ALIO3.

Se estiver presente um terceiro tipo de rede $r$, procede-se de maneira semelhante, estabelecendo-se a relação:

$\lambda_{\text {reder }}=\operatorname{Kr} \times \lambda_{\text {redep }}$

E sistematiza-se assim, sucessivamente, para os diferentes tipos de redes.

A forma de obtenção dessas diferentes taxas de falhas pode ser simplificada, se após várias simulações ficar constatado que os termos $\mathrm{Kq}, \mathrm{Kr}$, etc., mantêm-se constantes para os diferentes alimentadores de uma determinada região geográfica, ou ainda, para a empresa como um todo.

Dessa forma, de posse dos valores de $K q, K r$, etc., basta que sejam utilizadas as equações 3.8-3, 3.8-4, etc., juntamente com a equação 3.8-2. E após o cálculo das taxas de falhas, pode-se proceder conforme descrito no item 3.7, para a obtenção do $F E C_{P}$ futuro.

Obviamente que se procedendo dessa forma, têm-se diferentes valores para cada um dos alimentadores, das diferentes taxas de falhas de cada tipo de rede, ou seja: diferentes $\lambda_{\text {redep }}$ para os alimentadores ALIO1 e ALIO3; e diferentes $\lambda_{\text {redeq }}$ para os alimentadores ALIO2 e ALIO3.

Por isso, caso seja realizada uma construção de interligação, utilizando-se o tipo de rede $p$ entre os alimentadores ALI01 e ALI03, não se pode definir qual será a taxa de falhas a ser considerada para esse novo bloco.

Até agora, os cálculos consideraram a particularização de características regionais por alimentador, buscando-se relacionar as taxas de falhas de cada alimentador à sua área de influência.

Entretanto, em regiões onde há vários alimentadores, sujeitos às mesmas características locais, corre-se o risco de se introduzir alguns erros, que podem ser minimizados, quando o conceito é estendido para a região.

Dessa forma, a partir de agora, propõe-se determinar as taxas de falhas por Região Elétrica, através do $F E C_{P}$ da região. 
A delimitação dessa Região Elétrica é definida considerando-se aspectos geográficos e o grau de inter-relacionamento entre os alimentadores, ou seja, a possibilidade de trocas de cargas, através de manobras entre os mesmos.

A utilização desse conceito recebe melhor aderência, também pelo fato de que, como o Sistema de Distribuição é bastante dinâmico, muitos alimentadores podem ter suas configurações alteradas, ao longo do período analisado. E quando se busca segregar as taxas de falhas por alimentador, tais informações nem sempre são consideradas.

O conceito de Região Elétrica pode ser melhor compreendido, com o auxílio da Figura 3.8-1, onde estão ilustradas seis subestações (SE), com três alimentadores cada e suas respectivas chaves de interligação normalmente abertas, representadas por: $\square$. 


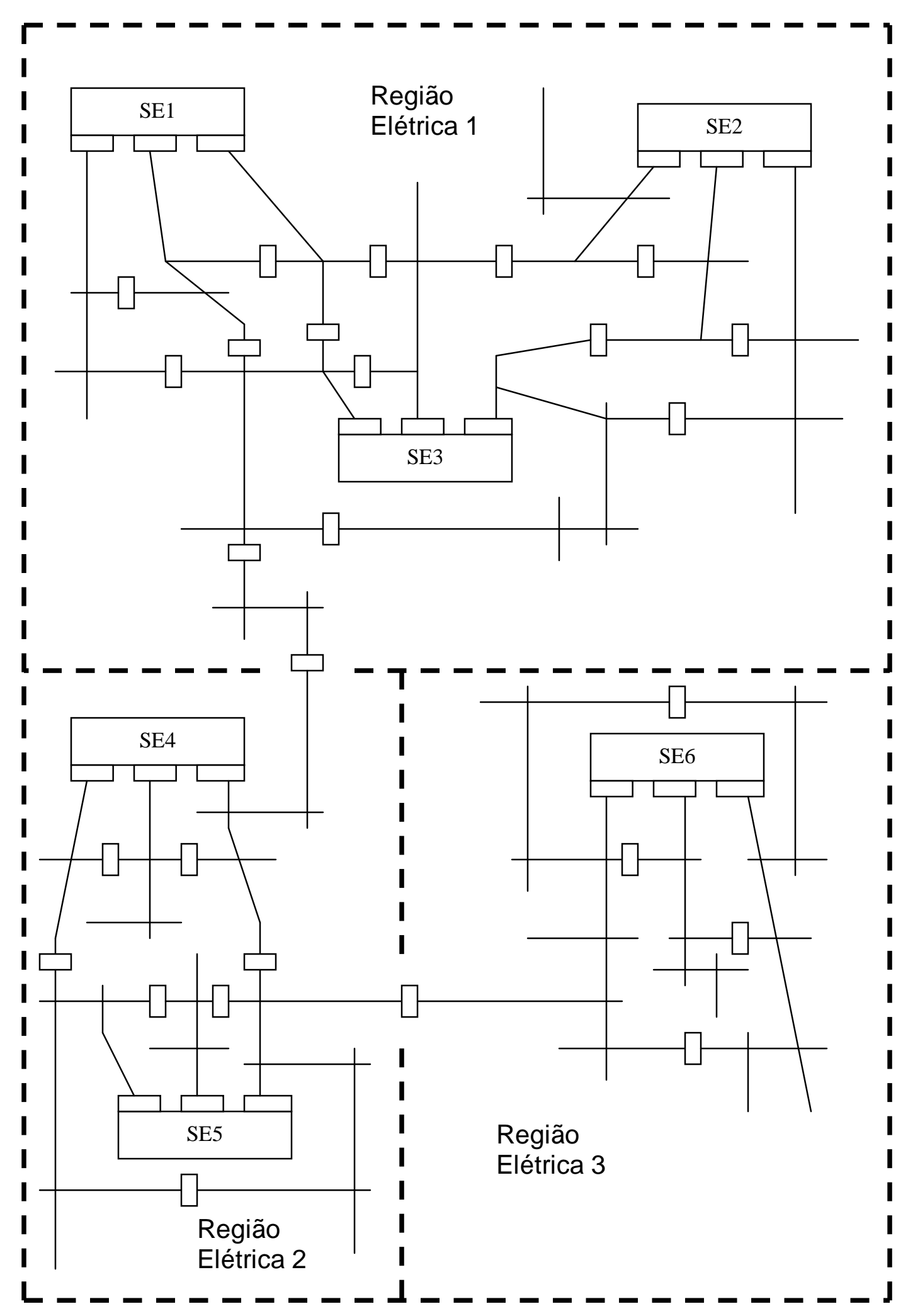

Figura 3.8-1 - Regiões Elétricas 
Pode-se perceber que os alimentadores das subestações SE1, SE2 e SE3 estão fortemente inter-relacionados e compartilham a mesma região geográfica.

O mesmo ocorre com os alimentadores das subestações SE4 e SE5 e com os alimentadores da SE6.

Pode-se ainda perceber que, embora haja interligações entre as Regiões Elétricas $1 \mathrm{e}$ 2 e entre 2 e 3, há fraca inter-relação entre as mesmas. Daí a razão para que sejam consideradas Regiões Elétricas diferentes.

\subsection{TEMPOS ENVOLVIDOS NOS RESTABELECIMENTOS DOS BLOCOS}

Quando ocorre uma interrupção no fornecimento de energia, em caráter permanente, o defeito chegará ao conhecimento da concessionária por uma das seguintes vias: ou a própria empresa deteta a ocorrência, por meio de equipamentos automatizados presentes no Sistema, ou recebe reclamações de seus clientes, através de sua Central de Atendimento.

No primeiro caso, o Centro de Operações já pode adotar algumas medidas para restringir o número de consumidores atingidos pela interrupção, através da mudança de estado de algumas das chaves do Sistema. Isso é conseguido através da utilização de Pontos de Telecontrole de Rede (PTR), que são chaves trifásicas automatizadas e que se encontram representadas na figura a seguir, pela letra P:

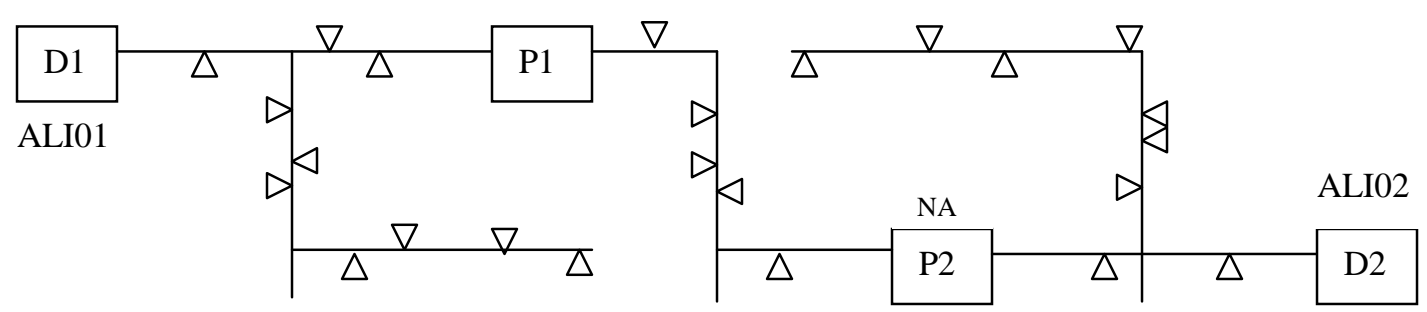

Figura 3.9-1 - Rede com dois alimentadores manobráveis

Quando ocorre uma falha permanente no alimentador ALIO1, o disjuntor D1 irá interromper todos os consumidores presentes no referido alimentador.

O Centro de Operações receberá a informação da atuação do Disjuntor $D 1$ e das medições de correntes durante a falta nas Chave $P 1$ e $P 2 e$ nos disjuntores $D 1$ e $D 2$. 
Se a medição em $P 1$ indicar valores de corrente normais de carga, então o defeito está a montante de $P 1$. O operador irá abrir $P 1$ e fechar $P 2$, transferindo os consumidores a jusante de $P 1$, do alimentador ALI-01 para o alimentador ALI-02.

Por outro lado, caso a medição em $P 1$ indique valores de corrente de curto-circuito, então o defeito está a jusante de $P 1$ e o operador irá abrir $P 1$ e fechar $D 1$, restabelecendo o fornecimento aos consumidores a montante de $P 1$.

Entretanto, embora tal tecnologia já esteja disponível, sua utilização pelas concessionárias no Brasil é bastante tímida.

Em alguns casos, por exemplo, ela não é inteiramente aplicada, devido à falta de confiabilidade nas medições de correntes de falta à terra, além da existência de procedimentos que impedem a realização de manobras na rede urbana, sem que seja realizada inspeção dos trechos interrompidos.

Pela existência desse tipo de política e por não haver garantia de que as operações de manobras se dariam em tempo inferior a 1 ou a 3 minutos, é que os PTR não foram considerados no cálculo do $F E C_{P}$ apresentado no item 3.7.

No entanto, os PTR serão considerados, quando da definição dos tempos de restabelecimento, pois são utilizados para transferências e re-energização de trechos já inspecionados pela Equipe de Campo.

Assim, podemos definir quatro diferentes tempos de resposta, quando da ocorrência de uma falta permanente:

- Tempo médio de preparação da turma de emergência, localização do defeito e abertura da chave de seccionamento e/ou proteção imediatamente a montante do bloco com defeito (TL);

- Tempo médio de reparo do defeito (TR);

- Tempo médio de abertura da chave de seccionamento e/ou proteção imediatamente a jusante do bloco com defeito e transferência manual dos Blocos Transferíveis (TM). Esse Tempo (TM) será considerado igual ao despendido para restabelecer manualmente os blocos a montante do bloco com defeito.

- Tempo médio de abertura da chave de seccionamento e/ou proteção imediatamente a jusante do bloco com defeito e transferência automatizada dos Blocos Transferíveis (TA). Esse Tempo (TA) será considerado igual ao despendido para restabelecer de maneira automatizada, os blocos a montante do 
bloco com defeito.

Para efeito de lógica, os tempos TM e TA serão denotados como TT e serão diferenciados de acordo com a automação do equipamento de manobra e/ou proteção a ser fechado. Da mesma forma, de posse da informação sobre a característica do bloco interrompido - se urbano ou rural - pode-se estabelecer valores diferenciados para cada um dos tempos (TL, TR e TT).

Logicamente, poder-se-iam diferenciar também os Tempos TL para os casos onde há presença de dispositivos confiáveis, com capacidade de deteção de faltas.

\subsection{ASSOCIAÇÃO DA CLASSIFICAÇÃO DOS BLOCOS, COM SEUS TEMPOS DE RESTABELECIMENTO}

Cada tipo de bloco estará sujeito a um determinado tempo de indisponibilidade de fornecimento, quando da ocorrência de falha no sistema. Essa duração pode ser definida em função dos tempos apresentados no item 3.9.

Considerando-se a classificação apresentada no item 3.2, faz-se necessária a verificação da seguinte lógica:

1) Se não há blocos do tipo Restabelecível nem do tipo Transferível na linha $i$ da Matriz de classificação de blocos (que no caso do exemplo utilizado, é representada pela Tabela 3.2-1), então teremos, para os termos da linha $i$, os seguintes tempos associados:

Tabela 3.10-1 - Tempos de restabelecimento para linhas $i$ sem blocos do tipo Restabelecível nem Transferível

\begin{tabular}{|c|c|}
\hline Classificação do Bloco & Tempo de Restabelecimento \\
\hline Não Atingido (N) & 0 \\
\hline Permanentemente Interrompido (I) & TL + TR \\
\hline
\end{tabular}


2) Se há blocos ou do tipo Restabelecível ou do tipo Transferível na linha $i$ da Matriz de classificação de blocos, então teremos, para os termos da linha $i$, os seguintes tempos associados:

Tabela 3.10-2 - Tempos de restabelecimento para linhas $i$, ou com blocos do tipo Restabelecível ou com blocos do tipo Transferível

\begin{tabular}{|c|c|}
\hline Classificação do Bloco & Tempo de Restabelecimento \\
\hline Não Atingido (N) & 0 \\
\hline Restabelecível (R) & $\mathrm{TL}+\mathrm{TT}$ \\
\hline Transferível (T) & $\mathrm{TL}+\mathrm{TT}$ \\
\hline Permanentemente Interrompido (I) & $\mathrm{TL}+\mathrm{TT}+\mathrm{TR}$ \\
\hline
\end{tabular}

3) Se há blocos tanto do tipo Restabelecível, como do tipo Transferível na linha $i$ da Matriz de classificação de blocos, então teremos, para os termos da linha $i$, os seguintes tempos associados:

Tabela 3.10-3 - Tempos de restabelecimento para linhas $i$, tanto com blocos do tipo Restabelecível como do tipo Transferível

\begin{tabular}{|c|c|}
\hline Classificação do Bloco & Tempo de Restabelecimento \\
\hline Não Atingido (N) & 0 \\
\hline Restabelecível (R) & $\mathrm{TL}+\mathrm{TT}$ \\
\hline Transferível (T) & $\mathrm{TL}+\mathrm{TT}+\mathrm{TT}$ \\
\hline Permanentemente Interrompido (I) & $\mathrm{TL}+\mathrm{TT}+\mathrm{TT}+\mathrm{TR}$ \\
\hline
\end{tabular}

A razão de se manter os termos [TT + TT] e não apresentá-los como [2 $x T T]$, para os blocos do tipo Transferível (T) e Permanentemente Interrompido (I) deve-se ao fato de que serão fechados dois dispositivos de proteção e/ou seccionamento até que 
sejam restabelecidos tais blocos, sendo que, um pode dispor de automação e outro não.

Além dos já citados Pontos de Telecontrole de Rede (PTR), há outros dispositivos de seccionamento e/ou proteção que também podem ser automatizados, como é o caso de muitos disjuntores nas saídas de alimentadores e de alguns Religadores Automáticos de Distribuição.

Assim, considerando-se o exemplo do alimentador da Figura 3.1-1 e associando-se as matrizes apresentadas nas Tabelas 3.2-1 e 3.6-1, com base na lógica anterior, é possível estabelecer novos relacionamentos:

Tabela 3.10-4 - Matriz da duração da

indisponibilidade dos blocos

\begin{tabular}{|c|c|c|c|c|c|}
\cline { 2 - 6 } \multicolumn{1}{c|}{} & $\mathbf{1}$ & $\mathbf{2}$ & $\mathbf{3}$ & $\mathbf{5}$ \\
\hline $\mathbf{1}$ & $\begin{array}{c}\lambda_{1} \times \mathrm{FP} \times(\mathrm{TL}+ \\
\mathrm{TT}+\mathrm{TR})\end{array}$ & $\begin{array}{c}\lambda_{1} \times \mathrm{FP} \times(\mathrm{TL}+ \\
\mathrm{TT})\end{array}$ & $\begin{array}{c}\lambda_{1} \times \mathrm{FP} \times(\mathrm{TL}+ \\
\mathrm{TT})\end{array}$ & $\begin{array}{c}\lambda_{1} \times \mathrm{FP} \times(\mathrm{TL}+ \\
\mathrm{TT})\end{array}$ & $\begin{array}{c}\lambda_{1} \times \mathrm{FP} \times(\mathrm{TL}+ \\
\mathrm{TT})\end{array}$ \\
\hline $\mathbf{2}$ & $\begin{array}{c}\lambda_{2} \times \mathrm{FP} \times(\mathrm{TL}+ \\
\mathrm{TT})\end{array}$ & $\begin{array}{c}\lambda_{2} \times \mathrm{FP} \times(\mathrm{TL}+ \\
\mathrm{TT}+\mathrm{TT}+\mathrm{TR})\end{array}$ & $\begin{array}{c}\lambda_{2} \times \mathrm{FP} \times(\mathrm{TL}+ \\
\mathrm{TT}+\mathrm{TT}+\mathrm{TR})\end{array}$ & $\begin{array}{c}\lambda_{2} \times \mathrm{FP} \times(\mathrm{TL}+ \\
\mathrm{TT}+\mathrm{TT})\end{array}$ & $\begin{array}{c}\lambda_{2} \times \mathrm{FP} \times(\mathrm{TL}+ \\
\mathrm{TT}+\mathrm{TT}+\mathrm{TR})\end{array}$ \\
\hline $\mathbf{3}$ & 0 & 0 & $\begin{array}{c}\lambda_{3} \times(\mathrm{TL}+\mathrm{TT}+ \\
\mathrm{TR})\end{array}$ & 0 & $\lambda_{3} \times(\mathrm{TL}+\mathrm{TT})$ \\
\hline $\mathbf{4}$ & 0 & 0 & 0 & $\begin{array}{c}\lambda_{4} \times \mathrm{FP} \times(\mathrm{TL}+ \\
\mathrm{TR})\end{array}$ & 0 \\
\hline $\mathbf{5}$ & 0 & 0 & $\lambda_{5} \times(\mathrm{TL}+\mathrm{TT})$ & 0 & $\begin{array}{c}\lambda_{5} \times(\mathrm{TL}+\mathrm{TT}+ \\
\mathrm{TR})\end{array}$ \\
\hline
\end{tabular}

A Tabela 3.10-4 traz as seguintes informações:

- As interrupções permanentes originadas no bloco 1 , que deverão ocorrer $\left[\lambda_{l} x\right.$ FP] vezes, no período considerado, causarão interrupções nos demais blocos, com duração de $[T L+T T]$ e no próprio bloco, com duração de $[T L+T T+T R]$;

- As interrupções permanentes no bloco 2, que deverão ocorrer $\left[\lambda_{2} x F P\right]$ vezes, no período considerado, causarão interrupções no bloco 1, com duração de $[T L+$ $T T]$; nos blocos 2, 3 e 5 com duração de $[T L+T T+T T+T R]$; e no bloco 4 , com duração de $[T L+T T+T T]$; 
- As interrupções permanentes no bloco 3, que deverão ocorrer $\lambda_{3}$ vezes, no período considerado, causarão interrupções nos blocos 3 e 5 , sendo que as do bloco 5 terão duração de $[T L+T T]$ e as do próprio bloco 3 , de $[T L+T T+T R]$;

- As interrupções permanentes no bloco 4, que deverão ocorrer $\left[\lambda_{4} x F P\right]$ vezes, no período considerado, causarão interrupções apenas no próprio bloco 4 , com duração de $[T L+T R]$;

- As interrupções permanentes no bloco 5, que deverão ocorrer $\lambda_{5}$ vezes, no período considerado, causarão interrupções nos blocos 3 e 5, sendo que as do bloco 3 terão duração de $[T L+T T]$ e as do bloco 5 , de $[T L+T T+T R]$;

No caso de falhas em blocos que sejam protegidos por chaves sem capacidade de religamento (chaves fusíveis) e em que não estão presentes dispositivos com capacidade de coordenação e religamento (religadores automáticos de distribuição) a montante, qualquer falha (momentânea ou permanente) provocará interrupção permanente (queima de elos fusíveis). Por essa razão, nesses casos, teoricamente, muitas vezes o tempo de reparo refere-se apenas à substituição dos elos fundidos. Assim, pode-se assumir que os Tempos médios de Reparo (TR) e Transferência (TT) já contemplam tal situação, ou então, utilizar nesses casos, valores de $T R$ e $T T$ proporcionais à quantidade de faltas permanentes. Nesse caso, os termos b $(3,3)$, b $(3,5)$, b $(5,3)$ e b $(5,5)$ da matriz da Figura 3.10-4 poderiam ser escritos respectivamente, como:

$$
\begin{aligned}
& \left.\lambda_{3} x\{T L+[(T T+T R) \times F P)]\right\} \\
& \lambda_{3} x[T L+(T T \times F P)] ; \\
& \lambda_{5} x[T L+(T T \times F P)] ; \\
& \left.\lambda_{5} x\{T L+[(T T+T R) \times F P)]\right\} .
\end{aligned}
$$

\subsection{CÁLCULO DO DEC REFERENTE À REDE PRIMÁRIA (DEC $\left.\mathrm{p}_{\mathrm{p}}\right)$}

Pode-se perceber ainda que, se efetuarmos o somatório no sentido das colunas da matriz da Tabela 3.10-4, teremos a duração total das interrupções dos blocos representados, devido a ocorrências não programadas, originadas na rede de distribuição primária $\left.\left[\mathrm{DI}_{\mathrm{P}}(\mathrm{j})\right]\right)$, durante o período analisado: 


$$
D I_{P}(j)=\sum_{i=1}^{N} b(i, j)[\text { horas] }
$$

Assim, espera-se que:

- O bloco 1 fique interrompido durante o tempo:

$$
\left\{\left[\lambda_{1} x F P x(T L+T T+T R)\right]+\left[\lambda_{2} x F P x(T L+T T)\right]\right\} ;
$$

- O bloco 2 fique interrompido durante o tempo:

$$
\left\{\left[\lambda_{1} x F P x(T L+T T)\right]+\left[\lambda_{2} x F P x(T L+T T+T T+T R)\right]\right\}
$$

- O bloco 3 fique interrompido durante o tempo:

$\left\{\left[\lambda_{1} x F P x(T L+T T)\right]+\left[\lambda_{2} x F P x(T L+T T+T T+T R)\right]+\left[\lambda_{3} x(T L+T T+\right.\right.$ $\left.T R)]+\left[\lambda_{5} x(T L+T T)\right]\right\} ;$

- O bloco 4 fique interrompido durante o tempo:

$$
\left\{\left[\lambda_{1} x F P x(T L+T T)\right]+\left[\lambda_{2} x F P x(T L+T T+T T)\right]+\left[\lambda_{4} x F P x(T L+T R)\right]\right\}
$$

- O bloco 5 fique interrompido durante o tempo:

$$
\begin{aligned}
& \left\{\left[\lambda_{1} \times F P x(T L+T T)\right]+\left[\lambda_{2} \times F P x(T L+T T+T T+T R)\right]+\left[\lambda_{3} x(T L+T T)\right]+\right. \\
& \left.\left[\lambda_{5} x(T L+T T+T R)\right]\right\} .
\end{aligned}
$$

Se tivéssemos somente consumidores primários no alimentador, já saberíamos o DIC provável de cada um deles. Como já discutido anteriormente, isso é válido para consumidores do grupo A4, que são atendidos em tensão primária de distribuição. Porém, no caso principalmente de blocos urbanos - onde há vários consumidores ligados à rede secundária - há necessidade de considerações adicionais, que serão apresentadas oportunamente, quando forem discutidos os cálculos de DIC e FIC.

Associando-se o número de consumidores de cada um dos blocos que deverão ser afetados pelos defeitos, pode-se re-escrever a matriz da Tabela 3.10-4, conforme a seguir: 
Tabela 3.11-1 - Matriz das ponderações dos consumidores à duração da indisponibilidade dos blocos

\begin{tabular}{|c|c|c|c|c|c|}
\cline { 2 - 6 } \multicolumn{1}{c|}{} & $\mathbf{2}$ & $\mathbf{3}$ & $\mathbf{4}$ & $\mathbf{5}$ \\
\hline $\mathbf{1}$ & $\begin{array}{c}\lambda_{1} \times \mathrm{FP} \times(\mathrm{TL}+ \\
\mathrm{TT}+\mathrm{TR}) \times \mathrm{N}_{1}\end{array}$ & $\begin{array}{c}\lambda_{1} \times \mathrm{FP} \times(\mathrm{TL}+ \\
\mathrm{TT}) \times \mathrm{N}_{2}\end{array}$ & $\begin{array}{c}\lambda_{1} \times \mathrm{FP} \times(\mathrm{TL}+ \\
\mathrm{TT}) \times \mathrm{N}_{3}\end{array}$ & $\begin{array}{c}\lambda_{1} \times \mathrm{FP} \times(\mathrm{TL}+ \\
\mathrm{TT}) \times \mathrm{N}_{4}\end{array}$ & $\begin{array}{c}\lambda_{1} \times \mathrm{FP} \times(\mathrm{TL}+ \\
\mathrm{TT}) \times \mathrm{N}_{5}\end{array}$ \\
\hline $\mathbf{2}$ & $\begin{array}{c}\lambda_{2} \times \mathrm{FP} \times(\mathrm{TL}+ \\
\mathrm{TT}) \times \mathrm{N}_{1}\end{array}$ & $\begin{array}{c}\lambda_{2} \times \mathrm{FP} \times(\mathrm{TL}+ \\
\mathrm{TT}+\mathrm{TT}+\mathrm{TR}) \times \\
\mathrm{N}_{2}\end{array}$ & $\begin{array}{c}\lambda_{2} \times \mathrm{FP} \times(\mathrm{TL}+ \\
\mathrm{TT}+\mathrm{TT}+\mathrm{TR}) \times \\
\mathrm{N}_{3}\end{array}$ & $\begin{array}{c}\lambda_{2} \times \mathrm{FP} \times(\mathrm{TL}+ \\
\mathrm{TT}+\mathrm{TT}) \times \mathrm{N}_{4}\end{array}$ & $\begin{array}{c}\lambda_{2} \times \mathrm{FP} \times(\mathrm{TL}+ \\
\mathrm{TT}+\mathrm{TT}+\mathrm{TR}) \\
\times \mathrm{N}_{5}\end{array}$ \\
\hline $\mathbf{3}$ & 0 & 0 & $\begin{array}{c}\lambda_{3} \times(\mathrm{TL}+\mathrm{TT}+ \\
\mathrm{TR}) \times \mathrm{N}_{3}\end{array}$ & 0 & $\begin{array}{c}\lambda_{3} \times(\mathrm{TL}+\mathrm{TT}) \\
\times \mathrm{N}_{5}\end{array}$ \\
\hline $\mathbf{5}$ & 0 & 0 & 0 & $\lambda_{4} \times \mathrm{FP} \times(\mathrm{TL}+$ \\
$\mathrm{TR}) \times \mathrm{N}_{4}$ & 0 \\
\hline
\end{tabular}

Pode-se, assim, obter o $D E C_{P}$ do alimentador da Figura 3.1-1, somando-se todos os elementos da matriz da Tabela 3.11-1 e dividindo-se o resultado pelo número total de consumidores do alimentador:

$D E C_{P}=\frac{\sum_{i, j=1}^{N} b(i, j)}{C s}$ [horas/consumidor

Esse $D E C_{P}$ refere-se, naturalmente, às interrupções não programadas, originadas na rede de distribuição primária e poderia também ser calculado por:

$D E C_{P}=\frac{\sum_{j=1}^{N} D I P(j) \times N(j)}{C s}$ [interrupções/consumidor]

Onde:

$N(j)$ é o número de consumidores ligados ao bloco $j$.

Outra informação interessante é que, se somarmos os elementos na direção das linhas e dividirmos pelo número total de consumidores do alimentador, obteremos as contribuições efetivas de cada um dos blocos para o $D E C_{P}$ anteriormente obtido: 
$\operatorname{CDEC}_{P}(i)=\frac{\sum_{j=1}^{N} b(i, j)}{C s}$

Onde:

$C D E C_{P}(i)$ é a contribuição do bloco $i \mathrm{p} /$ o $D E C_{P}$.

Esse resultado é bastante importante, pois pode direcionar ações específicas a serem implementadas nos blocos que mais afetam o referido indicador de qualidade.

\subsection{ESTIMATIVAS DOS TEMPOS DE RESTABELECIMENTO NA REDE PRIMÁRIA}

A partir dos valores médios dos diferentes tempos apresentados nos itens 3.9 e 3.10, para uma dada Região Elétrica, pode-se calcular o $D E C_{P}$, conforme item 3.11; e através da comparação entre o $D E C_{P}$ calculado e o $D E C_{P}$ histórico, promover correções análogas às apresentadas no item 3.8.

Assim, a partir dos dados de $D E C_{P}$ históricos, e das relações entre os valores de $T L$, $T A$, $T M$ e TR, são obtidos valores particularizados para cada um dos tempos peculiares à região elétrica avaliada.

Dessa maneira, é possível igualar os valores de $D E C_{P}$ calculado e $D E C_{P}$ histórico, através de um fator multiplicador de ajustamento.

Esse procedimento torna mais simples a aplicação prática mas, em contrapartida, introduz alguns erros, pois considera que há sempre uma relação constante entre os valores de $T L, T A, T M$ e $T R$ e despreza os efeitos das variações dos diferentes tempos em torno das suas médias.

A partir da Figura 3.12-1 pode-se perceber que, se for aplicado um único fator proporcional às médias dos dois tempos apresentados, ter-se-á diferentes incertezas para tais dados. 


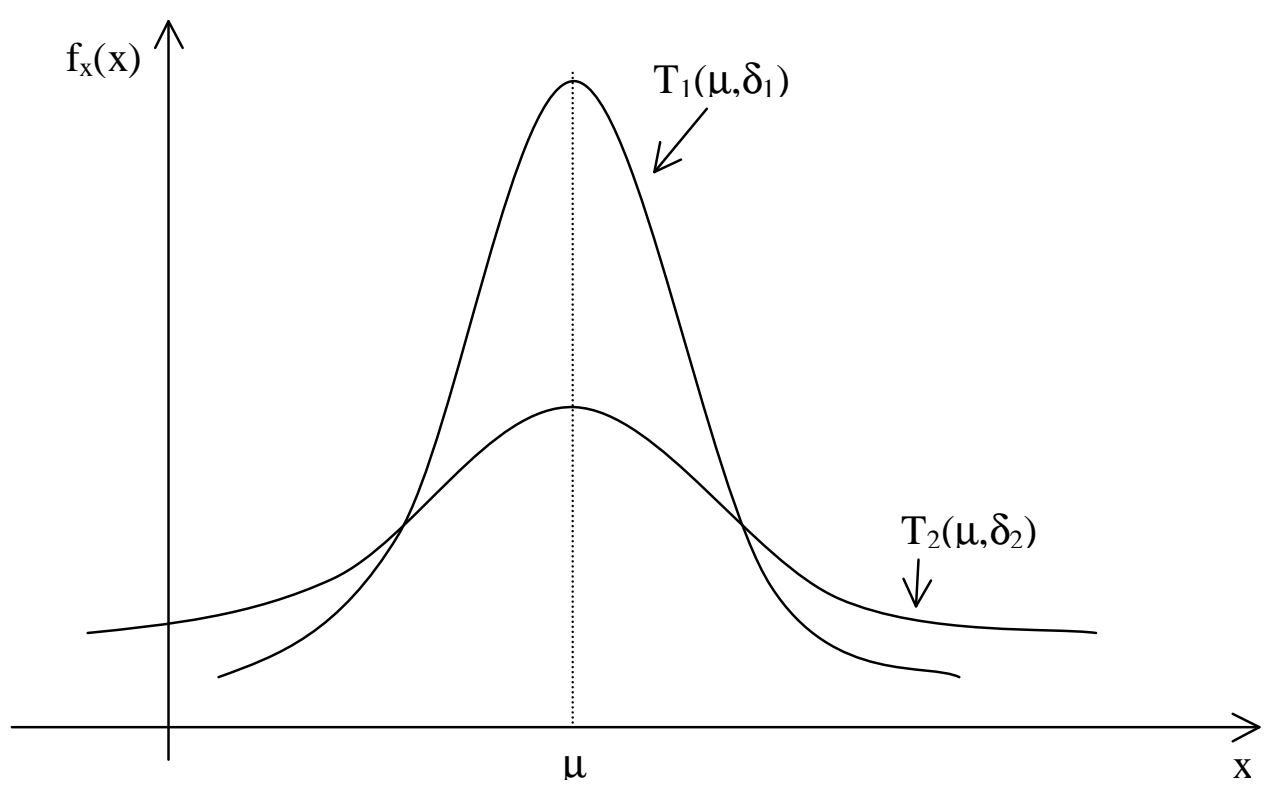

Figura 3.12-1 - Distribuições de probabilidades para duas variáveis com mesma média

Por essa razão, para se estimar os tempos envolvidos no restabelecimento do fornecimento de energia elétrica, poderiam ser considerados os efeitos das variações desses dados, em torno das suas médias, através de distribuições de probabilidade. Dessa forma, as variações estatísticas dos dados históricos utilizados não seriam desprezadas e poderiam auxiliar análises mais acuradas.

Para tal é necessário saber-se como os tempos de restabelecimento são distribuídos. Billinton; Wojczynski afirmam que, embora em alguns casos tais tempos sejam assumidos como exponencialmente distribuídos, muitas vezes, na prática, eles podem ser melhor representados por distribuições não exponenciais, como a log-normal, por exemplo.[18]

Entretanto, caso não se tenha conhecimento prévio do tipo de distribuição, segundo Anders, é possível gerar distribuições de probabilidades, a partir dos dados estatísticos disponíveis, de duas maneiras:

a) ajustando uma curva, definida numericamente a partir de um histograma de freqüências e adequando-a para que a área sob a curva seja unitária: 


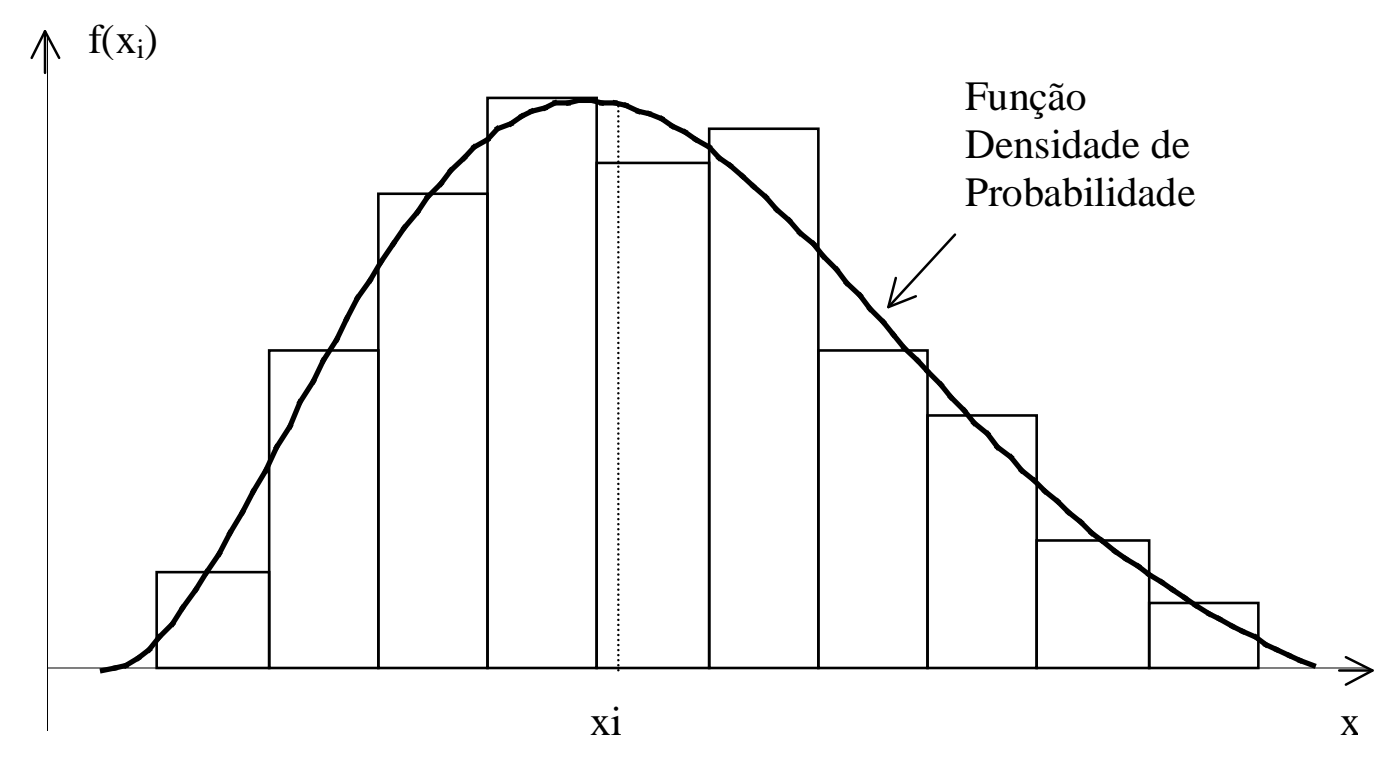

Figura 3.12-2 Ajustamento da Função Densidade ao histograma

b) escolhendo uma curva de distribuição teórica (normal, log-normal, exponencial, Weibull, etc.) - a partir de cartas gráficas padronizadas - que mais se ajusta aos dados. A partir dessa escolha, podem ser realizados testes de aderência, dos quais os mais comuns são Kolmogorov-Smirnov e o Qui-Quadrado. [33]

Assim, de posse das curvas de distribuição de probabilidades dos diferentes tempos, é possível promover ajustamentos em cada um deles, de maneira a manter seus intervalos de probabilidades proporcionais, visando aproximar os valores de $D E C_{P}$ calculado e de $D E C_{P}$ histórico, através de iterações sucessivas.

Dessa forma, tomando-se como exemplo três variáveis representativas dos tempos $T L, T R$ e $T T$ e supondo que apresentem distribuições normais, com valores médios iguais a $\mu_{T L}, \mu_{T R}$ e $\mu_{T T}$ e respectivos desvios padrões tais que: $\delta_{T L}>\delta_{T R}>\delta_{T T}$; teremos representações aproximadamente iguais às apresentadas na Figura 3.12-3. 

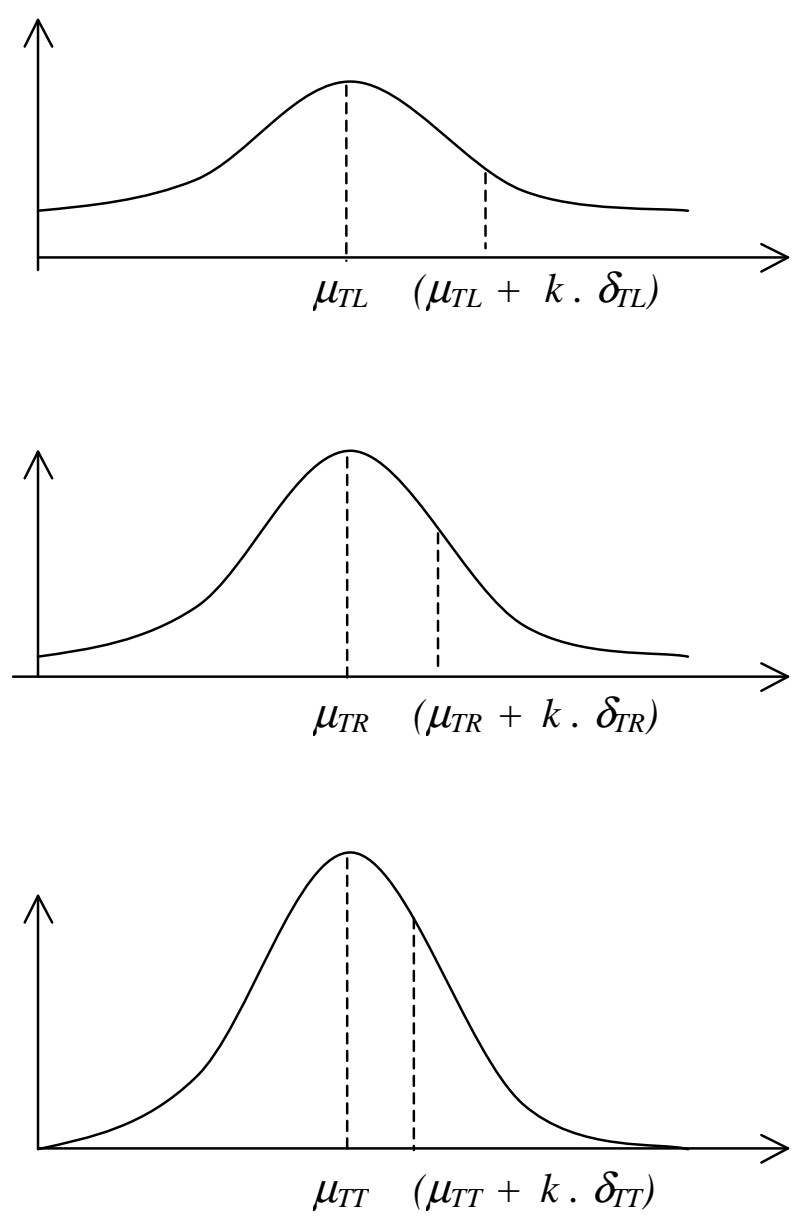

Figura 3.12-3 - Distribuições para os três tempos considerados

A partir dos valores médios dos tempos, caso constatemos que o valor de $D E C_{P}$ calculado é maior que o $D E C_{P}$ histórico, devemos proceder ao incremento dos valores dos tempos, buscando aproximarmos os dois valores de $D E C_{P}$.

Isso é feito através de acréscimos nesses tempos, proporcionais às suas medidas de dispersão (desvio padrão).

Essa proporcionalidade estabelecida pode ser visualizada na Figura 3.12-3, pelas áreas sob as curvas, entre $\mu \mathrm{e}[\mu+\mathrm{k} . \delta]$, que representam o mesmo intervalo de probabilidade para as diferentes variáveis. 


\subsection{CÁLCULO DA ENERGIA NÃO DISTRIBUíDA REFERENTE À REDE PRIMÁRIA (END)}

Efetuando-se a multiplicação de cada um dos elementos da matriz da Tabela 3.10-4, pelo consumo anual de cada um dos blocos [C(i)], pode-se construir uma nova matriz:

Tabela 3.13-1 - Matriz das ponderações dos consumos associados às durações das indisponibilidades dos blocos

\begin{tabular}{|c|c|c|c|c|c|}
\cline { 2 - 6 } \multicolumn{1}{c|}{} & $\mathbf{1}$ & $\mathbf{3}$ & $\mathbf{4}$ & $\mathbf{5}$ \\
\hline $\mathbf{1}$ & $\begin{array}{c}\lambda_{1} \times \mathrm{FP} \times(\mathrm{TL}+ \\
\mathrm{TT}+\mathrm{TR}) \times \mathrm{C}_{1}\end{array}$ & $\begin{array}{c}\lambda_{1} \times \mathrm{FP} \times(\mathrm{TL}+ \\
\mathrm{TT}) \times \mathrm{C}_{2}\end{array}$ & $\begin{array}{c}\lambda_{1} \times \mathrm{FP} \times(\mathrm{TL}+ \\
\mathrm{TT}) \times \mathrm{C}_{3}\end{array}$ & $\begin{array}{c}\lambda_{1} \times \mathrm{FP} \times(\mathrm{TL}+ \\
\mathrm{TT}) \times \mathrm{C}_{4}\end{array}$ & $\begin{array}{c}\lambda_{1} \times \mathrm{FP} \times(\mathrm{TL}+ \\
\mathrm{TT}) \times \mathrm{C}_{5}\end{array}$ \\
\hline $\mathbf{2}$ & $\begin{array}{c}\lambda_{2} \times \mathrm{FP} \times(\mathrm{TL}+ \\
\mathrm{TT}) \times \mathrm{C}_{1}\end{array}$ & $\begin{array}{c}\lambda_{2} \times \mathrm{FP} \times(\mathrm{TL}+ \\
\mathrm{TT}+\mathrm{TT}+\mathrm{TR}) \times \\
\mathrm{C}_{2}\end{array}$ & $\begin{array}{c}\lambda_{2} \times \mathrm{FP} \times(\mathrm{TL}+ \\
\mathrm{TT}+\mathrm{TT}+\mathrm{TR}) \times \\
\mathrm{C}_{3}\end{array}$ & $\begin{array}{c}\lambda_{2} \times \mathrm{FP} \times(\mathrm{TL}+ \\
\mathrm{TT}+\mathrm{TT}) \times \mathrm{C}_{4}\end{array}$ & $\begin{array}{c}\lambda_{2} \times \mathrm{FP} \times(\mathrm{TL}+ \\
\mathrm{TT}+\mathrm{TT}+\mathrm{TR}) \\
\times \mathrm{C}_{5}\end{array}$ \\
\hline $\mathbf{3}$ & 0 & 0 & $\begin{array}{c}\lambda_{3} \times(\mathrm{TL}+\mathrm{TT}+ \\
\mathrm{TR}) \times \mathrm{C}_{3}\end{array}$ & 0 & $\begin{array}{c}\lambda_{3} \times(\mathrm{TL}+\mathrm{TT}) \\
\times \mathrm{C}_{5}\end{array}$ \\
\hline $\mathbf{4}$ & 0 & 0 & 0 & $\lambda_{4} \times \mathrm{FP} \times(\mathrm{TL}+$ \\
$\mathrm{T}$ & 0 & 0 & $\begin{array}{c}\lambda_{5} \times(\mathrm{TL}+\mathrm{TT}) \times \\
\mathrm{C}_{3}\end{array}$ & 0 \\
\hline
\end{tabular}

Então, é possível obter o valor total da Energia não Distribuída $\left(\mathrm{END}_{\mathrm{P}}\right)$, somando-se todos os elementos da matriz da Tabela 3.13-1 e dividindo-se o resultado por 8760 (caso tenhamos os consumos anuais e os tempos em horas):

$E N D_{P}=\frac{\sum_{i, j=1}^{N} b(i, j)}{8760}[k W h / a n o]$

Novamente pode-se obter mais uma informação importante: somando-se os elementos na direção das linhas e dividindo o resultado por 8760, é possível quantificar as contribuições efetivas de cada um dos blocos para a $E N D_{P}$ total: 
$\operatorname{CEND}_{P}(i)=\frac{\sum_{j=1}^{N} b(i, j)}{8760}[k W h / a n o]$

Onde:

$C E N D_{P}(i)$ é a contribuição do bloco $i \mathrm{p} /$ a $E N D_{P}$.

Esse resultado também é bastante útil, pois pode direcionar ações específicas a serem implementadas, nos blocos que mais afetam o montante anual de energia não distribuída.

Uma outra informação, que também pode ser útil, é o quanto de energia deve deixar de ser distribuída para cada um dos blocos $\left[\operatorname{END}_{\mathrm{P}}(\mathrm{j})\right]$. Basta somar os elementos da matriz da Figura 3.13-1 na direção das colunas, dividindo o resultado por 8760, conforme a seguinte relação:

$\operatorname{END}_{P}(j)=\frac{\sum_{i=1}^{N} b(i, j)}{8760}[k W h / a n o]$

Como em cada bloco pode haver diferentes tipos de consumidores e, conseqüentemente, com tarifas diferenciadas, a equação 3.13-3 poderia auxiliar no direcionamento de ações que afetam o faturamento.

\subsection{CONSIDERAÇÃO DAS TAXAS DE FALHAS DOS EQUIPAMENTOS INSTALADOS NA REDE PRIMÁRIA}

As formas de obtenção das taxas de falhas dos blocos, apresentadas no item 3.8, consideraram apenas os trechos (ou ramos) dos alimentadores, de tal forma que as taxas de falhas dos equipamentos presentes na Rede de Distribuição Primária fossem "diluídas" nos trechos, quando o $F E C_{P}$ calculado é ajustado ao $F E C_{P}$ histórico.

$\mathrm{O}$ erro com esse tipo de cálculo é bastante reduzido, para casos em que os equipamentos encontram-se distribuídos uniformemente ao longo dos alimentadores e que apresentam taxas de falhas semelhantes entre si.

A metodologia aqui proposta seguirá esse procedimento, considerando tais aproximações.

Entretanto, se tais condições não forem satisfatórias e indicarem a necessidade de se 
levar em conta as diferentes taxas de falhas dos diferentes equipamentos presentes nas redes, pode-se considerar cada equipamento, como sendo um bloco fictício.

Tais blocos seriam considerados com número de consumidores igual a zero, o que, na prática, dispensaria a necessidade de classificá-los.

Além disso, qualquer falha nesses blocos especiais deverá ser considerada permanente, independente dos dispositivos de proteção existentes a montante, pois é improvável que os efeitos de religamentos desses dispositivos consigam eliminar tal falha.

Com esse artifício, seria ainda necessária a separação desses equipamentos em dois grupos: os que possuem chaves "by pass" (como, por exemplo, os reguladores de tensão, os auto boosters, os religadores automáticos de distribuição e os seccionalizadores) e os que não possuem (como é o caso das chaves facas, das chaves fusíveis e das chaves trifásicas).

- Quando o equipamento possuir chave "by pass", todos os blocos atingidos serão classificados como sendo do tipo Restabelecível;

- Quando o equipamento não possuir chave "by pass", a tratativa será a mesma utilizada para os blocos.

Assim, considerando-se o exemplo apresentado na Figura 3.1-1, ter-se-ia para a matriz da Tabela 3.2-1: 
Tabela 3.14-1 - Matriz de classificação de blocos, considerando-se os equipamentos como blocos especiais

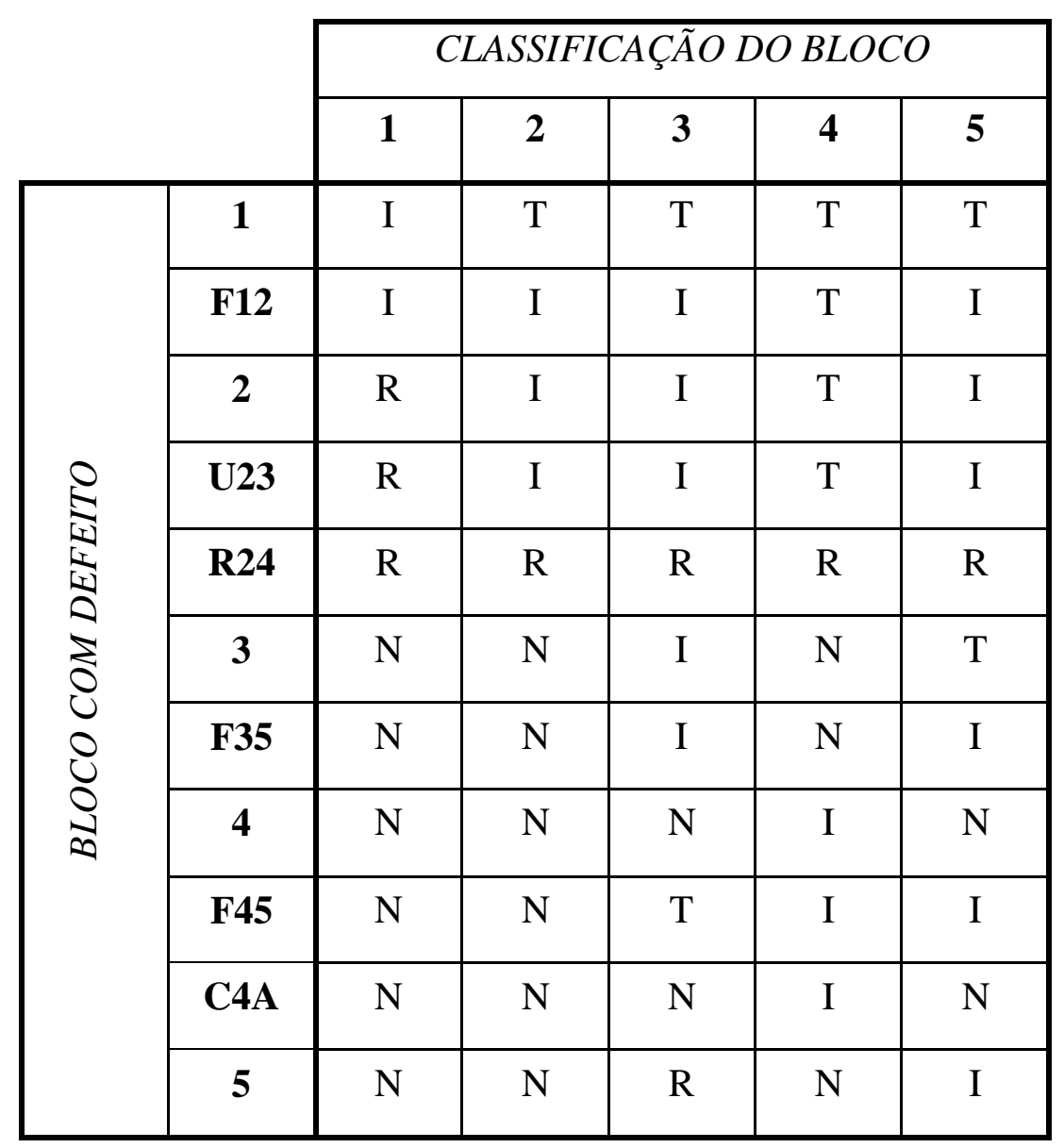

Onde:

F12, F35 e F45 são os blocos especiais representativos das chaves facas;

U23 é o bloco especial representativo da chave fusível;

$R 24$ é o bloco especial representativo do religador automático de distribuição (que possui “by pass”);

$C 4 A$ é o bloco especial representativo da chave trifásica normalmente aberta, de interligação com outro alimentador.

E a matriz apresentada na Tabela 3.6-1 seria escrita como: 
Tabela 3.14-2 - Matriz de quantidades prováveis de defeitos, considerando-se as taxas de falhas dos equipamentos

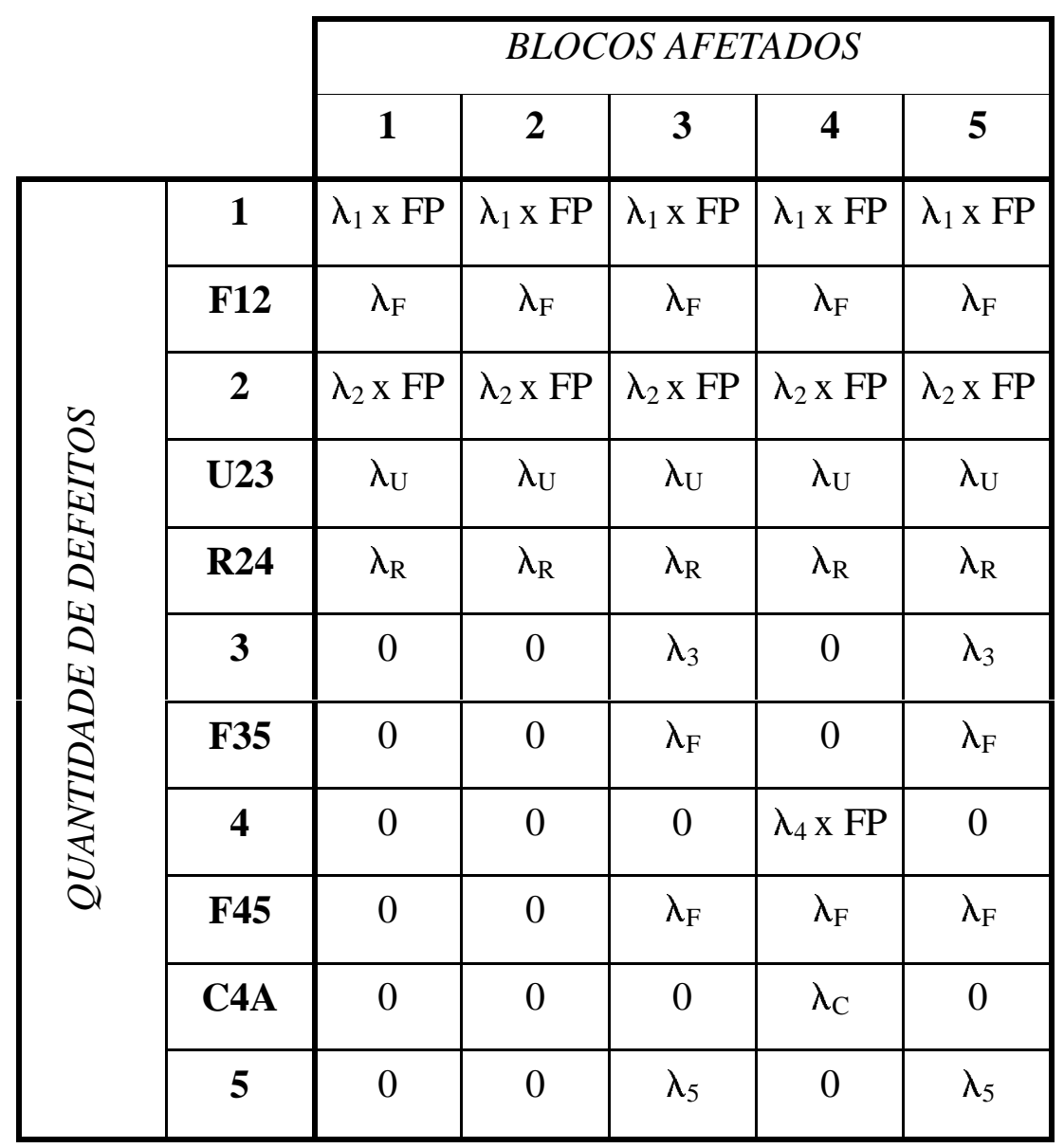

Onde:

$\lambda_{F}$ é a taxa de falhas das chaves facas;

$\lambda_{U}$ é a taxa de falhas das chaves fusíveis;

$\lambda_{R}$ é a taxa de falhas dos religadores automáticos de distribuição;

$\lambda_{C}$ é a taxa de falhas das chaves trifásicas.

É importante mais uma vez ressaltar, que as taxas de falhas dos equipamentos causarão interrupções permanentes, independente dos equipamentos de proteção presentes a montante. Por essa razão, os termos $\lambda_{F}, \lambda_{U}, \lambda_{R}$ e $\lambda_{C}$ não deverão ser multiplicados pelo Fator de Faltas Permanentes (FP).

A sistemática para obtenção da matriz apresentada na Tabela 3.7-1 seguiria a mesma lógica, além de todas as considerações apresentadas no item 3.7. 
E de maneira análoga à apresentada no item 3.8, podem ser estabelecidas relações entre as taxas de falhas dos equipamentos e dos tipos de redes e efetuados cálculos para ajustamentos dos valores de $F E C_{P}$ futuro (calculado) e $F E C_{P}$ histórico.

Da mesma forma, todos os procedimentos e considerações até aqui apresentadas, para os cálculos de $D E C_{P}$ e $E N D_{P}$, continuariam seguindo a mesma lógica.

\subsection{TAXAS DE MANUTENÇÕES}

Nos itens anteriores, são utilizados valores dos indicadores $F E C_{P}, D E C_{P}$ e $E N D_{P}$, para interrupções não programadas.

Para o objetivo principal da metodologia apresentada - que é a comparação entre diferentes alternativas de planejamento - esses valores possibilitam confrontar os efeitos causados por diversas proposições na rede de distribuição primária, como:

a. Alocação de dispositivos de seccionamento;

b. Alocação de diferentes dispositivos de proteção;

c. Construção de interligação, viabilizando transferências de cargas;

d. Automação de equipamentos de seccionamento e/ou proteção;

e. Substituição de redes nuas convencionais, por outras mais confiáveis;

f. Reconfiguração de redes existentes;

g. Expansão do Sistema.

Entretanto, se o objetivo principal fosse prever os valores totais futuros dos indicadores, para as redes de distribuição primária, haveria a necessidade de se considerar os efeitos das manutenções programadas.

Isso traria também melhor quantificação das ações anteriormente descritas, principalmente as apresentadas em $\underline{a} \underline{\mathrm{e}} \underline{c}$.

Assim, para o caso dos trechos (ramos) dos alimentadores, poder-se-iam associar taxas de manutenções - numa analogia às taxas de falhas - a cada um dos blocos, considerando-se o tipo de rede existente e sua respectiva extensão.

Ter-se-ia, então, para um bloco $j$, uma taxa de manutenções igual a $\lambda_{j}$, que representa a taxa de manutenções do bloco $j$, em número de ocorrências anuais. Essa taxa seria obtida, segundo a expressão:

$\lambda_{j}^{\prime}=\lambda_{\text {redet }}{ }^{\prime} \times l_{t}$ 
Onde:

$\lambda_{j}$ ' é a taxa anual de manutenções do bloco $j$

$\lambda_{\text {redet }}$ é a taxa de manutenções por $\mathrm{km}$, para o tipo de rede $t$;

$l_{t}$ é o comprimento do bloco, que possui o tipo de rede $t$, em $\mathrm{km}$.

Dessa maneira, seria possível avaliar as implicações das ações de manutenção em cada um dos blocos, para os demais.

Entretanto, cabe ressaltar que, em várias concessionárias, esses resultados só seriam válidos para análises de longo prazo, já que o Planejamento da Manutenção é freqüentemente determinado por situações de curto prazo. Por exemplo: se determinada região já apresenta valores de DEC e FEC acima dos padrões determinados pelo Órgão Regulador, todas as manutenções poderão ser postergadas ao máximo possível, mesmo que isso possa parecer paradoxal. Além disso, provavelmente a utilização de serviços de Linha Viva será intensificada.

Portanto, há variáveis controláveis no curto prazo, que podem provocar grandes distorções, quando se trabalha com modelos estatísticos.

\subsection{TAXAS DE FALHAS NA REDE SECUNDÁRIA}

Na Figura 3.1-1 são apresentados alguns dos componentes das redes de distribuição primária. Entretanto - com exceção dos casos em que consumidores do grupo A4 (que recebem energia em tensão primária e possuem um transformador exclusivo) a cada transformador lá representado por “ $\triangleleft$ “, está associada uma rede de distribuição secundária.

Assim: 


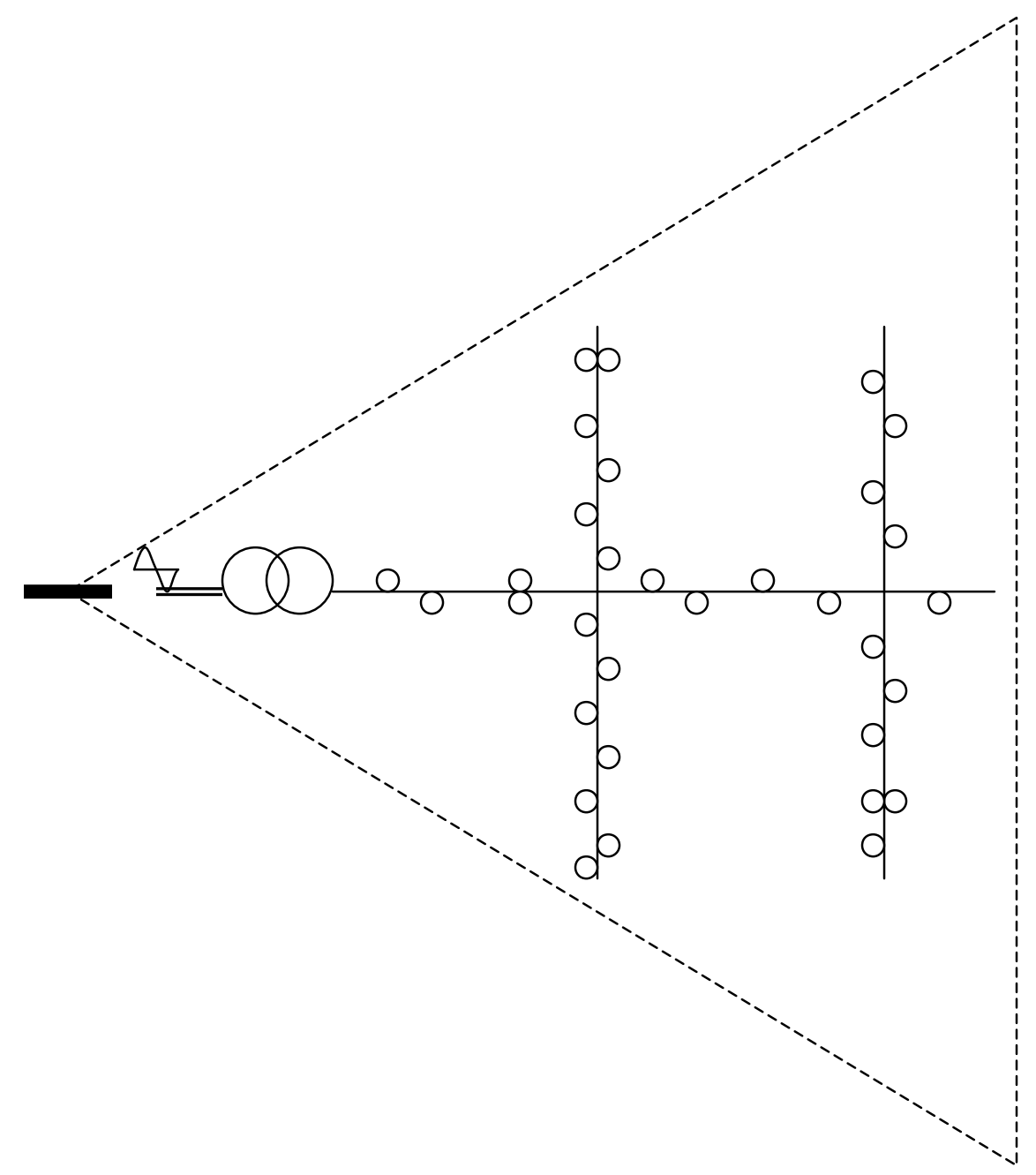

Figura 3.16-1 - Rede de Distribuição Secundária

Onde:

- Trecho de Rede de Distribuição Primária;

$\checkmark \quad$ Chave Fusível de Proteção da Rede de Distribuição Secundária;

C Condutor de Ligação da Chave Fusível aos bornes primários do Transformador de Distribuição;

Q 1 Transformador de Distribuição;

O Consumidor do Grupo B, atendido em baixa tensão; 


\section{Rede de Distribuição Secundária.}

Será assumido que, toda falha que venha a ocorrer na rede de distribuição secundária ou no transformador, provocará a queima dos elos fusíveis da chave representada na Figura 3.16-1, ocasionando interrupção no fornecimento de energia elétrica a todos os consumidores atendidos pelo respectivo transformador.

Em geral, as distribuidoras de energia elétrica brasileiras realizam acompanhamentos sistemáticos dos Índices de Queima de Transformadores de distribuição (IQT). Esse indicador é acompanhado e controlado há anos, sendo possível o estabelecimento de taxas de falhas confiáveis para tais equipamentos.

Assim podem ser estabelecidas as seguintes relações :

$N I_{S}(i)=\lambda_{Q T}(i)+\lambda_{R S}(i)$

$\lambda_{R S}(i)=\lambda_{R S t} x l_{t}(i)$

Onde:

$N I_{S}(i)$ é o número médio de interrupções a que estarão sujeitos todos os consumidores atendidos pelo transformador $i$, devido a falhas provenientes do próprio equipamento ou da respectiva rede secundária;

$\lambda_{Q T}(i)$ é a taxa de falhas do transformador $i$;

$\lambda_{R S}(i)$ é a taxa de falhas da rede secundária atendida pelo transformador $i$;

$\lambda_{R S t}$ é a taxa de falhas por $\mathrm{km}$, da rede secundária tipo $t$;

$l_{t}(i)$ é o comprimento do circuito secundário $i$, que possui o tipo de rede $t$, em $\mathrm{km}$.

\subsection{CÁLCULO DO FEC}

\subsubsection{FEC referente à Rede Secundária $\left(\mathrm{FEC}_{\mathrm{S}}\right)$}

O cálculo do valor do FEC referente a interrupções não programadas, originadas na rede de distribuição secundária $\left(\mathrm{FEC}_{\mathrm{S}}\right)$, de uma determinada região é calculado como sendo: 
$F E C_{S}=\frac{\sum_{i=1}^{M}\left\{\left[\lambda_{Q T}(i)+\lambda_{R S}(i)\right] \times N S(i)\right\}}{C S}$

Onde:

$N s(i)$ é o número de consumidores ligados à rede secundária atendida pelo transformador (i);

$C_{S}$ é o número total de consumidores atendidos pelo sistema de distribuição na região;

$M$ é o número de circuitos secundários.

De maneira similar à apresentada no item 3.8I, é possível estabelecer relações entre as taxas de falhas secundárias, igualando-se o $F E C_{S}$ histórico ao $F E C_{S}$ calculado.

A partir daí, de posse das taxas de falhas ajustadas, podem-se avaliar também os efeitos de ações de planejamento da rede de distribuição secundária, como por exemplo:

- A substituição de redes convencionais com cabos nus, por redes com cabos préreunidos multiplexados;

- A redução da extensão de circuitos secundários, proporcionando menores agrupamentos de consumidores por circuito.

\subsubsection{FEC Total}

O FEC total de uma determinada região elétrica, referente a interrupções não programadas, originadas na rede de distribuição será:

$F E C=F E C_{P}+F E C_{S}$

\subsection{CÁLCULO DO FIC}

Como já foi salientado no item 3.7, para consumidores atendidos em tensão de distribuição primária, o valor do FIC referente a interrupções não programadas originadas na rede de distribuição pode ser calculado diretamente através da equação 3.7-1.

Para o caso dos consumidores atendidos em tensão de distribuição secundária, esse 
valor pode ser obtido por:

$F I C(j)=\lambda_{Q T}(j)+\lambda_{R S}(j)+N I P J$

ou

$$
F I C(j)=N I_{S}(j)+N I P J
$$

Onde:

$F I C(j)$ é a quantidade média de interrupções não programadas, originadas na rede de distribuição, as quais todos os consumidores atendidos pelo transformador de distribuição $j$ deverão estar sujeitos, durante o período analisado;

NIPJ é a quantidade provável de interrupções - não programadas, originadas na rede de distribuição primária - do bloco onde está ligado o transformador $j$, durante o período analisado, conforme equação 3.7-1.

\subsection{TEMPOS ENVOLVIDOS NOS RESTABELECIMENTOS DA REDE SECUNDÁRIA}

Podem ser identificados dois intervalos de tempo, quando da ocorrência de interrupção na rede de distribuição secundária:

- Tempo médio de preparação da turma de emergência, localização do defeito e reparo do transformador de distribuição (TF);

- Tempo médio de preparação da turma de emergência, localização do defeito e reparo da rede secundária de distribuição (TS).

\subsection{CÁlCULO DO DEC}

\subsubsection{DEC referente à Rede Secundária $\left(\mathrm{DEC}_{\mathrm{S}}\right)$}

A partir da equação 3.17.1-1 e dos tempos estabelecidos no item 3.19, pode-se calcular o $D E C$ referente às interrupções não programadas, originadas na rede de distribuição secundária $\left(D E C_{S}\right)$, de uma determinada região:

$D E C_{S}=\frac{\sum_{i=1}^{M}\left\{\left[\left(\lambda_{Q T}(i) \times T F\right)+\left(\lambda_{R S}(i) \times T S\right)\right] \times N S(i)\right\}}{C S}$ 
Sendo:

$D I_{S}(i)=\left[\left(\lambda_{Q T}(i) x T F\right)+\left(\lambda_{R S}(i) x T S\right)\right]$

Onde:

$D I_{S}(i)$ é o tempo estimado, durante o qual os consumidores ligados ao circuito $\underline{\mathrm{i}}$ ficarão sem energia, devido a interrupções originadas no respectivo circuito secundário, durante o período considerado.

De maneira similar à apresentada no item 3.12, é possível estabelecer relações entre os tempos envolvidos nos restabelecimentos da rede secundária, determinando-se um fator de ajustamento entre o $D E C_{S}$ histórico e o $D E C_{S}$ calculado.

\subsubsection{DEC Total}

O DEC total de uma determinada região elétrica, referente a interrupções não programadas, originadas na rede de distribuição será:

$D E C=D E C_{P}+D E C_{S}$

\subsection{CÁLCULO DO DIC}

Para consumidores atendidos em tensão de distribuição primária, o valor do $D I C$ referente às interrupções não programadas, originadas na rede de distribuição, pode ser calculado diretamente através da equação 3.11-1, conforme já discutido no item 3.11 .

Entretanto, para o caso dos consumidores atendidos em tensão de distribuição secundária, esse valor é obtido através da seguinte equação:

$D I C(j)=\left[\left(\lambda_{Q T}(j) \times T F\right)+\left(\lambda_{R S}(j) \times T S\right)+D I P J\right]$

$\mathrm{ou}$

$D I C(j)=D I_{S}(j)+D I P J$

Onde:

$D I C(j)$ é a duração total média das interrupções não programadas, originadas na rede de distribuição, as quais todos os consumidores atendidos pelo transformador de distribuição $j$ deverão estar sujeitos, durante o período 
analisado;

DIPJ é a duração total provável das interrupções - não programadas, originadas na rede de distribuição primária - do bloco onde está ligado o transformador $j$, durante o período analisado, conforme equação 3.11-1.

É importante ressaltar que, quanto mais se busca a obtenção de valores particularizados, como no caso dos indicadores FIC e DIC, através de cálculos médios na rede secundária, maior a possibilidade de erros de previsão.

Caso se pretendesse estimar a probabilidade de descumprimento dos valores máximos padrões para esses indicadores, seria necessário o estabelecimento de curvas de distribuição de probabilidades.

Nos próximos anos, quando houver um banco de dados, com os valores históricos de DIC e FIC para cada consumidor, será possível estabelecer relações mais confiáveis para cada circuito secundário em particular, e os cálculos tenderão a se tornar mais precisos.

Dessa forma, poderão ser realizadas análises de riscos similares às apresentadas por Kagan; Oliveira, onde podem ser estabelecidas distribuições de probabilidades, conforme ilustração abaixo. [34]

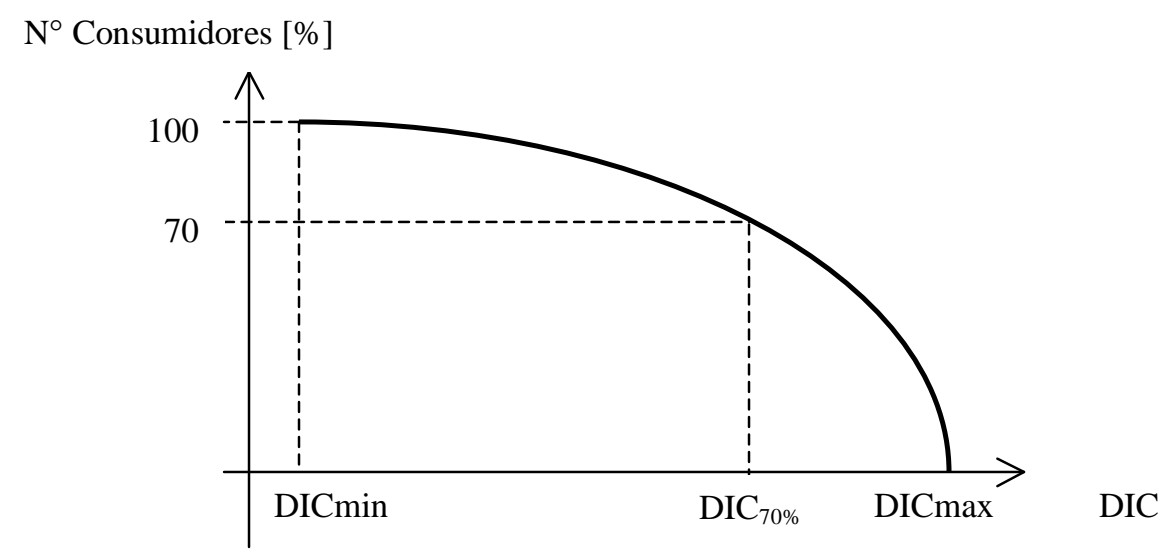

Figura 3.21-1 - Distribuição de probabilidade para DIC

Na Figura 3.21-1, pode-se perceber que 70\% dos consumidores apresentam valores de $D I C$ iguais ou superiores a $D I C_{70 \%}$. 
Entretanto, a metodologia aqui apresentada visa apenas estabelecer a comparação entre alternativas de planejamento; e seus resultados absolutos devem servir apenas como sinalizadores.

\subsection{CÁLCULO DA ENERGIA NÃO DISTRIBUÍDA (END)}

Por analogia aos cálculos do $D E C$ e $F E C$ referentes às interrupções não programadas, originadas na rede secundária, poder-se-iam desenvolver equações para $E N D_{S}$ e apresentar o valor da energia total não distribuída, como sendo:

$E N D=E N D_{P}+E N D_{S}$.

Entretanto, de posse dos valores de DIC para cada um dos transformadores de distribuição e dos respectivos consumos, é possível obter o valor total da Energia não Distribuída $(E N D)$, através da equação:

$E N D=\frac{\sum_{j=1}^{T}[D I C(j) \times C(j)]}{8760}[\mathrm{kWh} / \mathrm{ano}]$

Onde:

$T$ é o número total de transformadores de distribuição da região analisada;

$C(j)$ é o consumo anual médio do transformador $j$, considerando-se $D I C(j)$ em horas.

$\mathrm{Na}$ verdade, como interrupções originadas internamente nas instalações dos consumidores, não entram na contabilização do $D I C$, haverá um pequeno desvio no cálculo da $E N D$, apresentado pela equação 3.22-2.

\subsection{UTILIZAÇÃO DA METODOLOGIA}

A metodologia até aqui apresentada deve ser utilizada com o objetivo principal de se diagnosticar o estado atual do sistema de distribuição radial em análise e apresentar valores esperados para os indicadores DEC, FEC, DIC, FIC e END para cada uma das ações de planejamento, visando auxiliar nas tomadas de decisão, através da comparação dos diversos efeitos esperados sobre tais indicadores.

Obviamente que o planejador deve também considerar outros aspectos relevantes, 
referentes à exeqüibilidade das propostas, dificuldades operacionais, impactos na manutenção, bem como proceder a análises econômicas, etc.

Dessa forma pode-se estabelecer um quadro comparativo entre as alternativas, como por exemplo:

Tabela 3.23-1 - Quadro comparativo

\begin{tabular}{|c|c|c|l|c|}
\hline INDICADOR & PROPOSIÇÃO 1 & PROPOSIÇÃO 2 & $\cdots$ & PROPOSIÇÃO n \\
\hline DEC atual & DEC 1 & DEC 2 & $\cdots$ & DEC n \\
\hline FEC atual & FEC 1 & FEC 2 & $\cdots$ & FEC n \\
\hline END atual & END 1 & END 2 & $\cdots$ & END n \\
\hline- & Custo1 & Custo 2 & $\cdots$ & Custo n \\
\hline- & Benefício 1 & Benefício 2 & $\cdots$ & Benefício n \\
\hline- & Relação & Relação & $\cdots$ & $\begin{array}{c}\text { Relação } \\
\text { Benefício 1/Custo 1 }\end{array}$ \\
\hline
\end{tabular}




\section{ESTUDOS DE CASOS}

Com base na metodologia apresentada no Capítulo 3, serão apresentados dois casos, com uma região elétrica hipotética e uma real, onde será possível avaliar a eficiência da técnica desenvolvida.

\subsection{CASO 1: REGIÃO ELÉTRICA HIPOTÉTICA}

Para facilitar as simulações e o entendimento, será apresentada uma só região elétrica, composta por uma subestação com dois alimentadores. Cada alimentador é composto por quatro blocos, com dois circuitos secundários cada, conforme Figura abaixo.

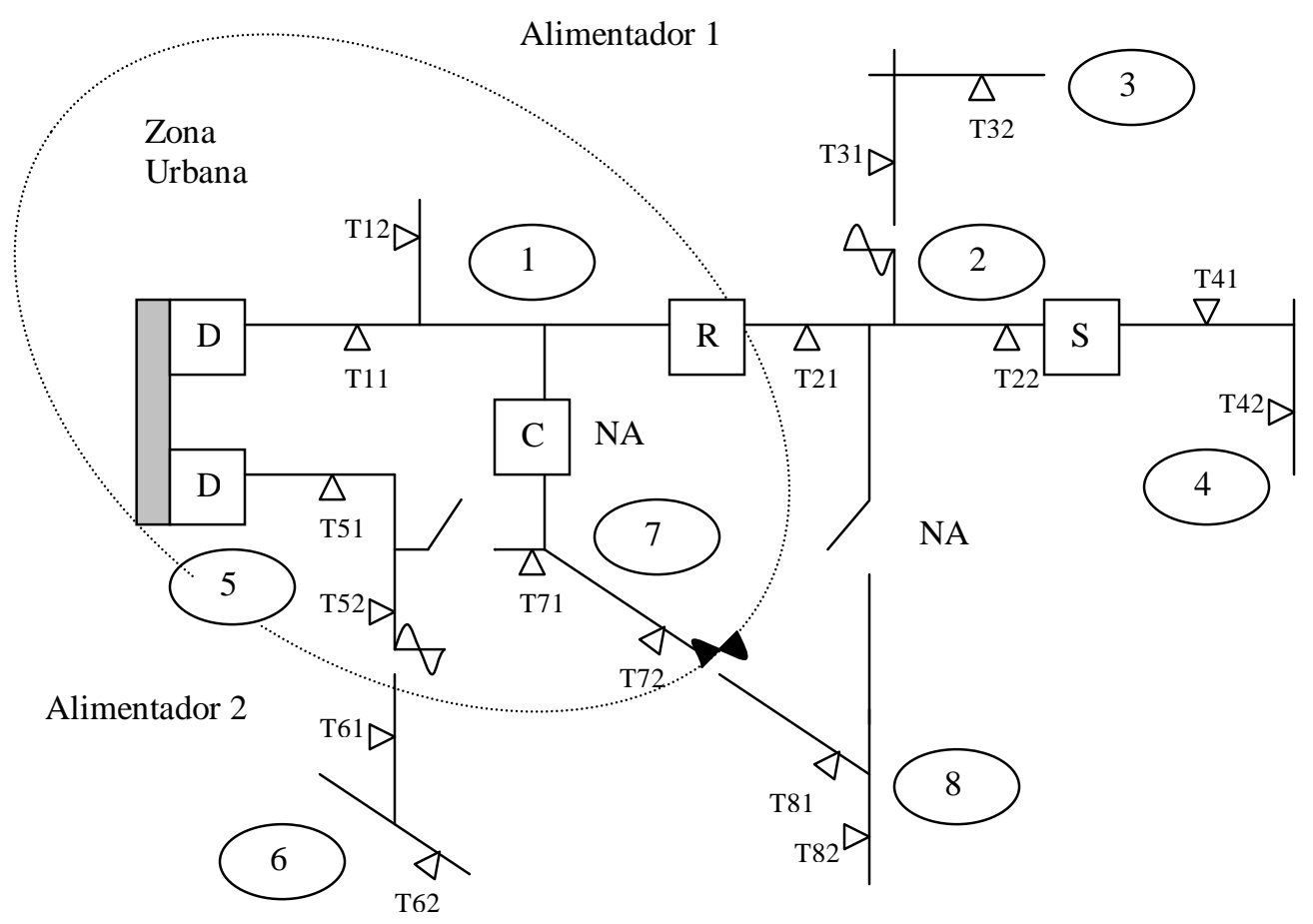

Figura 4.1-1 - Região Elétrica hipotética 
Onde:

Barramento de 15 kV da Subestação de Distribuição;

D Disjuntor;

R Religador Automático de Distribuição;

S Seccionalizador

C NA Chave Trifásica Normalmente Aberta (interligação entre dois alimentadores distintos);

_ C Chave Faca Normalmente Fechada;

$\perp^{\text {NA }}$ Chave Faca Normalmente Aberta;

8 - Chave Fusível;

- Chave Fusível Religadora;

$\triangle_{\text {Txv }}$ Tranformador de Distribuição, com respectiva rede de distribuição secundária, onde $\underline{x}$ é o número do bloco a que está associado e y é sequïencial;

3 Número do Bloco.

\subsubsection{Condições iniciais para cálculos na rede primária:}

- toda rede é composta pelo mesmo padrão: trifásico, aéreo, horizontal, convencional, com cabos nus de alumínio; 
- taxa anual de falhas (permanentes + momentâneas) constante e igual a duas ocorrências por quilômetro (2 falhas/km);

- não há qualquer dispositivo automatizado na rede e portanto, as transferências serão sempre manuais: $T T=T M$;

- a percentagem de falhas permanentes é de $20 \%(F P=0,2)$;

- tanto o religador automático de distribuição, como a chave fusível religadora estão ajustados para possibilitar manobras, sem que haja atuação indesejável desses dispositivos de proteção;*

- $F E C_{P}$ histórico anual da região elétrica é igual a 3 interrupções por consumidor;

- $D E C_{P}$ histórico anual da região elétrica é igual a 3,5 horas por consumidor.

Os demais dados utilizados são apresentados nas próximas tabelas.

Tabela 4.1.1-1 - Dados dos blocos da rede primária

\begin{tabular}{|c|c|c|c|}
\hline BLOCO & ZONA & $\begin{array}{c}\text { COMPRIMENTO } \\
{[\mathbf{k m}]}\end{array}$ & $\begin{array}{c}\text { TAXA DE FALHAS } \\
\text { DO BLOCO }\end{array}$ \\
\hline 1 & Urbana & 4,475 & 8,950 \\
\hline 2 & Rural & 3,137 & 6,274 \\
\hline 3 & Rural & 4,405 & 8,810 \\
\hline 4 & Rural & 4,786 & 9,572 \\
\hline 5 & Urbana & 2,323 & 4,646 \\
\hline 6 & Rural & 2,868 & 5,736 \\
\hline 7 & Urbana & 1,898 & 3,796 \\
\hline 8 & Rural & 3,937 & 7,874 \\
\hline
\end{tabular}

* NOTA do autor: Na prática, essa checagem é geralmente realizada pela área de proteção. No programa computacional que está em desenvolvimento, o planejador poderá definir o critério de transferências, escolhendo quais tipos de chaves poderão ser manobrados. 
Os tempos médios históricos e os respectivos desvios padrões para a região elétrica analisada são obtidos a partir do banco de dados do Centro de Operações e são mostrados na tabela a seguir, sendo que sua diferenciação - urbana ou rural - é aplicada sempre levando-se em conta a localização do bloco com defeito.

Será admitido que as distribuições de probabilidade dos tempos seguem o padrão da curva de distribuição normal.

Tabela 4.1.1-2 - Tempos de restabelecimento para áreas

urbana e rural

\begin{tabular}{|c|c|c|c|c|}
\hline \multirow{2}{*}{$\begin{array}{c}\text { TEMPOS DE } \\
\text { RESTABELECIMENTO }\end{array}$} & \multicolumn{4}{|c|}{ DURAÇÃO [horas] } \\
\cline { 2 - 5 } & \multicolumn{2}{|c|}{ ZONA URBANA } & \multicolumn{2}{c|}{ ZONA RURAL } \\
\cline { 2 - 5 } & Média $(\boldsymbol{\mu})$ & Desvio $(\boldsymbol{\delta})$ & Média $(\boldsymbol{\mu})$ & Desvio $(\boldsymbol{\delta})$ \\
\hline TL & 0,6 & 0,3 & 0,8 & 0,7 \\
\hline TR & 0,3 & 0,2 & 0,5 & 0,3 \\
\hline TT & 0,12 & 0,08 & 0,25 & 0,1 \\
\hline
\end{tabular}

\subsubsection{Condições iniciais para cálculos na rede secundária:}

- toda rede é composta pelo mesmo padrão: trifásico, aéreo, vertical, convencional, com cabos nus de alumínio;

- taxa anual de falhas constante e igual a duas ocorrências por quilômetro (2 falhas $/ \mathrm{km})$;

- Taxa de queima de transformadores constante e igual a 3\%;

- Tempo médio de preparação da turma de emergência, localização do defeito e reparo do transformador de distribuição (TF) igual a 2,0 horas;

- Tempo médio de preparação da turma de emergência, localização do defeito e reparo da rede (TS) igual a 1,0 hora;

- $F E C_{S}$ histórico anual da região é de 1,5 interrupções por consumidor;

- $D E C_{S}$ histórico anual da região é de 1,5 horas por consumidor;

- Transformadores com um só consumidor são de propriedade particular, pertencentes ao grupo A4 (atendidos em tensão primária), 
Tabela 4.1.2-1 - Dados da rede de distribuição secundária e número de consumidores

\begin{tabular}{|c|c|c|c|c|}
\hline CIRCUITO & $\begin{array}{c}\text { COMPRIMENTO } \\
{[\mathbf{k m}]}\end{array}$ & $\begin{array}{c}\text { TAXA DE FALHAS } \\
\text { TOTAL (REDE + } \\
\text { TRANSFORM. }\end{array}$ & $\begin{array}{c}\text { NÚMERO DE } \\
\text { CLIENTES }\end{array}$ & $\begin{array}{c}\text { CONSUMO } \\
\text { ANUAL [kWh] }\end{array}$ \\
\hline T11 & 0,6 & 1,23 & 36 & 93000 \\
\hline T12 & 0,4 & 0,83 & 26 & 70000 \\
\hline T21 & 0 & 0 & 1 & 2500 \\
\hline T22 & 0,4 & 0,83 & 8 & 22000 \\
\hline T31 & 0,5 & 1,03 & 26 & 75000 \\
\hline T32 & 0 & 0 & 1 & 2000 \\
\hline T41 & 0,35 & 0,73 & 17 & 47000 \\
\hline T42 & 0,5 & 1,03 & 31 & 86000 \\
\hline T51 & 0,8 & 1,63 & 69 & 205000 \\
\hline T52 & 0,7 & 1,43 & 44 & 130000 \\
\hline T61 & 0,4 & 0,83 & 7 & 21000 \\
\hline T62 & 0 & 0 & 1 & 1500 \\
\hline T71 & 0,65 & 1,33 & 42 & 123000 \\
\hline T72 & 0,35 & 0,73 & 25 & 86000 \\
\hline T81 & 0 & 0 & 1 & 1000 \\
\hline T82 & 0,5 & 1,03 & 11 & 34000 \\
\hline & & & & \\
\hline
\end{tabular}

\subsubsection{Cálculos Iniciais}

Seguindo a metodologia descrita no Capítulo 3, pode-se montar um equivalente da região elétrica apresentada na Figura 4.1-1 análogo ao da Figura 3.1-2.

Tal equivalente tem valor apenas didático, já que se pode efetuar a análise diretamente sobre o sistema real. 


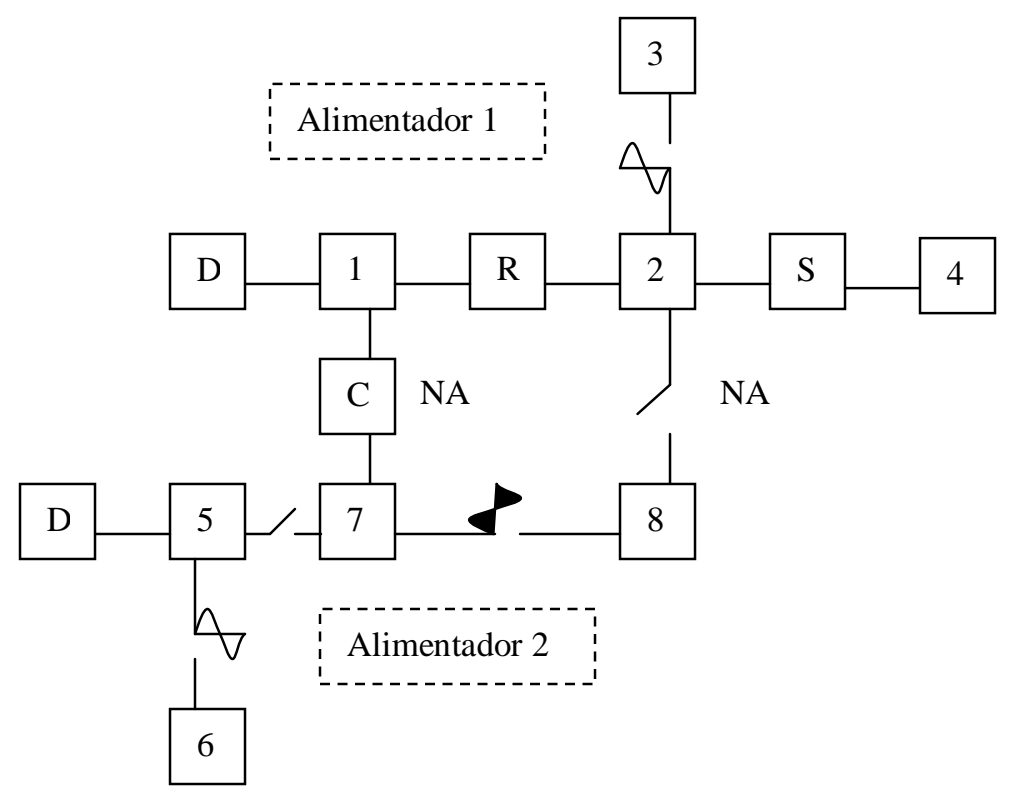

Figura 4.1.3-1 - Equivalente da região elétrica

As matrizes então podem ser construídas:

Conforme Tabela 3.2-1:

Tabela 4.1.3-1 - Matriz de classificação de blocos

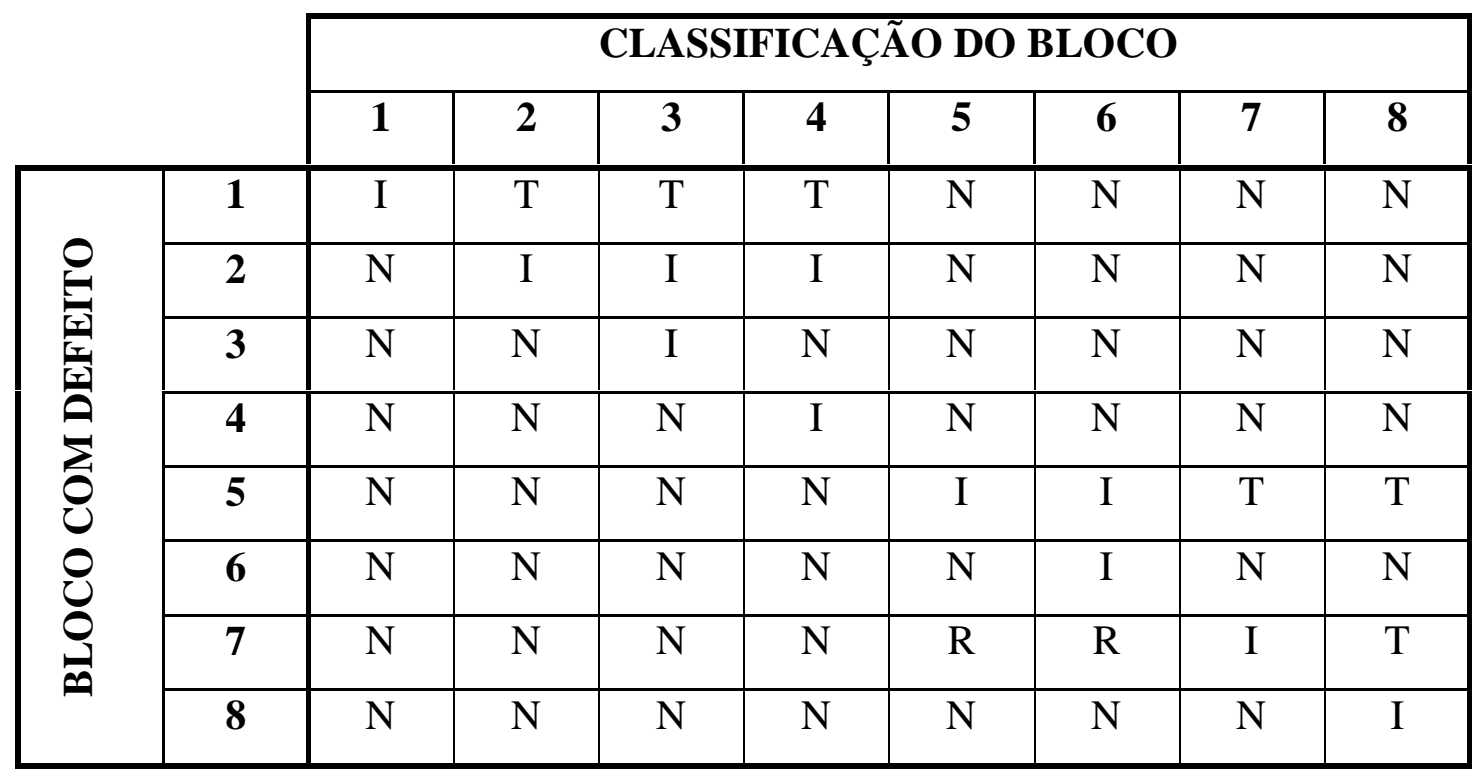




\subsubsection{Cálculos referentes ao $\mathrm{FEC}_{P}$}

Conforme Tabela 3.6-1:

Tabela 4.1.4-1 - Matriz de quantidades prováveis de defeitos na rede primária

\begin{tabular}{|c|c|c|c|c|c|c|c|c|c|}
\hline & \multicolumn{8}{|c|}{ BLOCOS AFETADOS } \\
\hline & & 1 & 2 & 3 & 4 & 5 & 6 & 7 & 8 \\
\hline \multirow{8}{*}{ 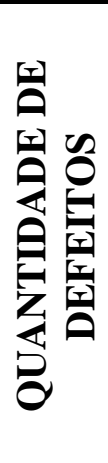 } & 1 & 1,7900 & 1,7900 & 1,7900 & 1,7900 & 0,0000 & 0,0000 & 0,0000 & 0,0000 \\
\hline & 2 & 0,0000 & 1,2548 & 1,2548 & 1,2548 & 0,0000 & 0,0000 & 0,0000 & 0,0000 \\
\hline & 3 & 0,0000 & 0,0000 & 1,7620 & 0,0000 & 0,0000 & 0,0000 & 0,0000 & 0,0000 \\
\hline & 4 & 0,0000 & 0,0000 & 0,0000 & 1,9144 & 0,0000 & 0,0000 & 0,0000 & 0,0000 \\
\hline & 5 & 0,0000 & 0,0000 & 0,0000 & 0,0000 & 0,9292 & 0,9292 & 0,9292 & 0,9292 \\
\hline & 6 & 0,0000 & 0,0000 & 0,0000 & 0,0000 & 0,0000 & 5,7360 & 0,0000 & 0,0000 \\
\hline & 7 & 0,0000 & 0,0000 & 0,0000 & 0,0000 & 0,7592 & 0,7592 & 0,7592 & 0,7592 \\
\hline & 8 & 0,0000 & 0,0000 & 0,0000 & 0,0000 & 0,0000 & 0,0000 & 0,0000 & 1,5748 \\
\hline
\end{tabular}

Conforme equação 3.7-1, poder-se-ia obter a quantidade total provável de interrupções não programadas, originadas na rede de distribuição primária, a que estará sujeito cada um dos blocos. Entretanto, primeiro será desenvolvido o cálculo do $F E C_{P}$, para que se possa ajustar a taxa de falhas ao $F E C_{P}$ histórico.

Conforme Tabela 3.7-1:

Tabela 4.1.4-2 - Matriz das ponderações do número de consumidores associados aos blocos afetados

\begin{tabular}{|c|c|c|c|c|c|c|c|c|c|}
\hline & \multicolumn{8}{|c|}{ BLOCOS AFETADOS } \\
\hline & & 1 & 2 & 3 & 4 & 5 & 6 & 7 & 8 \\
\hline \multirow{8}{*}{ 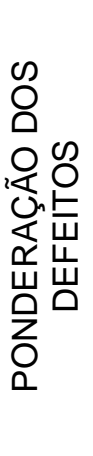 } & 1 & 110,9800 & 16,1100 & 48,3300 & 85,9200 & 0,0000 & 0,0000 & 0,0000 & 0,0000 \\
\hline & 2 & 0,0000 & 11,2932 & 33,8796 & 60,2304 & 0,0000 & 0,0000 & 0,0000 & 0,0000 \\
\hline & 3 & 0,0000 & 0,0000 & 47,5740 & 0,0000 & 0,0000 & 0,0000 & 0,0000 & 0,0000 \\
\hline & 4 & 0,0000 & 0,0000 & 0,0000 & 91,8912 & 0,0000 & 0,0000 & 0,0000 & 0,0000 \\
\hline & 5 & 0,0000 & 0,0000 & 0,0000 & 0,0000 & 104,9996 & 7,4336 & 62,2564 & 11,1504 \\
\hline & 6 & 0,0000 & 0,0000 & 0,0000 & 0,0000 & 0,0000 & 45,8880 & 0,0000 & 0,0000 \\
\hline & 7 & 0,0000 & 0,0000 & 0,0000 & 0,0000 & 85,7896 & 6,0736 & 50,8664 & 9,1104 \\
\hline & 8 & 0,0000 & 0,0000 & 0,0000 & 0,0000 & 0,0000 & 0,0000 & 0,0000 & 18,8976 \\
\hline
\end{tabular}


Conforme equação 3.7-2, temos que:

$\mathrm{FEC}_{\mathrm{P}}=2,6262$

Portanto, pode-se perceber que o $F E C_{P}$ calculado difere do $F E C_{P}$ histórico, para a região elétrica considerada.

É necessário então, o ajustamento das taxas de falhas, conforme apresentado no item 3.8. Assim, nesse caso, a taxa de falhas real, para a região elétrica é:

$\lambda$ redehistórica $=\lambda$ redeconsiderada $\times \frac{F E C_{P} \text {.histórico }}{F E C_{P . \text { calculado }}}=2,2847$

A Tabela 4.1.1-1 será então alterada, considerando-se esse novo valor:

Tabela 4.1.4-3 - Dados dos blocos da rede primária, considerando-se o histórico das taxas de falhas para a região elétrica considerada

\begin{tabular}{|c|c|c|c|}
\hline BLOCO & ZONA & $\begin{array}{c}\text { COMPRIMENTO } \\
{[\mathbf{k m}]}\end{array}$ & $\begin{array}{c}\text { TAXA DE FALHAS } \\
\text { DO BLOCO }\end{array}$ \\
\hline 1 & Urbana & 4,475 & 10,224 \\
\hline 2 & Rural & 3,137 & 7,167 \\
\hline 3 & Rural & 4,405 & 10,064 \\
\hline 4 & Rural & 4,786 & 10,935 \\
\hline 5 & Urbana & 2,323 & 5,307 \\
\hline 6 & Rural & 2,868 & 6,553 \\
\hline 7 & Urbana & 1,898 & 4,336 \\
\hline 8 & Rural & 3,937 & 8,995 \\
\hline
\end{tabular}

A Tabela 4.1.4-1 será re-escrita como: 
Tabela 4.1.4-4 - Matriz de quantidades prováveis de defeitos na rede primária, considerando-se as taxas de falhas próprias da região

\begin{tabular}{|c|c|c|c|c|c|c|c|c|c|}
\hline & \multicolumn{8}{|c|}{ BLOCOS AFETADOS } \\
\hline & & 1 & 2 & 3 & 4 & 5 & 6 & 7 & 8 \\
\hline \multirow{8}{*}{ 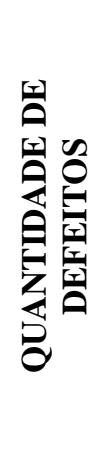 } & 1 & 2,0448 & 2,0448 & 2,0448 & 2,0448 & 0,0000 & 0,0000 & 0,0000 & 0,0000 \\
\hline & 2 & 0,0000 & 1,4334 & 1,4334 & 1,4334 & 0,0000 & 0,0000 & 0,0000 & 0,0000 \\
\hline & 3 & 0,0000 & 0,0000 & 2,0128 & 0,0000 & 0,0000 & 0,0000 & 0,0000 & 0,0000 \\
\hline & 4 & 0,0000 & 0,0000 & 0,0000 & 2,1869 & 0,0000 & 0,0000 & 0,0000 & 0,0000 \\
\hline & 5 & 0,0000 & 0,0000 & 0,0000 & 0,0000 & 1,0615 & 1,0615 & 1,0615 & 1,0615 \\
\hline & 6 & 0,0000 & 0,0000 & 0,0000 & 0,0000 & 0,0000 & 6,5525 & 0,0000 & 0,0000 \\
\hline & 7 & 0,0000 & 0,0000 & 0,0000 & 0,0000 & 0,8673 & 0,8673 & 0,8673 & 0,8673 \\
\hline & 8 & 0,0000 & 0,0000 & 0,0000 & 0,0000 & 0,0000 & 0,0000 & 0,0000 & 1,7990 \\
\hline
\end{tabular}

Agora sim, já se pode obter a quantidade total de interrupções não programadas, originadas na rede de distribuição primária, a que estará sujeito cada um dos blocos, de acordo com a equação 3.7-1:

Tabela 4.1.4-5 - Número de interrupções anuais prováveis em cada bloco

\begin{tabular}{|c|c|c|c|c|c|c|c|}
\hline \multicolumn{7}{|c|}{ NÚMERO DE INTERRUPÇÕES NOS BLOCOS [NIP(j)] } \\
\hline $\mathbf{1}$ & $\mathbf{2}$ & $\mathbf{3}$ & $\mathbf{4}$ & $\mathbf{5}$ & $\mathbf{6}$ & $\mathbf{7}$ & $\mathbf{8}$ \\
\hline 2,0448 & 3,4782 & 5,4910 & 5,6651 & 1,9287 & 8,4813 & 1,9287 & 3,7277 \\
\hline
\end{tabular}

No caso dos consumidores primários pertencentes ao grupo $\mathrm{A} 4$, atendidos pelos transformadores T21, T32, T62 e T81, já se pode afirmar que os FIC prováveis são respectivamente iguais a 3,4782; 5,4910; 8,4813 e 3,7277.

Utilizando-se a equação 3.7-3 pode-se então comprovar o valor de $F E C_{P}=3$, que é o valor histórico anual, para a região elétrica em questão.

A Tabela 4.1.4-2 pode ser re-escrita como: 
Tabela 4.1.4-6 - Matriz das ponderações dos consumidores associados aos blocos afetados

\begin{tabular}{|c|c|c|c|c|c|c|c|c|c|}
\hline & \multicolumn{8}{|c|}{ BLOCOS AFETADOS } \\
\hline & & 1 & 2 & 3 & 4 & 5 & 6 & 7 & 8 \\
\hline \multirow{8}{*}{ 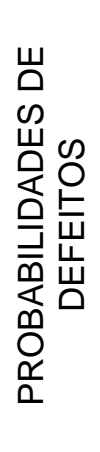 } & 1 & 126,7780 & 18,4033 & 55,2098 & 98,1507 & 0,0000 & 0,0000 & 0,0000 & 0,0000 \\
\hline & 2 & 0,0000 & 12,9008 & 38,7024 & 68,8042 & 0,0000 & 0,0000 & 0,0000 & 0,0000 \\
\hline & 3 & 0,0000 & 0,0000 & 54,3462 & 0,0000 & 0,0000 & 0,0000 & 0,0000 & 0,0000 \\
\hline & 4 & 0,0000 & 0,0000 & 0,0000 & 104,9719 & 0,0000 & 0,0000 & 0,0000 & 0,0000 \\
\hline & 5 & 0,0000 & 0,0000 & 0,0000 & 0,0000 & 119,9463 & 8,4918 & 71,1186 & 12,7377 \\
\hline & 6 & 0,0000 & 0,0000 & 0,0000 & 0,0000 & 0,0000 & 52,4202 & 0,0000 & 0,0000 \\
\hline & 7 & 0,0000 & 0,0000 & 0,0000 & 0,0000 & 98,0017 & 6,9382 & 58,1072 & 10,4073 \\
\hline & 8 & 0,0000 & 0,0000 & 0,0000 & 0,0000 & 0,0000 & 0,0000 & 0,0000 & 21,5877 \\
\hline
\end{tabular}

E de acordo com a equação 3.7-4, pode-se determinar as contribuições efetivas de cada um dos blocos para o $F E C_{P}$ calculado anteriormente:

Tabela 4.1.4-7 - Contribuições absolutas e relativas das falhas de cada bloco para o $F E C_{P}$ da região elétrica

\begin{tabular}{|c|c|c|c|c|c|c|c|c|}
\hline \multicolumn{6}{|c|}{ CONTRIBUIÇÕES DAS FALHAS PRÓPRIAS DOS BLOCOS P/ FEC } \\
\hline $\mathbf{P}$ & {$\left[\right.$ CFEC $\left._{\mathbf{P}}(\mathbf{i})\right]$} \\
\hline $\mathbf{1}$ & $\mathbf{2}$ & $\mathbf{3}$ & $\mathbf{4}$ & $\mathbf{5}$ & $\mathbf{6}$ & $\mathbf{7}$ & $\mathbf{8}$ & Total \\
\hline 0,8628 & 0,3480 & 0,1571 & 0,3034 & 0,6136 & 0,1515 & 0,5013 & 0,0624 & 3,0001 \\
\hline $28,76 \%$ & $11,60 \%$ & $5,24 \%$ & $10,11 \%$ & $20,45 \%$ & $5,05 \%$ & $16,71 \%$ & $2,08 \%$ & $100,00 \%$ \\
\hline
\end{tabular}

\subsubsection{Cálculos referentes ao $\mathrm{DEC}_{P}$}

O cálculo do $D E C_{P}$ é inicialmente realizado considerando-se os tempos médios apresentados na Tabela 4.1.1-2.

E conforme Tabela 3.10-4, tem-se: 
Tabela 4.1.5-1 - Matriz da duração da

indisponibilidade dos blocos

\begin{tabular}{|c|c|c|c|c|c|c|c|c|}
\cline { 2 - 9 } \multicolumn{1}{c|}{} & $\mathbf{1}$ & $\mathbf{2}$ & $\mathbf{3}$ & $\mathbf{4}$ & $\mathbf{5}$ & $\mathbf{6}$ & $\mathbf{7}$ & $\mathbf{8}$ \\
\hline $\mathbf{1}$ & 2,0857 & 1,4723 & 1,4723 & 1,4723 & 0,0000 & 0,0000 & 0,0000 & 0,0000 \\
\hline $\mathbf{2}$ & 0,0000 & 1,8634 & 1,8634 & 1,8634 & 0,0000 & 0,0000 & 0,0000 & 0,0000 \\
\hline $\mathbf{3}$ & 0,0000 & 0,0000 & 2,6167 & 0,0000 & 0,0000 & 0,0000 & 0,0000 & 0,0000 \\
\hline $\mathbf{4}$ & 0,0000 & 0,0000 & 0,0000 & 2,8430 & 0,0000 & 0,0000 & 0,0000 & 0,0000 \\
\hline $\mathbf{5}$ & 0,0000 & 0,0000 & 0,0000 & 0,0000 & 1,0827 & 1,0827 & 0,7643 & 0,7643 \\
\hline $\mathbf{6}$ & 0,0000 & 0,0000 & 0,0000 & 0,0000 & 0,0000 & 8,5183 & 0,0000 & 0,0000 \\
\hline $\mathbf{7}$ & 0,0000 & 0,0000 & 0,0000 & 0,0000 & 0,6244 & 0,6244 & 0,9887 & 0,7285 \\
\hline $\mathbf{8}$ & 0,0000 & 0,0000 & 0,0000 & 0,0000 & 0,0000 & 0,0000 & 0,0000 & 2,3387 \\
\hline
\end{tabular}

Conforme Tabela 3.11-1:

Tabela 4.1.5-2 - Matriz das ponderações dos consumidores à duração da indisponibilidade dos blocos

\begin{tabular}{|c|c|c|c|c|c|c|c|c|}
\cline { 2 - 9 } \multicolumn{1}{c|}{} & $\mathbf{1}$ & $\mathbf{2}$ & $\mathbf{3}$ & $\mathbf{4}$ & $\mathbf{5}$ & $\mathbf{6}$ & $\mathbf{7}$ & $\mathbf{8}$ \\
\hline $\mathbf{1}$ & 129,3136 & 13,2503 & 39,7510 & 70,6685 & 0,0000 & 0,0000 & 0,0000 & 0,0000 \\
\hline $\mathbf{2}$ & 0,0000 & 16,7710 & 50,3131 & 89,4455 & 0,0000 & 0,0000 & 0,0000 & 0,0000 \\
\hline $\mathbf{3}$ & 0,0000 & 0,0000 & 70,6500 & 0,0000 & 0,0000 & 0,0000 & 0,0000 & 0,0000 \\
\hline $\mathbf{4}$ & 0,0000 & 0,0000 & 0,0000 & 136,4635 & 0,0000 & 0,0000 & 0,0000 & 0,0000 \\
\hline $\mathbf{5}$ & 0,0000 & 0,0000 & 0,0000 & 0,0000 & 122,3452 & 8,6616 & 51,2054 & 9,1711 \\
\hline $\mathbf{6}$ & 0,0000 & 0,0000 & 0,0000 & 0,0000 & 0,0000 & 68,1462 & 0,0000 & 0,0000 \\
\hline $\mathbf{7}$ & 0,0000 & 0,0000 & 0,0000 & 0,0000 & 70,5613 & 4,9955 & 66,2422 & 8,7421 \\
\hline $\mathbf{8}$ & 0,0000 & 0,0000 & 0,0000 & 0,0000 & 0,0000 & 0,0000 & 0,0000 & 28,0640 \\
\hline
\end{tabular}

De acordo com a equação 3.11-2:

$\mathrm{DEC}_{\mathrm{P}}=3,0484$

Portanto, o valor de $D E C_{P}$ calculado é diferente do $D E C_{P}$ histórico, considerando-se os valores dos tempos médios históricos.

É necessário então estabelecer um ajustamento nos tempos.

Para uma primeira iteração, serão considerados todos os tempos como sendo iguais a $(\mu+0,2 . \delta)$ e os novos valores são mostrados na Tabela 4.1.5-3. 
Tabela 4.1.5-3 - Tempos de restabelecimento para áreas

urbana e rural

\begin{tabular}{|c|c|c|}
\hline \multirow{2}{*}{ TEMPOS DE } & \multicolumn{2}{|c|}{ DURAÇÃO [horas] } \\
\cline { 2 - 3 } RESTABELECIMENTO & ZONA URBANA & ZONA RURAL \\
\hline TL & 0,660 & 0,940 \\
\hline TR & 0,400 & 0,560 \\
\hline TT & 0,136 & 0,270 \\
\hline
\end{tabular}

Assim, os cálculos são refeitos e as Tabelas 4.1.5-1 e 4.1.5-2 alteradas.

Tabela 4.1.5-4 - Matriz das da duração da indisponibilidade dos blocos, após acertos dos tempos de restabelecimento

\begin{tabular}{|c|c|c|c|c|c|c|c|c|}
\cline { 2 - 8 } \multicolumn{1}{c|}{} & $\mathbf{1}$ & $\mathbf{2}$ & $\mathbf{3}$ & $\mathbf{4}$ & $\mathbf{5}$ & $\mathbf{6}$ & $\mathbf{7}$ & $\mathbf{8}$ \\
\hline $\mathbf{1}$ & 2,4456 & 1,6277 & 1,6277 & 1,6277 & 0,0000 & 0,0000 & 0,0000 & 0,0000 \\
\hline $\mathbf{2}$ & 0,0000 & 2,1501 & 2,1501 & 2,1501 & 0,0000 & 0,0000 & 0,0000 & 0,0000 \\
\hline $\mathbf{3}$ & 0,0000 & 0,0000 & 3,0192 & 0,0000 & 0,0000 & 0,0000 & 0,0000 & 0,0000 \\
\hline $\mathbf{4}$ & 0,0000 & 0,0000 & 0,0000 & 3,2804 & 0,0000 & 0,0000 & 0,0000 & 0,0000 \\
\hline $\mathbf{5}$ & 0,0000 & 0,0000 & 0,0000 & 0,0000 & 1,2695 & 1,2695 & 0,8449 & 0,8449 \\
\hline $\mathbf{6}$ & 0,0000 & 0,0000 & 0,0000 & 0,0000 & 0,0000 & 9,8288 & 0,0000 & 0,0000 \\
\hline $\mathbf{7}$ & 0,0000 & 0,0000 & 0,0000 & 0,0000 & 0,6903 & 0,6903 & 1,1552 & 0,8083 \\
\hline $\mathbf{8}$ & 0,0000 & 0,0000 & 0,0000 & 0,0000 & 0,0000 & 0,0000 & 0,0000 & 2,6985 \\
\hline
\end{tabular}

Tabela 4.1.5-5 - Matriz das ponderações dos consumidores à duração da indisponibilidade dos blocos, após acertos dos tempos de restabelecimento

\begin{tabular}{|c|c|c|c|c|c|c|c|c|}
\cline { 2 - 9 } \multicolumn{1}{c|}{} & $\mathbf{1}$ & $\mathbf{2}$ & $\mathbf{3}$ & $\mathbf{4}$ & $\mathbf{5}$ & $\mathbf{6}$ & $\mathbf{7}$ & $\mathbf{8}$ \\
\hline $\mathbf{1}$ & 151,6265 & 14,6490 & 43,9470 & 78,1280 & 0,0000 & 0,0000 & 0,0000 & 0,0000 \\
\hline $\mathbf{2}$ & 0,0000 & 19,3512 & 58,0535 & 103,2063 & 0,0000 & 0,0000 & 0,0000 & 0,0000 \\
\hline $\mathbf{3}$ & 0,0000 & 0,0000 & 81,5192 & 0,0000 & 0,0000 & 0,0000 & 0,0000 & 0,0000 \\
\hline $\mathbf{4}$ & 0,0000 & 0,0000 & 0,0000 & 157,4579 & 0,0000 & 0,0000 & 0,0000 & 0,0000 \\
\hline $\mathbf{5}$ & 0,0000 & 0,0000 & 0,0000 & 0,0000 & 143,4558 & 10,1562 & 56,6104 & 10,1392 \\
\hline $\mathbf{6}$ & 0,0000 & 0,0000 & 0,0000 & 0,0000 & 0,0000 & 78,6302 & 0,0000 & 0,0000 \\
\hline $\mathbf{7}$ & 0,0000 & 0,0000 & 0,0000 & 0,0000 & 78,0094 & 5,5228 & 77,3988 & 9,6996 \\
\hline $\mathbf{8}$ & 0,0000 & 0,0000 & 0,0000 & 0,0000 & 0,0000 & 0,0000 & 0,0000 & 32,3815 \\
\hline
\end{tabular}


De acordo com a equação 3.11-2:

$\mathrm{DEC}_{\mathrm{P}}=3,4969$ [horas/consumidor]

Nesse caso, com apenas uma iteração já se chegou a um valor satisfatório para $D E C_{P}$ histórico da região elétrica em análise. Entretanto, caso o valor não fosse aceito, novos valores de $(\mu+\mathrm{k} . \delta)$ seriam escolhidos.

As durações prováveis das interrupções dos blocos, devido a interrupções não programadas, originadas na rede de distribuição primária, podem ser calculadas de acordo com a equação 3.11-1:

Tabela 4.1.5-6 - Tempo anual médio em que os blocos estarão interrompidos, em horas

\begin{tabular}{|c|c|c|c|c|c|c|c|}
\hline \multicolumn{7}{|c|}{ DURAÇÃO DAS INTERRUPÇ्̃ES NOS BLOCOS [DI $\mathbf{P}(\mathbf{j})]$} \\
\hline $\mathbf{1}$ & $\mathbf{2}$ & $\mathbf{3}$ & $\mathbf{4}$ & $\mathbf{5}$ & $\mathbf{6}$ & $\mathbf{7}$ & $\mathbf{8}$ \\
\hline 2,4456 & 3,7778 & 6,7970 & 7,0582 & 1,9599 & 11,7886 & 2,0001 & 4,3517 \\
\hline
\end{tabular}

No caso dos consumidores primários pertencentes ao grupo A4, atendidos pelos transformadores T21, T32, T62 e T81, já se pode afirmar que os DIC prováveis são respectivamente iguais a 3,$7778 ; 6,7970 ; 11,7886$ e 4,3517 .

E de acordo com a equação 3.11-4, pode-se determinar as contribuições efetivas de cada um dos blocos para o $D E C_{P}$ calculado anteriormente:

Tabela 4.1.5-7 - Contribuições absolutas e relativas das falhas de cada bloco para o $\mathrm{DEC}_{P}$ da região elétrica

\begin{tabular}{|c|c|c|c|c|c|c|c|c|}
\hline \multicolumn{1}{|c|}{ CONTRIBUIÇÕES DAS FALHAS PRÓPRIAS DOS BLOCOS [CDEC } \\
\hline $\mathbf{1}$ & $\mathbf{2}$ & $\mathbf{3}$ & $\mathbf{4}$ & $\mathbf{5}$ & $\mathbf{6}$ & $\mathbf{7}$ & $\mathbf{8}$ & Total \\
\hline 0,8334 & 0,5220 & 0,2356 & 0,4551 & 0,6369 & 0,2273 & 0,4932 & 0,0936 & 3,4969 \\
\hline $23,83 \%$ & $14,93 \%$ & $6,74 \%$ & $13,01 \%$ & $18,21 \%$ & $6,50 \%$ & $14,10 \%$ & $2,68 \%$ & $100,00 \%$ \\
\hline
\end{tabular}

\subsubsection{Cálculos referentes a END}

Conforme Tabela 3.13-1: 
Tabela 4.1.6-1 - Matriz das ponderações dos consumos associados às durações das indisponibilidades dos blocos

\begin{tabular}{|r|r|r|r|r|r|r|r|r|}
\cline { 2 - 9 } \multicolumn{1}{c|}{} & \multicolumn{1}{c|}{$\mathbf{1}$} & $\mathbf{2}$ & $\mathbf{3}$ & $\mathbf{4}$ & $\mathbf{5}$ & $\mathbf{6}$ & $\mathbf{7}$ & $\mathbf{8}$ \\
\hline $\mathbf{1}$ & 398631 & 39878 & 125330 & 216480 & 0 & 0 & 0 & 0 \\
\hline $\mathbf{2}$ & 0 & 52678 & 165560 & 285967 & 0 & 0 & 0 & 0 \\
\hline $\mathbf{3}$ & 0 & 0 & 232481 & 0 & 0 & 0 & 0 & 0 \\
\hline $\mathbf{4}$ & 0 & 0 & 0 & 436290 & 0 & 0 & 0 & 0 \\
\hline $\mathbf{5}$ & 0 & 0 & 0 & 0 & 425289 & 28564 & 176591 & 29573 \\
\hline $\mathbf{6}$ & 0 & 0 & 0 & 0 & 0 & 221148 & 0 & 0 \\
\hline $\mathbf{7}$ & 0 & 0 & 0 & 0 & 231267 & 15533 & 241438 & 28290 \\
\hline $\mathbf{8}$ & 0 & 0 & 0 & 0 & 0 & 0 & 0 & 94446 \\
\hline
\end{tabular}

Pode-se então calcular a energia não distribuída estimada, para a região elétrica, de acordo com a equação 3.13-1:

$\mathrm{END}_{\mathrm{P}}=393,3 \mathrm{kWh} / \mathrm{ano}$

As contribuições de cada bloco para a energia não distribuída, podem ser calculadas através da equação 3.13-2:

Tabela 4.1.6-2 - Contribuições absolutas e relativas das falhas de cada bloco para a $E N D_{P}$ da região elétrica

\begin{tabular}{|c|c|c|c|c|c|c|c|c|}
\hline \multicolumn{1}{|c|}{ CONTRIBUIÇÕES DAS FALHAS PRÓPRIAS DOS BLOCOS [CEND $(\mathbf{i})]$} \\
\hline $\mathbf{1}$ & $\mathbf{2}$ & $\mathbf{3}$ & $\mathbf{4}$ & $\mathbf{5}$ & $\mathbf{6}$ & $\mathbf{7}$ & $\mathbf{8}$ & Total \\
\hline 89,0775 & 57,5577 & 26,5389 & 49,8047 & 75,3444 & 25,2452 & 58,9644 & 10,7815 & 393,3143 \\
\hline $22,65 \%$ & $14,63 \%$ & $6,75 \%$ & $12,66 \%$ & $19,16 \%$ & $6,42 \%$ & $14,99 \%$ & $2,74 \%$ & $100,00 \%$ \\
\hline
\end{tabular}

Da equação 3.13-3 é possível obter a quantidade de energia anual, que deverá deixar de ser distribuída para cada bloco, em kWh.

Tabela 4.1.6-3 - END por bloco

\begin{tabular}{|c|c|c|c|c|c|c|c|}
\hline \multicolumn{7}{|c|}{ ENERGIA ANUAL NÃO DISTRIBUÍDA POR BLOCO [END $\mathbf{P}(\mathbf{j})]$} \\
\hline $\mathbf{1}$ & $\mathbf{2}$ & $\mathbf{3}$ & $\mathbf{4}$ & $\mathbf{5}$ & $\mathbf{6}$ & $\mathbf{7}$ & $\mathbf{8}$ \\
\hline 45,5058 & 10,5658 & 59,7456 & 107,1617 & 74,9493 & 30,2791 & 47,7202 & 17,3869 \\
\hline
\end{tabular}




\subsubsection{Cálculos referentes ao $\mathrm{FEC}_{S}$}

Utilizando-se os dados da Tabela 4.1.2-1 e a equação 3.17.1-1, pode-se encontrar:

$\mathrm{FEC}_{\mathrm{S}}=1,1857$

Para o ajustamento das taxas de falhas, visando igualar os valores de $F E C_{S}$ histórico

e $F E C_{S}$ calculado, é possível promover alterações utilizando-se conceitos estatísticos, levando-se em conta as dispersões do $F E C_{S}$ histórico e de $\lambda_{Q T}$, conforme apresentado no item 3.12, ou então de várias outras maneiras não exploradas no presente trabalho.

Entretanto, no caso do exemplo, serão considerados constantes os valores de $F E C_{S}$ histórico e de $\lambda_{Q T}$.

Assim, de acordo com as equações 3.16-2 e 3.17.1-1, tem-se:

$(1,5 \times 346)=10,4+\left(200 \times \lambda_{R S}\right)$.

De onde conclui-se que:

$\lambda_{R S}=2,543$

Assim, os números de interrupções estimados, a que estarão submetidos os consumidores, devido às falhas provenientes do transformador ou da respectiva rede secundária $\left(N I_{S}\right)$, de acordo com a equação 3.16-1 será: 
Tabela 4.1.7-1 - Número de interrupções devido a falhas no circuito secundário

\begin{tabular}{|c|c|}
\hline CIRCUITO & NI $_{\mathbf{S}}$ \\
\hline T11 & 1,5558 \\
\hline T12 & 1,0472 \\
\hline T21 & 0,0000 \\
\hline T22 & 1,0472 \\
\hline T31 & 1,3015 \\
\hline T32 & 0,0000 \\
\hline T41 & 0,9201 \\
\hline T42 & 1,3015 \\
\hline T51 & 2,0644 \\
\hline T52 & 1,8101 \\
\hline T61 & 1,0472 \\
\hline T62 & 0,0000 \\
\hline T71 & 1,6830 \\
\hline T72 & 0,9201 \\
\hline T81 & 0,0000 \\
\hline T82 & 1,3015 \\
\hline
\end{tabular}

\subsubsection{Cálculo do FIC}

A estimativa do FIC, de acordo com a equação 3.18-1 será então: 
Tabela 4.1.8-1 - FIC para cada um dos consumidores ligados nos respectivos circuitos

\begin{tabular}{|c|c|}
\hline CIRCUITO & FIC \\
\hline T11 & 3,6006 \\
\hline T12 & 3,0920 \\
\hline T21 & 3,4782 \\
\hline T22 & 4,5254 \\
\hline T31 & 6,7925 \\
\hline T32 & 5,4910 \\
\hline T41 & 6,5852 \\
\hline T42 & 6,9666 \\
\hline T51 & 3,9931 \\
\hline T52 & 3,7388 \\
\hline T61 & 9,5285 \\
\hline T62 & 8,4813 \\
\hline T71 & 3,6117 \\
\hline T72 & 2,8488 \\
\hline T81 & 3,7277 \\
\hline T82 & 5,0292 \\
\hline
\end{tabular}

\subsubsection{Cálculos referentes ao $\mathrm{DEC}_{S}$}

A partir dos dados apresentados no item 4.1.2 e calculados no item 4.1.7; e de acordo com a equação 3.20.1-1, tem-se:

$\mathrm{DEC}_{\mathrm{S}}=1,5292$

Da mesma forma, poder-se-ia ajustar o valor de $D E C_{S}$ calculado, para que ficasse igual ao valor de $D E C_{S}$ histórico, utilizando-se ferramentas estatisticamente adequadas para os dois tempos de restabelecimento considerados.

Entretanto, no caso do presente exemplo, esse ajustamento não será efetuado, até porque, há grande proximidade entre os valores de $D E C_{S}$ calculado e $D E C_{S}$ histórico.

Assim, a partir da equação 3.20.1-2, pode-se estimar o tempo durante o qual os consumidores ligados a cada circuito ficarão sem energia, devido a interrupções originadas no transformador ou na respectiva rede secundária: 
Tabela 4.1.9-1 - Duração das interrupções, devido a falhas no circuito secundário, em horas

\begin{tabular}{|c|c|}
\hline CIRCUITO & DI $_{\mathbf{S}}$ \\
\hline $\mathrm{T} 11$ & 1,5858 \\
\hline $\mathrm{T} 12$ & 1,0772 \\
\hline $\mathrm{T} 21$ & 0,0000 \\
\hline $\mathrm{T} 22$ & 1,0772 \\
\hline $\mathrm{T} 31$ & 1,3315 \\
\hline $\mathrm{T} 32$ & 0,0000 \\
\hline $\mathrm{T} 41$ & 0,9501 \\
\hline $\mathrm{T} 42$ & 1,3315 \\
\hline $\mathrm{T} 51$ & 2,0944 \\
\hline $\mathrm{T} 52$ & 1,8401 \\
\hline $\mathrm{T} 61$ & 1,0772 \\
\hline $\mathrm{T} 62$ & 0,0000 \\
\hline $\mathrm{T} 71$ & 1,7130 \\
\hline $\mathrm{T} 72$ & 0,9501 \\
\hline $\mathrm{T} 81$ & 0,0000 \\
\hline $\mathrm{T} 82$ & 1,3315 \\
\hline
\end{tabular}

\subsubsection{Cálculo do DIC}

A partir da equação 3.21-2: 
Tabela 4.1.10-1 - DIC para cada um dos consumidores ligados nos respectivos circuitos

\begin{tabular}{|c|c|}
\hline CIRCUITO & DIC \\
\hline T11 & 4,0314 \\
\hline T12 & 3,5228 \\
\hline T21 & 3,7778 \\
\hline T22 & 4,8550 \\
\hline T31 & 8,1285 \\
\hline T32 & 6,7970 \\
\hline T41 & 8,0083 \\
\hline T42 & 8,3897 \\
\hline T51 & 4,0543 \\
\hline T52 & 3,800 \\
\hline T61 & 12,8658 \\
\hline T62 & 11,7886 \\
\hline T71 & 3,7131 \\
\hline T72 & 2,9502 \\
\hline T81 & 4,3517 \\
\hline T82 & 5,6832 \\
\hline
\end{tabular}

\subsubsection{Cálculos referentes a END}

A expressão para cálculo da Energia não Distribuída, devido a ocorrências em cada um dos circuitos secundários $\left(E N D_{S}\right)$ pode ser escrita como:

$E N D_{S}(j)=\frac{\sum_{j=1}^{T}[D I s(j) \times C(j)]}{8760}$ [kWh/ano] 
Tabela 4.1.11-1 - ENDs, em kWh

\begin{tabular}{|c|c|}
\hline CIRCUITO & END $_{\mathbf{~}}$ \\
\hline T11 & 16,8355 \\
\hline T12 & 8,6078 \\
\hline T21 & 0,0000 \\
\hline T22 & 2,7053 \\
\hline T31 & 11,3998 \\
\hline T32 & 0,0000 \\
\hline T41 & 5,0973 \\
\hline T42 & 13,0718 \\
\hline T51 & 49,0128 \\
\hline T52 & 27,3074 \\
\hline T61 & 2,5823 \\
\hline T62 & 0,0000 \\
\hline T71 & 24,0517 \\
\hline T72 & 9,3270 \\
\hline T81 & 0,0000 \\
\hline T82 & 5,1679 \\
\hline
\end{tabular}

E de acordo com a equação 3.22-2, tem-se:

$\mathrm{END}=568,5 \mathrm{kWh} / \mathrm{ano}$

\subsubsection{Discussão dos primeiros resultados}

Após os cálculos apresentados nos itens de 4.1.1 a 4.1.6, pode-se montar um resumo, com os principais resultados obtidos.

Tabela 4.1.12-1 - Resultados globais

\begin{tabular}{|c|c|c|}
\hline $\mathrm{DEC}_{\mathrm{P}}=3,50[\mathrm{~h}]$ & $\mathrm{FEC}_{\mathrm{P}}=3,00$ & $\mathrm{END}_{\mathrm{P}}=393,3[\mathrm{kWh}]$ \\
\hline $\mathrm{DEC}_{\mathrm{S}}=1,53[\mathrm{~h}]$ & $\mathrm{FEC}_{\mathrm{S}}=1,50$ & $\mathrm{END}_{\mathrm{S}}=175,2[\mathrm{kWh}]$ \\
\hline $\mathrm{DEC}=5,03[\mathrm{~h}]$ & $\mathrm{FEC}=4,50$ & $\mathrm{END}=568,5[\mathrm{kWh}]$ \\
\hline
\end{tabular}


Tabela 4.1.12-2 - Principais resultados na rede primária

\begin{tabular}{|c|c|c|c|c|c|c|}
\hline Bloco & DI $_{P}[\mathrm{~h}]$ & $\mathrm{NI}_{\mathrm{P}}$ & END $_{\mathrm{P}}[\mathrm{kWh}]$ & $\mathrm{CDEC}_{\mathrm{P}}[\mathrm{h}]$ & CFEC $_{\mathrm{P}}$ & CEND $_{\mathrm{P}}[\mathrm{kWh}]$ \\
\hline 1 & 2,45 & 2,04 & 45,5 & 0,833 & 0,863 & 89,1 \\
\hline 2 & 3,78 & 3,48 & 10,6 & 0,522 & 0,348 & 57,6 \\
\hline 3 & 6,80 & 5,49 & 59,7 & 0,236 & 0,157 & 26,5 \\
\hline 4 & 7,06 & 5,67 & 107,2 & 0,455 & 0,303 & 49,8 \\
\hline 5 & 1,96 & 1,93 & 74,9 & 0,637 & 0,614 & 75,3 \\
\hline 6 & 11,79 & 8,48 & 30,3 & 0,227 & 0,152 & 25,3 \\
\hline 7 & 2,00 & 1,93 & 47,7 & 0,493 & 0,501 & 58,9 \\
\hline 8 & 4,35 & 3,73 & 17,4 & 0,094 & 0,062 & 10,8 \\
\hline
\end{tabular}

Tabela 4.1.12-3 - Outros resultados globais

\begin{tabular}{|c|c|c|c|c|}
\hline Circuito & $\mathrm{DIC}[\mathrm{h}]$ & FIC & $\mathrm{END}_{\mathrm{S}}[\mathrm{kWh}]$ & $\mathrm{END}_{\mathrm{P}}+\mathrm{END}_{\mathrm{S}}[\mathrm{kWh}]$ \\
\hline $\mathrm{T} 11$ & 4,03 & 3,60 & 16,8 & \multirow{2}{*}{70,9} \\
\hline $\mathrm{T} 12$ & 3,52 & 3,09 & 8,6 & \\
\hline $\mathrm{T} 21$ & 3,78 & 3,48 & 0,0 & \multirow{2}{*}{13,3} \\
\hline $\mathrm{T} 22$ & 4,86 & 4,53 & 2,7 & \\
\hline T31 & 8,13 & 6,79 & 11,4 & \multirow{2}{*}{71,1} \\
\hline $\mathrm{T} 32$ & 6,80 & 5,49 & 0,0 & \\
\hline $\mathrm{T} 41$ & 8,01 & 6,59 & 5,1 & \multirow{2}{*}{125,4} \\
\hline $\mathrm{T} 42$ & 8,39 & 6,97 & 13,1 & \\
\hline T51 & 4,05 & 3,99 & 49,0 & \multirow{2}{*}{151,2} \\
\hline T52 & 3,80 & 3,74 & 27,3 & \\
\hline T61 & 12,87 & 9,53 & 2,6 & \multirow{2}{*}{32,9} \\
\hline T62 & 11,79 & 8,48 & 0,0 & \\
\hline $\mathrm{T} 71$ & 3,71 & 3,61 & 24,1 & \multirow{2}{*}{81,1} \\
\hline $\mathrm{T} 72$ & 2,95 & 2,85 & 9,3 & \\
\hline T81 & 4,35 & 3,73 & 0,0 & \multirow{2}{*}{22,6} \\
\hline $\mathrm{T} 82$ & 5,68 & 5,03 & 5,2 & \\
\hline
\end{tabular}

Cabe ressaltar que, até agora, não houve qualquer alteração na rede existente. Apenas foram utilizados os dados gerais já disponíveis para a região elétrica em questão, para que, a partir deles, outras informações não disponíveis fossem obtidas.

Entretanto, aproveitando esse tratamento dos dados, é possível realizar um diagnóstico do estado atual da rede de distribuição.

Pode-se observar por exemplo que: 
- Falhas nos blocos 1 e 5, são as que mais contribuem para qualquer dos indicadores analisados. São responsáveis por $42 \%$ do $D E C_{P}$, cerca de $49 \%$ do $F E C_{P}$ e $42 \%$ da $E N D_{P}$. Portanto, é de se supor que seja dada prioridade nos investimentos que minimizem falhas originadas nos mesmos;

- Embora as falhas originadas no bloco 6 não contribuem significativamente para os indicadores da região, é necessário atenção, pois tanto a freqüência, quanto a duração de interrupções no referido bloco estão relativamente elevadas;

- O bloco 4 apresenta uma $E N D_{P}$ relativamente elevada. Por essa razão, uma análise nos tipos de consumidores (tipos de tarifas) pode indicar vantagem econômica em se promover melhorias no fornecimento aos respectivos consumidores;

- Da mesma forma, os circuitos T51 e T52 contribuem de maneira significativa para a ENDs.

É possível ainda, tirar outras conclusões sobre o atual estado do sistema de distribuição. No entanto passaremos a promover algumas alterações na rede, para que possamos avaliar os impactos dessas ações nos indicadores de confiabilidade.

\subsubsection{Análise dos impactos das ações de planejamento, nos indicadores de confiabilidade}

Neste item serão efetuadas proposições de planejamento, visando estabelecer os efeitos dessas propostas, nos indicadores até aqui discutidos.

Como serão apresentados também alguns resultados parciais, poderá ocorrer alguma aparente inexatidão nos resultados globais, devido a aproximações decimais.

\subsubsection{Substituição do tipo de rede primária}

Supondo que, para o bloco 1 , sejam substituídas as estruturas primárias, com condutores nus, por tipos mais confiáveis, como cabos cobertos, spacer-cables, préreunidos isolados, etc.; e que tais cabos apresentem taxa de falhas 50\% inferior à dos condutores nus. 
Neste caso, teríamos:

Tabela 4.1.13.1-1 - Previsão dos resultados globais, com substituição do tipo de rede primária

\begin{tabular}{|c|c|c|}
\hline $\mathrm{DEC}_{\mathrm{P}}=3,08[\mathrm{~h}]$ & $\mathrm{FEC}_{\mathrm{P}}=2,57$ & $\mathrm{END}_{\mathrm{P}}=348,7[\mathrm{kWh}]$ \\
\hline $\mathrm{DEC}_{\mathrm{S}}=1,53[\mathrm{~h}]$ & $\mathrm{FEC}_{\mathrm{S}}=1,50$ & $\mathrm{END}_{\mathrm{S}}=175,2[\mathrm{kWh}]$ \\
\hline $\mathrm{DEC}=4,61[\mathrm{~h}]$ & $\mathrm{FEC}=4,07$ & $\mathrm{END}=523,9[\mathrm{kWh}]$ \\
\hline
\end{tabular}

Tabela 4.1.13.1-2 - Outros resultados previstos para a substituição da rede primária

\begin{tabular}{|c|c|c|c|c|c|c|}
\hline Bloco & $\mathrm{Dl}_{P}[\mathrm{~h}]$ & $\mathrm{NI}_{\mathrm{P}}$ & END $_{P}[\mathrm{kWh}]$ & $\mathrm{CDEC}_{P}[\mathrm{~h}]$ & $\mathrm{CFEC}_{P}$ & $\mathrm{CEND}_{P}[\mathrm{kWh}]$ \\
\hline 1 & 1,22 & 1,02 & 22,7 & 0,417 & 0,431 & 44,5 \\
\hline 2 & 2,96 & 2,46 & 8,3 & 0,522 & 0,348 & 57,6 \\
\hline 3 & 5,98 & 4,47 & 52,6 & 0,236 & 0,157 & 26,5 \\
\hline 4 & 6,24 & 4,64 & 94,7 & 0,455 & 0,303 & 49,8 \\
\hline 5 & 1,96 & 1,93 & 75,0 & 0,637 & 0,614 & 75,3 \\
\hline 6 & 11,79 & 8,48 & 30,3 & 0,227 & 0,152 & 25,3 \\
\hline 7 & 2,00 & 1,93 & 47,7 & 0,493 & 0,501 & 58,9 \\
\hline 8 & 4,35 & 3,73 & 17,4 & 0,094 & 0,062 & 10,8 \\
\hline
\end{tabular}

Obviamente que se buscou tomar alguma ação no bloco que mais causava impacto nos indicadores.

São válidas as seguintes considerações:

- Houve melhoria dos três indicadores globais (DEC, FEC e END);

- Nesse caso, os blocos do alimentador 2 não sofreram qualquer alteração, como era de se esperar. Em conseqüência, também os indicadores DIC e FIC dos consumidores ligados a ele, não se alteraram;

- Em todos os blocos do alimentador 1 houve melhoria nos indicadores, embora as contribuições dos blocos 2, 3 e 4 tenham se mantido constantes. Em conseqüência, os indicadores DIC e FIC dos consumidores ligados no respectivo alimentador, também melhoraram, conforme mostra a Tabela abaixo: 
Tabela 4.1.13.1-3 - DIC e FIC para os circuitos ligados ao alimentador 1

\begin{tabular}{|c|c|c|}
\hline Circuito & DIC $[\mathrm{h}]$ & FIC \\
\hline T11 & 2,80 & 2,58 \\
\hline T12 & 2,29 & 2,07 \\
\hline T21 & 2,96 & 2,46 \\
\hline T22 & 4,04 & 3,51 \\
\hline T31 & 7,31 & 5,77 \\
\hline T32 & 5,98 & 4,47 \\
\hline T41 & 7,19 & 5,56 \\
\hline T42 & 7,57 & 5,94 \\
\hline
\end{tabular}

\subsubsection{Instalação de dispositivo de seccionamento}

Se ao invés de se substituir os condutores do bloco 1 , fosse instalada uma chave faca dividindo o bloco 5, dando origem a dois novos blocos (que serão chamados de 5.1 e 5.2), conforme abaixo:

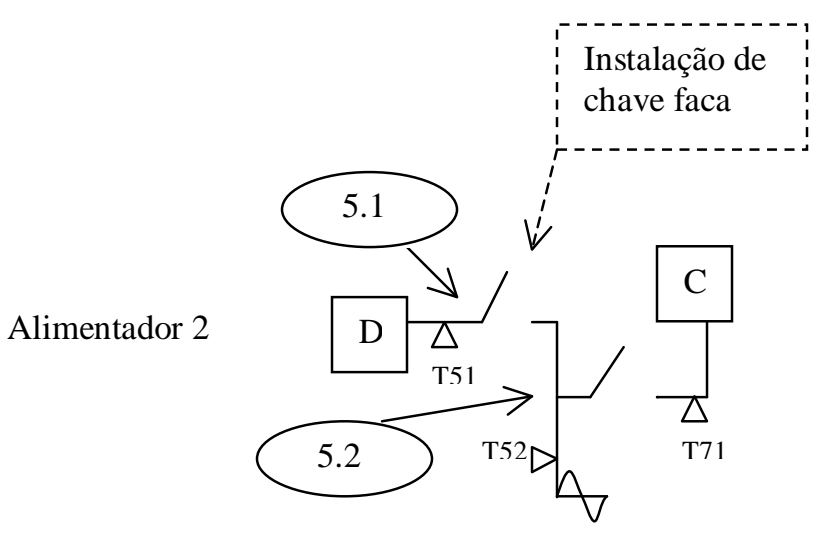

Figura 4.1.13.2-1 - Instalação de chave faca no bloco 5

Nesse caso, os novos indicadores previstos seriam: 
Tabela 4.1.13.2-1 - Previsão dos resultados globais, com instalação de dispositivo de seccionamento

\begin{tabular}{|c|c|c|}
\hline $\mathrm{DEC}_{\mathrm{P}}=3,45[\mathrm{~h}]$ & $\mathrm{FEC}_{\mathrm{P}}=3,00$ & $\mathrm{END}_{\mathrm{P}}=388,0[\mathrm{kWh}]$ \\
\hline $\mathrm{DEC}_{\mathrm{S}}=1,53[\mathrm{~h}]$ & $\mathrm{FEC}_{\mathrm{S}}=1,50$ & $\mathrm{END}_{\mathrm{S}}=175,2[\mathrm{kWh}]$ \\
\hline $\mathrm{DEC}=4,98[\mathrm{~h}]$ & $\mathrm{FEC}=4,50$ & $\mathrm{END}=563,2[\mathrm{kWh}]$ \\
\hline
\end{tabular}

Tabela 4.1.13.2-2 - Outros resultados previstos, com a instalação de dispositivo de seccionamento

\begin{tabular}{|c|c|c|c|c|c|c|}
\hline Bloco & $\mathrm{DI}_{\mathrm{P}}[\mathrm{h}]$ & $\mathrm{NI}_{\mathrm{P}}$ & END $_{\mathrm{P}}[\mathrm{kWh}]$ & $\mathrm{CDEC}_{\mathrm{P}}[\mathrm{h}]$ & $\mathrm{CFEC}_{\mathrm{P}}$ & $\mathrm{CEND}_{\mathrm{P}}[\mathrm{kWh}]$ \\
\hline 1 & 2,45 & 2,04 & 45,5 & 0,833 & 0,863 & 89,1 \\
\hline 2 & 3,78 & 3,48 & 10,6 & 0,522 & 0,348 & 57,6 \\
\hline 3 & 6,80 & 5,49 & 59,7 & 0,236 & 0,157 & 26,5 \\
\hline 4 & 7,06 & 5,67 & 107,2 & 0,455 & 0,303 & 49,8 \\
\hline 5.1 & 1,70 & 1,93 & 39,8 & 0,231 & 0,248 & 27,4 \\
\hline 5.2 & 1,87 & 1,93 & 27,8 & 0,361 & 0,365 & 42,8 \\
\hline 6 & 11,70 & 8,48 & 30,1 & 0,227 & 0,152 & 25,3 \\
\hline 7 & 2,08 & 1,93 & 49,6 & 0,493 & 0,501 & 58,9 \\
\hline 8 & 4,44 & 3,73 & 17,7 & 0,094 & 0,062 & 10,8 \\
\hline
\end{tabular}

Dos resultados anteriores, pode-se dizer que:

- Não houve nenhuma alteração nos indicadores do alimentador 1;

- Os indicadores relacionados à freqüência de interrupções (FEC e FIC) também não apresentaram melhoria em nenhum seguimento da região elétrica. Isso já era de se esperar, pois a instalação de equipamentos de seccionamento não previne a ocorrência da interrupção, nem tampouco restringe o número de consumidores atingidos por ela;

- Em sistemas de distribuição reais, a instalação de dispositivos de seccionamento geralmente implica na melhoria dos indicadores relacionados à duração das interrupções (DEC, DIC e END). No nosso caso, isso também pôde ser observado. Entretanto, um fato curioso é que, aumentou a duração das interrupções para os consumidores ligados aos blocos 7 e 8 . Isso ocorreu porque, anteriormente, para faltas ocorridas no bloco 5, a equipe de campo despendia apenas o tempo de localização e transferência $(T L+T T)$, para restabelecer os 
blocos 7 e 8. Agora, para faltas ocorridas no bloco 5.2, a equipe despende um tempo adicional (TT), para antes restabelecer o bloco 5.1. Embora haja um procedimento padrão, na prática, a equipe de campo possui flexibilidade para avaliar a melhor sequiência de procedimentos. Entretanto, mesmo nos casos reais, onde determinadas ações de planejamento propiciam melhoria dos indicadores globais, é possível que alguns agrupamentos específicos de consumidores tenham sua confiabilidade de fornecimento discretamente piorada. Isso pode ser ilustrado pelos DIC do presente exemplo, apresentados abaixo:

Tabela 4.1.13.2-3 - DIC para os circuitos ligados aos blocos 7 e 8

\begin{tabular}{|c|c|}
\hline Circuito & DIC $[\mathrm{h}]$ \\
\hline T71 & 3,79 \\
\hline T72 & 3,03 \\
\hline T81 & 4,44 \\
\hline T82 & 5,77 \\
\hline
\end{tabular}

\subsubsection{Instalação de dispositivos de proteção}

Tomando-se novamente a configuração inicial da rede, conforme dados apresentados no item 4.1.12, pode-se verificar os efeitos de várias propostas de instalação dos diferentes dispositivos de proteção.

Supondo por exemplo, que a chave fusível localizada a montante do bloco 6 viesse a ser substituída por um religador automático de distribuição, teriam-se:

Tabela 4.1.13.3-1 - Previsão dos resultados globais, com substituição de chave fusível por religador automático de distribuição

\begin{tabular}{|c|c|c|}
\hline $\mathrm{DEC}_{\mathrm{P}}=3,32[\mathrm{~h}]$ & $\mathrm{FEC}_{\mathrm{P}}=2,88$ & $\mathrm{END}_{\mathrm{P}}=373,1[\mathrm{kWh}]$ \\
\hline $\mathrm{DEC}_{\mathrm{S}}=1,53[\mathrm{~h}]$ & $\mathrm{FEC}_{\mathrm{S}}=1,50$ & $\mathrm{END}_{\mathrm{S}}=175,2[\mathrm{kWh}]$ \\
\hline $\mathrm{DEC}=4,85[\mathrm{~h}]$ & $\mathrm{FEC}=4,38$ & $\mathrm{END}=548,3[\mathrm{kWh}]$ \\
\hline
\end{tabular}


Tabela 4.1.13.3-2 - Outros resultados previstos, com a substituição de chave fusível por religador automático de distribuição

\begin{tabular}{|c|c|c|c|c|c|c|}
\hline Bloco & $\mathrm{DI}_{\mathrm{P}}[\mathrm{h}]$ & $\mathrm{NI}_{\mathrm{P}}$ & END $_{\mathrm{P}}[\mathrm{kWh}]$ & $\mathrm{CDEC}_{\mathrm{P}}[\mathrm{h}]$ & $\mathrm{CFEC}_{\mathrm{P}}$ & CEND $_{\mathrm{P}}[\mathrm{kWh}]$ \\
\hline 1 & 2,45 & 2,04 & 45,6 & 0,833 & 0,863 & 89,1 \\
\hline 2 & 3,78 & 3,48 & 10,6 & 0,522 & 0,348 & 57,6 \\
\hline 3 & 6,80 & 5,49 & 59,8 & 0,236 & 0,157 & 26,5 \\
\hline 4 & 7,06 & 5,67 & 107,2 & 0,455 & 0,303 & 49,8 \\
\hline 5 & 1,96 & 1,93 & 75,0 & 0,637 & 0,614 & 75,3 \\
\hline 6 & 3,93 & 3,24 & 10,1 & 0,045 & 0,030 & 5,1 \\
\hline 7 & 2,00 & 1,93 & 47,7 & 0,493 & 0,501 & 58,9 \\
\hline 8 & 4,35 & 3,73 & 17,4 & 0,094 & 0,062 & 10,8 \\
\hline
\end{tabular}

Pode-se perceber que:

- Houve melhoria em todos os indicadores globais, devido exclusivamente à melhora dos índices do bloco 6. Isso ocorreu pois não há outro bloco a jusante do 6, que pudesse ser também beneficiado pela instalação do religador automático de distribuição;

- Como consequiência da melhoria do fornecimento ao bloco 6, teríamos para os consumidores ligados a ele, os seguintes indicadores:

\section{Tabela 4.1.13.3-3 - DIC e FIC para os circuitos}

ligados ao bloco 6

\begin{tabular}{|c|c|c|}
\hline Circuito & DIC [h] & FIC \\
\hline T61 & 5,01 & 4,29 \\
\hline T62 & 3,93 & 3,24 \\
\hline
\end{tabular}

Além de se substituir a chave fusível pelo religador automático de distribuição anterior, poder-se-ia substituir a chave faca normalmente fechada, localizada a montante do bloco 7 , por um seccionalizador.

Os resultados são apresentados nas duas próximas tabelas. 
Tabela 4.1.13.3-4 - Previsão dos resultados globais, com substituição de chave faca por seccionalizador, além da substituição anterior

\begin{tabular}{|c|c|c|}
\hline $\mathrm{DEC}_{\mathrm{P}}=3,05[\mathrm{~h}]$ & $\mathrm{FEC}_{\mathrm{P}}=2,58$ & $\mathrm{END}_{\mathrm{P}}=341,7[\mathrm{kWh}]$ \\
\hline $\mathrm{DEC}_{\mathrm{S}}=1,53[\mathrm{~h}]$ & $\mathrm{FEC}_{\mathrm{S}}=1,50$ & $\mathrm{END}_{\mathrm{S}}=175,2[\mathrm{kWh}]$ \\
\hline $\mathrm{DEC}=4,58[\mathrm{~h}]$ & $\mathrm{FEC}=4,08$ & $\mathrm{END}=516,9[\mathrm{kWh}]$ \\
\hline
\end{tabular}

Tabela 4.1.13.3-5 - Outros resultados previstos, com substituição de chave faca por seccionalizador, além da substituição anterior

\begin{tabular}{|c|c|c|c|c|c|c|}
\hline Bloco & $\mathrm{DI}_{\mathrm{P}}[\mathrm{h}]$ & $\mathrm{NI}_{\mathrm{P}}$ & END $_{\mathrm{P}}[\mathrm{kWh}]$ & $\mathrm{CDEC}_{\mathrm{P}}[\mathrm{h}]$ & $\mathrm{CFEC}_{\mathrm{P}}$ & $\mathrm{CEND}_{\mathrm{P}}[\mathrm{kWh}]$ \\
\hline 1 & 2,45 & 2,04 & 45,6 & 0,833 & 0,863 & 89,1 \\
\hline 2 & 3,78 & 3,48 & 10,6 & 0,522 & 0,348 & 57,6 \\
\hline 3 & 6,80 & 5,49 & 59,8 & 0,236 & 0,157 & 26,5 \\
\hline 4 & 7,06 & 5,67 & 107,2 & 0,455 & 0,303 & 49,8 \\
\hline 5 & 1,27 & 1,06 & 48,6 & 0,637 & 0,614 & 75,3 \\
\hline 6 & 3,24 & 2,37 & 8,3 & 0,045 & 0,030 & 5,1 \\
\hline 7 & 1,88 & 1,93 & 44,9 & 0,225 & 0,198 & 27,5 \\
\hline 8 & 4,23 & 3,73 & 16,9 & 0,094 & 0,062 & 10,8 \\
\hline
\end{tabular}

Pode-se observar que:

- A instalação do dispositivo de proteção, em substituição ao de seccionamento, minimizou a freqüência e a duração das interrupções aos consumidores localizados a montante do mesmo;

- Os blocos localizados a jusante do dispositivo de proteção continuam sujeitos ao mesmo número de interrupções. Entretanto, tiveram suas durações reduzidas;

- Os valores dos indicadores do alimentador 1 não se alteraram e os novos valores de DIC e FIC para o alimentador 2 serão: 
Tabela 4.1.13.3-6 - DIC e FIC previstos, com substituição de chave faca por seccionalizador, além da substituição anterior

\begin{tabular}{|c|c|c|}
\hline Circuito & DIC $[\mathrm{h}]$ & FIC \\
\hline T51 & 3,36 & 3,12 \\
\hline T52 & 3,11 & 2,87 \\
\hline T61 & 4,32 & 3,42 \\
\hline T62 & 3,24 & 2,37 \\
\hline T71 & 3,59 & 3,61 \\
\hline T72 & 2,83 & 2,85 \\
\hline T81 & 4,23 & 3,73 \\
\hline T82 & 5,56 & 5,03 \\
\hline
\end{tabular}

\subsubsection{Construção de interligação}

Tomando-se novamente a rede básica inicial, com os dados apresentados no item 4.1.12 e supondo que seja construída uma interligação entre os blocos 6 e 7, com 774 metros de extensão (que serão acrescidos ao bloco 6), conforme Figura abaixo:

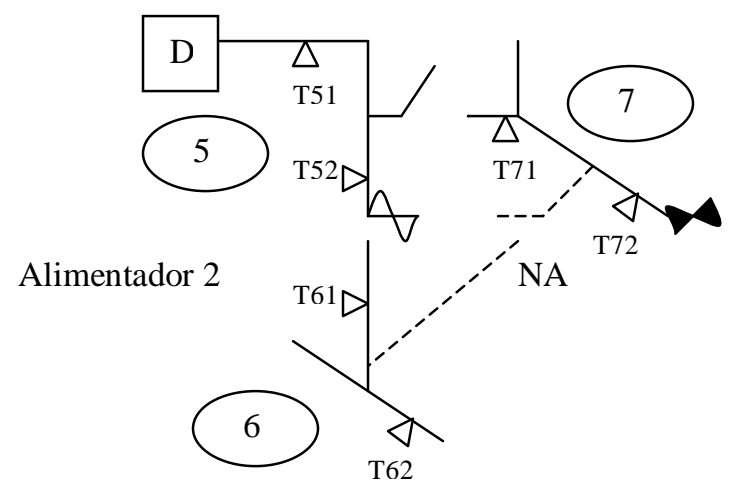

Figura 4.1.13.4-1 - Construção de interligação

Teremos: 
Tabela 4.1.13.4-1 - Previsão dos resultados globais, com a interligação entre alimentadores

\begin{tabular}{|c|c|c|}
\hline $\mathrm{DEC}_{\mathrm{P}}=3,56[\mathrm{~h}]$ & $\mathrm{FEC}_{\mathrm{P}}=3,04$ & $\mathrm{END}_{\mathrm{P}}=400,1[\mathrm{kWh}]$ \\
\hline $\mathrm{DEC}_{\mathrm{S}}=1,53[\mathrm{~h}]$ & $\mathrm{FEC}_{\mathrm{S}}=1,50$ & $\mathrm{END}_{\mathrm{S}}=175,2[\mathrm{kWh}]$ \\
\hline $\mathrm{DEC}=5,09[\mathrm{~h}]$ & $\mathrm{FEC}=4,54$ & $\mathrm{END}=575,3[\mathrm{kWh}]$ \\
\hline
\end{tabular}

Tabela 4.1.13.4-2 - Outros resultados previstos, com a interligação entre alimentadores

\begin{tabular}{|c|c|c|c|c|c|c|}
\hline Bloco & $\mathrm{DI}_{P}[\mathrm{~h}]$ & $\mathrm{NI}_{\mathrm{P}}$ & $\mathrm{END}_{\mathrm{P}}[\mathrm{kWh}]$ & $\mathrm{CDEC}_{\mathrm{P}}[\mathrm{h}]$ & $\mathrm{CFEC}_{\mathrm{P}}$ & $\mathrm{CEND}_{\mathrm{P}}[\mathrm{kWh}]$ \\
\hline 1 & 2,45 & 2,04 & 45,6 & 0,833 & 0,863 & 89,1 \\
\hline 2 & 3,78 & 3,48 & 10,6 & 0,522 & 0,348 & 57,6 \\
\hline 3 & 6,80 & 5,49 & 59,8 & 0,236 & 0,157 & 26,5 \\
\hline 4 & 7,06 & 5,67 & 107,2 & 0,455 & 0,303 & 49,8 \\
\hline 5 & 1,96 & 1,93 & 75,0 & 0,637 & 0,614 & 75,3 \\
\hline 6 & 14,44 & 10,25 & 37,1 & 0,289 & 0,192 & 32,1 \\
\hline 7 & 2,00 & 1,93 & 47,7 & 0,493 & 0,501 & 58,9 \\
\hline 8 & 4,35 & 3,73 & 17,4 & 0,094 & 0,062 & 10,8 \\
\hline
\end{tabular}

De onde se pode comentar que:

- Todos os indicadores globais pioraram;

- Todos os indicadores permaneceram inalterados em todos os blocos, com exceção do 6, como já era esperado, uma vez que as interrupções nesse bloco contribuem apenas para si mesmo;

- Em casos reais, a interligação só poderia trazer benefícios exclusivamente ao bloco 6, pois possibilitaria a transferência das cargas ligadas no mesmo, para o bloco 7, quando da ocorrência de falhas originadas no bloco 5. Entretanto esse benefício deve ser ponderado com o conseqüente aumento da extensão (ou exposição) da rede. No presente exemplo, o aumento das taxas de falhas provocado pelo aumento da extensão da rede - superou os benefícios esperados até porque, pela metodologia empregada, essa transferência não seria realizada.

- Conclui-se então, pela não implementação dessa ação de planejamento, nesse caso. 


\subsubsection{Automação de dispositivos de proteção e/ou seccionamento}

Considerando a rede inicial, com os dados apresentados no item 4.1.12 e supondo que:

- o disjuntor do alimentador 2 e a chave trifásica normalmente aberta sejam automatizados;

- a chave faca normalmente aberta seja substituída por Ponto de Telecontrole de Rede (PTR);

- o tempo de manobra automatizada seja igual a 0,02 horas $(\mathrm{TA}=0,02 \mathrm{~h})$.

Nessas condições, os resultados seriam:

Tabela 4.1.13.5-1 - Previsão dos resultados globais com automação da rede

\begin{tabular}{|c|c|c|}
\hline $\mathrm{DEC}_{\mathrm{P}}=3,24[\mathrm{~h}]$ & $\mathrm{FEC}_{\mathrm{P}}=3,00$ & $\mathrm{END}_{\mathrm{P}}=364,4[\mathrm{kWh}]$ \\
\hline $\mathrm{DEC}_{\mathrm{S}}=1,53[\mathrm{~h}]$ & $\mathrm{FEC}_{\mathrm{S}}=1,50$ & $\mathrm{END}_{\mathrm{S}}=175,2[\mathrm{kWh}]$ \\
\hline $\mathrm{DEC}=4,77[\mathrm{~h}]$ & $\mathrm{FEC}=4,50$ & $\mathrm{END}=539,6[\mathrm{kWh}]$ \\
\hline
\end{tabular}

Tabela 4.1.13.5-2 - Outros resultados previstos com automação da rede

\begin{tabular}{|c|c|c|c|c|c|c|}
\hline Bloco & $\mathrm{DI}_{P}[\mathrm{~h}]$ & $\mathrm{NI}_{P}$ & END $_{P}[\mathrm{kWh}]$ & $\mathrm{CDEC}_{P}[\mathrm{~h}]$ & $\mathrm{CFEC}_{\mathrm{P}}$ & $\mathrm{CEND}_{\mathrm{P}}[\mathrm{kWh}]$ \\
\hline 1 & 2,21 & 2,04 & 41,1 & 0,733 & 0,863 & 78,3 \\
\hline 2 & 3,54 & 3,48 & 9,9 & 0,522 & 0,348 & 57,6 \\
\hline 3 & 6,56 & 5,49 & 57,7 & 0,236 & 0,157 & 26,5 \\
\hline 4 & 6,82 & 5,67 & 103,6 & 0,455 & 0,303 & 49,8 \\
\hline 5 & 1,74 & 1,93 & 66,5 & 0,566 & 0,614 & 66,9 \\
\hline 6 & 11,57 & 8,48 & 29,7 & 0,227 & 0,152 & 25,3 \\
\hline 7 & 1,68 & 1,93 & 40,0 & 0,412 & 0,501 & 49,3 \\
\hline 8 & 4,03 & 3,73 & 16,1 & 0,094 & 0,062 & 10,8 \\
\hline
\end{tabular}

Conforme discutido no item 3.9, os indicadores referentes à frequiência de interrupções não se alteraram. No entanto, pode-se perceber a melhoria dos indicadores referentes à duração. 
Os novos valores previstos para DIC serão:

Tabela 4.1.13.5-3 - DIC previstos

com automação da rede

\begin{tabular}{|c|c|}
\hline CIRCUITO & DIC \\
\hline T11 & 3,79 \\
\hline T12 & 3,28 \\
\hline T21 & 3,54 \\
\hline T22 & 4,62 \\
\hline T31 & 7,89 \\
\hline T32 & 6,56 \\
\hline T41 & 7,77 \\
\hline T42 & 8,15 \\
\hline T51 & 3,83 \\
\hline T52 & 3,58 \\
\hline T61 & 12,65 \\
\hline T62 & 11,57 \\
\hline T71 & 3,39 \\
\hline T72 & 2,63 \\
\hline T81 & 4,03 \\
\hline T82 & 5,36 \\
\hline
\end{tabular}

\subsubsection{Substituição do tipo de rede secundária}

Como pode ser constatado pela observação dos resultados até aqui obtidos - no decorrer de todo o item 4.1.13 - as ações sobre a rede primária podem trazer benefícios abrangentes e contemplar um grande número de consumidores pertencentes à região elétrica.

Entretanto, se houver interesse em se obter sinalizações sobre os benefícios auferidos com ações mais localizadas - sobre a rede secundária - pode-se estimar os ganhos obtidos, guardadas as ressalvas apresentadas ao final do item 3.21.

Supondo por exemplo, que se promova a substituição dos condutores do circuito T51, por cabos pré-reunidos multiplexados, com taxa de falhas $50 \%$ inferior.

Nesse caso, teremos os valores globais de DEC, FEC e END e, para o circuito T51, os valores de DIC e FIC, conforme abaixo. 
Tabela 4.1.13.6-1 - Indicadores após substituição

da rede secundária

\begin{tabular}{|c|c|c|}
\hline INDICADOR & ANTES & APÓS \\
\hline DEC & 5,03 & 4,83 \\
\hline FEC & 4,50 & 4,30 \\
\hline END & 568,5 & 544,7 \\
\hline DIC & 3,80 & 3,04 \\
\hline FIC & 3,74 & 2,98 \\
\hline
\end{tabular}

\subsubsection{Desmembramento de circuito secundário}

Se ao invés de se substituir o tipo de rede secundária, fosse promovida a separação do circuito T51 em outros dois (T51.1 e T51.2), de tal forma que cada um dos novos circuito tivesse as mesmas características (com metade do comprimento, metade do número de consumidores e metade do consumo de T51); teríamos:

Tabela 4.1.13.7-1 - Indicadores após desmembramento

do circuito secundário

\begin{tabular}{|c|c|c|}
\hline INDICADOR & ANTES & APÓS \\
\hline DEC & 5,03 & 4,83 \\
\hline FEC & 4,50 & 4,30 \\
\hline END & 568,5 & 544,7 \\
\hline DIC (T51.1) & \multirow{2}{*}{3,80} & 3,04 \\
\hline DIC (T51.2) & & 3,04 \\
\cline { 1 - 2 } FIC (T51.1) & \multirow{2}{*}{3,74} & 2,98 \\
\cline { 1 - 2 } FIC (T51.2) & & 2,98 \\
\hline
\end{tabular}

Os resultados obtidos com a substituição dos condutores secundários, conforme item 4.1.13.6 são idênticos aos obtidos, quando se procedeu ao desmembramento do circuito secundário de $T 51$, como pode ser observado pela comparação entre as 
Tabelas 4.1.13.6-1 e 4.1.13.7-1.

Essa constatação já era esperada, pois as duas proposições são matematicamente idênticas.

A escolha por uma das alternativas deve ser então norteada por outros parâmetros, que auxiliem a tomada de decisão.

Esses parâmetros podem ser de natureza econômica, física, geográfica, etc.

\subsubsection{Comparação técnico-econômica das opções}

Conforme discutido no item 3.23, além da metodologia apresentada, outros parâmetros devem ser considerados pelo planejador, de forma a ampliar sua capacidade de análise.

Principalmente em casos similares aos apresentados nos itens 4.1.13.6 e 4.1.13.7, essas análises adicionais seriam imprescindíveis.

A título de exemplo, iremos proceder à análise econômica das alternativas de planejamento descritas no item 4.1.13-2 e no início do item 4.1.13-3 (substituição da chave fusível, por religador automático de distribuição).

Para tal, são necessários alguns dados adicionais:

- $\quad$ Custo de instalação da chave faca $=\mathrm{R} \$ 800,00$;

- Custo de substituição da chave fusível, por religador automático de distribuição = $\mathrm{R} \$ 25.000,00$;

- Redução dos custos de manutenção e operação, obtidos com a substituição da chave fusível $=\mathrm{R} \$ 500,00$ ao ano;

- Vida útil dos equipamentos $=25$ anos;

- Custo médio da Energia não Distribuída = R \$ 0,20 por kWh;

- Taxa de juros de $12 \%$ ao ano;

A opção apresentada no item 4.1.13-2 proporcionaria uma redução na $E N D$ de 5,3 $\mathrm{kWh}$ ao ano, ou $\mathrm{R} \$ 8,31$ em valor presente, durante a vida útil do equipamento.

A outra opção representaria uma redução na END de $20,2 \mathrm{kWh}$ e de custos de operação e manutenção de $\mathrm{R} \$ 500,00$ ao ano, totalizando $\mathrm{R} \$ 3.953,26$ em valor presente, durante os 25 anos. 
Percebe-se que, embora o exemplo não tenha sido feliz - devido aos baixos valores de $E N D$ envolvidos - é possível estabelecer um quadro comparativo, similar à Tabela 3.23-1:

Tabela 4.1.14-1 - Quadro comparativo para o exemplo

\begin{tabular}{|c|c|c|c|}
\hline INDICADOR & SITUAÇÃO ATUAL & PROPOSIÇÃO 1 & PROPOSIÇÃO 2 \\
\hline DEC [h] & 5,03 & 4,98 & 4,85 \\
\hline FEC & 4,50 & 4,50 & 4,38 \\
\hline END [kWh] & 568,5 & 563,2 & 548,2 \\
\hline Custo [R\$] & - & 800,00 & $25.000,00$ \\
\hline Benefício [R\$] & - & 8,31 & $3.953,26$ \\
\hline $\begin{array}{c}\text { Relação } \\
\text { Benefício/Custo }\end{array}$ & - & 0,0104 & 0,1581 \\
\hline
\end{tabular}

Além do quadro anterior, outros poderiam ser montados, levando-se em conta a comparação entre os indicadores de DIC e $F I C$, além da consideração de outros aspectos, tais como as previsões de crescimento de mercado, a disponibilidade orçamentária, etc. 


\subsection{CASO 2: REGIÃO ELÉTRICA REAL}

Com base na metodologia até aqui apresentada, foi desenvolvida uma rotina computacional capaz de efetuar cálculos dos indicadores referentes à rede de distribuição primária .*

Com o auxílio dessa ferramenta, será apresentado um caso real, de um município atendido pela CPFL e localizado na região nordeste do estado de São Paulo.

\subsubsection{Descrição da região elétrica analisada}

O sistema elétrico considerado possui 2 subestações com um transformador de 25 MVA cada. Há 4 alimentadores por subestação, divididos em 520 blocos. São cerca de $569 \mathrm{~km}$ de rede, no padrão aéreo trifásico convencional, com cabos nus, sendo $171 \mathrm{~km}$ na zona urbana e $398 \mathrm{~km}$ na zona rural.

A região elétrica possui 33.646 consumidores, com consumo mensal de 11.265.086 [kWh], assim distribuídos conforme Tabela 4.2.1-1.

Tabela 4.2.1-1 Dados dos alimentadores da região elétrica considerada

\begin{tabular}{|c|c|c|c|}
\hline Subestação/Alimentador & $\begin{array}{c}\text { Extensão } \\
{[\mathbf{k m}]}\end{array}$ & $\begin{array}{c}\text { Consumo } \\
{[\mathbf{k W h} / \mathbf{m e ̂ s}]}\end{array}$ & $\mathbf{N}^{\circ}$ Consumidores \\
\hline SEA001 & 226,4 & 852.893 & 2.412 \\
\hline SEA002 & 39,7 & 1.257 .066 & 5.559 \\
\hline SEA003 & 20,7 & 1.340 .534 & 3.984 \\
\hline SEA004 & 114,3 & 1.106 .656 & 5.277 \\
\hline SEB001 & 107,1 & 1.490 .776 & 7.143 \\
\hline SEB002 & 36,3 & 1.221 .617 & 5.424 \\
\hline SEB003 & 14,7 & 1.187 .345 & 3.303 \\
\hline SEB004 & 9,7 & 2.808 .199 & 544 \\
\hline
\end{tabular}

* Essa rotina vem sendo gradualmente transformada em linguagem computacional pelo Eng. L. R. Manhães e já possibilita vários cálculos na rede primária. 
Os equipamentos presentes no sistema são:

Chaves facas: 78 conjuntos;

Chaves fusíveis: 454 conjuntos;

Chaves trifásicas: 36 unidades

Religadores automáticos de distribuição: 7 unidades;

Seccionalizadores: 2 unidades;

Total de dispositivos de seccionamento e proteção: 577 pontos;

Reguladores de tensão de linha: 2 bancos;

Transformadores trifásicos de distribuição: 1.938 unidades, totalizando $93.735 \mathrm{kVA}$ instalados;

Bancos de capacitores: 15 bancos, totalizando $9.000 \mathrm{kVAr}$ instalados.

No ano de 2001 foram registradas 333 interrupções originadas na rede de distribuição primária, com duração superior a 1 minuto, ocasionando os valores de:

$\mathrm{DEC}_{\mathrm{P}}=4,35$ horas/consumidor;

FECP = 5,23 interrupções/consumidor;

Tabela 4.2.1-2 - Tempos de restabelecimento para áreas

urbana e rural

\begin{tabular}{|c|c|c|c|c|}
\hline \multirow{2}{*}{$\begin{array}{c}\text { TEMPOS DE } \\
\text { RESTABELECIMENTO }\end{array}$} & \multicolumn{4}{|c|}{ DURAÇÃO [horas] } \\
\cline { 2 - 5 } & \multicolumn{2}{|c|}{ ZONA URBANA } & \multicolumn{2}{c|}{ ZONA RURAL } \\
\cline { 2 - 5 } & Média $(\boldsymbol{\mu})$ & Desvio $(\boldsymbol{\delta})$ & Média $(\boldsymbol{\mu})$ & Desvio $(\boldsymbol{\delta})$ \\
\hline TL & 0,40 & 0,21 & 1,02 & 0,60 \\
\hline TR & 0,20 & 0,27 & 0,23 & 0,27 \\
\hline TT & 0,08 & 0,11 & 0,10 & 0,12 \\
\hline
\end{tabular}

Há várias regiões em que se têm os valores de $F P$, mas no caso da região em questão, como não há tais registros, será considerado $F P=0,2$. 


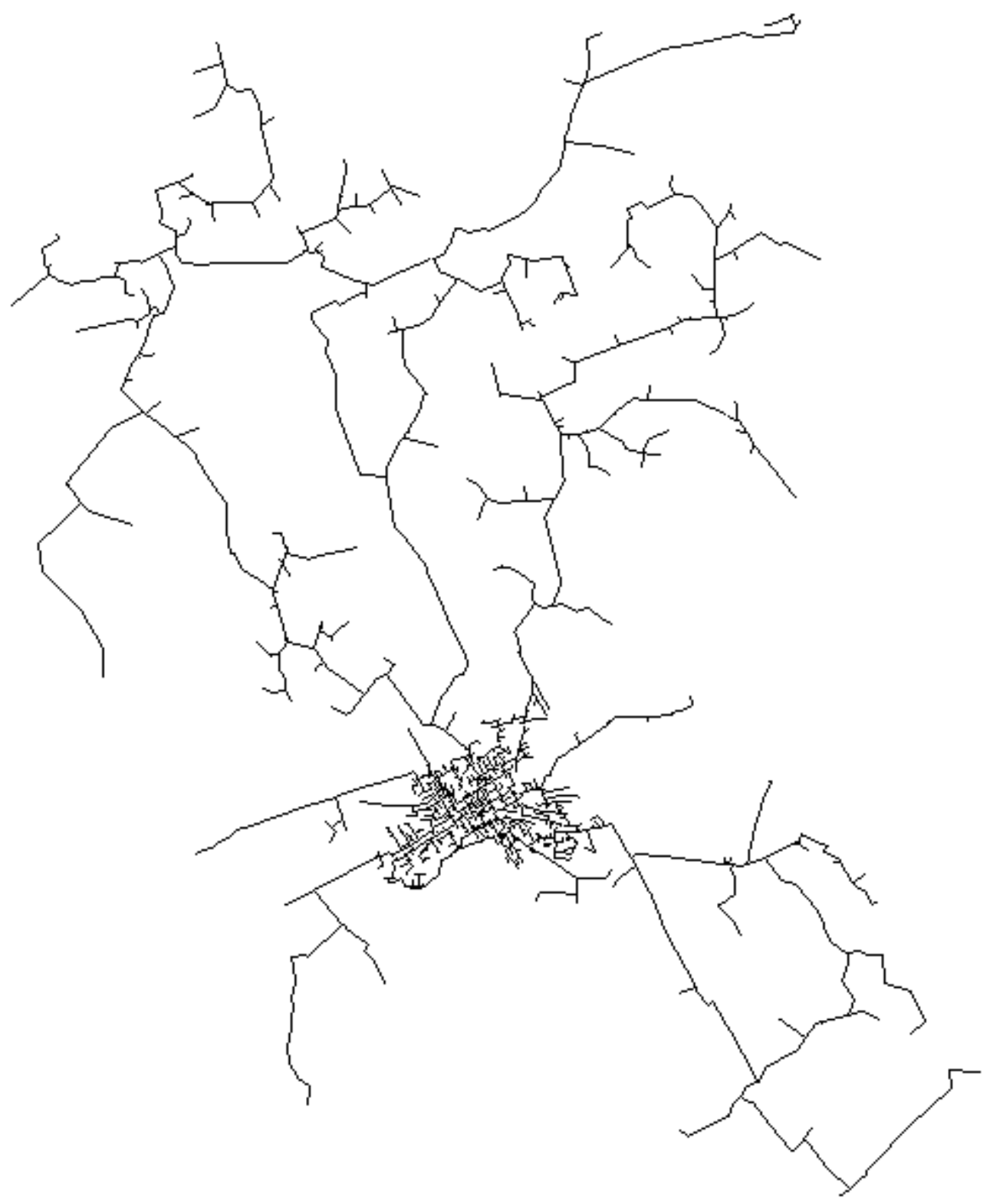

Figura 4.2.1-1 - Região elétrica real 


\subsubsection{Estimativa da taxa de falhas $(\lambda)$}

Inicialmente foram utilizados os valores médios dos tempos e taxa de falhas igual a 1 ocorrência por quilômetro (1 falha/km).

Com esses dados, os valores anuais calculados, para os indicadores foram:

$\operatorname{DEC}_{\mathrm{P}}=1,990[\mathrm{~h}]$

$\mathrm{FEC}_{\mathrm{P}}=3,276$

$\mathrm{END}_{\mathrm{P}}=26.244[\mathrm{kWh}]$

É necessário então, o ajustamento das taxas de falhas, conforme apresentado no item 3.8. Assim, nesse caso, a taxa de falhas real, para a região elétrica é:

$\lambda$ redehistórica $=\lambda$ redeconsiderada $\times \frac{F E C_{P} \text {.histórico }}{F E C_{P . \text { calculado }}}=1,5965$

E os indicadores:

$\mathrm{DEC}_{\mathrm{P}}=3,177[\mathrm{~h}]$

$\mathrm{FEC}_{\mathrm{P}}=5,23$

$\mathrm{END}_{\mathrm{P}}=41.899[\mathrm{kWh}]$

\subsubsection{Estimativa dos tempos de restabelecimento}

Observando-se o valor do $D E C_{P}$ calculado anteriormente, pode-se verificar que há necessidade de ajustamento nos valores dos tempos considerados.

Assim, supondo que os tempos possuam distribuições normais, pode-se refazer os cálculos, considerando seus valores iguais a $\mu+0,3 . \delta$.

E os resultados obtidos para os indicadores seriam:

$\operatorname{DEC}_{\mathrm{P}}=3,877[\mathrm{~h}]$

$\mathrm{FEC}_{\mathrm{P}}=5,23$

$\mathrm{END}_{\mathrm{P}}=51.127[\mathrm{kWh}]$

Vale a pena refazer os cálculos a fim de melhorar o valor do $D E C_{P}$ calculado, até porque, cada nova simulação apresenta baixo tempo de processamento (36 segundos, utilizando um processador Pentium $120 \mathrm{MHz}$, com 32 MB de memória RAM, ou 3 
segundos, utilizando um processador Pentium III - $933 \mathrm{MHz}$, com $64 \mathrm{MB}$ de memória RAM).

Então, a nova simulação será realizada considerando-se os tempos iguais a $\mu+0,5 . \delta$.

E os novos valores encontrados são:

$\mathrm{DEC}_{\mathrm{P}}=4,343[\mathrm{~h}]$

$\mathrm{FEC}_{\mathrm{P}}=5,23$

$\mathrm{END}_{\mathrm{P}}=57.278[\mathrm{kWh}]$

Caso desejássemos valores mais ajustados para o $D E C_{P}$, poderíamos tentar outras variações para os desvios padrões dos tempos envolvidos. Assim poderíamos efetuar várias simulações, até encontrarmos valores mais próximos para $D E C_{P}$. Entretanto, iremos considerar os valores de tempo, como sendo iguais a $\mu+0,5 . \delta$, conforme tabela abaixo.

Tabela 4.2.3-1 - Tempos de restabelecimento para áreas

urbana e rural

\begin{tabular}{|c|c|c|}
\hline TEMPOS DE & \multicolumn{2}{|c|}{ DURAÇãO [horas] } \\
RESTABELECIMENTO & ZONA URBANA & ZONA RURAL \\
\hline TL & 0,505 & 1,320 \\
\hline TR & 0,335 & 0,365 \\
\hline TT & 0,135 & 0,160 \\
\hline
\end{tabular}

\subsubsection{Resultados iniciais}

Utilizando-se os valores obtidos nos itens 4.2.2 e 4.2.3 já é possível apresentar os seguintes resultados anuais: 
Tabela 4.2.4-1 - Dados globais da região elétrica

\begin{tabular}{|l|r|}
\hline DEC $_{\mathbf{P}}[\mathbf{h}]$ & 4,34 \\
\hline FEC $_{\mathbf{P}}$ & 5,23 \\
\hline END $_{\mathbf{P}}[\mathbf{k W h}]$ & $\mathbf{5 7 . 2 7 8}$ \\
\hline N. de consumidores & 33.646 \\
\hline Consumo [kWh] & 135.181 .032 \\
\hline
\end{tabular}

Tabela 4.2.4-2 - Resultados por subestação

\begin{tabular}{|c|c|c|c|}
\hline Subestação & DEC $_{\mathbf{P}}[\mathbf{h}]$ & FEC $_{\mathbf{P}}$ & END $_{\mathbf{P}}[\mathbf{k W h}]$ \\
\hline SEA & 4,27 & 5,02 & 28.516 \\
\hline SEB & 4,42 & 5,45 & 28.762 \\
\hline
\end{tabular}

Tabela 4.2.4-3 - Resultados por alimentador

\begin{tabular}{|c|c|c|c|}
\hline Alimentador & DEC $_{\mathbf{P}}[\mathbf{h}]$ & FEC $_{\mathbf{P}}$ & END $_{\mathbf{P}}[\mathbf{k W h}]$ \\
\hline SEA001 & 7,58 & 6,97 & 10.141 \\
\hline SEA002 & 3,27 & 4,06 & 5.759 \\
\hline SEA003 & 3,17 & 4,29 & 5.678 \\
\hline SEA004 & 4,65 & 5,69 & 6.939 \\
\hline SEB001 & 5,90 & 6,98 & 12.010 \\
\hline SEB002 & 3,66 & 4,79 & 5.945 \\
\hline SEB003 & 2,72 & 3,58 & 4.408 \\
\hline SEB004 & 2,76 & 3,29 & 6.399 \\
\hline
\end{tabular}

Outras informações:

Bloco mais extenso : $\mathrm{n}^{\circ} 427$, com $10.232 \mathrm{~m}$

Bloco com maior consumo anual....................... $\mathrm{n}^{\circ}$ 520, com 21.693.252 [kWh];

Bloco com maior número de consumidores.......... n 367 , com 772 consumidores;

Bloco que ficará maior tempo interrompido........: $\mathrm{n}^{\circ} 2$, com 33,136 horas;

Bloco que sofrerá maior número de interrupções: $n^{\circ} 2, \operatorname{com} 22,669$ ocorrências;

Bloco com maior $E N D_{P}$ : $\mathrm{n}^{\circ} 520$, com $4.113 \mathrm{kWh}$ 
Bloco mais prejudicial ao $D E C_{P}$ da área $\therefore \mathrm{n}^{\circ} 423$, contribuindo com 0,286 horas por consumidor;

Bloco mais prejudicial ao $F E C_{P}$ da área $: \mathrm{n}^{\circ} 412$, contribuindo com 0,216 interrupções por consumidor;

Bloco mais prejudicial à $E N D_{P}$ da área. $\therefore \mathrm{n}^{\circ} 510$, contribuindo com 3.008 $\mathrm{kWh}$.

Além dos dados anteriores, é possível obter uma listagem com as informações sobre cada um dos 520 blocos, conforme apresentada no Anexo A.

\subsubsection{Análise dos impactos das ações de planejamento nos indicadores de confiabilidade}

Serão efetuadas algumas proposições na rede primária, visando estabelecer os efeitos dessas propostas nos indicadores de confiabilidade.

\subsubsection{Substituição do tipo de rede primária}

Supondo que sejam substituídos os condutores do bloco 423 - que pertence ao alimentador SEB001 - por outros que apresentem taxa de falhas igual a 1/3 da atual. É de se esperar melhorias apenas nos alimentadores da subestação SEB, ou mais especificamente no alimentador SEB001. Nesse caso, ter-se-iam:

Tabela 4.2.5.1-1 - Dados globais da região elétrica, após substituição dos condutores do bloco 423

\begin{tabular}{|l|r|}
\hline DEC $_{\mathbf{P}}[\mathbf{h}]$ & 4,15 \\
\hline FEC $_{\mathbf{P}}$ & 5,10 \\
\hline END $_{\mathbf{P}}[\mathbf{k W h}]$ & 55.435 \\
\hline
\end{tabular}


Tabela 4.2.5.1-2 - Resultados por subestação

\begin{tabular}{|c|c|c|c|}
\hline Subestação & DEC $_{\mathbf{P}}[\mathbf{h}]$ & FEC $_{\mathbf{P}}$ & END $_{\mathbf{P}}[\mathbf{k W h}]$ \\
\hline SEA & 4,27 & 5,02 & 28.516 \\
\hline SEB & 4,03 & 5,19 & 26.919 \\
\hline
\end{tabular}

Tabela 4.2.5.1-3 - Resultados por alimentador

\begin{tabular}{|c|c|c|c|}
\hline Alimentador & DEC $_{\mathbf{P}}[\mathbf{h}]$ & FEC $_{\mathbf{P}}$ & END $_{\mathbf{P}}[\mathbf{k W h}]$ \\
\hline SEB001 & 5,00 & 6,38 & 10.166 \\
\hline SEB002 & 3,66 & 4,79 & 5.945 \\
\hline SEB003 & 2,72 & 3,58 & 4.408 \\
\hline SEB004 & 2,76 & 3,29 & 6.399 \\
\hline
\end{tabular}

Outros resultados:

Bloco que ficará maior tempo interrompido........: $\mathrm{n}^{\circ} 2$, com 33,136 horas;

Bloco que sofrerá maior número de interrupções: $n^{\circ} 2, \operatorname{com} 22,669$ ocorrências;

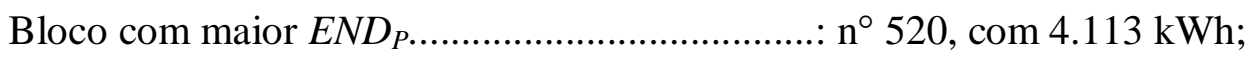

Bloco mais prejudicial ao $D E C_{P}$ da área............ $\mathrm{n}^{\circ} 412$, contribuindo com 0,155 horas por consumidor;

Bloco mais prejudicial ao $F E C_{P}$ da área............... n $n^{\circ} 412$, contribuindo com 0,216 interrupções por consumidor;

Bloco mais prejudicial à $E N D_{P}$ da área................. n n 510, contribuindo com 3.008 kWh.

Pode-se perceber melhoria apenas nos indicadores do alimentador SEB001.

\subsubsection{Instalação de dispositivos de seccionamento}

Tomando-se novamente a região elétrica em seu estado inicial, pode-se instalar uma chave faca em cada alimentador.

Esses equipamentos serão instalados nos 10 blocos que mais afetam o $D E C_{P}$ da região elétrica, conforme Anexo A; ou seja, os blocos 177 e 194, pertencentes ao 
alimentador SEA002; os blocos 244, 249 e 297, pertencentes ao alimentador SEA004; os blocos 412, 423, 432 e 434, pertencentes ao alimentador SEB001; e o bloco 465, pertencente ao alimentador SEB002;

Os valores referentes à frequiência de interrupções não se alterarão. Os demais serão:

Tabela 4.2.5.2-1 - Indicadores globais da região elétrica, após instalação de dispositivos de seccionamento

\begin{tabular}{|l|r|}
\hline DEC $_{\mathbf{P}}[\mathbf{h}]$ & 4,30 \\
\hline END $_{\mathbf{P}}[\mathbf{k W h}]$ & 56.751 \\
\hline
\end{tabular}

Tabela 4.2.5.2-2 - Resultados por subestação

\begin{tabular}{|c|c|c|}
\hline Subestação & DEC $_{\mathbf{P}}[\mathbf{h}]$ & END $_{\mathbf{P}}[\mathbf{k W h}]$ \\
\hline SEA & 4,20 & 28.093 \\
\hline SEB & 4,40 & 28.658 \\
\hline
\end{tabular}

Tabela 4.2.5.2-3 - Resultados por alimentador

\begin{tabular}{|c|c|c|}
\hline Alimentador & DEC $_{\mathbf{P}}[\mathbf{h}]$ & END $_{\mathbf{P}}[\mathbf{k W h}]$ \\
\hline SEA001 & 7,58 & 10.141 \\
\hline SEA002 & 3,18 & 5.560 \\
\hline SEA003 & 3,17 & 5.678 \\
\hline SEA004 & 4,49 & 6.714 \\
\hline SEB001 & 5,87 & 11.915 \\
\hline SEB002 & 3,65 & 5.936 \\
\hline SEB003 & 2,72 & 4.408 \\
\hline SEB004 & 2,76 & 6.399 \\
\hline
\end{tabular}

Outros resultados:

Bloco que ficará maior tempo interrompido........: $\mathrm{n}^{\circ} 2$, com 33,136 horas;

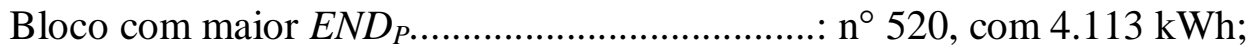


Bloco mais prejudicial ao $D E C_{P}$ da área : $\mathrm{n}^{\circ} 423$, contribuindo com 0,156 horas por consumidor.

Bloco mais prejudicial à $E N D_{P}$ da área. $\therefore \mathrm{n}^{\circ} 510$, contribuindo com 3.008 kWh.

Pode-se perceber a melhoria dos indicadores em todos os alimentadores onde ocorreram obras de instalação de chaves e uma redução na contribuição do bloco 423 para o $D E C_{P}$

\subsubsection{Instalação de dispositivos de proteção}

Partindo-se da região elétrica em seu estado inicial, podemos simular os efeitos da instalação de uma chave fusível em cada alimentador.

Esses equipamentos serão instalados nos blocos 14, 179, 222, 244, 409, 440, 482 e 510, pertencentes respectivamente aos alimentadores SEA001, SEA002, SEA003, SEA004, SEB001, SEB002, SEB003 e SEB004; de onde se obtêm:

\section{Tabela 4.2.5.3-1 - Indicadores globais após instalação} de chaves fusíveis

\begin{tabular}{|l|r|}
\hline DEC $_{\mathbf{P}}[\mathbf{h}]$ & 4,46 \\
\hline FEC $_{\mathbf{P}}$ & 5,37 \\
\hline END $_{\mathbf{P}}[\mathbf{k W h}]$ & 65.613 \\
\hline
\end{tabular}

Tabela 4.2.5.3-2 - Resultados por subestação

\begin{tabular}{|c|c|c|c|}
\hline Subestação & DEC $_{\mathbf{P}}[\mathbf{h}]$ & FEC $_{\mathbf{P}}$ & END $_{\mathbf{P}}[\mathbf{k W h}]$ \\
\hline SEA & 4,33 & 5,09 & 31.059 \\
\hline SEB & 4,60 & 5,66 & 34.554 \\
\hline
\end{tabular}


Tabela 4.2.5.3-3 - Resultados por alimentador

\begin{tabular}{|c|c|c|c|}
\hline Alimentador & DEC $_{\mathbf{P}}[\mathbf{h}]$ & FEC $_{\mathbf{P}}$ & END $_{\mathbf{P}}[\mathbf{k W h}]$ \\
\hline SEA001 & 7,57 & 6,96 & 10.134 \\
\hline SEA002 & 3,27 & 4,06 & 5.729 \\
\hline SEA003 & 3,99 & 5,20 & 9.045 \\
\hline SEA004 & 4,22 & 5,24 & 6.151 \\
\hline SEB001 & 5,90 & 6,98 & 11.997 \\
\hline SEB002 & 3,65 & 4,79 & 5.912 \\
\hline SEB003 & 3,50 & $4 ., 47$ & 6.251 \\
\hline SEB004 & 3,67 & 4,38 & 10.394 \\
\hline
\end{tabular}

Outros resultados:

Bloco que ficará maior tempo interrompido......... $\mathrm{n}^{\circ} 2$ 2, com 32,594 horas;

Bloco que sofrerá maior número de interrupções: $n^{\circ} 2$, com 22,667 ocorrências;

Bloco com maior $E N D_{P}$ : $\mathrm{n}^{\circ} 520, \operatorname{com} 8.446 \mathrm{kWh}$

Bloco mais prejudicial ao $D E C_{P}$ da área. $: \mathrm{n}^{\circ} 423$, contribuindo com 0,286 horas por consumidor;

Bloco mais prejudicial ao $F E C_{P}$ da área $: \mathrm{n}^{\circ} 412$, contribuindo com 0,216 interrupções por consumidor;

Bloco mais prejudicial à $E N D_{P}$ da área. . $\mathrm{n}^{\circ} 528$, contribuindo com 4.100 kWh. Este bloco surgiu da cisão do bloco 510, provocada pela instalação da chave fusível.

Fusíveis tanto podem contribuir positivamente quanto negativamente, para os indicadores.

Quando as chaves são instaladas a jusante de equipamentos com capacidade de religamento há melhoria dos indicadores, devido à boa coordenação que se obtém. Foi o que ocorreu no caso dos alimentadores SEA001, SEA002, SEB001 e SEB002. Entretanto, a instalação dessas chaves também pode contribuir para a ocorrência de interrupções permanentes, provocadas por falhas momentâneas. Foi o que ocorreu no caso dos alimentadores SEA003, SEB003 e SEB004, onde não havia equipamentos 
com capacidade de religamento e coordenação localizados a montante das chaves fusíveis propostas.

No caso do alimentador SEA004, mesmo não se tendo equipamentos com capacidade de religamento e coordenação a montante da chave fusível, pôde-se verificar a vantagem da proposição.

Tomando-se novamente a configuração inicial e substituindo os dispositivos de seccionamento localizados do "lado fonte" de cada bloco que mais contribui para o $D E C_{P}$ de cada alimentador, por religador automático de distribuição, teremos os resultados apresentados a partir da Tabela 4.2.5.3-5.

Tabela 4.2.5.3-4 Blocos que mais contribuem para o $D E C_{P}$ de cada alimentador, conforme Anexo A

\begin{tabular}{|c|c|}
\hline Bloco & Alimentador \\
\hline 103 & SEA001 \\
\hline 177 & SEA002 \\
\hline 222 & SEA003 \\
\hline 244 & SEA004 \\
\hline 423 & SEB001 \\
\hline 465 & SEB002 \\
\hline 482 & SEB003 \\
\hline 510 & SEB004 \\
\hline
\end{tabular}

Tabela 4.2.5.3-5 - Indicadores globais após instalação de religadores automáticos de distribuição

\begin{tabular}{|l|r|}
\hline DEC $_{\mathbf{P}}[\mathbf{h}]$ & 3,36 \\
\hline FEC $_{\mathbf{P}}$ & 4,20 \\
\hline END $_{\mathbf{P}}[\mathbf{k W h}]$ & 46.067 \\
\hline
\end{tabular}


Tabela 4.2.5.3-6 - Resultados por subestação

\begin{tabular}{|c|c|c|c|}
\hline Subestação & DEC $_{\mathbf{P}}[\mathbf{h}]$ & FEC $_{\mathbf{P}}$ & END $_{\mathbf{P}}[\mathbf{k W h}]$ \\
\hline SEA & 3,18 & 3,78 & 22.745 \\
\hline SEB & 3,55 & 4,64 & 23.322 \\
\hline
\end{tabular}

Tabela 4.2.5.3-7 - Resultados por alimentador

\begin{tabular}{|c|c|c|c|}
\hline Alimentador & DEC $_{\mathbf{P}}[\mathbf{h}]$ & FEC $_{\mathbf{P}}$ & END $_{\mathbf{P}}[\mathbf{k W h}]$ \\
\hline SEA001 & 6,87 & 6,49 & 9.546 \\
\hline SEA002 & 2,02 & 2,59 & 3.856 \\
\hline SEA003 & 2,21 & 3,00 & 4.271 \\
\hline SEA004 & 3,45 & 4,38 & 5.072 \\
\hline SEB001 & 4,59 & 6,10 & 9.365 \\
\hline SEB002 & 3,22 & 4,13 & 5.230 \\
\hline SEB003 & 2,15 & 2,81 & 3.751 \\
\hline SEB004 & 1,53 & 1,80 & 4.977 \\
\hline
\end{tabular}

Outros resultados:

Bloco que ficará maior tempo interrompido......... $\mathrm{n}^{\circ} 2, \operatorname{com} 28,1$ horas;

Bloco que sofrerá maior número de interrupções: $n^{\circ} 2$, com 19,266 ocorrências;

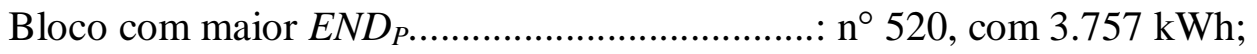

Bloco mais prejudicial ao $D E C_{P}$ da área...........: $n^{\circ} 412$, contribuindo com 0,155 horas por consumidor;

Bloco mais prejudicial ao $F E C_{P}$ da área.............. $\mathrm{n}^{\circ} 412$, contribuindo com 0,216 interrupções por consumidor;

Bloco mais prejudicial à $E N D_{P}$ da área................. n $n^{\circ}$ 510, contribuindo com 1.772 kWh.

Pode-se perceber que a instalação de religadores automáticos de distribuição contribui positivamente para todos os indicadores.

Isso ocorre em maior ou menor grau, dependendo das contribuições dos blocos para os indicadores e da existência de outros equipamentos de proteção a montante ou a 
jusante do local de instalação proposto.

Essa constatação está em consonância com as conclusões de Warren, que afirma que a instalação de um religador automático de distribuição traz significativas melhorias para os indicadores; entretanto, a instalação de dois ou mais, não reduz a duração e frequiência da interrupção, na mesma proporção que a instalação do primeiro. [35]

\subsubsection{Construções de interligações}

A partir do estado inicial da região elétrica apresentada no item 4.2.4, pode-se realizar construções de interligações, visando aumentar a flexibilidade operativa do sistema.

Assim, supondo que sejam realizadas tais obras entre os alimentadores SEA001 e SEA004; entre SEA003 e SEB004; e entre dois ramais do alimentador SEB001; obteriam-se os seguintes resultados:

Tabela 4.2.5.4-1 - Indicadores globais após interligações

\begin{tabular}{|l|r|}
\hline DEC $_{\mathbf{P}}[\mathbf{h}]$ & 4,33 \\
\hline FEC $_{\mathbf{P}}$ & 5,23 \\
\hline END $_{\mathbf{P}}[\mathbf{k W h}]$ & $\mathbf{5 7 . 1 8 8}$ \\
\hline
\end{tabular}

Tabela 4.2.5.4-2 - Resultados por subestação

\begin{tabular}{|c|c|c|c|}
\hline Subestação & DEC $_{\mathbf{P}}[\mathbf{h}]$ & FEC $_{\mathbf{P}}$ & END $_{\mathbf{P}}[\mathbf{k W h}]$ \\
\hline SEA & 4,27 & 5,02 & 28.464 \\
\hline SEB & 4,40 & 5,45 & 28.724 \\
\hline
\end{tabular}


Tabela 4.2.5.4-3 - Resultados por alimentador

\begin{tabular}{|c|c|c|c|}
\hline Alimentador & DEC $_{\mathbf{P}}[\mathbf{h}]$ & FEC $_{\mathbf{P}}$ & END $_{\mathbf{P}}[\mathbf{k W h}]$ \\
\hline SEA001 & 7,52 & 6,97 & 10.067 \\
\hline SEA002 & 3,27 & 4,06 & 5.759 \\
\hline SEA003 & 3,19 & 4,31 & 5.708 \\
\hline SEA004 & 4,65 & 5,69 & 6.930 \\
\hline SEB001 & 5,89 & 6,98 & 11.988 \\
\hline SEB002 & 3,66 & 4,79 & 5.945 \\
\hline SEB003 & 2,72 & 3,58 & 4.408 \\
\hline SEB004 & 2,57 & 3,29 & 6.382 \\
\hline
\end{tabular}

Outros resultados:

Bloco que ficará maior tempo interrompido......... $\mathrm{n}^{\circ}$ 2, com 32,997 horas;

Bloco que sofrerá maior número de interrupções: $n^{\circ}$ 2, com 22,669 ocorrências;

Bloco com maior $E N D_{P}$ $\therefore \mathrm{n}^{\circ} 520$, com $4.113 \mathrm{kWh}$

Bloco mais prejudicial ao $D E C_{P}$ da área. $\therefore \mathrm{n}^{\circ} 423$, contribuindo com 0,286 horas por consumidor;

Bloco mais prejudicial ao $F E C_{P}$ da área $: n^{\circ} 412$, contribuindo com 0,216 interrupções por consumidor;

Bloco mais prejudicial à $E N D_{P}$ da área..... : $\mathrm{n}^{\circ} 510$, contribuindo com 2.992 kWh.

Pode-se perceber que os indicadores dos alimentadores podem tanto melhorar, quanto piorar, por conta das ponderações já discutidas no item 4.1.13.4.

Cabe ressaltar entretanto, que só foram realizadas exclusivamente construções de interligações, não se procedendo a nenhuma reconfiguração da rede, que poderia potencializar os ganhos obtidos com as obras propostas. 


\subsubsection{Automação de dispositivos de proteção e/ou seccionamento}

Novamente, tomando-se a rede nas condições descritas no item 4.2.4, e considerando que todos os dispositivos de proteção e/ou seccionamento são automatizados, com $\mathrm{TA}=0,03$ horas:

Tabela 4.2.5.5-1 - Indicadores globais com automação

\begin{tabular}{|l|r|}
\hline DEC $_{\mathbf{P}}[\mathbf{h}]$ & 3,74 \\
\hline FEC $_{\mathbf{P}}$ & 5,23 \\
\hline END $_{\mathbf{P}}[\mathbf{k W h}]$ & 48.725 \\
\hline
\end{tabular}

Tabela 4.2.5.5-2 - Resultados por subestação

\begin{tabular}{|c|c|c|c|}
\hline Subestação & DEC $_{\mathbf{P}}[\mathbf{h}]$ & FEC $_{\mathbf{P}}$ & END $_{\mathbf{P}}[\mathbf{k W h}]$ \\
\hline SEA & 3,69 & 5,02 & 24.745 \\
\hline SEB & 3,80 & 5,45 & 23.980 \\
\hline
\end{tabular}

Tabela 4.2.5.5-3 - Resultados por alimentador

\begin{tabular}{|c|c|c|c|}
\hline Alimentador & DEC $_{\mathbf{P}}[\mathbf{h}]$ & FECP & ENDP [kWh] \\
\hline SEA001 & 6,83 & 6,97 & 9.210 \\
\hline SEA002 & 2,82 & 4,06 & 4.950 \\
\hline SEA003 & 2,66 & 4,29 & 4.705 \\
\hline SEA004 & 3,94 & 5,69 & 5.879 \\
\hline SEB001 & 5,13 & 6,98 & 10.357 \\
\hline SEB002 & 3,12 & 4,79 & 5.080 \\
\hline SEB003 & 2,25 & 3,58 & 3.633 \\
\hline SEB004 & 2,40 & 3,29 & 4.910 \\
\hline
\end{tabular}

Outros resultados:

Bloco que ficará maior tempo interrompido......... $\mathrm{n}^{\circ} 2$, com 30,415 horas;

Bloco que sofrerá maior número de interrupções: $n^{\circ} 2, \operatorname{com} 22,669$ ocorrências;

Bloco com maior $E N D_{P}$ : $\mathrm{n}^{\circ} 520, \operatorname{com} 3.062 \mathrm{kWh}$ 
Bloco mais prejudicial ao $D E C_{P}$ da área : $\mathrm{n}^{\circ} 423$, contribuindo com 0,261 horas por consumidor;

Bloco mais prejudicial ao $F E C_{P}$ da área...... $: n^{\circ} 412$, contribuindo com 0,216 interrupções por consumidor;

Bloco mais prejudicial à $E N D_{P}$ da área. $\therefore \mathrm{n}^{\circ} 423$, contribuindo com 2.524 kWh.

Como era de se esperar, houve melhoria em todos os indicadores relacionados à duração das interrupções, devido à redução no tempo de transferência $(\mathrm{TT}=\mathrm{TA})$. 


\section{CONCLUSÕES}

Especialmente a partir de agora, com a fixação de padrões de qualidade mais exigentes, a metodologia desenvolvida apresenta-se como uma poderosa ferramenta de análise, que é perfeitamente aplicável a sistemas reais, a partir de dados históricos facilmente disponíveis.

Ela possibilita diagnosticar o estado atual do sistema elétrico, identificando pontos de atenção e oportunidades de melhoria.

A partir desse diagnóstico, é possível prever os efeitos de várias proposições de planejamento, sobre os indicadores de continuidade considerados, tais como:

- Alocação de dispositivos de seccionamento;

- Alocação de diferentes dispositivos de proteção;

- Construção de interligação, viabilizando transferências de cargas;

- Automação de equipamentos de seccionamento e/ou proteção;

- Substituição de redes, por outras mais confiáveis;

- Reconfiguração de redes existentes;

- Expansão do Sistema, com novos trechos ou "bays" de alimentadores.

A partir da utilização sistemática da metodologia, é possível estabelecer alguns efeitos de determinadas ações sobre determinados indicadores, em redes de distribuição radiais. Assim, pode-se dizer que:

a) A substituição de padrões (tipos) de redes com menores taxas de falhas contribui para a melhoria de todos os indicadores da região, devido à redução das freqüências e durações de interrupções no alimentador em que se procedeu a alteração.

b) A instalação de dispositivos de seccionamento de forma a reduzir o número de consumidores por bloco, leva à melhoria dos indicadores globais, relacionados à duração das interrupções (DEC e END). Entretanto, ocasionalmente, alguns consumidores podem ter piorados seus indicadores individuais (DIC);

c) Não há alteração nos indicadores relacionados à freqüência de interrupções, quando se procede à instalação de dispositivos de seccionamentos;

d) Cada equipamento de proteção possui diferentes características quanto à 
capacidade de coordenação e religamento. A metodologia considera tais diferenças e auxilia, por exemplo, na tomada de decisão quanto à validade de se instalar equipamentos sem capacidade de religamento a jusante de equipamentos com capacidade de religamento, mas sem coordenação;

e) O benefício obtido com construções de interligações - que possibilitam segunda fonte de alimentação - deve ser ponderado com o conseqüente aumento da extensão (ou exposição) da rede. O mesmo ocorre quando da construção de novos alimentadores, objetivando a redistribuição de consumidores e o aumento da flexibilidade operativa da rede

f) A automação de equipamentos melhora o desempenho dos indicadores relacionados à duração das interrupções;

g) $\mathrm{Na}$ rede secundária, é possível comparar os benefícios entre as alternativas de desmembramento do circuito e substituição do padrão (tipo) de rede;

h) A metodologia fornece bom subsídio à avaliação de alternativas, dentro do contexto da qualidade do serviço de distribuição; entretanto, obviamente, não prescinde da habilidade, conhecimento e experiência dos planejadores, que devem considerar outros aspectos relevantes, referentes à exeqüibilidade das propostas, dificuldades operacionais, impactos na manutenção, bem como proceder a análises econômicas, etc..

Certamente há grande potencial de melhoria na metodologia apresentada. Um dos aspectos que mereceriam uma análise mais aprofundada seriam as variações estatísticas dos próprios valores históricos de $D E C_{P}, F E C_{P}, D E C_{S}$ e $F E C_{S}$. 


\section{BIBLIOGRAFIA}

[1] ROSA, L. P.; SENRA, P. M. A. "Participação Privada na Expansão do Setor Elétrico ou Venda das Empresas Públicas?", COPPE/UFRJ, Rio de Janeiro, 1995.

[2] LEITE, A. D. “A Energia do Brasil”, Nova Fronteira, Rio de Janeiro, 1997 - $2^{\text {a }}$ impressão.

[3] CONTRATO DE CONCESSÃO No 014/97, assinado entre a União e a CPFL, Brasília, 20/11/1997.

[4] TODD, Z. G. “A Probability Method for Transmission and Distribution Outage Calculations". IEEE Transactions (Power Apparatus and Systems), Vol. 83, July 1964.

[5] LUZ, A. D.; COSENZA, C. R.; MAGAlHÃES, J. C. M.; MARTINS, V. L. "Incorporação da Confiabilidade no Planejamento da Distribuição". XI Seminário Nacional de Distribuição de Energia Elétrica - XI SENDI - Blumenau (SC), Setembro 1992.

[6] MANHÃES, L. R. "Programa para Planejamento de Redes Primárias de Distribuição”. XIV Seminário Nacional de Distribuição de Energia Elétrica - XIV SENDI - Foz do Iguaçu (PR), Novembro 2000.

[7] BILLINTON, R. "Bibliography on the Application of Probability Methods in Power System Reliability Evaluation”. IEEE Transactions on Power Apparatus and Systems, Vol. 91, no 2, 1972.

[8] LYMAN, W. J. "Fundamental Consideration in Preparing Master System Plan". Electrical World, Vol. 101, nº 24, June 17, 1933.

[9] SMITH Jr, S. A. "Spare Capacity Fixed by Probabilities of Outage". Electrical World, Vol. 103, February 10, 1934. 
[10] PATTON, A. D. "Determination and Analysis of Data for Reliability Studies". IEEE Transactions on Power Apparatus and Systems, Vol. 87, n 1, January 1968.

[11] GAVER, D. P.; MONTMEAT, F. E.; PATTON, A. D. "Power System Reliability - I - Measures of Reliability and Methods of Calculation". IEEE Transactions (Power Apparatus and Systems), July 1964.

[12] MONTMEAT, F. E.; PATTON, A. D.; ZEMKOSKI, J.; CUMMinG, D. J. “Power System Reliability - II - Applications and a Computer Program". IEEE Transactions (Power Apparatus and Systems), Vol. 84, July 1965.

[13] OPRISAN, M.; FILIPPELli, F.; CLARK, I. M.; BILLINTON, R. “A Reliability Data System for the Reporting of Forced Outages of Distribution Equipment". IEEE Western Canada Conference on Computer, Power and Communications System in a Rural Environment, 1991, p. 267-270.

[14] CONNOR, R. A. W.; PARKINS, R. A. "Operational Statistics in the Management of Large Distribution Systems". Proceedings of the Institution of Electrical Engineers, November 1966.

[15] NOLAN, P. J.; O'KELLY, M. E. J.; FAHY, C. "Assesment of Ways of Improving the Supply Continuity in Electric Power Systems - A Simulation Approach”. Proceedings of the 1993 Winter Simulation Conference, p. 1192 - 1200.

[16] DeSIENO, C. F.; STINE, L. L. "A Probability Method for Determining the Reliability of Electric Power Systems". IEEE Transactions on Power Apparatus and Systems, Vol 83, February 1964.

[17] CHRISTIAANSE, W. R. “A New Technique for Reliability Calculations". IEEE Transactions on Power Apparatus and Systems, Vol. 89, $\mathrm{n}^{\mathbf{o}}$ 8, November/December 1970.

[18] BILLINTON, R.; WOJCZYNSKI, E. "Distributional Variation of Distribution System Reliability Indices". IEEE Transactions on Power Apparatus and Systems, Vol. PAS-104, nº 11, November 1985. 
[19] BILLINTON, R.; GOEL, R. “An Analytical Approach to Evaluate Probability Distributions Associated With the Reliability Indices of Electric Distribution Systems”. IEEE Transactions on Power Delivery, Vol. PWRD-1, nº 3, July 1986.

[20] HELMAN, H.; ANDERY, P. R. P. “Análise de Falhas (Aplicação do Métodos de FMEA - FTA)”. Belo Horizonte: Fundação Christiano Ottoni, 1995.

[21] GAlYEAN, W. J.; FOWLER, R. D.; ClOSE, J. A.; DONLEY, M. E. "Case Study: Reliability of the INEL-Site Power System”. IEEE Transactions on Reliability, Vol. 38, nº 3, August 1989.

[22] BILlinTON, R.; WANG, P. "A Generalized Method for Distribution System Reliability Evaluation". IEEE WESCANEX Communications, Power and Computing, Vol. 2, May 15-16, 1995.

[23] KJOLLE, G.; SAND, K. "RELRAD - An Analytical Approach for Distribution System Reliability Assesment”. IEEE Transactions on Power Delivery, Vol. 7, $\mathrm{n}^{\circ}$ 2, April 1992.

[24] GOEL, L.; BILlinTON, R. "Monte Carlo simulation Applied to Distribution Feeder Reliability Evaluation”. Electric Power Systems Research, Vol. 29, n 3, May 1994.

[25] LEVITIN, G.; MAZAL-TOV, S.; ELMAKIS, D. "Reliability Indices of a Radial Distribution System With Sectionalizing as a Function of Network Structure Parameters”. Electric Power Systems Research, Vol. 36, February 1996.

[26] EL-SAYED, M. A. H. "Fuzzy Clustering and Fuzzy Sets for Reliability Analysis of Recent Distribution Systems". IEEE International Conference on Intelligent Engineering Systems, Proceedings. September 15-17, 1997.

[27] Silva, E. S.; MANHÃES, L. R.; OliVEIRA, P. R. P.; JOLY, S. V. Z. "Previsão de Confiabilidade de Alimentadores". CPFL. Relatório Interno, 1992. 
[28] SIMÕES, A. C. "Análise do Custo-Benefício da Instalação de Equipamentos de Proteção em Redes Aéreas de Distribuição". Dissertação de Mestrado - Escola Politécnica da Universidade de São Paulo (SP), 1997.

[29] BROWN, R. E.; OCHOA, J. R. "Distribution System Reliability: Default Data and Model Validation". IEEE Transactions on Power Systems, Vol. 13, n 2, May 1998.

[30] ALlAN, R. N.; BILliNTON, R.; SJARIEF, I.; GOEL, L.; SO, K. S. "A Reliability Test System for Educational Purposes - Basic Distribution System Data And Results”. IEEE Transactions on Power Systems, Vol. 6, n² 2, May 1991.

[31] BROWN, R. E.; HANSON, A. P.; WILLIS, H. L.; LUEDTKE, F. A.; BORN, M. F. "Assessing the Reliability of Distribution Systems". IEEE Computer Applications in Power, Vol. 14, n 1, January 2001.

[32] RELATÓRIOS Físicos: Equipamentos, Condutores, Postes e Iluminação Pública (PPR-56 - PRODADIS), CPFL, $2^{\circ}$ Trimestre de 2001.

[33] ANDERS, G. J. "Probability Concepts in Electric Power Systems". A WileyInterscience publication. USA, 1989. Cap. 3, p. 43-104.

[34] KAGAN, N.; OLIVEIRA, C. C. B. "Goal Planning and Risk Analysis for Distribution Reliability Indices". CIRED Conference Papers. Amsterdam Netherlands, June 18-21, 2001.

[35] WARREN, C. M.; "The Effect of Reducing Momentary Outages on Distribution Reliability Indices”. IEEE Transactions on Power Delivery, Vol. 7, nº 3, July 1992. 


\section{ANEXO A}

Resultados completos, referentes ao item 4.2.4

\begin{tabular}{|c|c|c|c|c|c|c|c|c|}
\hline $\begin{array}{l}\text { No. } \\
\text { Bloco }\end{array}$ & Alimentador & $\mathrm{Dl}_{\mathrm{P}}[\mathrm{h}]$ & $\mathrm{NI}_{\mathrm{P}}$ & $\begin{array}{c}\text { No. } \\
\text { Clientes }\end{array}$ & $\begin{array}{c}\text { Consumo } \\
\text { Anual [kWh] }\end{array}$ & $\begin{array}{c}\text { CDEC } \\
{[\mathrm{h}]}\end{array}$ & CFEC & $\begin{array}{l}\text { CEND } \\
\text { [kWh] }\end{array}$ \\
\hline 1 & SEA001 & 0,00 & 0,00 & 0 & 0 & 0,000 & 0,001 & 7 \\
\hline 2 & SEA001 & 33,14 & 22,67 & 1 & 1560 & 0,000 & 0,000 & 0 \\
\hline 3 & SEA001 & 29,12 & 19,42 & 1 & 360 & 0,000 & 0,000 & 0 \\
\hline 4 & SEA001 & 25,62 & 17,34 & 1 & 1992 & 0,000 & 0,000 & 0 \\
\hline 5 & SEA001 & 29,57 & 19,96 & 65 & 67.188 & 0,001 & 0,001 & 4 \\
\hline 6 & SEA001 & 29,11 & 19,42 & 12 & 33.372 & 0,000 & 0,000 & 0 \\
\hline 7 & SEA001 & 0,00 & 0,00 & 0 & 0 & 0,000 & 0,000 & 0 \\
\hline 8 & SEA001 & 29,11 & 19,42 & 13 & 9420 & 0,000 & 0,000 & 0 \\
\hline 9 & SEA001 & 0,00 & 0,00 & 0 & 0 & 0,000 & 0,000 & 0 \\
\hline 10 & SEA001 & 29,32 & 20,82 & 2 & 12.516 & 0,000 & 0,000 & 0 \\
\hline 11 & SEA001 & 24,46 & 16,66 & 11 & 21.492 & 0,015 & 0,009 & 74 \\
\hline 12 & SEA001 & 0,00 & 0,00 & 0 & 0 & 0,000 & 0,000 & 0 \\
\hline 13 & SEA001 & 9,70 & 7,20 & 4 & 3192 & 0,000 & 0,000 & 4 \\
\hline 14 & SEA001 & 25,92 & 18,38 & 10 & 23.520 & 0,008 & 0,005 & 68 \\
\hline 15 & SEA001 & 2,91 & 3,39 & 193 & 607.320 & 0,035 & 0,044 & 564 \\
\hline 16 & SEA001 & 0,00 & 0,00 & 0 & 0 & 0,000 & 0,000 & 4 \\
\hline 17 & SEA001 & 2,95 & 3,39 & 286 & 527.652 & 0,027 & 0,037 & 440 \\
\hline 18 & SEA001 & 0,00 & 0,00 & 0 & 0 & 0,000 & 0,000 & 204 \\
\hline 19 & SEA001 & 13,76 & 9,93 & 1 & 27.648 & 0,000 & 0,000 & 3 \\
\hline 20 & SEA001 & 7,03 & 5,79 & 3 & 158.136 & 0,000 & 0,000 & 73 \\
\hline 21 & SEA001 & 0,00 & 0,00 & 0 & 0 & 0,000 & 0,000 & 0 \\
\hline 22 & SEA001 & 17,83 & 13,15 & 1 & 1200 & 0,000 & 0,000 & 0 \\
\hline 23 & SEA001 & 0,00 & 0,00 & 0 & 0 & 0,000 & 0,000 & 0 \\
\hline 24 & SEA001 & 9,70 & 7,21 & 2 & 3324 & 0,000 & 0,000 & 0 \\
\hline 25 & SEA001 & 23,30 & 15,67 & 5 & 6276 & 0,002 & 0,001 & 183 \\
\hline 26 & SEA001 & 0,00 & 0,00 & 0 & 0 & 0,000 & 0,000 & 0 \\
\hline 27 & SEA001 & 0,00 & 0,00 & 0 & 0 & 0,000 & 0,000 & 0 \\
\hline 28 & SEA001 & 7,69 & 6,11 & 1 & 102.840 & 0,000 & 0,000 & 0 \\
\hline 29 & SEA001 & 2,98 & 3,39 & 13 & 170.412 & 0,008 & 0,012 & 127 \\
\hline 30 & SEA001 & 3,10 & 3,39 & 208 & 570.132 & 0,025 & 0,036 & 421 \\
\hline 31 & SEA001 & 15,59 & 11,05 & 1 & 1044 & 0,000 & 0,000 & 0 \\
\hline 32 & SEA001 & 7,69 & 6,11 & 2 & 6048 & 0,000 & 0,000 & 0 \\
\hline 33 & SEA001 & 2,93 & 3,39 & 84 & 204.480 & 0,026 & 0,033 & 428 \\
\hline 34 & SEA001 & 19,91 & 13,66 & 1 & 1200 & 0,000 & 0,000 & 0 \\
\hline 35 & SEA001 & 0,00 & 0,00 & 0 & 0 & 0,000 & 0,000 & 0 \\
\hline 36 & SEA001 & 0,00 & 0,00 & 0 & 0 & 0,000 & 0,000 & 0 \\
\hline 37 & SEA001 & 0,00 & 0,00 & 0 & 0 & 0,000 & 0,000 & 2 \\
\hline 38 & SEA001 & 16,43 & 11,67 & 1 & 648 & 0,000 & 0,000 & 0 \\
\hline 39 & SEA001 & 7,73 & 6,14 & 11 & 1.139 .952 & 0,000 & 0,000 & 7 \\
\hline 40 & SEA001 & 2,92 & 3,39 & 26 & 2.044 .140 & 0,014 & 0,022 & 270 \\
\hline 41 & SEA001 & 29,45 & 20,90 & 3 & 1104 & 0,000 & 0,000 & 0 \\
\hline 42 & SEA001 & 0,00 & 0,00 & 0 & 0 & 0,000 & 0,000 & 0 \\
\hline 43 & SEA001 & 19,59 & 13,46 & 1 & 2580 & 0,008 & 0,005 & 161 \\
\hline 44 & SEA001 & 30,04 & 21,30 & 1 & 3588 & 0,000 & 0,000 & 0 \\
\hline 45 & SEA001 & 30,00 & 21,28 & 1 & 1200 & 0,000 & 0,000 & 0 \\
\hline 46 & SEA001 & 0,00 & 0,00 & 0 & 0 & 0,000 & 0,000 & 0 \\
\hline 47 & SEA001 & 9,10 & 6,85 & 1 & 3168 & 0,000 & 0,000 & $\overline{1}$ \\
\hline
\end{tabular}




\begin{tabular}{|c|c|c|c|c|c|c|c|c|}
\hline $\begin{array}{c}\text { No. } \\
\text { Bloco }\end{array}$ & Alimentador & $\mathrm{Dl}_{\mathrm{P}}[\mathrm{h}]$ & $\mathrm{Nl}_{\mathbf{P}}$ & $\begin{array}{c}\text { No. } \\
\text { Clientes }\end{array}$ & $\begin{array}{c}\text { Consumo } \\
\text { Anual [kWh] }\end{array}$ & $\begin{array}{c}\text { CDEC } \\
{[\mathrm{h}]}\end{array}$ & CFEC & $\begin{array}{l}\text { CEND } \\
\text { [kWh] }\end{array}$ \\
\hline 48 & SEA001 & 0,00 & 0,00 & 0 & 0 & 0,000 & 0,000 & 0 \\
\hline 49 & SEA001 & 24,72 & 16,51 & 2 & 2400 & 0,000 & 0,000 & 0 \\
\hline 50 & SEA001 & 5,57 & 6,72 & 704 & 1.204 .368 & 0,059 & 0,070 & 385 \\
\hline 51 & SEA001 & 19,78 & 13,58 & 1 & 1200 & 0,000 & 0,000 & 0 \\
\hline 52 & SEA001 & 9,91 & 7,33 & 1 & 2028 & 0,000 & 0,000 & 0 \\
\hline 53 & SEA001 & 12,60 & 9,24 & 1 & 11808 & 0,000 & 0,000 & 0 \\
\hline 54 & SEA001 & 26,46 & 18,71 & 2 & 2544 & 0,000 & 0,000 & 0 \\
\hline 55 & SEA001 & 11,59 & 8,64 & 1 & 3012 & 0,000 & 0,000 & 0 \\
\hline 56 & SEA001 & 0,00 & 0,00 & 0 & 0 & 0,000 & 0,000 & 0 \\
\hline 57 & SEA001 & 29,48 & 20,50 & 7 & 8904 & 0,002 & 0,001 & 13 \\
\hline 58 & SEA001 & 10,23 & 7,52 & 2 & 18.948 & 0,000 & 0,000 & 1 \\
\hline 59 & SEA001 & 0,00 & 0,00 & 0 & 0 & 0,058 & 0,038 & 961 \\
\hline 60 & SEA001 & 0,00 & 0,00 & 0 & 0 & 0,000 & 0,000 & 0 \\
\hline 61 & SEA001 & 0,00 & 0,00 & 0 & 0 & 0,000 & 0,000 & 0 \\
\hline 62 & SEA001 & 7,70 & 6,12 & 2 & 12.060 & 0,000 & 0,000 & 0 \\
\hline 63 & SEA001 & 11,60 & 8,65 & 1 & 9336 & 0,000 & 0,000 & 0 \\
\hline 64 & SEA001 & 11,69 & 8,70 & 1 & 1200 & 0,000 & 0,000 & 0 \\
\hline 65 & SEA001 & 23,34 & 15,69 & 2 & 8556 & 0,000 & 0,000 & 0 \\
\hline 66 & SEA001 & 0,00 & 0,00 & 0 & 0 & 0,000 & 0,000 & 0 \\
\hline 67 & SEA001 & 29,78 & 20,68 & 1 & 6156 & 0,000 & 0,000 & 0 \\
\hline 68 & SEA001 & 7,69 & 6,11 & 1 & 31.668 & 0,000 & 0,000 & 0 \\
\hline 69 & SEA001 & 0,00 & 0,00 & 0 & 0 & 0,000 & 0,000 & 0 \\
\hline 70 & SEA001 & 0,00 & 0,00 & 0 & 0 & 0,000 & 0,000 & 0 \\
\hline 71 & SEA001 & 29,71 & 20,63 & 1 & 1200 & 0,000 & 0,000 & 0 \\
\hline 72 & SEA001 & 11,55 & 8,62 & 1 & 7080 & 0,005 & 0,004 & 458 \\
\hline 73 & SEA001 & 19,13 & 13,28 & 4 & 43.368 & 0,001 & 0,000 & 354 \\
\hline 74 & SEA001 & 12,32 & 9,07 & 1 & 6540 & 0,000 & 0,000 & 0 \\
\hline 75 & SEA001 & 4,62 & 5,20 & 197 & 370.608 & 0,009 & 0,011 & 64 \\
\hline 76 & SEA001 & 29,39 & 20,86 & 1 & 1728 & 0,000 & 0,000 & 0 \\
\hline 77 & SEA001 & 29,80 & 20,69 & 1 & 5940 & 0,000 & 0,000 & 0 \\
\hline 78 & SEA001 & 0,00 & 0,00 & 0 & 0 & 0,000 & 0,000 & 0 \\
\hline 79 & SEA001 & 0,00 & 0,00 & 0 & 0 & 0,000 & 0,000 & 0 \\
\hline 80 & SEA001 & 18,00 & 13,25 & 1 & 1260 & 0,000 & 0,000 & 0 \\
\hline 81 & SEA001 & 9,53 & 7,10 & 1 & 3576 & 0,000 & 0,000 & 0 \\
\hline 82 & SEA001 & 29,57 & 20,55 & 2 & 3888 & 0,000 & 0,000 & 0 \\
\hline 83 & SEA001 & 0,00 & 0,00 & 0 & 0 & 0,013 & 0,007 & 59 \\
\hline 84 & SEA001 & 0,00 & 0,00 & 0 & 0 & 0,000 & 0,000 & 2 \\
\hline 85 & SEA001 & 18,92 & 13,79 & 1 & 2736 & 0,000 & 0,000 & 0 \\
\hline 86 & SEA001 & 16,28 & 11,59 & 9 & 41.460 & 0,008 & 0,004 & 771 \\
\hline 87 & SEA001 & 16,93 & 12,61 & 6 & 5136 & 0,001 & 0,000 & 3 \\
\hline 88 & SEA001 & 3,00 & 3,40 & 1 & 11064 & 0,000 & 0,000 & 0 \\
\hline 89 & SEA001 & 11,51 & 8,38 & 3 & 4920 & 0,001 & 0,001 & 6 \\
\hline 90 & SEA001 & 27,75 & 19,94 & 3 & 4704 & 0,000 & 0,000 & $\overline{2}$ \\
\hline 91 & SEA001 & 16,71 & 11,84 & 1 & 3144 & 0,000 & 0,000 & 0 \\
\hline 92 & SEA001 & 0,00 & 0,00 & 0 & 0 & 0,000 & 0,000 & 0 \\
\hline 93 & SEA001 & 0,00 & 0,00 & 0 & 0 & 0,000 & 0,000 & 0 \\
\hline 94 & SEA001 & 0,00 & 0,00 & 0 & 0 & 0,000 & 0,000 & 0 \\
\hline 95 & SEA001 & 23,30 & 15,67 & 1 & 1200 & 0,000 & 0,000 & 0 \\
\hline 96 & SEA001 & 9,23 & 6,93 & 1 & 7128 & 0,000 & 0,000 & 0 \\
\hline 97 & SEA001 & 29,32 & 20,82 & 27 & 49.068 & 0,005 & 0,003 & 41 \\
\hline 98 & SEA001 & 16,29 & 11,59 & 4 & 51.648 & 0,000 & 0,000 & 0 \\
\hline
\end{tabular}




\begin{tabular}{|c|c|c|c|c|c|c|c|c|}
\hline $\begin{array}{l}\text { No. } \\
\text { Bloco }\end{array}$ & Alimentador & $\mathrm{Dl}_{\mathrm{P}}[\mathrm{h}]$ & $\mathrm{Nl}_{\mathbf{P}}$ & $\begin{array}{l}\text { No. } \\
\text { Clientes }\end{array}$ & $\begin{array}{c}\text { Consumo } \\
\text { Anual [kWh] }\end{array}$ & $\begin{array}{c}\text { CDEC } \\
\text { [h] }\end{array}$ & CFEC & $\begin{array}{l}\text { CEND } \\
{[\mathrm{kWh}]}\end{array}$ \\
\hline 99 & SEA001 & 2,67 & 3,39 & 56 & 111.228 & 0,008 & 0,010 & 123 \\
\hline 100 & SEA001 & 23,30 & 15,67 & 3 & 412.920 & 0,000 & 0,000 & 0 \\
\hline 101 & SEA001 & 29,45 & 20,90 & 1 & 1200 & 0,000 & 0,000 & 0 \\
\hline 102 & SEA001 & 0,00 & 0,00 & 0 & 0 & 0,003 & 0,002 & 194 \\
\hline 103 & SEA001 & 0,00 & 0,00 & 0 & 0 & 0,063 & 0,043 & 744 \\
\hline 104 & SEA001 & 2,87 & 3,39 & 3 & 52.884 & 0,008 & 0,011 & 131 \\
\hline 105 & SEA001 & 0,00 & 0,00 & 0 & 0 & 0,000 & 0,000 & 0 \\
\hline 106 & SEA001 & 7,69 & 6,11 & 1 & 10308 & 0,000 & 0,000 & 0 \\
\hline 107 & SEA001 & 0,00 & 0,00 & 0 & 0 & 0,000 & 0,000 & 0 \\
\hline 108 & SEA001 & 0,00 & 0,00 & 0 & 0 & 0,000 & 0,000 & 0 \\
\hline 109 & SEA001 & 7,68 & 6,11 & 5 & 12.888 & 0,004 & 0,003 & 702 \\
\hline 110 & SEA001 & 0,00 & 0,00 & 0 & 0 & 0,000 & 0,000 & 0 \\
\hline 111 & SEA001 & 14,94 & 10,67 & 2 & 6732 & 0,000 & 0,000 & 0 \\
\hline 112 & SEA001 & 19,61 & 13,78 & 1 & 672 & 0,002 & 0,001 & 8 \\
\hline 113 & SEA001 & 23,68 & 15,89 & 1 & 1200 & 0,000 & 0,000 & 0 \\
\hline 114 & SEA001 & 11,71 & 8,50 & 1 & 3192 & 0,000 & 0,000 & 0 \\
\hline 115 & SEA001 & 0,00 & 0,00 & 0 & 0 & 0,000 & 0,000 & 1 \\
\hline 116 & SEA001 & 12,46 & 9,15 & 1 & 2460 & 0,000 & 0,000 & 0 \\
\hline 117 & SEA001 & 10,37 & 7,60 & 1 & 4428 & 0,000 & 0,000 & 0 \\
\hline 118 & SEA001 & 21,65 & 15,50 & 2 & 5412 & 0,000 & 0,000 & 0 \\
\hline 119 & SEA001 & 5,26 & 4,69 & 7 & 9492 & 0,000 & 0,000 & 0 \\
\hline 120 & SEA001 & 21,55 & 15,44 & 2 & 3180 & 0,015 & 0,010 & 114 \\
\hline 121 & SEA001 & 28,21 & 20,21 & 1 & 1200 & 0,000 & 0,000 & 0 \\
\hline 122 & SEA001 & 21,31 & 15,86 & 108 & 191.604 & 0,002 & 0,002 & 14 \\
\hline 123 & SEA001 & 20,12 & 13,86 & 1 & 12.600 & 0,000 & 0,000 & 1 \\
\hline 124 & SEA001 & 0,00 & 0,00 & 0 & 0 & 0,000 & 0,000 & 0 \\
\hline 125 & SEA001 & 0,00 & 0,00 & 0 & 0 & 0,000 & 0,000 & 0 \\
\hline 126 & SEA001 & 16,28 & 11,59 & 2 & 2400 & 0,000 & 0,000 & 0 \\
\hline 127 & SEA001 & 0,00 & 0,00 & 0 & 0 & 0,000 & 0,000 & 0 \\
\hline 128 & SEA001 & 32,80 & 22,47 & 1 & 1200 & 0,000 & 0,000 & 0 \\
\hline 129 & SEA001 & 23,38 & 15,80 & 4 & 1.032 .240 & 0,000 & 0,000 & 297 \\
\hline 130 & SEA001 & 0,00 & 0,00 & 0 & 0 & 0,000 & 0,000 & 0 \\
\hline 131 & SEA001 & 0,00 & 0,00 & 0 & 0 & 0,000 & 0,000 & 0 \\
\hline 132 & SEA001 & 4,51 & 5,45 & 169 & 384.888 & 0,009 & 0,010 & 76 \\
\hline 133 & SEA001 & 16,36 & 11,63 & 3 & 12.048 & 0,000 & 0,000 & 0 \\
\hline 134 & SEA001 & 17,82 & 13,14 & 4 & 4008 & 0,000 & 0,000 & 0 \\
\hline 135 & SEA001 & 16,80 & 11,89 & 1 & 3924 & 0,000 & 0,000 & 1 \\
\hline 136 & SEA001 & 8,63 & 6,57 & 3 & 9060 & 0,008 & 0,005 & 563 \\
\hline 137 & SEA001 & 0,00 & 0,00 & 0 & 0 & 0,000 & 0,000 & 0 \\
\hline 138 & SEA001 & 0,00 & 0,00 & 0 & 0 & 0,000 & 0,000 & 0 \\
\hline 139 & SEA001 & 30,32 & 21,41 & 1 & 16.536 & 0,000 & 0,000 & 0 \\
\hline 140 & SEA001 & 0,00 & 0,00 & 0 & 0 & 0,000 & 0,000 & 0 \\
\hline 141 & SEA001 & 16,80 & 11,90 & 2 & 8616 & 0,000 & 0,000 & 0 \\
\hline 142 & SEA001 & 25,81 & 18,74 & 2 & 2532 & 0,001 & 0,000 & 7 \\
\hline 143 & SEA001 & 17,54 & 12,07 & 2 & 3816 & 0,008 & 0,005 & 138 \\
\hline 144 & SEA001 & 0,00 & 0,00 & 0 & 0 & 0,000 & 0,000 & 0 \\
\hline 145 & SEA001 & 0,00 & 0,00 & 0 & 0 & 0,000 & 0,000 & 0 \\
\hline 146 & SEA001 & 29,32 & 20,82 & 4 & 12.624 & 0,000 & 0,000 & 0 \\
\hline 147 & SEA001 & 19,81 & 13,59 & 3 & 1956 & 0,000 & 0,000 & 0 \\
\hline 148 & SEA001 & 16,69 & 11,83 & 3 & 8508 & 0,000 & 0,000 & 0 \\
\hline 149 & SEA001 & 19,38 & 13,67 & 5 & 23.688 & 0,027 & 0,018 & 208 \\
\hline
\end{tabular}




\begin{tabular}{|c|c|c|c|c|c|c|c|c|}
\hline $\begin{array}{l}\text { No. } \\
\text { Bloco }\end{array}$ & Alimentador & $\mathrm{Dl}_{\mathrm{P}}[\mathrm{h}]$ & $\mathrm{NI}_{\mathbf{P}}$ & $\begin{array}{c}\text { No. } \\
\text { Clientes }\end{array}$ & $\begin{array}{c}\text { Consumo } \\
\text { Anual }[k W h]\end{array}$ & $\begin{array}{c}\text { CDEC } \\
{[\mathrm{h}]}\end{array}$ & CFEC & $\begin{array}{l}\text { CEND } \\
\text { [kWh] }\end{array}$ \\
\hline 150 & SEA001 & 30,05 & 21,25 & 4 & 3708 & 0,000 & 0,000 & 0 \\
\hline 151 & SEA001 & 14,93 & 10,66 & 5 & 29.328 & 0,049 & 0,030 & 608 \\
\hline 152 & SEA001 & 9,53 & 7,10 & 2 & 33.228 & 0,000 & 0,000 & 4 \\
\hline 153 & SEA001 & 0,00 & 0,00 & 0 & 0 & 0,000 & 0,000 & 0 \\
\hline 154 & SEA001 & 0,00 & 0,00 & 0 & 0 & 0,000 & 0,000 & 0 \\
\hline 155 & SEA001 & 0,00 & 0,00 & 0 & 0 & 0,000 & 0,000 & 0 \\
\hline 156 & SEA001 & 14,88 & 10,38 & 5 & 6252 & 0,001 & 0,000 & 2 \\
\hline 157 & SEA001 & 19,59 & 13,47 & 1 & 1296 & 0,000 & 0,000 & 0 \\
\hline 158 & SEA001 & 0,00 & 0,00 & 0 & 0 & 0,000 & 0,000 & 1 \\
\hline 159 & SEA001 & 30,26 & 21,38 & 2 & 4728 & 0,000 & 0,000 & 2 \\
\hline 160 & SEA001 & 19,38 & 13,67 & 1 & 3000 & 0,000 & 0,000 & 0 \\
\hline 161 & SEA001 & 25,13 & 18,38 & 1 & 2196 & 0,002 & 0,001 & 18 \\
\hline 162 & SEA001 & 10,49 & 7,67 & 1 & 1200 & 0,000 & 0,000 & 0 \\
\hline 163 & SEA001 & 29,48 & 20,50 & 2 & 3612 & 0,000 & 0,000 & 0 \\
\hline 164 & SEA001 & 0,00 & 0,00 & 0 & 0 & 0,000 & 0,000 & 0 \\
\hline 165 & SEA001 & 4,91 & 4,60 & 14 & 32.460 & 0,001 & 0,001 & 8 \\
\hline 166 & SEA001 & 14,94 & 10,66 & 1 & 3204 & 0,000 & 0,000 & 0 \\
\hline 167 & SEA001 & 3,37 & 3,68 & 1 & 2472 & 0,000 & 0,000 & 0 \\
\hline 168 & SEA001 & 0,00 & 0,00 & 0 & 0 & 0,000 & 0,000 & 0 \\
\hline 169 & SEA001 & 7,69 & 6,11 & 1 & 13.524 & 0,000 & 0,000 & 0 \\
\hline 170 & SEA001 & 16,97 & 12,64 & 2 & 1200 & 0,000 & 0,000 & 0 \\
\hline 171 & SEA001 & 0,00 & 0,00 & 0 & 0 & 0,000 & 0,000 & 1 \\
\hline 172 & SEA001 & 15,59 & 11,05 & 1 & 11376 & 0,000 & 0,000 & 1 \\
\hline 173 & SEA002 & 1,63 & 2,55 & 1 & 9228 & 0,001 & 0,002 & 11 \\
\hline 174 & SEA002 & 3,25 & 3,95 & 408 & 809.004 & 0,044 & 0,052 & 281 \\
\hline 175 & SEA002 & 2,98 & 4,02 & 321 & 601.392 & 0,012 & 0,014 & 85 \\
\hline 176 & SEA002 & 5,34 & 4,65 & 1 & 9408 & 0,001 & 0,001 & 105 \\
\hline 177 & SEA002 & 2,03 & 2,55 & 336 & 907.704 & 0,102 & 0,126 & 1.130 \\
\hline 178 & SEA002 & 10,07 & 7,27 & 5 & 407.640 & 0,001 & 0,001 & 213 \\
\hline 179 & SEA002 & 0,00 & 0,00 & 0 & 0 & 0,001 & 0,000 & 78 \\
\hline 180 & SEA002 & 2,55 & 3,16 & 143 & 320.448 & 0,002 & 0,003 & 19 \\
\hline 181 & SEA002 & 1,79 & 2,55 & 116 & 222.852 & 0,046 & 0,058 & 476 \\
\hline 182 & SEA002 & 3,87 & 4,69 & 464 & 621.708 & 0,009 & 0,010 & 44 \\
\hline 183 & SEA002 & 2,74 & 3,46 & 28 & 154.764 & 0,001 & 0,001 & 14 \\
\hline 184 & SEA002 & 0,00 & 0,00 & 0 & 0 & 0,000 & 0,000 & 0 \\
\hline 185 & SEA002 & 2,08 & 2,55 & 2 & 630.000 & 0,000 & 0,000 & 0 \\
\hline 186 & SEA002 & 3,33 & 4,04 & 241 & 440.040 & 0,006 & 0,007 & 42 \\
\hline 187 & SEA002 & 1,89 & 2,55 & 436 & 937.620 & 0,051 & 0,074 & 526 \\
\hline 188 & SEA002 & 4,47 & 5,18 & 189 & 363.600 & 0,005 & 0,005 & 33 \\
\hline 189 & SEA002 & 1,83 & 2,55 & 34 & 238.548 & 0,012 & 0,017 & 123 \\
\hline 190 & SEA002 & 2,86 & 3,88 & 283 & 719.148 & 0,009 & 0,011 & 92 \\
\hline 191 & SEA002 & 0,00 & 0,00 & 0 & 0 & 0,000 & 0,000 & 0 \\
\hline 192 & SEA002 & 4,20 & 5,03 & 390 & 707.016 & 0,039 & 0,045 & 276 \\
\hline 193 & SEA002 & 3,35 & 4,06 & 235 & 437.160 & 0,006 & 0,007 & 43 \\
\hline 194 & SEA002 & 2,07 & 2,55 & 196 & 708.480 & 0,083 & 0,098 & 822 \\
\hline 195 & SEA002 & 6,67 & 5,26 & 1 & 0 & 0,000 & 0,000 & 0 \\
\hline 196 & SEA002 & 3,55 & 4,75 & 24 & 50.880 & 0,000 & 0,000 & 133 \\
\hline 197 & SEA002 & 6,68 & 5,26 & 3 & 2304 & 0,000 & 0,000 & 0 \\
\hline 198 & SEA002 & 3,55 & 4,75 & 1 & 2.613 .228 & 0,000 & 0,000 & 2 \\
\hline 199 & SEA002 & 3,67 & 4,22 & 250 & 550.884 & 0,022 & 0,023 & 496 \\
\hline 200 & SEA002 & 6,67 & 8,96 & 34 & 131.364 & 0,003 & 0,003 & 41 \\
\hline
\end{tabular}




\begin{tabular}{|c|c|c|c|c|c|c|c|c|}
\hline $\begin{array}{c}\text { No. } \\
\text { Bloco }\end{array}$ & Alimentador & $\mathrm{DI}_{\mathrm{P}}[\mathrm{h}]$ & $\mathbf{N l}_{\mathbf{P}}$ & $\begin{array}{c}\text { No. } \\
\text { Clientes } \\
\end{array}$ & $\begin{array}{c}\text { Consumo } \\
\text { Anual [kWh] }\end{array}$ & $\begin{array}{c}\text { CDEC } \\
{[\mathrm{h}]}\end{array}$ & CFEC & $\begin{array}{l}\text { CEND } \\
\text { [kWh] }\end{array}$ \\
\hline 201 & SEA002 & 2,42 & 3,29 & 137 & 276.108 & 0,003 & 0,003 & 20 \\
\hline 202 & SEA002 & 6,67 & 5,26 & 1 & 0 & 0,000 & 0,000 & 0 \\
\hline 203 & SEA002 & 6,67 & 5,26 & 1 & 0 & 0,000 & 0,000 & 0 \\
\hline 204 & SEA002 & 4,16 & 5,03 & 477 & 726.264 & 0,030 & 0,035 & 173 \\
\hline 205 & SEA002 & 2,60 & 3,22 & 145 & 263.028 & 0,002 & 0,003 & 17 \\
\hline 206 & SEA002 & 3,96 & 5,73 & 192 & 312.144 & 0,004 & 0,005 & 30 \\
\hline 207 & SEA002 & 2,49 & 3,04 & 59 & 145.620 & 0,007 & 0,008 & 48 \\
\hline 208 & SEA002 & 4,15 & 5,02 & 383 & 652.368 & 0,010 & 0,012 & 67 \\
\hline 209 & SEA002 & 1,97 & 2,55 & 14 & 92.592 & 0,030 & 0,046 & 317 \\
\hline 210 & SEA002 & 2,08 & 2,55 & 4 & 6792 & 0,000 & 0,000 & 0 \\
\hline 211 & SEA002 & 10,07 & 7,28 & 2 & 4176 & 0,000 & 0,000 & 0 \\
\hline 212 & SEA002 & 10,07 & 7,28 & 2 & 11280 & 0,000 & 0,000 & 0 \\
\hline 213 & SEA003 & 0,00 & 0,00 & 0 & 0 & 0,001 & 0,001 & 13 \\
\hline 214 & SEA003 & 2,51 & 3,58 & 248 & 739.584 & 0,031 & 0,047 & 473 \\
\hline 215 & SEA003 & 6,00 & 7,49 & 147 & 764.952 & 0,014 & 0,017 & 287 \\
\hline 216 & SEA003 & 2,72 & 3,58 & 368 & 704.916 & 0,047 & 0,063 & 706 \\
\hline 217 & SEA003 & 3,32 & 4,42 & 8 & 9024 & 0,000 & 0,000 & 1 \\
\hline 218 & SEA003 & 4,22 & 5,49 & 125 & 274.248 & 0,002 & 0,003 & 19 \\
\hline 219 & SEA003 & 3,04 & 4,42 & 122 & 332.052 & 0,003 & 0,003 & 27 \\
\hline 220 & SEA003 & 2,80 & 4,06 & 104 & 222.072 & 0,001 & 0,001 & 10 \\
\hline 221 & SEA003 & 2,49 & 3,58 & 2 & 2.424 .360 & 0,004 & 0,007 & 78 \\
\hline 222 & SEA003 & 2,67 & 3,58 & 516 & 1.168 .008 & 0,054 & 0,071 & 828 \\
\hline 223 & SEA003 & 3,80 & 5,14 & 62 & 265.596 & 0,002 & 0,003 & 40 \\
\hline 224 & SEA003 & 2,41 & 3,58 & 12 & 40.428 & 0,007 & 0,009 & 103 \\
\hline 225 & SEA003 & 3,74 & 5,51 & 107 & 1.423 .032 & 0,001 & 0,002 & 74 \\
\hline 226 & SEA003 & 2,62 & 3,58 & 384 & 667.860 & 0,039 & 0,055 & 574 \\
\hline 227 & SEA003 & 2,71 & 3,58 & 65 & 3.109 .560 & 0,038 & 0,059 & 646 \\
\hline 228 & SEA003 & 4,98 & 6,27 & 345 & 553.344 & 0,023 & 0,028 & 142 \\
\hline 229 & SEA003 & 2,37 & 3,58 & 39 & 58.644 & 0,007 & 0,009 & 103 \\
\hline 230 & SEA003 & 2,52 & 3,58 & 395 & 1.012 .932 & 0,030 & 0,042 & 453 \\
\hline 231 & SEA003 & 3,05 & 4,10 & 111 & 241.524 & 0,001 & 0,002 & 12 \\
\hline 232 & SEA003 & 2,45 & 3,58 & 233 & 510.900 & 0,032 & 0,040 & 492 \\
\hline 233 & SEA003 & 3,63 & 4,78 & 155 & 339.036 & 0,008 & 0,010 & 70 \\
\hline 234 & SEA003 & 2,44 & 3,58 & 117 & 272.076 & 0,016 & 0,022 & 254 \\
\hline 235 & SEA003 & 3,01 & 4,05 & 97 & 165.084 & 0,001 & 0,001 & 7 \\
\hline 236 & SEA003 & 3,75 & 4,97 & 222 & 787.176 & 0,012 & 0,014 & 265 \\
\hline 237 & SEA004 & 0,00 & 0,00 & 0 & 0 & 0,005 & 0,007 & 45 \\
\hline 238 & SEA004 & 4,18 & 5,09 & 222 & 416.628 & 0,004 & 0,005 & 67 \\
\hline 239 & SEA004 & 0,00 & 0,00 & 0 & 0 & 0,000 & 0,000 & 0 \\
\hline 240 & SEA004 & 0,00 & 0,00 & 0 & 0 & 0,000 & 0,000 & 0 \\
\hline 241 & SEA004 & 4,53 & 5,19 & 21 & 31.356 & 0,001 & 0,001 & 7 \\
\hline 242 & SEA004 & 0,00 & 0,00 & 0 & 0 & 0,000 & 0,000 & 0 \\
\hline 243 & SEA004 & 7,52 & 6,53 & 1 & 1200 & 0,000 & 0,000 & 0 \\
\hline 244 & SEA004 & 4,04 & 4,40 & 567 & 1.072 .596 & 0,113 & 0,163 & 1.076 \\
\hline 245 & SEA004 & 7,72 & 6,65 & 33 & 75.444 & 0,004 & 0,002 & 35 \\
\hline 246 & SEA004 & 0,00 & 0,00 & 0 & 0 & 0,000 & 0,000 & 0 \\
\hline 247 & SEA004 & 0,00 & 0,00 & 0 & 0 & 0,000 & 0,000 & 0 \\
\hline 248 & SEA004 & 0,00 & 0,00 & 0 & 0 & 0,000 & 0,000 & 0 \\
\hline 249 & SEA004 & 3,92 & 4,40 & 11 & 32.112 & 0,104 & 0,070 & 1.010 \\
\hline 250 & SEA004 & 0,00 & 0,00 & 0 & 0 & 0,000 & 0,000 & 0 \\
\hline 251 & SEA004 & 0,00 & 0,00 & 0 & 0 & 0,000 & 0,000 & 0 \\
\hline
\end{tabular}




\begin{tabular}{|c|c|c|c|c|c|c|c|c|}
\hline $\begin{array}{c}\text { No. } \\
\text { Bloco }\end{array}$ & Alimentador & $\mathrm{DI}_{\mathrm{P}}[\mathrm{h}]$ & $\mathrm{NI}_{\mathrm{P}}$ & $\begin{array}{c}\text { No. } \\
\text { Clientes }\end{array}$ & $\begin{array}{c}\text { Consumo } \\
\text { Anual [kWh] }\end{array}$ & $\begin{array}{c}\text { CDEC } \\
{[\mathrm{h}]}\end{array}$ & CFEC & $\begin{array}{l}\text { CEND } \\
\text { [kWh] }\end{array}$ \\
\hline 252 & SEA004 & 0,00 & 0,00 & 0 & 0 & 0,000 & 0,000 & 0 \\
\hline 253 & SEA004 & 5,86 & 6,49 & 1 & 2184 & 0,000 & 0,000 & 0 \\
\hline 254 & SEA004 & 10,96 & 8,58 & 2 & 1200 & 0,000 & 0,000 & 0 \\
\hline 255 & SEA004 & 0,00 & 0,00 & 0 & 0 & 0,000 & 0,000 & 4 \\
\hline 256 & SEA004 & 4,49 & 5,27 & 100 & 179.364 & 0,002 & 0,003 & 15 \\
\hline 257 & SEA004 & 0,00 & 0,00 & 0 & 0 & 0,000 & 0,000 & 0 \\
\hline 258 & SEA004 & 3,46 & 4,40 & 266 & 471.384 & 0,070 & 0,088 & 673 \\
\hline 259 & SEA004 & 0,00 & 0,00 & 0 & 0 & 0,000 & 0,000 & 6 \\
\hline 260 & SEA004 & 11,69 & 9,01 & 2 & 1176 & 0,001 & 0.001 & 17 \\
\hline 261 & SEA004 & 8,69 & 11,16 & 352 & 574.368 & 0,024 & 0,028 & 149 \\
\hline 262 & SEA004 & 0,00 & 0,00 & 0 & 0 & 0,000 & 0,000 & 0 \\
\hline 263 & SEA004 & 0,00 & 0,00 & 0 & 0 & 0,000 & 0,000 & 0 \\
\hline 264 & SEA004 & 5,84 & 6,48 & 22 & 59.100 & 0,000 & 0,000 & 3 \\
\hline 265 & SEA004 & 0,00 & 0,00 & 0 & 0 & 0,000 & 0,000 & 0 \\
\hline 266 & SEA004 & 0,00 & 0,00 & 0 & 0 & 0,000 & 0,000 & 0 \\
\hline 267 & SEA004 & 0,00 & 0,00 & 0 & 0 & 0,000 & 0,000 & 0 \\
\hline 268 & SEA004 & 4,13 & 5,24 & 123 & 230.364 & 0,003 & 0,003 & 19 \\
\hline 269 & SEA004 & 0,00 & 0,00 & 0 & 0 & 0,000 & 0,000 & 0 \\
\hline 270 & SEA004 & 4,43 & 5,51 & 278 & 899.436 & 0,008 & 0,009 & 96 \\
\hline 271 & SEA004 & 5,69 & 5,96 & 3 & $\begin{array}{l}16.776 \\
\end{array}$ & 0,001 & 0,001 & 11 \\
\hline 272 & SEA004 & 0,00 & 0,00 & 0 & 0 & 0,000 & 0,000 & 0 \\
\hline 273 & SEA004 & 5,83 & 5,47 & 32 & 51.984 & 0,002 & 0,001 & 12 \\
\hline 274 & SEA004 & 0,00 & 0,00 & 0 & 0 & 0,000 & 0,000 & 0 \\
\hline 275 & SEA004 & 0,00 & 0,00 & 0 & 0 & 0,000 & 0,000 & 0 \\
\hline 276 & SEA004 & 0,00 & 0,00 & 0 & 0 & 0,000 & 0,000 & 0 \\
\hline 277 & SEA004 & 6,42 & 8,46 & 38 & 171.312 & 0,023 & 0,028 & 181 \\
\hline 278 & SEA004 & 3,41 & 4,40 & 112 & 222.924 & 0,020 & 0,026 & 195 \\
\hline 279 & SEA004 & 6,71 & 5,99 & 1 & 4152 & 0,000 & 0,000 & 0 \\
\hline 280 & SEA004 & 0,00 & 0,00 & 0 & 0 & 0,013 & 0,019 & 127 \\
\hline 281 & SEA004 & 5,63 & 7,02 & 266 & 688.236 & 0,017 & 0,021 & 173 \\
\hline 282 & SEA004 & 0,00 & 0,00 & 0 & 0 & 0,000 & 0,000 & 0 \\
\hline 283 & SEA004 & 0,00 & 0,00 & 0 & 0 & 0,000 & 0,000 & 0 \\
\hline 284 & SEA004 & 7,17 & 6,33 & 4 & 4704 & 0,000 & 0,000 & 1 \\
\hline 285 & SEA004 & 7,52 & 6,53 & 1 & 720 & 0,000 & 0,000 & 0 \\
\hline 286 & SEA004 & 8,88 & 7,34 & 2 & 3516 & 0,002 & 0,001 & 20 \\
\hline 287 & SEA004 & 0,00 & 0,00 & 0 & 0 & 0,000 & 0,000 & 0 \\
\hline 288 & SEA004 & 5,82 & 5,53 & 5 & 23.580 & 0,002 & 0,001 & 24 \\
\hline 289 & SEA004 & 0,00 & 0,00 & 0 & 0 & 0,000 & 0,000 & 0 \\
\hline 290 & SEA004 & 17,42 & 12,41 & 2 & 37.776 & 0,000 & 0,000 & 0 \\
\hline 291 & SEA004 & 3,65 & 4,63 & 49 & 110.016 & 0,000 & 0,000 & 2 \\
\hline 292 & SEA004 & 4,29 & 5,50 & 1 & 690.060 & 0,000 & 0,000 & 27 \\
\hline 293 & SEA004 & 0,00 & 0,00 & 0 & 0 & 0,000 & 0,000 & 0 \\
\hline 294 & SEA004 & 0,00 & 0,00 & 0 & 0 & 0,000 & 0,000 & 0 \\
\hline 295 & SEA004 & 0,00 & 0,00 & 0 & 0 & 0,000 & 0,000 & 0 \\
\hline 296 & SEA004 & 0,00 & 0,00 & 0 & 0 & 0,000 & 0,000 & 0 \\
\hline 297 & SEA004 & 3,76 & 4,40 & 488 & 931.620 & 0,072 & 0,101 & 679 \\
\hline 298 & SEA004 & 0,00 & 0,00 & 0 & 0 & 0,000 & 0,000 & 1 \\
\hline 299 & SEA004 & 0,00 & 0,00 & 0 & 0 & 0,000 & 0,000 & 11 \\
\hline 300 & SEA004 & 4,79 & 6,11 & 248 & 740.184 & 0,011 & 0,013 & 121 \\
\hline 301 & SEA004 & 3,35 & 4,40 & 36 & 144.756 & 0,006 & 0,007 & 54 \\
\hline 302 & SEA004 & 14,51 & 10,68 & 2 & 552 & 0,000 & 0,000 & 0 \\
\hline
\end{tabular}




\begin{tabular}{|c|c|c|c|c|c|c|c|c|}
\hline $\begin{array}{c}\text { No. } \\
\text { Bloco }\end{array}$ & Alimentador & $\mathrm{Dl}_{\mathrm{P}}[\mathrm{h}]$ & $\mathrm{Nl}_{\mathbf{P}}$ & $\begin{array}{c}\text { No. } \\
\text { Clientes }\end{array}$ & $\begin{array}{c}\text { Consumo } \\
\text { Anual [kWh] }\end{array}$ & $\begin{array}{c}\text { CDEC } \\
\text { [h] }\end{array}$ & CFEC & $\begin{array}{l}\text { CEND } \\
\text { [kWh] }\end{array}$ \\
\hline 303 & SEA004 & 0,00 & 0,00 & 0 & 0 & 0,000 & 0,000 & 0 \\
\hline 304 & SEA004 & 17,50 & 12,46 & 1 & 0 & 0,000 & 0,000 & 0 \\
\hline 305 & SEA004 & 0,00 & 0,00 & 0 & 0 & 0,000 & 0,000 & 0 \\
\hline 306 & SEA004 & 0,00 & 0,00 & 0 & 0 & 0,000 & 0,000 & 0 \\
\hline 307 & SEA004 & 0,00 & 0,00 & 0 & 0 & 0,005 & 0,007 & 52 \\
\hline 308 & SEA004 & 6,76 & 8,87 & 122 & 179.928 & 0,001 & 0,001 & 7 \\
\hline 309 & SEA004 & 0,00 & 0,00 & 0 & 0 & 0,000 & 0,000 & 0 \\
\hline 310 & SEA004 & 0,00 & 0,00 & 0 & 0 & 0,000 & 0,000 & 0 \\
\hline 311 & SEA004 & 3,40 & 4,40 & 123 & 205.332 & 0,013 & 0,017 & 123 \\
\hline 312 & SEA004 & 0,00 & 0,00 & 0 & 0 & 0,000 & 0,000 & 6 \\
\hline 313 & SEA004 & 3,71 & 4,75 & 96 & 179.004 & 0,001 & 0,001 & 6 \\
\hline 314 & SEA004 & 0,00 & 0,00 & 0 & 0 & 0,000 & 0,000 & 0 \\
\hline 315 & SEA004 & 0,00 & 0,00 & 0 & 0 & 0,000 & 0,000 & 0 \\
\hline 316 & SEA004 & 0,00 & 0,00 & 0 & 0 & 0,000 & 0,000 & 0 \\
\hline 317 & SEA004 & 4,39 & 5,57 & 183 & 425.016 & 0,005 & 0,006 & 48 \\
\hline 318 & SEA004 & 14,42 & 10,63 & 1 & 1776 & 0,000 & 0,000 & 0 \\
\hline 319 & SEA004 & 0,00 & 0,00 & 0 & 0 & 0,000 & 0,000 & 0 \\
\hline 320 & SEA004 & 5,83 & 5,53 & 2 & 15.072 & 0,000 & 0,000 & 0 \\
\hline 321 & SEA004 & 0,00 & 0,00 & 0 & 0 & 0,000 & 0,000 & 0 \\
\hline 322 & SEA004 & 3,46 & 4,40 & 61 & 128.616 & 0,014 & 0,019 & 135 \\
\hline 323 & SEA004 & 0,00 & 0,00 & 0 & 0 & 0,000 & 0,000 & 0 \\
\hline 324 & SEA004 & 6,18 & 5,74 & 1 & 1200 & 0,000 & 0,000 & 3 \\
\hline 325 & SEA004 & 0,00 & 0,00 & 0 & 0 & 0,000 & 0,000 & 0 \\
\hline 326 & SEA004 & 7,00 & 8,80 & 10 & 58.200 & 0,000 & 0,000 & 4 \\
\hline 327 & SEA004 & 10,92 & 8,55 & 1 & 6120 & 0,000 & 0,000 & 0 \\
\hline 328 & SEA004 & 0,00 & 0,00 & 0 & 0 & 0,000 & 0,000 & 0 \\
\hline 329 & SEA004 & 0,00 & 0,00 & 0 & 0 & 0,000 & 0,000 & 0 \\
\hline 330 & SEA004 & 3,45 & 4,40 & 289 & 998.232 & 0,046 & 0,059 & 449 \\
\hline 331 & SEA004 & 0,00 & 0,00 & 0 & 0 & 0,000 & 0,000 & 0 \\
\hline 332 & SEA004 & 0,00 & 0,00 & 0 & 0 & 0,000 & 0,000 & 0 \\
\hline 333 & SEA004 & 0,00 & 0,00 & 0 & 0 & 0,000 & 0,000 & 0 \\
\hline 334 & SEA004 & 0,00 & 0,00 & 0 & 0 & 0,000 & 0,000 & 0 \\
\hline 335 & SEA004 & 0,00 & 0,00 & 0 & 0 & 0,000 & 0,000 & 0 \\
\hline 336 & SEA004 & 3,55 & 4,40 & 176 & 561.096 & 0,041 & 0,062 & 402 \\
\hline 337 & SEA004 & 0,00 & 0,00 & 0 & 0 & 0,000 & 0,000 & 0 \\
\hline 338 & SEA004 & 17,42 & 12,41 & 1 & 564 & 0,000 & 0,000 & 9 \\
\hline 339 & SEA004 & 0,00 & 0,00 & 0 & 0 & 0,000 & 0,000 & 0 \\
\hline 340 & SEA004 & 0,00 & 0,00 & 0 & 0 & 0,000 & 0,000 & 0 \\
\hline 341 & SEA004 & 0,00 & 0,00 & 0 & 0 & 0,000 & 0,000 & 0 \\
\hline 342 & SEA004 & 5,61 & 6,40 & 2 & 23.064 & 0,000 & 0,000 & 0 \\
\hline 343 & SEA004 & 5,33 & 7,01 & 200 & 555.336 & 0,006 & 0,007 & 64 \\
\hline 344 & SEA004 & 3,50 & 4,40 & 163 & 570.300 & 0,035 & 0,045 & 342 \\
\hline 345 & SEA004 & 7,73 & 6,66 & 2 & 5436 & 0,000 & 0,000 & 0 \\
\hline 346 & SEA004 & 0,00 & 0,00 & 0 & 0 & 0,000 & 0,000 & 0 \\
\hline 347 & SEA004 & 17,65 & 12,54 & 1 & 0 & 0,000 & 0,000 & 0 \\
\hline 348 & SEA004 & 13,22 & 9,92 & 1 & 1200 & 0,000 & 0,000 & 0 \\
\hline 349 & SEA004 & 22,50 & 15,42 & 3 & 9876 & 0,000 & 0,000 & 3 \\
\hline 350 & SEA004 & 0,00 & 0,00 & 0 & 0 & 0,000 & 0,000 & 0 \\
\hline 351 & SEA004 & 3,62 & 4,80 & 56 & 284.616 & 0,001 & 0,001 & 11 \\
\hline 352 & SEA004 & 4,08 & 5,14 & 162 & 346.812 & 0,003 & 0,004 & 25 \\
\hline 353 & SEA004 & 0,00 & 0,00 & 0 & 0 & 0,000 & 0,000 & 0 \\
\hline
\end{tabular}




\begin{tabular}{|c|c|c|c|c|c|c|c|c|}
\hline $\begin{array}{c}\text { No. } \\
\text { Bloco }\end{array}$ & Alimentador & $\mathrm{Dl}_{\mathrm{P}}[\mathrm{h}]$ & $\mathrm{Nl}_{\mathbf{P}}$ & $\begin{array}{c}\text { No. } \\
\text { Clientes }\end{array}$ & $\begin{array}{c}\text { Consumo } \\
\text { Anual [kWh] }\end{array}$ & $\begin{array}{c}\text { CDEC } \\
{[\mathrm{h}]}\end{array}$ & CFEC & $\begin{array}{l}\text { CEND } \\
\text { [kWh] }\end{array}$ \\
\hline 354 & SEA004 & 5,59 & 6,39 & 11 & 41.616 & 0,001 & 0,001 & 12 \\
\hline 355 & SEA004 & 4,79 & 5,81 & 117 & 381.288 & 0,010 & 0,013 & 117 \\
\hline 356 & SEA004 & 5,66 & 6,66 & 199 & 342.408 & 0,036 & 0,049 & 260 \\
\hline 357 & SEA004 & 6,48 & 8,53 & 2 & 66.984 & 0,000 & 0,000 & 0 \\
\hline 358 & SEB001 & 0,00 & 0,00 & 0 & 0 & 0,002 & 0,003 & 21 \\
\hline 359 & SEB001 & 0,00 & 0,00 & 0 & 0 & 0,000 & 0,000 & 0 \\
\hline 360 & SEB001 & 0,00 & 0,00 & 0 & 0 & 0,000 & 0,000 & 0 \\
\hline 361 & SEB001 & 0,00 & 0,00 & 0 & 0 & 0,000 & 0,000 & 0 \\
\hline 362 & SEB001 & 0,00 & 0,00 & 0 & 0 & 0,000 & 0,000 & 0 \\
\hline 363 & SEB001 & 0,00 & 0,00 & 0 & 0 & 0,000 & 0,000 & 0 \\
\hline 364 & SEB001 & 5,12 & 6,35 & 184 & 391.284 & 0,004 & 0,004 & 29 \\
\hline 365 & SEB001 & 0,00 & 0,00 & 0 & 0 & 0,000 & 0,000 & 0 \\
\hline 366 & SEB001 & 0,00 & 0,00 & 0 & 0 & 0,000 & 0,000 & 0 \\
\hline 367 & SEB001 & 6,91 & 8,58 & 772 & 1.362 .144 & 0,058 & 0,069 & 392 \\
\hline 368 & SEB001 & 0,00 & 0,00 & 0 & 0 & 0,000 & 0,000 & 0 \\
\hline 369 & SEB001 & 10,88 & 8,59 & 2 & 204.180 & 0,000 & 0,000 & 0 \\
\hline 370 & SEB001 & 4,74 & 5,58 & 449 & 861.960 & 0,056 & 0,073 & 534 \\
\hline 371 & SEB001 & 0,00 & 0,00 & 0 & 0 & 0,000 & 0,000 & 0 \\
\hline 372 & SEB001 & 0,00 & 0,00 & 0 & 0 & 0,000 & 0,000 & 0 \\
\hline 373 & SEB001 & 6,18 & 7,00 & 7 & 56.748 & 0,000 & 0,000 & 8 \\
\hline 374 & SEB001 & 7,04 & 8,74 & 392 & 678.168 & 0,024 & 0,029 & 154 \\
\hline 375 & SEB001 & 13,39 & 10,61 & 1 & 3156 & 0,000 & 0,000 & 3 \\
\hline 376 & SEB001 & 4,44 & 5,58 & 27 & 194.532 & 0,015 & 0,023 & 144 \\
\hline 377 & SEB001 & 4,80 & 6,05 & 46 & 322.968 & 0,001 & 0,001 & 14 \\
\hline 378 & SEB001 & 5,63 & 6,43 & 125 & 197.592 & 0,003 & 0,003 & 16 \\
\hline 379 & SEB001 & 5,51 & 6,44 & 225 & 367.464 & 0,005 & 0,006 & 30 \\
\hline 380 & SEB001 & 0,00 & 0,00 & 0 & 0 & 0,000 & 0,000 & 0 \\
\hline 381 & SEB001 & 0,00 & 0,00 & 0 & 0 & 0,000 & 0,000 & 0 \\
\hline 382 & SEB001 & 11,52 & 9,13 & 1 & 696 & 0,000 & 0,000 & 0 \\
\hline 383 & SEB001 & 0,00 & 0,00 & 0 & 0 & 0,000 & 0,000 & 0 \\
\hline 384 & SEB001 & 5,77 & 6,61 & 177 & 384.252 & 0,005 & 0,005 & 38 \\
\hline 385 & SEB001 & 5,10 & 6,36 & 126 & 223.068 & 0,002 & 0,003 & 17 \\
\hline 386 & SEB001 & 5,35 & 6,24 & 177 & 245.292 & 0,003 & 0,003 & 15 \\
\hline 387 & SEB001 & 4,93 & 5,58 & 342 & 438.924 & 0,060 & 0,088 & 560 \\
\hline 388 & SEB001 & 6,32 & 7,78 & 759 & 1.409 .052 & 0,042 & 0,050 & 297 \\
\hline 389 & SEB001 & 0,00 & 0,00 & 0 & 0 & 0,000 & 0,000 & 0 \\
\hline 390 & SEB001 & 10,04 & 8,43 & 90 & 190.044 & 0,001 & 0,001 & 6 \\
\hline 391 & SEB001 & 4,43 & 5,58 & 106 & 196.272 & 0,033 & 0,042 & 316 \\
\hline 392 & SEB001 & 5,98 & 6,99 & 300 & 525.684 & 0,011 & 0,013 & 71 \\
\hline 393 & SEB001 & 6,18 & 7,69 & 445 & 957.084 & 0,023 & 0,028 & 193 \\
\hline 394 & SEB001 & 5,42 & 6,09 & 2 & 19.116 & 0,000 & 0,000 & 1 \\
\hline 395 & SEB001 & 18,22 & 12,95 & 1 & 0 & 0,000 & 0,000 & 0 \\
\hline 396 & SEB001 & 0,00 & 0,00 & 0 & 0 & 0,000 & 0,000 & 0 \\
\hline 397 & SEB001 & 0,00 & 0,00 & 0 & 0 & 0,000 & 0,000 & 0 \\
\hline 398 & SEB001 & 4,84 & 5,58 & 51 & 2.532 .660 & 0,045 & 0,071 & 467 \\
\hline 399 & SEB001 & 0,00 & 0,00 & 0 & 0 & 0,000 & 0,000 & 0 \\
\hline 400 & SEB001 & 0,00 & 0,00 & 0 & 0 & 0,003 & 0,002 & 43 \\
\hline 401 & SEB001 & 0,00 & 0,00 & 0 & 0 & 0,000 & 0,000 & 1 \\
\hline 402 & SEB001 & 9,62 & 8,31 & 2 & 27.864 & 0,000 & 0,000 & $\overline{1}$ \\
\hline 403 & SEB001 & 9,76 & 8,09 & 1 & 8064 & 0,000 & 0,000 & 0 \\
\hline 404 & SEB001 & 5,63 & 7,05 & 331 & 588.300 & 0,033 & 0,039 & 217 \\
\hline
\end{tabular}




\begin{tabular}{|c|c|c|c|c|c|c|c|c|}
\hline $\begin{array}{c}\text { No. } \\
\text { Bloco }\end{array}$ & Alimentador & $\mathrm{Dl}_{\mathrm{P}}[\mathrm{h}]$ & $\mathrm{Nl}_{\mathbf{P}}$ & $\begin{array}{c}\text { No. } \\
\text { Clientes }\end{array}$ & $\begin{array}{c}\text { Consumo } \\
\text { Anual [kWh] }\end{array}$ & $\begin{array}{c}\text { CDEC } \\
\text { [h] }\end{array}$ & CFEC & $\begin{array}{l}\text { CEND } \\
\text { [kWh] }\end{array}$ \\
\hline 405 & SEB001 & 0,00 & 0,00 & 0 & 0 & 0,000 & 0,000 & 0 \\
\hline 406 & SEB001 & 0,00 & 0,00 & 0 & 0 & 0,005 & 0,003 & 45 \\
\hline 407 & SEB001 & 0,00 & 0,00 & 0 & 0 & 0,000 & 0,000 & 0 \\
\hline 408 & SEB001 & 12,73 & 9,69 & 4 & 8832 & 0,001 & 0,000 & 8 \\
\hline 409 & SEB001 & 0,00 & 0,00 & 0 & 0 & 0,008 & 0,004 & 72 \\
\hline 410 & SEB001 & 5,36 & 6,27 & 204 & 287.988 & 0,004 & 0,004 & 19 \\
\hline 411 & SEB001 & 11,52 & 9,13 & 2 & 3060 & 0,000 & 0,000 & 0 \\
\hline 412 & SEB001 & 4,92 & 5,58 & 215 & 312.684 & 0,155 & 0,216 & 1.507 \\
\hline 413 & SEB001 & 6,72 & 7,64 & 3 & 1.074 .360 & 0,000 & 0,000 & 212 \\
\hline 414 & SEB001 & 0,00 & 0,00 & 0 & 0 & 0,000 & 0,000 & 0 \\
\hline 415 & SEB001 & 0,00 & 0,00 & 0 & 0 & 0,000 & 0,000 & 0 \\
\hline 416 & SEB001 & 4,47 & 5,58 & 143 & 219.504 & 0,035 & 0,050 & 328 \\
\hline 417 & SEB001 & 0,00 & 0,00 & 0 & 0 & 0,000 & 0,000 & 0 \\
\hline 418 & SEB001 & 18,22 & 12,95 & 27 & 4368 & 0,000 & 0,000 & 0 \\
\hline 419 & SEB001 & 18,21 & 12,94 & 7 & 24.012 & 0,011 & 0,006 & 145 \\
\hline 420 & SEB001 & 0,00 & 0,00 & 0 & 0 & 0,000 & 0,000 & 0 \\
\hline 421 & SEB001 & 0,00 & 0,00 & 0 & 0 & 0,000 & 0,000 & 0 \\
\hline 422 & SEB001 & 6,09 & 6,98 & 88 & 126.312 & 0,003 & 0,004 & 17 \\
\hline 423 & SEB001 & 5,32 & 5,58 & 1 & 4164 & 0,286 & 0,192 & 2.765 \\
\hline 424 & SEB001 & 18,22 & 12,95 & 4 & 170.592 & 0,000 & 0,000 & 0 \\
\hline 425 & SEB001 & 4,48 & 5,58 & 139 & 460.764 & 0,038 & 0,053 & 356 \\
\hline 426 & SEB001 & 5,82 & 6,80 & 257 & 415.956 & 0,008 & 0,009 & 49 \\
\hline 427 & SEB001 & 0,00 & 0,00 & 0 & 0 & 0,000 & 0,000 & 0 \\
\hline 428 & SEB001 & 18,40 & 13,17 & 22 & 26.124 & 0,000 & 0,000 & 1 \\
\hline 429 & SEB001 & 4,91 & 5,58 & 278 & 394.440 & 0,055 & 0,081 & 517 \\
\hline 430 & SEB001 & 7,57 & 9,36 & 177 & 274.236 & 0,003 & 0,003 & 16 \\
\hline 431 & SEB001 & 0,00 & 0,00 & 0 & 0 & 0,000 & 0,000 & 0 \\
\hline 432 & SEB001 & 4,64 & 5,58 & 383 & 739.644 & 0,091 & 0,126 & 890 \\
\hline 433 & SEB001 & 10,88 & 8,59 & 1 & 4476 & 0,012 & 0,007 & 285 \\
\hline 434 & SEB001 & 4,99 & 5,58 & 39 & 940.044 & 0,112 & 0,166 & 1.189 \\
\hline 435 & SEB001 & 18,22 & 12,95 & 6 & 7020 & 0,000 & 0,000 & 0 \\
\hline 436 & SEB001 & 9,64 & 8,33 & 2 & 4164 & 0,000 & 0,000 & 0 \\
\hline 437 & SEB002 & 0,00 & 0,00 & 0 & 0 & 0,004 & 0,007 & 45 \\
\hline 438 & SEB002 & 0,00 & 0,00 & 0 & 0 & 0,000 & 0,000 & 0 \\
\hline 439 & SEB002 & 3,21 & 4,22 & 228 & 390.108 & 0,007 & 0,009 & 49 \\
\hline 440 & SEB002 & 5,95 & 5,24 & 1 & 1800 & 0,001 & 0,000 & 177 \\
\hline 441 & SEB002 & 6,02 & 8,22 & 174 & 383.424 & 0,012 & 0,015 & 105 \\
\hline 442 & SEB002 & 5,87 & 7,06 & 160 & 257.232 & 0,007 & 0,008 & 42 \\
\hline 443 & SEB002 & 3,37 & 3,63 & 90 & 153.780 & 0,003 & 0,002 & 21 \\
\hline 444 & SEB002 & 0,00 & 0,00 & 0 & 0 & 0,000 & 0,000 & 0 \\
\hline 445 & SEB002 & 0,00 & 0,00 & 0 & 0 & 0,004 & 0,006 & 46 \\
\hline 446 & SEB002 & 5,67 & 5,25 & 1 & 403.200 & 0,000 & 0,000 & 0 \\
\hline 447 & SEB002 & 2,03 & 2,92 & 162 & 337.872 & 0,045 & 0,056 & 460 \\
\hline 448 & SEB002 & 2,19 & 2,92 & 196 & 1.209 .264 & 0,037 & 0,055 & 399 \\
\hline 449 & SEB002 & 2,62 & 3,61 & 89 & 336.144 & 0,002 & 0,002 & 22 \\
\hline 450 & SEB002 & 5,54 & 5,24 & 5 & 12.924 & 0,001 & 0,001 & 262 \\
\hline 451 & SEB002 & 4,50 & 5,97 & 234 & 393.432 & 0,026 & 0,035 & 196 \\
\hline 452 & SEB002 & 2,07 & 2,92 & 60 & 126.288 & 0,018 & 0,025 & 179 \\
\hline 453 & SEB002 & 5,54 & 5,25 & 1 & 24.600 & 0,000 & 0,000 & 0 \\
\hline 454 & SEB002 & 2,85 & 3,66 & 73 & 361.260 & 0,001 & 0,002 & 26 \\
\hline 455 & SEB002 & 2,11 & 2,92 & 311 & 735.972 & 0,048 & 0,060 & 498 \\
\hline
\end{tabular}




\begin{tabular}{|c|c|c|c|c|c|c|c|c|}
\hline $\begin{array}{c}\text { No. } \\
\text { Bloco }\end{array}$ & Alimentador & $\mathrm{Dl}_{\mathrm{P}}[\mathrm{h}]$ & $\mathrm{NI}_{\mathbf{P}}$ & $\begin{array}{c}\text { No. } \\
\text { Clientes }\end{array}$ & $\begin{array}{c}\text { Consumo } \\
\text { Anual }[k W h]\end{array}$ & $\begin{array}{c}\text { CDEC } \\
{[\mathrm{h}]}\end{array}$ & CFEC & $\begin{array}{l}\text { CEND } \\
\text { [kWh] }\end{array}$ \\
\hline 456 & SEB002 & 5,66 & 5,24 & 3 & 95.724 & 0,000 & 0,000 & 48 \\
\hline 457 & SEB002 & 5,37 & 7,43 & 396 & 543.864 & 0,023 & 0,027 & 121 \\
\hline 458 & SEB002 & 2,04 & 2,92 & 88 & 216.792 & 0,007 & 0,011 & 73 \\
\hline 459 & SEB002 & 4,43 & 5,36 & 218 & 376.344 & 0,045 & 0,051 & 303 \\
\hline 460 & SEB002 & 1,99 & 2,92 & 132 & 239.388 & 0,022 & 0,028 & 224 \\
\hline 461 & SEB002 & 5,96 & 5,25 & 2 & 534.444 & 0,000 & 0,000 & 0 \\
\hline 462 & SEB002 & 2,67 & 3,67 & 97 & 419.652 & 0,002 & 0,002 & 30 \\
\hline 463 & SEB002 & 3,12 & 4,07 & 158 & 590.208 & 0,005 & 0,005 & 66 \\
\hline 464 & SEB002 & 0,00 & 0,00 & 0 & 0 & 0,000 & 0,000 & 0 \\
\hline 465 & SEB002 & 2,22 & 2,92 & 168 & 652.092 & 0,072 & 0,111 & 761 \\
\hline 466 & SEB002 & 4,49 & 5,97 & 261 & 384.264 & 0,030 & 0,034 & 236 \\
\hline 467 & SEB002 & 5,96 & 5,25 & 6 & 95.820 & 0,000 & 0,000 & 0 \\
\hline 468 & SEB002 & 2,31 & 3,25 & 140 & 251.052 & 0,001 & 0,001 & 8 \\
\hline 469 & SEB002 & 5,84 & 5,42 & 1 & 3840 & 0,000 & 0,000 & 0 \\
\hline 470 & SEB002 & 5,54 & 7,23 & 206 & 396.072 & 0,006 & 0,008 & 48 \\
\hline 471 & SEB002 & 2,17 & 2,92 & 65 & 227.880 & 0,040 & 0,057 & 424 \\
\hline 472 & SEB002 & 3,63 & 4,76 & 240 & 914.688 & 0,011 & 0,013 & 162 \\
\hline 473 & SEB002 & 2,74 & 3,76 & 184 & 452.820 & 0,004 & 0,005 & 37 \\
\hline 474 & SEB002 & 2,81 & 3,78 & 135 & 624.636 & 0,003 & 0,003 & 52 \\
\hline 475 & SEB002 & 5,11 & 6,71 & 61 & 357.396 & 0,001 & 0,001 & 25 \\
\hline 476 & SEB002 & 3,58 & 4,59 & 291 & 500.952 & 0,012 & 0,015 & 81 \\
\hline 477 & SEB002 & 4,16 & 5,12 & 376 & 683.640 & 0,041 & 0,050 & 255 \\
\hline 478 & SEB002 & 2,54 & 3,49 & 150 & 348.972 & 0,002 & 0,003 & 19 \\
\hline 479 & SEB002 & 2,15 & 2,92 & 113 & 394.188 & 0,037 & 0,054 & 399 \\
\hline 480 & SEB002 & 6,24 & 7,52 & 148 & 227.376 & 0,008 & 0,009 & 47 \\
\hline 481 & SEB003 & 0,00 & 0,00 & 0 & 0 & 0,001 & 0,002 & 23 \\
\hline 482 & SEB003 & 2,53 & 3,32 & 347 & 1.845 .060 & 0,044 & 0,052 & 789 \\
\hline 483 & SEB003 & 3,25 & 4,39 & 193 & 445.476 & 0,005 & 0,006 & 46 \\
\hline 484 & SEB003 & 2,84 & 3,56 & 45 & 111.420 & 0,000 & 0,000 & 3 \\
\hline 485 & SEB003 & 2,64 & 3,32 & 198 & 2.539 .068 & 0,012 & 0,017 & 202 \\
\hline 486 & SEB003 & 3,14 & 4,26 & 148 & 325.944 & 0,003 & 0,004 & 30 \\
\hline 487 & SEB003 & 2,98 & 3,73 & 73 & 192.588 & 0,001 & 0,001 & 8 \\
\hline 488 & SEB003 & 2,38 & 3,32 & 32 & 78.516 & 0,015 & 0,021 & 234 \\
\hline 489 & SEB003 & 3,05 & 3,82 & 99 & 199.128 & 0,001 & 0,001 & 9 \\
\hline 490 & SEB003 & 2,63 & 3,32 & 243 & 1.045 .848 & 0,036 & 0,050 & 584 \\
\hline 491 & SEB003 & 2,68 & 3,70 & 86 & 254.856 & 0,001 & 0,001 & 9 \\
\hline 492 & SEB003 & 2,42 & 3,32 & 316 & 799.392 & 0,033 & 0,041 & 540 \\
\hline 493 & SEB003 & 2,84 & 3,69 & 88 & 994.272 & 0,001 & 0,001 & 36 \\
\hline 494 & SEB003 & 2,50 & 3,32 & 274 & 1.592 .892 & 0,023 & 0,032 & 381 \\
\hline 495 & SEB003 & 3,45 & 4,50 & 138 & 846.156 & 0,004 & 0,005 & 96 \\
\hline 496 & SEB003 & 2,61 & 3,32 & 75 & 303.156 & 0,005 & 0,008 & 93 \\
\hline 497 & SEB003 & 2,48 & 3,32 & 163 & 430.188 & 0,025 & 0,037 & 408 \\
\hline 498 & SEB003 & 2,63 & 3,47 & 29 & 116.940 & 0,000 & 0,000 & 2 \\
\hline 499 & SEB003 & 2,86 & 3,89 & 139 & 289.032 & 0,002 & 0,002 & 16 \\
\hline 500 & SEB003 & 2,42 & 3,32 & 70 & 180.948 & 0,013 & 0,019 & 207 \\
\hline 501 & SEB003 & 2,40 & 3,32 & 77 & 195.360 & 0,017 & 0,011 & 278 \\
\hline 502 & SEB003 & 2,86 & 3,89 & 141 & 277.128 & 0,002 & 0,002 & 15 \\
\hline 503 & SEB003 & 2,92 & 3,79 & 77 & 473.160 & 0,001 & 0,001 & 21 \\
\hline 504 & SEB003 & 2,69 & 3,32 & 252 & 711.612 & 0,023 & 0,033 & 381 \\
\hline 505 & SEB004 & 1,37 & 2,11 & 1 & 18.384 & 0,000 & 0,001 & 101 \\
\hline 506 & SEB004 & 1,63 & 2,14 & 4 & 362.364 & 0,000 & 0,000 & 2 \\
\hline
\end{tabular}




\begin{tabular}{|r|c|r|c|r|r|r|r|r|}
\hline $\begin{array}{c}\text { No. } \\
\text { Bloco }\end{array}$ & Alimentador & DI $_{\mathbf{P}}[\mathbf{h}]$ & N $_{\mathbf{P}}$ & $\begin{array}{c}\text { No. } \\
\text { Clientes }\end{array}$ & $\begin{array}{c}\text { Consumo } \\
\text { Anual }[\mathbf{k W h}]\end{array}$ & $\begin{array}{c}\text { CDEC } \\
{[\mathbf{h}]}\end{array}$ & CFEC & $\begin{array}{r}\text { CEND } \\
{[\mathbf{k W h}]}\end{array}$ \\
\hline 507 & SEB004 & 1,67 & 2,16 & 3 & 42.972 & 0,000 & 0,000 & 0 \\
\hline 508 & SEB004 & 1,59 & 2,11 & 1 & 10.188 .456 & 0,000 & 0,000 & 5 \\
\hline 509 & SEB004 & 1,59 & 2,11 & 6 & 51.612 & 0,004 & 0,006 & 1.217 \\
\hline 510 & SEB004 & 1,97 & 2,11 & 1 & 5820 & 0,015 & 0,017 & 3.008 \\
\hline 511 & SEB004 & 4,43 & 5,04 & 121 & 167.988 & 0,007 & 0,008 & 37 \\
\hline 512 & SEB004 & 4,03 & 4,56 & 101 & 142.656 & 0,005 & 0,005 & 25 \\
\hline 513 & SEB004 & 2,49 & 2,73 & 65 & 85.440 & 0,004 & 0,005 & 24 \\
\hline 514 & SEB004 & 0,00 & 0,00 & 0 & 0 & 0,000 & 0,000 & 0 \\
\hline 515 & SEB004 & 1,46 & 2,11 & 51 & 67.836 & 0,001 & 0,002 & 328 \\
\hline 516 & SEB004 & 1,64 & 2,11 & 2 & 471.144 & 0,000 & 0,000 & 9 \\
\hline 517 & SEB004 & 0,00 & 0,00 & 0 & 0 & 0,001 & 0,001 & 299 \\
\hline 518 & SEB004 & 1,62 & 2,13 & 2 & 104.484 & 0,000 & 0,000 & 0 \\
\hline 519 & SEB004 & 1,54 & 2,11 & 179 & 295.980 & 0,006 & 0,006 & 1.181 \\
\hline 520 & SEB004 & 1,66 & 2,11 & 7 & 21.693 .252 & 0,001 & 0,001 & 163 \\
\hline
\end{tabular}

